\title{
WOL F
}

\section{POTENTILLEN - STUDIEN}




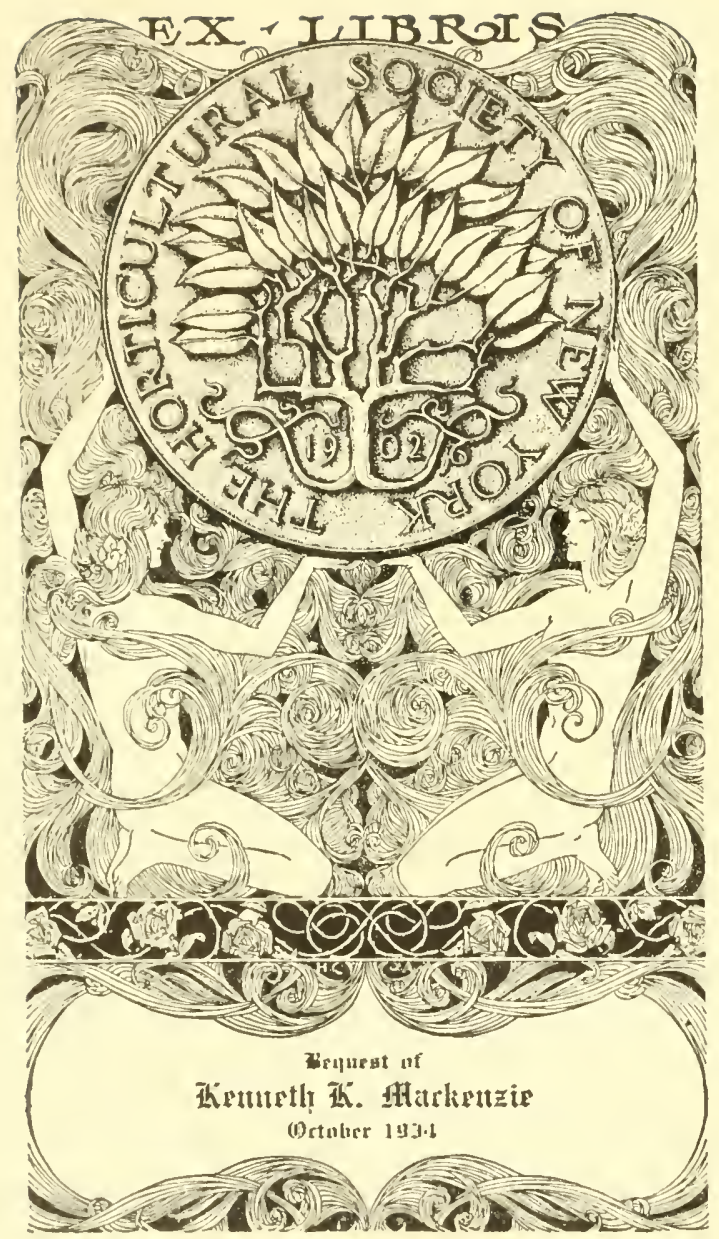

THE LUESTHER T. MERTZIIBRARY

THE NEW YOPK BOTANICAL GARDE: 




\section{DR. THEODOR WOLF}

\section{PO'TEN'TILLEN-S'TUDIEN}

I.

Die sächsischen Potentillen und ihre Verbreitıng besonders im Elbhügellande,

mit Ausblicken auf die moderne Potentillenforschung.

Mit Abbildungen im l'ext.

Dresden

Druck und Verlag von Wilhelm Baensch 


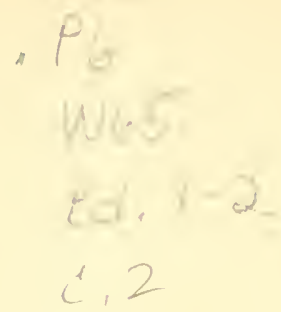

$70 x^{2}=$

THE LUESTHER T. MERTZ LIBRARY 


\title{
Die sächsischen Potentillen und ihre Verbreitung besonders im Elbhügellande,
}

\author{
mit Ausblicken anf die moderne Potentillenforschung.
}

Wä beeren und Posen von einigen sächsischen Botanikern seit längerer Zeit eingehender untersucht wurlen - erstere ron Herrn Oberlebrer C. Wobst in Dresden und neuerdings von Herrn Bürgerschullehrer H. Hofmann in Grossenhain, letztere rom verstorbenen Herrn Apotheker A. II. Schlimpert in Meissen - hat man unsere heimischen Potentillen fast ganz rernachlässigt. Dieses Missverhältniss macht sich noch in der neuesten Auflage von Wünsche's Excursionsflora (1899) bemerklich, welche bezüglich der formenreichen Gattung Potentilla sich nicht ïber das Niveau der vor 60 Jahren erschienenen F'lora saxonica ron Reichenbach erhebt. Schreiber dieser 'Zeilen hat nun seit mehreren Jahren die sächsischen Potentillen zu seinem Specialstulium erkoren und möchte im Folgenden einen kurzen Bericht über die bis jetzt erzielten Resultate geben.

Um das reiche Material, das besonders unser Elbhügelland bietet, zu sichtell, war es selbstverständlich nothwendig, sich nicht nur in die älteren Monographien der Gattung, sondern besonders auch in die moderne Potentillenforschung, wie sie hauptsächlich durch A. Zimineter angebahnt wurde, hineinzuarbeiten, ausserdem ein umfangreiches Vergleichsmaterial zu beschaffen. In keiner Beziehung hat es der Terfasser an Fleiss und Ausdauer fehlen lassen, muss aber von rornhereiu gestehen, dass er sich nicht entschliessen konnte, bezüglich des Speciesbegriffes und der Nomenclatur auf der bereits sehr breitgetretenen Bahn der Modernen und Jodernsten zu wandeln, sich im Gegentheil mehr und mehr davon überzeugte, dass - und zwar nicht nur bei Potentilla - eine Pückkehr zum Alten wicht immer einen wissenschaftlichen Riickschritt bedeutet. Seine Absicht war nicht, neue ,S pecies" aufzusuchen und zu benennen nicht einmal eine, , Yarietas nova“, "Hybrida nova: oder .,Forma nova mili“* gestattete er sich, obwohl es nicht an Gelegenheit dazu gefehlt hätte sondern den Versuch zu machen, die viel zu vielen Zimmeter schen und andere ,Species", die Sachsen ebenso besitzt wie andere Länder Centraleuropas, einzuziehen und sie als Varietäten und Formen den guten alten Species zu subordiniren, also sozusagen wieder auf den Lehmann'sclien Standpunkt zurïckzukommen. 
Mit diesen offenen Gestäulniss hat es der Verfasser wahrscheinlich mit manchem . modernen“ P'otentillenforscher" zum voraus grïndlich verdorben und muss gewärtigen, dass er und seine Arbeit recht niedrig ,bewerthet" werle. Das ist ilnn aber ganz gleich; vielleicht gielit er doch Anlass dazu, Manches ron neuem zu priffen und zu bedenken. In der Bewerthung der Species, Varietäten und Formen steht er ungefïlur auf dem standjunkte Ascherson's, der darin kamm von mseren älteren klassisehen Botanikern abweicht, in der Nomenclaturfrage aber nicht auf dem des extremen Priorititspuncips, sondern etwa anf lem liocke's, welcher ilm der vernünftigste mu durchführharste zu sein scheint. Verschiedene Bemerkungen dariiber werden an den gehörigen Stellen ihreu Platz finden.

Dresten-Planen, im Februar 1901.

\section{Th. Wolf.}

Die Potentillen sind im Königreiche Sachsen sehr ungleich vertheilt. Während sie im höheren Erzgebirge nur in wenigen der gemeinsten Species vertreten sind, entfalten sie im Elbhïgelland einen für ein verhältnissmässig so kleines Gebict ausserordentlichen lormenreichthum in einer bedeutenden Anzahl von Species und Bastarden.

Das Quadersandsteingebinge łer sächsischen Schweiz ist, abgesehen ron ein pair der Elbe nahe gelegenen l'mkten, fast ebenso arm als das Erzgebirge. Die Oberlansitz, das Vogtland, und der südliche Theil des Leipziger Kreises (die mittleren Muldegegenden) scheinen elenfalls spärlich bedacht worden zu sein. Freilich kemne ich die drei znletzt genannten Gegenden nur wenig aus eigener Anschaumg, nud aus dem Fehlen interessanter P'otentillen in den Herbarien oder von standortsangaben in unseren hisherigen Floren lässt sich kein sicherer Schluss ziehen, weil man eben in Saclisen den Potentillen bisłang wenig beachtung geselrenkt hat. Da aber dort die $\mathrm{P}$. arenaria sicher ganz fehlt mud die P. opaca nur sehr spärlich und zerstreut aufzutreten scheint, so lässt sich a priori annehmen, dass der l'ormenreichthum der l'otentilla nirgends in Sachsen an den iles Elbhiigellandes heranreicht, welcher besonders anch durch die Formen mul Bastade der zwei genannten Species bedingt wird.

Der nördlichste Theil Sachsens, nördlich der Elbe im Gebiet der Röder, P'ulsnitz, schwarzen Eister und der spree, mit seinem theils fast ebenen, theils sanftwelligen Terrain und seinen See- und Teichlandschaften er beginnt gleich iiber Dresden mit der Hresdner Heide - schliesst sich geologisch, landschaftlich und floristisch unmittelbar an die analogen Gegenden der preussischen Nieder-Lausitz an und ist, hei spärlichem Auftreten von l'otentillen aus den Terminales-Gruppen, ein Tummelplatz für die Axilliflor:te-Gruppe, anf welchem sich P. Tormentilla, procumbens, reptans und deren Bastarde an mannigfaltigsten gestalten.

So viel im allgemeinsten über die Verlneitung der Potentillen in Sachsen, und num noch ein par. Worte ïber mein specielles lieobachtungsgehiet, das Elbhïgellánd. - Bei Tetschen und Bodenhach, wo die Elbe, aus Iböhnen kommend, in die enge Schlucht des Quadersandsteingeluirges eintritt, hört plötzlich die sehöne, von so vielen pontischen Ele- 
menten durchsetzte Flora des böhmischen Nittelgebirges auf, und an ihre Stelle tritt die verhältnissmässig arme und eintönige Flora der sächsischen Schweiz - eintönig, wie der Sandstein selbst! Nur wenige Angehörige der ersteren, die man eigentlich durch den Elbstrom verbreitete Adrentivpflanzen nennen möchte, finden sich hier noch, hart an den Fluss gedrängt. Sobald wir aber mit der Elbe bei Pirna, wenige Stunden oberhalb Dresden, die landschaftlich so romantische Schlucht des Elbsandsteins verlassen und in den weiten Thalkessel von Dresden eintreten, erljlicken wir ein geologisch und floristisch ganz verschiedenes Bild. Die sanften, nur an wenigen Stellen ron nackten Felsabstürzen unterbrochenen Gelände der von der Elbe bald mehr, bald weniger weit zurücktretenden Berg- und Hügelzüge haben Granit und Syenit zur Grundlage mnd sind hier und dort von Plänerkalk, Diluvialschotter, Heidesand, Diluviallehm und Löss ïberlagert. Auf diesen Höhen findet sich nun wieder eine ganz beträchtliche Anzahl von Bürgern der pontischen Flora zusammen und stellenweise wird man lebhaft an die des böhmischen Mittelgebirges erinnert. Diese Flora ist nicht zu verwechseln mit der durch den Eihstrom vermittelten Adrentivflora, und Drude, der schon mehrfach über sie geschrieben*), hat es wahrscheinlich gemacht. dass sie nicht der Elbe entlang, sondern durch die Einsattelung zwischen dem Erzgebirge und dem Elbsandstein bei Nollendorf aus dem Osten eingewandert ist, vielleicht bald nach der Eiszeit. Sie scheint ïberhaupt nur noch den auf die günstigsten Punkte reducirten Piest einer ehemals rerbreiteteren Elbthalflora darzustellen, welche durch ihre Elemente auf ein steppenartiges Klima deutet. Durch die in dem dichtberölkerten Sachsen Alles in Anspruch nehmende Cultur des Bodens dürfte sie dem gänzlichen Verschwinden nahe sein. Wie Vieles ist in den letzten 50 oder 60 Jahren, seit Reichenbach seine Flora saxonica herausgab, schon verschwunden!

Der Streifen, welchen diese Flora rechts und links der Elbe einnimmt. ist nicht breit. Die Charakterptlanzen verschwinden bald hinter den den Fluss begleitenden Berg- und Hügelzügen, oder anf den Plateaus iiber denselben; nur in einigen Seitenthälern des grossen Elbthales ziehen sie sich an deren Abhängen mehr oder weniger weit (bis 4 Stunden) in's Land hinein. Besonders reich ist das Elbthal von Meissen bis zu den Granitfelsen ron Diesbar und Seusslitz, ron wo ab das Hügelland dann schnell in die Ebene übergeht und die letzten Reste der pontischen Flora gegen die Landesgrenze hin verschwinden.

Nun, dieses Elbhïgelland mit seiner stark pontisch angehauchten Flora von Pirna bis Riesa ist das Eldorado unserer Vermales-P'otentillen! Die für die Potentillenforschung wichtigsten Punkte lassen sich von Dresden aus per Eisenbahn oder Dampfschiff leicht und schnell erreichen, viele sogar auf Nachmittagsaustlügen und kurzen Spaziergängen.

Die eingehende mehrjährige Durchforschung einer auf wenige Quadratmeilen beschränkten, aber potentillenreichen Gegend, wie die des sächsischen Elbhïgellandes, fördert den Specialisten mehr in der kienntniss seiner Gattung, als das Zusammenbringen von einzelnen Stichproben aus allen Gauen des deutschen Reiches, über deren Standortsverhältnisse. Association mit anderen Arten, Aussehen und Benehmen im lebenden Zustande etc.

*) Abhandlungen der natmrwissenschaftl. Ges. Isis in Dresden 1885, S. 75-10\%, und 1896, S. $35-6 \%$. 
er keine eigenen und andauernden Beohachtungen anstellen kinn. Die werthrollsten Exsiceaten sind immer die, welche man selbst macht und mit ausfühlichen Bemerkungen versehen seinem llerbar einverleilst. Ihre Durchsicht ist immer ein liepetitorim der im freien erlaltenen Lectionen. Ich hofte, dass verschjedene an unseren sächsischen l'otentillen gemachte Beobachtungen einen allgemeineren als nur local-floristischen Werth laben und Einges zur Aufklärmıg des Formenreichthums der Gattung beitragen werden.

Da das Folgende nicht eine Einführung in das Studinm der Potentillen, auch keine Monographie derselben sein soll, gehe ich über die systematische Gliederung der Gattung in Gruppen hinwegr, auch setze ich die lienntniss unserer Hauptarten und einige Orientirung über den heutigen Stand der l'otentillenforschung volaus. Der Hauptzweck dieser Arbeit besteht in der l'rüfung der Varietäten, Formen und Bastarle. Ich werle jede Species nur mit einem Namen anffüluen, wenn nicht, um Missverständnisse zu vermeiden, die beifügmug eines Synonyms in Klammern als nitzlich erscheint. Die vollständige Aufzählung der Synonyma und Litteraturangaben bei jeder species, welche bei einjoen derselben ganze Seiten einnälnme (und den Arbeiten ein so schrecklich gelehrtes Aussehen giebt!), gehört in eine Monographie der Gattung. In dieser Abhandlung iiber die sächsischen P'otentillen - wie in jeder Specialarbeit, die nicht gerade nomenclatorische Tïfteleien zum \%weck hat würde ich das Mitschleppen dieses Ballastes für umütze /eit- und Papierverschwendung halten.

Unter fortlaufenden Nummern sind alle in Sachsen rorkommenden Hauptarten aufgefuilıt. Ich werde bei jeder derselben ihre Verbreitung angeben, soweit sie mir bekannt geworden ist, bei den gewöhnlichen Arten meln im allgemeinen, bei ten selteneren im einzelnen. Die von mir selbst aufgefundenen oder wenigstens selbst besuchten Standorte bezeichne ich - wie heutzutage üblich — mit!!, jenc, von welchen ich Belegexemplare besitze, oder welche ich in anderen llerlorien eingesehen habe, mit !, und die sonst in unseren Floren aufgeführten olıne Ausrufungszeichen, aber womöglich mit Angabe der Gewälrsmänner. Es ist leider dem Einzelnen nicht möglich, alle Localitäten zu besuchen. An manchen der alten Standorte dürften die betreffenden Arten und Formen versehwunden sein von einigen ist dies bereits nachgewiesen - , und es wäre selı zu wünschen, dass allmählich diejenigen festgesellt wïrden, welche noch jetzt Geltung haben. Für jede diesbezïgliche Angabe, sowie selbstverständlich auch für jede Mittheilung nener Standorte (womöglich mit Belegexemplaren) wäre ich den Herren Floristen selu dankbar. An dieser Stelle sage ich allen jenen Herren, dic mich schon bisher durch ihre Mitheilungen unterstützt laben, meinen lierzlichsten Dank. - Hinter dem ! werde ich diejenigen Floristen nennen. denen ich belegexemplare von den betreffenden Standorten verdanke oder in deren Ilerbarien ich dieselben einsehen konnte, und zwar die häufig zu nemnenden in Abkürzung: Fr. = F. Fritzsehe in Kötzschenhroda, $\mathrm{H} \mathrm{fm}$. = II. Hofmann in Grossenhain, Stf. $=$ H. Stiefelliagen in Dresden. H. Dr. bedeutet, dass siclı Relegexemplare im Königl. 
Herbar zu Dresden befinden, H. Lpz., dass ich solche im Leipziger Universitäts-Herbar und H.Pet, dass ich sie im Petermann'schen Herbar zu Leipzig eingesehen habe. Mit Richb. citire ich die Flora saxonica von Reichenbach (1842), mit Peterm. die Flora lipsiensis excursoria (1838) von Petermann, sowie dessen Analytischen Pflanzenschlïssel (1846), und mit Wsch. die neneste Auflage (1899) ron Wi in sche's Excursionstlora. Da es sich nu darum handelt, das Vorkommen an den betreffenden Localitäten sicher festzustellen, citire ich der Kürze halber bei den von mir selbst besuchten und untersuchten keine weiteren Belege, auch wenn ich die Pflanze ron denselben Standorten in rerschiedenen Herbarien gesehen habe. Ebenso verfahre ich bei den nur durch Einsicht in fremde Herbarien constatirten Standorten, indem ich gewöhnlich nur eines derselben nenne. Bei den durch kein auffindbares Belegexemplar bestätigten Standortsangaben halte ich mich bezüglich der älteren an Rchb., bezüglich der neveren an Wsch., wenn der eigentliche Entdecker nicht genannt wird (was ja leider bei Wünsche fast immer der Fall ist). Es ist tief zu bedauern, dass das Reichenbach'sche Herbar, welches ohne Zweifel Belegexemplare für die meisten, wenigstens sehr viele Standorte enthielt, nicht in Sachsen geblieben und so der Benutzung der sächsischen Floristen entzogen ist. Um es zu consultiren, muss man eine Reise nach Wien unternehmen.

Ich habe meist davon abgesehen, bei den Standorten deren geologische Unterlage anzugeben, nicht weil ich dieselbe unbeachtet gelassen hätte, sondern weil ich durchaus keinen Einfluss derselben auf unsere Potentillen-Formen wahrnehmen kounte. Es ist mir dies besonders bei unseren Vernales, Argenteae und Rectae aufgefallen, bei denen ich oft Veranlassung fand, Individuen mit einander zu vergleichen, welche in nicht zu grossen Abständen von einander auf Granit oder Syenit, Kalkstein, schwerem Dihuriallehm und leichtem Sandboden wuchsen. So sehr auch andere Standortsverhältuisse (feucht oder trocken, sonnig oder schattig etc.) die Formen beeinflussen, scheint doch die chemische und mineralogische Verschiedenheit des Untergrundes keine sichtbare Wirkung auf sie auszuïben. Ich spreche natiirlich nur von unseren sächsischen Arten und will durchaus nicht in Abrede stellen, dass es anderwärts in der That z. B. kalkliebende oder kalkständige Formen gebe.

Die Besprechung der Varietäten und Formen der Arten sowie ihrer Bastarde, wenn solche vorhanden sind, folgt auf das Standortsverzeichniss oder geht demselben voraus, je nachdem es zweckmässiger erscheint, überhaupt werde ich mich nicht an eine in den Floren übliche Schablone binden, sondern in zwangloser Form meine Beobachtungen vorbringen und diejenigen Schlïsse daraus ziehen, die sich mir zu ergeben scheinen, was nicht immer wird geschehen können, ohne die entgegengesetzten Meinungen anderer Forscher zu berühren. - Diejenigen Floristen, welche sich nur über Sächsisches zu orientiren wünschen und welchen meine .Ausblicke auf die moderne Potentillenforschung ${ }^{6}$ und Digressionen auf entferntere Gebiete hin und wicder zu weitschweifig erscheinen, mögen deren Lectüre den Specialisten, für die sie geschrieben sind, überlassen. sie werden mschwer das sie allein Interessirende zusammenfinden.

Ich nehme davon Abstand, hier ein rollständiges Verzeichniss der Potentillen-Litteratur, oder auch nur der von mir beniitzten Wrerke und Arbeiten zu geben, möchte aber doch Jenen, welche sich mit unserer 
Gattung etwas eingehender zu beschäftigen wïnschen, ein paar Werke und Schriften empfehlen.

Chr. Lehmann, "Revisio Potentillarum iconibus illustrata“. (Supplement des Bd. XXIII, der Verhandl. der kaiserl, leopold.-carolin. Akad. d. Naturforscher.) Breslau und Bonn 1856.

Dieses Werk, gleichsam eine zweite vermehrte Auflage der ,Monographia generis Potentillarum" (Hamburg 1820) desselben Verfassers, ist und bleibt noch immer das unentbehrlichste für die Wïnführung in das Studium der Potentillen, trotz seines veralteten Standpunktes beziiglich der Gruppirung der Arten. Nur antiquarisch zu beschaffen, für etwa 20-25 Mark. Ich citire es mit „Rev. Pot.“.

A. Zimmeter (I), „Die europäischen Arten der Gattung Potentilla. Versuch eimer systematischen Gruppirung und Aufä̈llung, nebst kurzen Notizen ïher Synonymik, Litteratur und Verbreitung derselben." (I'rogramm der Ober-Realschule zu Steyr.) Steyr 1884.

A. Zimmeter (II), "Beiträge zur Kenntniss der Gattung Potentilla". Innsbruck 1889. Ist eine Fortsetzung der ersten Arbeit, im Programm der Ober-Realschule zu Innsbruck.

Diese zwei Broschüren - beim Citiren werde ich sie der Kürze halber nur mit I und II unterscheiden - von nur 31, bez. 36 Seiten, (Preis je 1 Mark), in welchen Zimmeter die moderne Potentillenforschung angebahnt hat, sind die nothwendigsten Schriften, um sich in der letzteren zu orientiren. In ihnen, sowie in Lehmamn's Revisio kann die umfangreiche Litteratur nachgesehen werden, die in Zimmeter II fast bis 1890 fortgeführt ist.

Ans rielen Bemerkmngen, die ich im Laufe des Folgenden über Zimmeters Arbeiten zu machen haben werle, kömte vielleicht Einer oder der Andere schliessen, dass ich gegen seine Person besonders eingenommen sei. Dies ist keineswegs der Fall, ich bin es nur gegen seine Methode, die von so Vielen angenommen mi weiter ausgebant worden ist, muss mich aber oft an seinen Namen halten, weil er eben diese IIethode, die ich bekämpfe, am besten repräsentirt. Zimmeter selbst schätze ich als einen Mann, der nit nugeheurem Fleiss höchst werthvolle Materialien zum Studium der Potentillen zusammengetragen und nenes Leben in dieses gebracht hat. Aber Poeverlein ïberschätzt ihn meines Erachtens, wenn er ihn, ,den neuesten Nonographen der Gattung" nennt. Dies ist Zimmeter nicht und wollte es wohl anch nicht sein, wie aus verschieilenen seiner Bemerkmngen hervorgeht. (Auf 31 Octarseiten lässt sich ïbrigens keine Monographie der europäischen Potentillen schreiben.) Von einem Monographen erwarte ich, dass er in seiner Gattung vor allem Ordnnng schaffe. Gewiss finden wir bei Zimmeter einige gute Ileen und Nenerungen beziiglich der Abgrenzung der höheren Gruppen und anch bezïglich der Stellmng einiger Species, aber im ganzen hat er eben die Lehmann'sche IIonographie anfgelöst, ohne eine nene an ihre Stelle zu setzen; er hat - und das ist das Schlimmste - die wenn anch nicht immer richtig snbordinirten V'arietäten und Formen der Species auseinander gerissen, als gleichwerthig mit binären (Species-) Namen ordnungslos nebeneinander gestellt, nud so die uferlose Zer'splitterung der Gattung eingeleitet, die wir Alle beklagen. Er hat endlich vermöge seiner nicht ganz verdienten Auctorität, durch umzählige, oft recht oberflächliche und nicht selten geradezn falsche Bestimmmgen an fremdem Herbarmaterial grosse Unsicherheit und Verwirmng unter den Botanikern gestiftet, wie Jeiler erfalın wird, der viel mit solchem "revidirtem" Naterial zu thm haben mnss. Von der Verwirmng, die er durch sein exagerirtes Prioritätsprincip) in der Nomenclatur' angerichtet hat, will ich hier schweigen. - Sollte ich durch diese freien Bemerkungen den Groll einiger Potentillisten ans der Zimmeter'schen Schmle auf mich larlen, so weiss ich doch, dass ich hundert Anderen aus der Seele spreche, welche gerade so wic ich denken, aber mit ihrer Ansicht ans irgend einem Grunde hinter dem Berge halten, oder keine Gelegenheit haben, sie zn änssern. 
Wichtig für die Systematik der Gattung ist auch:

0. W. Focke, "Anmerkungen zur Gattung Potentilla", in den Abhandlungen des naturwissenschaftl. Vereins zu Bremen, Bd. X, Heft 3. Bremen 1889. - Vergl. auch die Bearbeitung der Gattung Potentilla von demselben Auctor in der neuesten ungearbeiteten Auflage von Koch's Synopsis. Leipzig 1892. S. 802.

Eine sehr beachtenswerthe neuere Arbeit ist:

A. N. Petunnikor, ,Die Potentillen Central-Russlands", in Acta horti Petropolitani, tom. XIV, fasc. I. St. Petersburg 1895. - Die Abhandlung greift weit ïber Pussland hinaus und bringt viele hochinteressante Beobachtungen ron allgemeinem Interesse, besonders für die schwierige Gruppe der Potentilla collina.

Endlich möchte ich besonders unseren sächsischen Botanikern die neueste Arbeit über Potentillen auf"s wärmste empfehlen, da sie sich auf ein uns benachbartes Gebiet, auf das Königreich Bayern bezieht und eine Fülle der trefflichsten Bemerkungen und Ausführungen allgemeiner Art bringt. Ich meine die vorzügliche Abhandlung von

H. Poeverlein, ,Die bayrischen Arten, Formen und Bastarde der Gattung Potentilla'". Separat-Abdruck aus den Denkschriften der Königl. bot. Ges, in Regensburg. VII. Bd. Neue Folge I, Bd. 1898.

Da ich auf diese Arbeit wiederholt Bezug nehmen muss, wird es gut sein, um jedem Missverständniss von vornherein rorzubeugen, iiber meine Stellung zu ihr ein paar Worte zu sagen. Sobald ich dieselbe (1899) genau durchzusehen Gelegenheit gehabt, war ich von deren Wichtigkelt überzengt, und zugleich hocherfreut zu sehen, dass so viele meiner Beobachtungen, die mir neu zu sein geschienen hatten, durch Herrn Poererlein eine Bestätignng fanden. Mit Freuden stimme ich in rlas allgemeine Lob, das dem Verfasser in den Recensionen verschiedener Zeitschriften mit Recht gespendet wurde, und meine, dass Ascherson kanm einen geeigneteren Bearbeiter der Gattung Potentilla für seine breitangelegte .Synopsis der mitteleuropäischen Flora" auswählen könnte, als eben Herm Poeverlein. " Tach Erscheinen dieser Arbeit glaubte ich vorläufig auf die Veröffentlichung eines Aufsatzes iber die sächsischen Potentillen. den ich bereits halb und halb Herm Knenker fïr die allgemeine bot. Zeitschrift angeboten hatte, verzichten und Herrn Poererlein all mein gesammeltes Material zur Verwerthung antragen zu sollen. Wenn ich num dennoch mich zu einer Veröftentlichung entschliesse, so geschieht dies 1. weil Herr Poeverlein bislang noch keine Veranlassung gefunden hat, von meinem Anerbieten (iebranch zu machen. 2. weil es bis zu einer neuen Bearbeitung der Gattung Potentilla (wahrscheinlich erst in der Synopsis Ascherson's), also bis zur Jitbenutzung meines Naterials und meiner Arbeit wohl noch viele Jahre anstehen dürfte. 3. aut wiederholtes Drängen meiner botanischen Freunde, die möglichst bald etwas Näheres ïber die sächsischen Potentillen zu erfahren wiinschen, und 4. endlich, weil meine Gesundheitsverhältnisse derart sind, dass ich mir kein langes Leben mehr versprechen kann und ich doch meine Beobachtungen nicht ganz für mich allein gemacht zu baben wiinschte. Ilit Dank muss ich hervorheben, dass ich Poererlein's Arbeit viele Anregung rerdanke und durch sie veranlasst wurde. im Laufe des letzten Jahres Manches, wortiber ich bei mir schon im klaren zu sein glaubte, von nenem zn prüfen. Wenn ich nun in mehreven Dingen, z. B. in der Nomenclaturfrage, einen anderen Standpunkt eimnehme als Herr Poeverlein, wem ich manchmal eine Beobachtung bemängele oder seinen Ansichten und Schliissen freimithig widerspreche, so brauche ich kaum zu versichern. dass dies meiner Hochschätzung nicht den geringsten Eintrag thut, dass es nur aus objectiven Grïncen, aus rein wissenschaftlichem Interesse. zur Anregung weiterer Forschung geschieht, ja sogar mit dem ITunsche, eines Bessern belehit zu werden. Nicht aus unbedingter Zustimmung. sonderu a us WViterspruch und $\mathrm{Zw}$ eifel entsteht der Fortschritt in der Wissenschaft! So betrachte ich mich denn in jedem Falle nicht als Gegner, sondern als Mitarbeiter Poeverlein's. Besonders möchte ich mich gegen den Verdacht rerwaliren. als ob meine oft etwas scharfen Glossen zur modemen Potentillenforschung durch dessen Arbeit veranlasst 
seien; sie waren lange vor Ersheinen derselben geschrieben und jeh habe lieinen Grund, sie abzuindern. Allerdiugs habe ich es sehr bedanert, dass Herr Poeverlein, nachdem er doch zugestanden, diss die Bearbeitung der (iattung „in den letzten Decennien in ein Stadium getreten ist, las gegeniiber dem friberen Stande der Forschung zwar eine sehr weitgehende specialisirung nud Zersplitterung, lieineswegs aber cinen Fortschritt crkennen lässt". mul während er so oft durhblicken lässt, wie niederig er viele mit Artemamen aufgestellte Formen bewerthet, und wie bedentungslos sie ihm oft erscheinen. es democh ,fuir verfriiht gehalten, mit der (Zimmeter'schen) Tradition schon jetzt zu hrechen". Wenn ein lecensent der Poeverlein schen Arbeit, E. K. Blïmml (in der deutsch. bot. Monatsschr. 18:99, Heft $\gamma$ und s) dieses Festhaltun am Zimmeter schen Standpunkt, also an der weitgeheudeu Zersplitterung, als einen ganz besonderen Torzug derselben herroheht, so muss ich lejder der gegentheiligen Meinnng sein und darin ihre Schattenseite sehen. Wenn dorh cinmal mit diser unglickseligen, unhaltbaren Zersplitterung und Systemlosigkeit gehrochen werlen mus., so kam dies nicht früh genng geschehen. Ith fürchte, dass von Tielen die ron Poeverlein in der Einleitnng angedeutete Absioht, einstens selbst mit diesen System zu brechen, unbeachtet bleiben diurte, mul dass sie soin jetziges Vorwelien ohne weiteres als eine Sanctionirme der Zimmeterschen Tradition und als eine Anfmuternug dazn ansehen werden. an der weiteren Zersplittermg mitzuabeiten Es kommt ja gewissen strebsamen Lenten (Strehern?) sehr gelegen. llass sie ruhig fortfahren liomen, ms mit ..nenen Species" (mihi!) zn beglïclien! Lis ist zu bedaneru, lass num die systematische Ein- und Unterordnumg der Formen wioder ad Calendas graecas repsisholjen ist; deun wann wird die (iattung l'otentilla in Ascherson's synopsis an die Reihe kommen"*) Nach wir ror ist es lem angehenden Potentillen-Fremd iiberlassen, sich zurechtzulegen, wie er die nebeneinander gestellten Formen ordnen mul muteroduen soll. Ein kleiner Fehlgriff in der Bewerthmg mu Unterordnung der Tarietäten und Formen wäre meines Erachtens nicht so empfindlich und leichter zo beseitigen, als die durch Poeverlein's Vorgehen gleichsam sanctionirte Coordination, ans der wir doch endlich eimmal heranskommen niissen. - Es wäre gewiss anch den Verfassern ron Floren, die sich an der Subordination der Formen nicht vorbeidricken diirfen, von hohem Interesse gewesen, eine Ancturität wie Poeverlein consultiren zn kömmen.

\section{Potentilla alba L.}

Dies ist die einzige Art, welche Sachsen aus der Abtheilnug der Frayariustra besitzt (vergl. die folgende). D)urch das mittlere Europa in troekenen lichten Wäldern und Gebüschen, besonders aut sonnigen Anhöhen zerstrent, zeigt sie sich überall sehr gleichartig, und bietet anch an unseren wenigen Standorten nichts Erwähnenswerthes.

Alle säichsischen Standorte liegen, mit Ausmalme von einem, in Elbhügellande zwischen Pina und Diesbar. Sicher verbürgt sind folgende: in der Lössnitz auf dem Himmelsbnsch bei Kötzschenbroda !!, bei Lindenau! (lr.) und bei Radel,eul (,,auf tem grasigen Abliange vor der grossen Sumpfwiese", wie Ileynhold schon vor 60 Jahren angal)) ! (Stf., II. Dr.): sodamn unterhalb Meissen: bei Diesbar! (H. Dr.), Naundörfel bej Diera! (Fr.) und im Thale des Lomıntzschwassers zwischen Wahuitz und Leuhen! (H. Dr.). - Als rereinzeltor, abgetrenuter Standort jst sodann der Bienit\% bei Leipzig! (Fr., H. I)r.) zu nemen, jener Kalkliagel, der floristisch in westlichen Sachsen eine Ausnahmestellung eimimmt und als Standort

*) Soeben geht mir lie 13. Lieferung ron Ascherson's synopsis zu, in welcher plötzlich zu Band VI. mit der Reihe der Rosales ïbergesprimgen wird und worin R. Keller die (inttung losa zu bearbeiten begonnen hat. Danach haben wir doch Hoffumng, dass auch die Gattmog Potentilla in nicht gar zu fermer Zeit an die Reihe kommen wirl. 
mehrerer Seltenheiten vou Alters her beriibmt ist. - Der Bestätigung bedürfen die alten Standorte nach Rchh. oberhalb Dresden: Fischhaus, Loschwitz, Hosterwitz und Priesnitztlal, sowie Spitzgrund bei Coswig. Tielleicht ist die Pflanze an einigen orler allen diesen Orten schon verschwunden. Wünsche giebt auch noch Trachau (sein ,Lindenthal" soll wahrscheinlich Lindenau heissen), und Lautzschen bei Lommatzsch. Da Wïnsche leider niemals einen Gewälırsmann für seine Standorte nennt, auch viele anerkannt längst verschwundene aus alten Floren noch immer mitschleppt, so müssen wir viele seiner Angaben vorläufig zu den der Bestätigung bediurftigen stellen.

Unsere $P$. alba ist durchans drüsenlos, ebenso wal es die jetzt in Sachsen wieder verschwundene P. Fragariastrum. - Welch' sonderbare Bemerkung! wird man denken: wer hat je behauptet, dass die P. alba oler eine ihrer Terwandten drisig sei? Nun, gerade weil es noch Niemand behauptet hat, möchte ich an dieser Stelle daraut anfmerksam machen, dass es auch in der grossen Abtheilung der Leucotricha, speciell in der Gruppe der Fragariastra sehr driisenreiche Formen giebt, und dies cliurte doch manchem Botanilier nel sein; ich wenigstens habe in der Litteratur kamm spärliche Andeutungen dariiber gefunden. - TVie es sich im Verlauf dieser Abhandhnng herausstellen wird, habe ich den Drïsenhaaren der Potentillen eine ganz besondere Beachtung geschenkt, und so möge man mir es zu gute halten, wemn ich gleich bei der crsten Nummer iiber Sachsens Grenzpfähle hinausgteife und einige Beobachtungen vorbringe, die ich an verschiedenen uns fehlenden Arten der Giuppe gemacht habe.

Lehunann kannte 19 Species der Fragariastra, von denen nur drei anssereuropäisch sind (die $P$. libanotica Boiss. ans dem Libanon, die $P$. brachypetala Fisch. u. Mey, aus Armenien und die sonderbare, noch nicht geniigend mutersuchte $P$. ovalis Lehm. ans Hexico), die iibrigen sind sïd- und mitteleuropäisch. Zimmeter konnte den Lehmann'schen Sjecics mur ein paar europäische Subspecies oder Varietäten beifügen. Die europäischen guten Arten besitze ich vollzählig. konnte also alle auf ilure Behaarmgsverhältnisse untersuchen, und la fiel mir sofort eine merkwürdige Analogie zwischen der Gruppe der Fragariastra und der weit davon entfernten Gruppe "Quinqucfolium" aus der Abtheilung der Ltricha auf, die darin besteht, dass sich in beiden kraushaarige und schlichtharige Arten unterscheiden lassen, je nachdem die Blätter neben den geraden oder nur geschlängelten starken Haaren noch einen Filz ansserordentlich diimer, wollig-gekränselter Haare tragen oder nicht, und dass die Anwesenheit der letzteren in beiden Gruppen die Drïsenhare auszuschliessen scheint, solange keine Kreuzung der kraushaarigen Arten mit schlichthaarigen eintritt. In beilen Gruppen treten viele schlichtharige Species, selbst wenn sie eine sehr dichte, seidenglänzende Behaarung tragen, wie unsere $P$. alba, in der forma glandulosa auf, miissen es aber nicht, demn es kommt bei mehreren auch die forma eglandulosa zugleich ror. Dieses Resultat glaube ich schon jetzt als sicher hinstellen zu kömmen, wenn auch meine Untersuchungen über die ganze FragariastraGruppe, behufs einer naturgemässen Eintheilnug ihrer Arten anf Grund der Behaarung, noch nicht abgeschlossen sind.

Die Beschaffenheit der Driisenhaare ist ganz dieselbe, wie ich sie später bei der Besprechung der $P$. recta beschreiben werle.

Keine Drüsenhare konnte ich finden bei der ausserordentlich dicht wolligkranshaarigen $P$. speciosa Tilld, ebenso bei der stark filzigen $P$. Vulderia L., bei $P$. apennina Ten. und deren Subspecies $P$. Deornm Boiss., sowie bei der dicht seidig (schlicht-) haarigen $P$. alchemilloiles Lap. - Bei allen andern schlich thaarigen Arten findensich Drüsenhare, wenn auch oft nurspärlich oder sporadisch: $P$. Saxifraga Ant., $P$. nivalis Lap., P. Haynaldiana Janka und P. crassinervia Vis. sind sebr drüsenreich; $P$. caulescens L. ist am Stengel spärlich, an den Blättern oft reichlich drüsenharig (besonders in der Truviscosa Hut.): $P$. petiolulata Gaul. ziemlich reich driisig, $P$. petrophila Boiss. etwas weniger: $P$. clusiuna Jacq. mit spärlichen, aber oft ziemlich langen Stieldriisen; $P$. alba L. ist meist driisenfrei. zeigt aber auch hin und wieder sporadische, sehr kurz gestielte Driisen; $P$. nitida L. besitzt oft (nicht immer) zahheiche kurze Stieldrisen; $P$. gramopetala Mor. ist ausserordentlich reich an grossen, langen Stieldrüsen an allen Pflanzentheilen: P. Fragariastrum Ehrh. theils drüsenlos, theils mit spärlichen sehr kurz gestielten Driisen (Sitzdriizen): P. splcndens Ram. (non Koch), nur an einem Exemplar aus Coimbra spälliche Sit\%- 
drüsen gefunden: P. micrantha Kan. besitzt hin und wieder (\%. B. Euganeen!) kurz gestielte Drïsenhaare; endlich besitzt die der micrantha nahe verwandte $P$. carniolica A. Kern. sehr reichlich die schönsten und längsten Drïsenhare der ganzen Gruppe.

\title{
$\ngtr$ P Potentilla Fragariastrum Ehrlı.
}

\author{
(P. sterilis Garke.)
}

Diese Art ist leirler aus der Flora von Sachsen wienler zu streichen. Schon zu Reichenbach's \%eit scheint sie fast ganz ausgestorben gewesen zu sein. Er sagt in seiner 1842 ersehienenen Flora saxonica bei ihr in Kilammern, „['lauen, Konstappel nach Bucher; Schemenberg, Kasehendorf nach Ficinus; Struppen nach Löber. Nenerlich nichts dem Aehnliches.]" Allerlings wurle später ein sicherer Standort an der Weisseritz im Rabenauer Grund bej Tharandt entdeckt, den auch ich besuchte; aber bei der verderblichen Hoehtluth in Sommer $189 \%$ wurde dieser hart am Ufer des Wildbaches gelegene Standort zerstört und weggerissen. Ich war wohl der Letzte, der einige P'tänzchen ron dort, wenige Wochen vor der Fluth, einlegte. Ummöglich ist es nicht, dass diese Art noch eimnal an einem anderen Orte entdeckt wird, aber wahscheinlich ist es nicht, wenigstens nicht in jener wohldurehforschten Gegend. Die meiste Aussicht auf ein Wiederfinden wiuden wohl die westlichsten, an Thüringen grenzenden Theile Sachsens bieten, demn sie wird für Greiz, Weida und Gera angegeben. - ,.Bei Tharandt" (Wsch.) habe ich sie jahrelang vergebens gesucht, auch konnte mir kein anderer Florist diesen angeblichen Standort bestätigen. Wahrscheinlich soll es in W'sch. heissen: Rabenauer Grund bei 'Tharandt.

Ich kam mich nicht zu „P. sterilis Grke" entschliessen, einem Namen, der fïr mich einen Nonsens involvirt und den Linné gewiss nie einer Potentilla, welche reichlich Früchte 1rägt, gegeben hätte. Wem er eine Fragaria sterilis anfistellte. so wnsste alle Welt, was er dimit meinte, er stellte sie llen essbaren Erdbeeren als trockenfrïchtig, ungeniessbar, also für den egoistischen Mensehen werthlos und steril gegenïber. (Gilibert nannte sie in Fl. Lithuan. Fragaria sicca.) In ähnlichem, itbertragenen Sinn hat er eine Avena sterilis der Avena sativa gegenüber benant. Die Uebertragung des Speciesnamens sterilis auf eine sehr fertile Potentilla ist gewiss nicht im Sinne Limnés, verstösst auch gegen den Pariser Corlex $\leqslant 60$ n. 3., wonach Niemand einen Namen anerkemen soll, der eine Eigenschaft ausdriickt, lie fïr die bezeichneten Pflanzen absolut falsch ist. Nun. wir haben eben hier eine der sonderbaren Blithen, welche das übertriebene Prioritätsprineip treibt. - Zu meiner Freule sehe ich, lass auch A. Schwarz in seiner ausgezeichneten nenesten Flora von Niunberg-Erlangen (1899) wieler zu P. Fragariastrum Ehrh. zurückgekehrt ist. Andere werlen ihm mit der Zeit folgen.

\section{Potentilla supina L.}

Diese einjährige, selten zweijährige, lkleinblüthige Art mit gefiederten Blättern kommt, mit Ausmahne des mittleren und höheren Erzgebirges sowie des Vogtlandes, dureh ganz Sachsen vor, tritt aber nur an wenigen geeigneten Orten in grösserer Menge, an den meisten dagegen vereinzelt und unbestindig. ja wie es scheint nur versehleppt auf (so anf Kulturland und Sehuthaufen, an Wegen und Bahmbïfen); am häufigsten und beständigsten trifit man sie der libe entlang, luamptsächlich an leren Altwassern, den sogenannten Buhnen auf Sand- und Sehlammboden (!!), auf welch' letzterem sie sich oft erst im Herbst massenhaft und in Riesen- 
exemplaren entwickelt, sodann an den Teichrändern der Gegend um Moritzburg (!!) und der Niederlausitz. In der Gegend von Leipzig ziemlich rerbreitet! (H. Pet.), auch in der forma limosa! - Eine Aufzählung der vielen bekannt gewordenen ,zerstreuten" Standorte scheint hier ïberflüssig und zwecklos zu sein, da die Pflanze bald an einem Ort verscliwindet, bald an einem anderen wieder neu auftaucht.

Auch die I'. supina gehört zu den constanten, wenig zu Abänderungen neigenden Arten. Nlan hat zwar eine kleine, aufrechte Form als Tarietas limosa Boeningh. (var. erecta Spenn.) aufgestellt und Zimmeter hat dieselhe gar zur Species erhoben. Aber schon Blocki, der doch wahrlich mit Aufstellung und Anerkennung neuer Potentillenspecies nicht kargt, erklärt sie als eine blosse Standortsform der P. supina. Dieselbe Ansicht hat neuerdings Poeverlein ausgesprochen, er sieht in ihr , die Form feuchter und ror allem sumpfiger Standorte" (l. c. S. 9).

Davon, dass die P. limosa weiter nichts als eine zwerghafte aufrechte Standortsform der P. supina ist, die kaum den Namen einer Varietät verdient, bin auch ich vollständig überzengt, nur finde ich, dass sie nicht an feuchte und sumpfige Orte gebunden ist, sondern bei uns gerade an stark ausgetrockneten, kiesigen und sandigen Stellen wächst, so z. B. an den Elb-Bulmen bei Loschwitz!! (vereinzelt) und an den Teichen um Moritzburg!! Im Angust 1894 fand ich am Grossteich bei Bärnsdorf (unweit Horitzburg), welcher den Sommer über stark abgelassen war, die I. supina in hunderten ron aufrechten Zwergexemplaren a uf dem abgetrockneten sandigen Strand, zusammen mit ebenso vielen ebenfalls stramm aufrechten Zwergexemplaren der P. norregica. Wenige Schritte davon standen auf feuchtem fettem Schlammgrund zwischen Riedgras beide Arten in riesigen, ansgebreiteten Exemplaren. Leider habe ich damais, da ich mich noch nicht speciell mit der Gattung befasste, versäumt, von jenen Kümmerformen einzulegen - ich hielt sie eben für zu mberleutend. In den letzten Jalnen, als ich die I'. limosa wieder aufsuchte, um Samen zu Culturversuchen zu sammeln, fand ich jährlich nur die gewöhnliche Form bei hohem Wasserstand. Wahrscheinlich wird der Samen der P. limosa auf gutem Culturland sofort die P. supina typica ergeben. Immerhin empfehle ich unseren Floristen, auf diese Form und ihr Vorkommen weiter zu achten, ferner, ob sich da, wo sie mit der P. norvegica zusammen wächst, etwa Zwischenformen zwischen beiden finden. (Siehe P. norvegica L.)

Petermann hat in der Flora lipsiensis, ausser der var. limosa Boeningh., eine Tar. villosiuscula und im Anal. Schlïssel noch eine Var. ternata aufgestellt; aber nach genauer Einsicht der Original-Exemplare in seinem Herbar zu Leipzig (!) kam ich diese beiden Varietäten nicht höher bewerthen, als die Yar. limosa. Die Namen besagen schon alles, was sich über sie sagen lässt: die erste ist nämlich eine etwas stärker behaarte Form, und die zweite eine solche mit vorherrschend dreizähligen (statt gefiederter) Blättern; andere Abweichungen von der typischen P. supina konnte ich nicht wahrnehmen.

Zum Schlusse sei noch bemerkt, dass die P. supina oft an den Stengeln, Blüthenstielen und Kelchen mehr oder weniger zahlreiche kurzgestielte Drïsen aufweist, die freilich nur mit dem Mikroskop deutlich wahrzunehmen sind. 


\section{Potentilla norvegica $\mathbf{L}$.}

Verbreitet und wirklich einheimisch ist die P. norvegica in Sachsen nur nördlich der Elbe, mm die Teiche der Gegend von Moritzburg !!, Dippelsclorf !!, Volkersdorf !!, Kílotzsche !!, Lausa!!, Radeburg ! (H. Dr.), lionigsbriick! (H. Dr.) und anderen Orten der Niederlansitz, wie Bautzen und Königswartha. (Seh" verbreitet in der preussischen Lausitz und weiterhin gegren Norden.) Im höheren Erzgebirge und im Vogtlande fehlt sie (nach Artzt. Säurich. Pause), elenso in der sächsischen Schweiz; dagegen tritt sie in den übrigen 'Theilen Sachsens sehr zerstreut und unbeständig auf, so ein paramal bei Chemnitz "verschleppt" (Pause), in dem unteren Muldengebiet und in der Gegend von Leipzig (I'eterm.), Rohrbach! und Grosssteinberg bei Grimma! (H. Lpz.), in der Oberlansitz, auch am Elbufer bei Dresden! (H. Müller). Es hätte kaum einen Zweck, alle die Orte zu nennen, wo sie cimmal verschleppt und als Gast beobachtet wurle.

Nur mit Wirlerstreben setze ich die P. norvegica vorläufig wieder neben die P. supina, mit der sie ausserordentlich wenig gemeinsam hat, nit welcher man sie nichtslestoweniger in der ganz mnatiirlichen Gruppe der "Acephalae" zu vereinigen ptlegt. lis vor kurzem habe ich sie, besonder's anf (irund ron Petunnikov's Ausführungen (1. c. S. 12), der sich wieder anf die Untersuchungen Ruprecht's bezielst, in die Gruppe der Canescentes, neben die bei ms fehlende P. intermedia L. gestellt, mit welcher sie in der That eine viel nähere Verwandschaft zu besitzen scheint als mit I'. supina. Auch Poeverlein führt (l. c. S. $\boldsymbol{\tau}$ ) dafür eine nene ..Bestätigung". sowie die bestätigenden Beobachtungen ron Focke, leck und Petunnikor an, kann sich aber nicht entschliessen, die bisher iibliche Nebeneinanderstellung ron l'. norvegica und supina - die ja auch Focke beibehalten hat - aufzugeben, ,vor allem durch den Umstand, dass Ascherson und Graebner in der Flora des nordostdentschen Flachlandes (\$. 407) von ihnen selhst gesehene Mittelformen zwischen P. norregica und supina, welche Scharlock gezüchtet, erwähnen". Dies wäre nun für mich kein (irund zur Wiedervereinigung beider Arten in eine (iluppe; demn, so sehr ich auch die sozusagen sponture Bastardbildung im Freien für einen wichtigen Fingerzeig bei der leurtheilung des Verwandtschaftsgrades der Species halte - ich sehe z. B. in der l'. opaca hauptsäehlich wegen ihrer so ungemein häufigen Vermischung mit der 1'. verna eine selır nahe l'erwantte ron dieser - , so möchte ich doch sehr bezweifehn, ob die ans einer '/wangsehe entsprossenen Bastarde (um eine solche himdelt es sich wohl bei den Scharlock'schen Versuchen) denselben phylogenetischen Werth hahen, wie die l'roducte freier Liebe (figürlich gesprochen). Ein natiirlicher Bastard ist meines Wissens zwischen P. norvegica und l'. supina noch nicht bekannt geworden. Auch ich halse am Grossteich bei Moritzhurg. wo hunderte von Exemplaren beider Arten durcheinander standen (cfr. 1'. supina), nichts dem Aehnliches beobachtet. - Mit der Acephalie der L'. norverrica ist es auch so eine Sache. Petunnikor bestreitet sie und häilt sie für zweijährig; ,Der Büischel von Wurzelb] iittern entwickelt sich immer erst im Herhst an Grunde der fruchttragenden Stengel, wie bei P'. intermedia und den meisten mehrjährigen Arten". Von der lichtigkeit dieser Beobachtung kann sich Jeder iiberzeugen, der sich im Herbst an die Volkerstorfer Waldteiche 
unweit Ioritzburg begeben will, wie ich am 1. October 1899 gethan. Er wird am Grunde der allermeisten abblühenden oder schon abgeblühten Stengel eine oder auch zwei Rosetten von Wurzelblättern finden, die im nächsten Jahre sich weiter entwickeln werden, daneben aber auch nicht selten noch den deutlichen Rest eines vorjährigen Stengels, so dass also riele Pflanzen wenigstens drei Jahre auszudauern scheinen. - Auch in der Inflorescenz sind beide zusammengekuppelte Arten sehr rerschieden: nach dieser gehört die P. norregica zu den Potentillae terminales, die P. supina dagegen zu den Potentillae axillares (axilliflorae), wenigstens mit demselben Recht wie die P. Tormentilla. - Endlich zeigen beile Arten eine ganz verschiedene Behaarungsart. Dieses Moment aber, nämlich die Behaarungsart, ron dessen grosser phylogenetischer Bedeutung ich im Verlanf meiner Potentillen-Studien jeden Tag mehr überzeugt werde, hat mich bewogen, die P. norregica wieder aus der Gruppe der Canescentes zu entfernen, nicht um sie eng mit der P. supina zu vereinigen, sondern um sie, wie diese, vorläufig ausser engeren Verband mit unseren anderen Arten hinzustellen. bis ihre systematische Stellung weiter geprüft sein wird.

Die P. norregica zeigt zunächst, auch unter dem Mikroskop, keine Spur von dem bekannten gekräuselten Filz der ganzen Canescens-Gruppe, und wemn Uebergänge zu der I'. intermedia L. beobachtet wurden, können solche meines Erachtens nur Bastardformen darstellen. Uebrigens scheint auch die Natur und Stellung der P. intermedia selbst durchans noch nicht vollständig aufgeklärt zu sein. Vergleichen wir aber die langen schlichten Haare der Canescentes (unter dem Mikroskop) mit denen der P. norregica, so finden wir einen ganz merkwürdigen Unterschied: schon bei schwacher Vergrösserung erscheinen die der letzteren mit doppelter Contour der Zellwand und wenigstens dreimal so dick als die der P. canescens oder argentea. Die starke Zellwand allein ist schon so dick, wie das ganze Haar der P. canescens. Die P. norvegica besitzt ron allen europäischen Potentillen, die ich untersucht habe, die stärksten und dicksten Haare und erinnert ( - merkwürdigerweise auch in den ähnlichen dreizähligen Blättern -) an die mit ,stechenden“ Haaren versehene P. asperrima Turcz. aus Dahurien (cfr. Lehm. Rev. Pot. S. 153 u. t. 52.) sie stellt einen besonderen Beharrungstypus dar! Stieldrüsen (wie bei P. supina) habe ich bei ihr nie beobachtet, wohl aber sporadische Sitzdrïsen. Die langen starken Haare sitzen, ähnlich wie bei P. recta nnd P. thuringiaca, auf' kleinen Tuberkeln ("pilis majoribus tuberculis insidentibus"), wie schon Lehmann richtig bemerkt, und was in der ganzen Canescens-Gruppe niemals vorkommt. - Mehr Aehnlichkeit hat die Behaarung der P. norvegica mit der der Recta-Gruppe, doch fehlt ihr unter anderem der liurze Filz steifer Borstenhärchen am Stengel, welcher diese so gut charakterisirt.

Mag nun später die P. norregica eine Stellung in System eimnehmen welche sie wolle, so viel scheint mir schon jetzt gewiss, dass sie weder in der unmittelbaren Nähe der P'. intermedia, noch in der ron l's supina Platz finden wird. Um über die Stellung beider weitere Aufschlüsse zu erlangen, dürfte es sich empfehlen, ihre aussereuropäischen nächsten Verwandten zum vergleichenden Studium heranzuziehen: für unsere P. norvegica die P. labradorica Lehm. und $P$. millegrana Engelm., für unsere P. supina die P. cicutariaefolia Willd., P. Heynii Roth, P. paradoxa Nutt. und P. rivalis Nutt. 


\section{Potentilla rupestris $\mathbf{L}$.}

Diese schöne weissblühende Art mit gefiederten Blättern wächst am liebsten auf somnigen Ilügeln und an trockenen Felsabhängen zwischen lichtem Gebüsch, ist aber in Sachsen wenig verbreitet. Zunächst finden wir sie wieder im Elbh ügellande zwischen Meissen und Riesa: Proschwitz bei Meissen ! (H. Dr.), Ablänge bei Zadel !!, Diesbar ! (H. Dr.). Seusslitz !!, Blatterslebener Grund !! (Hfm.), bei Merschwitz!! und Leckwitz ! (H. Dr.); sodamn im Thal des Lommatzschwassers: bei Schieritz!! (rechte Thalscite), Prositz! (H. Dr.), Wachtnitz!! und Leuben! (Hfm.). - In der Lössnitz bei Dresden (Rehb., Wsch.) scheint sie in nenerer \%eit nicht mehr beobachtet worden zu sein. - Ausser dem Elbhïgellande ist sie sehr selten; sie wurde schon von Rchb. in den Hohburger Bergen bei Wurzen angegeben und daselbst von H. Miiller 1898 wieder gefunden! Ob sie jetzt noch bei Kileinwelka und Loga unweit B a u tzen (Rchb.) vorkommt, konnte ich nicht in Erfahrung bringen. - Im Zeisigwald bei Chemnitz fand sie sich verwildert mit anderen Gartenfliichtlingen! (Säurich).

Die P. rupestris besitzt am oberen Theil des Stengels und an den Blüthenstielen meistens rejchliche Dr üs enhare. Ich bemerke dies erstens, weil es in vielen Floren nicht angegeben wird (z. B. in unseren sächsischen), während es in anderen (z. B. in Lehmann's Monographie und Ascherson's Flora des nordostdeutschen Flachlandes) in die Charakteristik der Species aufgenommen ist, und zweitens weil ich auf die Bedeutung der Drïsenhaare bei den Potentillen noch besonders zu sprechen kommen werde. Ich untersuchte Exemplare der P. rupestris aus anderen mitteleuropäischen Ländern, welche sehr spärliche Drüsen (nur unter dem Mikroskop) erkennen lassen - an einem Cultur-Exemplar des Siegfried'schen Potentillarium in Winterthur entdeckte ich mit Niihe nur ein paar - und möchte die Frage aufstellen, ob es nicht auch eine "forma eglandulosa" gebe? in welchem Fall wir dann die gewöhnliche Pflanze (auch alle unsere sächsischen) als "forma glandulosa" unterscheiden müssten, wie dies bei der P. arenaria und der P. opaca geschehen wird.

An recht sonnigen trockenen Abhängen wird die P. rupestris zur P. mulicaulis Jord., die anch Zimmeter unter besonderer Nummer mit diesem binären Namen aufführt, obgleich er sie selbst nur als ,eine unbedentende Varietät mit tief blutrothem Stengel" erklärt. Warum dann aber noch die Coordination neben der P. rupestris und nicht gleich die Subordination unter dieselbe als ,forma rubricaulis"? Ich sage forma, denn sie ist nicht einmal eine Varietät, sondern nur eine kaum erwähnenswerthe Standortsform, wie sie bei hundert anderen Pflanzen rorkommt. Von dem Zadeler Felsabhang - auch bei Wachtwitz fand ich sie - in meinen Garten unter dichtes Gebiisch verpflanzt, wurden in folgenden Jahre ilıre Stengel grün, und im nächstfolgenden, wieder an eine somige Steingruppe versetzt, rötheten sie sich stark. - Die Röthung des Stengels an sonnigen, trockenen Standorten tritt bei einer grossen Zahl von Potentillen-Arten auf, so bei $P$. argentea, canescens, recta, rema, opaca, reptans etc., auch bei mehreren alpinen Species. Es ist ganz überflüssig, bei allen diesen eine "forma rubricaulis" aufzustellen.

Die P. mbricaulis Jord. ist ein gutes Beispiel zur Erläuterung des Werthes vieler Jordan'schen „Species". Ton dieser Sorte und von solchem 
Werthe sind die meisten seiner zu Dutzenden aufgestellten PotentillenSpecies. Nachdem sie lange Zeit der verdienten Vergessenheit und Nichtbeachtung anheimgegeben waren (so auch von Lehmann in seiner ausgezeichneten Monographie) hat sie Zimmeter wenigstens zum grossen Theil wieder ausgegraben und zu Ehren gebracht. Nun, wenn dies im Jahre 1884 ,nur der Vollständigkeit des Litteraturverzeichnisses halber", wie Zimmeter sagt, geschah, so mag es lingehen, aber wemn man heute, nach 20jähriger Potentillenforschung nicht nur solche Formen noch immer als „Species" mit binärem Namen fortschleppt, sondern auch täglich noch immer neue, ebenso hoch einzuschätzende ,Species" dazu stiftet, so wird es doch zu arg und an der Zeit darïber nachzudenken, ob man diesen sich bergehoch anhäufenden Wust, wenn auch nur als litterarischen Synonymenballast, noch mitzuschleppen gezwungen werden könne, oder ob man ihn nicht einfach ignoriren dürfe, ohne gerade den Vorwurf der Unvollständigkeit und Oberflächlichkeit auf sich zu laden. - Was soll man dazu sagen, wenn ein gewisser Florist in seinen ,Beiträgen zur Flora des Trentino “*) auf einmal, sozusagen auf einem Spaziergange von Trient zum Gardasee, anno 189615 neue Potentilla-Species und 2 neue Varietäten aufstellt! Ist es da leicht, den Argwohn zu unterdrücken, dass so etwas um des lieben „mihi“ willen geschieht? Wenn man bedenkt, dass oft jahrelange Beobachtung dazu gehört, um iiber die richtige Stellung einer Varietät oder eines Bastardes in's klare zu kommen, so muss man entwerler sich selbst füir den unfähigsten Beobachter halten, oder jene "Specialisten" und "Mihilisten", welche die Species schockweise fabriciren, des grössten Leichtsinnes zeihen, denn ,der einmal gedruckte Name versteinert, wenn auch nur zum Koprolithen; er lässt sich nicht wieder ans der "Welt bringen", sagt Focke**); er vermehrt den Inhalt des „Augiasstalles" der PotentillaNomenclatur, oder des litterarischen "Composthaufens" wie ihn Focke ebenfalls benennt. Wohin sollten wir denn schliesslich in der Systematik kommen, wem alle Gattungen und Species des Pflanzenreiches so bearbeitet und zerarbeitet würden wie Potentilla oder Rubus und Rosa von gewisser Seite? Vor lauter Bämmen sieht man den Wald nicht mehr. die Uebersicht geht verloren! Verschafft man sich durch Tausch und Kauf die neugeprägten, nicht selten nur anf individuelle Abweichungen gegrïndeten Species, muss man sich oft genug ärgern, dass man sein Geld für nichtssagende Standortsformen ausgegeben hat. Nun, man muss eben die Enttäuschung nicht zu tragisch nehmen und sich trösten:

\section{,Zwar seh ich selber nichts _ - - \\ Auch Bileam sah nicht, was mit erstauntem Blicke Sein Thier erleuchtet sah."}

Glücklicherweise bricht sich in neuester Zeit die Ansicht mehr und mehr Bahn, dass es mit der Speciesmacherei nicht so fortgehen könne und dürfe. Zu dieser Wendung zum Bessern und zu der Rïckkehr zu einem praktischen Speciesbegriff, welche einen wahren Fortschritt bedeutet, hat besonders die Auctorität Ascherson's, auch weit über Deutsch-

*) Vernandl. d. 'k. k. zoolog.-bot. Ges. in Wien, 1896, S. ว5.

**) Synopsis Ruborum Germaniae (1877), S. 58. Was dort über die Rubus-Nomen. clatur und -Forschung, zum Theil mit recht drastischen Worten gesagt wird, kam noch heute auf die Potentillen-Nomenclatur und - Forschung angewendet werden. 
lands Grenzen hinaus, heigetragen, dessen grösstes Verdienst ich darin erlolicke, dass er mit krïftiger Hand die rom Specialisten besonders in den letzten Deeenuien gemachten ,.Species" zu Dutzenden, ja zu Hunderten streicht, sie ihres unverdienten hinären (Species-) Namens berauht und sie dahin verweist, wohin sie gehören: zu den Varietïten und lormen, umbl dass er fïr diese letzteren, soweit immer thunlich, eine einfache treffende bezeichnung wïhlt.

Wem ich mich entschieden anf den Standymlit einer erweitert en Auffassung der Species stelle, wie sie Limné, Kónch. Lehmann mul die meisten älteren Botaniker vertreten haben. so bin ich doch weit entfernt daron, zn leren Definition ofer zu deren duffassung tes Wesens der naturhistorischen Species zunickinkehren, nach welcher sie etwas in sich Alugeschlossenes, etwas tiir sich ohne genetischen Bezug anf ihre Mitspecies Erschaffenes sein sullte, mach tler alle Individuen, welche unter sich fruchtbare Nachkommen erzengen, eine Species bilden sollten und was dergleichen mehr ist. leh stehe durehaus anf dem Borlen der Erohtions-oder Descendenz-Theorie. Die Natur schafft keine Species mnl Gattungen, sondern nur Individnen, von denen jedes ron allen anderen unterschieden ist. Im engsten Sim ist jedes Individum eine Speeies mul es wäre ja recht schön und geradezu ideal, wenn wir jedes Individum mit einem binären Namen anrufen kömnten, wie wir jeden Nenschen cinen Vor- und Zunamen gebern: aber dies geht iiber die Fassungskraft des beschränkten Mensehengeistes hinaus (- mu .. Gott der Herr rief sie mit Namen, dass sie all' in's Leben kamen" -). Die (iattungen und Species schafit ijh der Mensch durch Abstraction a us praktischem Bedïrfuiss, und der naturhistoriselse Begrift der Species ist weit verschieden von der scholastisch - philosophischen Idee derselben, die ms hier gar nichts angeht, weil sie sich nicht anf unsere maturhistorische species iiluertragen lässt.

Da nun die naturhistorische species eines ler Mittel ist, dem beschränkten Fassungsvemögen des menschlichen Geistes zu Hilfe zn kommen, muss sie, um ihren Zweek zu rreichen. eminent praktisch sein, weit gefasst und weit umgremzt werden, und dieser erweiterten Auffassung muss sich lie Nomenclatnr anpassen, indem nur die Species - nicht aber Varietäten und Formen - einen binären Namen tragen diinfen W'em wir daran nicht festhalten, gelangen wir allmählich in eine nicht mehr zn bewältigende Kersplittermg md Ordnungslosigkeit hinein, welebe das phylogenetische Verstäldniss der Arten nicht nur nicht erleichtert, sondern sogar mendich erschwert. Gierade rom Standpunkt der Descendenz-Theorie ans seheint es mir noch mehr ats rom reralteten Stanlpunkt ans gehoten, den Begriff der Species elier zu erweitern als zu verengern, da ja die sie repräsentirenden Individuen keine fertig erschaffenen. scharf mmrenzten und stabil bleibenden Typen, sondern nur die Durchmangsprukte einer mendlichen Reihe sich ewig umbildender und daher verändertichen Formen vorstellen. - Es ist ein gliicklicher Zutall, dass die alten Botaniker mit ihren Begriffen über las Wesen der Species zu einer so weiten Umgrenzmng derselben gekommen siml, dass diese Umglenzung in den meisten Fällen auch nach der neuen Auffassung des Speciesbegriffes weiter bestehen kamn.

Aber nicht nur die Erhebung ron Formen zu Species, sondern auch die Aufstellung ron zu vielen Formen ist verwerflich und praktisch wie theoretiseh werthlos. Der gewiss richtige Grundsatz, dass wir uns nicht meln, wie so lange in friberen \%eiten, mit dem Kemenlernen und Einsammeln der, guten Speeies" begnügen diirfen, sondern auch den Varietäten und Formen msere Aufmerksankeit schenken mïssen, ist von Manchen so anf die Spitze getrieben und übertrieben worden, dass seine Auswüchse an's Kindische und lächerliche grenzen - wem sie nur nicht auch ihre ernste Seite hiitten, Der Specialist wird bei seinen Forschungen natürlich jede Form beachten und jede Abweichung auf seinen Herbar-Etiquetten notiren; aber die öffentliche, sozusagen officielle Aufstellung in der Litteratur von vielen ganz sellustverstïndlichen, Eormen", die sich bei unzähligen Pflanzen wiederholen und oft noch weniger als Standortsformen sind, wie z. B. forma elatior, hunilior, major, minor, internedia, umbrosa, apriea, minima, pusilla, minuta, pygmaea ete., stets mit den obligaten 
„n. f. mithi" dahinter, die Aussehreibung und Anpreisung derselben, oft als gute Varietäten, in Kauf- und Tauschkatologen, ihre Ausgabe in theuren Exsiccatenwerken, lässt die Frage aufwerfen: hat an der Schaffung soleher Formen in der Litteratur mehr die Auctoren-Eitelkeit, orer der Gelderwerb oder die Verlegenheit, die Lieferung eines Exsiceatenwerkes completiren zu müssen, Antheil? Nenlich hörte ich zwei Botaniker darüber streiten, ob ein solehes Gebahren in den Paragraphen des "Groben Unfuges" oder in den des "Unlauteren Wettbewerbes" falle. - Auch die botanischen Zeitschriften, die ja hin und wieder an Stoffmangel leiden mögen, könnten doch manchmal ihren Lesern etwas Besseres hieten, als die minutiöse Beschreibung solcher Waaren, die mit einer lächerlichen Wichtigthnerei breitgeschlagen werden, um in kïrzester Zeit der verdienten Vergessenheit anheimgegeben oder auf Focke's, ,itterarischen Composthaufen" geworfen zı werden, welchen damn später wieder irgend ein „,botanischer Lumpensammler" durchwiihlt.

\section{Potentilla palustris Scop.}

(Comarum palustre L.)

Die P. palustris ist, wie ihr Name sagt, eine Sumpfpflanze, die Moorboden vorzieht; man findet sie an den geeigneten Stellen ziemlich verbreitet durch das ganze Gebiet, am häufigsten in den Teichgegenden nördlich der Elbe und durch die Niederlausitz, sowie auf den Hochmooren des Erzgebirges und Vogtlandes; wo grössere Teiche und Moore fehlen, wird sie natürlich selten oder fehlt ganz.

Es ist merkwürdig, wie verschieden sich die Floren über die Behaarung der Blättchen bei P. palustris ausdrïcken; Ascherson nennt sie „unterseits blaugriin, filzig", Karsten: ,unterseits zart- und dichtfilzig, oberseits seidenhaarig", Heynhold: „oberseits kahl, unterseits angedrückt feinhaarig", Lehmann: ,foliolis subtus glaucis, puberulis" ete. Am besten drückt sich Schlechtendal's Flora von Deutschland (5. Aufl. von Hallier) aus: „Blättchen je nach dem Standorte mehr oder weniger mit kleinen anliegenden Haaren besetzt". So ist es in der That; es kommen alle Uebergänge von fast ganz verkahlten bis zu stark behaarten Formen vor, aber auf diese Behaarungsstufen Varietäten zu gründen, geht meines Erachtens nicht an, deshalb halte ich auch die Var. subsericea W. Becker (sub Comaro, in Deutsch. bot. Monatsschr. 1897. 3.) - es liegen mir Original-Exemplare vom locus classicus, „Sumpf bei Wettelrode am Harz, $189 \%$ "vor - für eine blosse Standortsform, die nicht eimmal zu den stark behaarten gehört.

Schon Lehmann hat eine Var. $\beta$ villosa ,foliis supra villosiusculis, subtus subtomentosis" unterschieden (giebt aber für ihr Vorkommen nur Groenland an). Diesen Charakter zeigen Exemplare ,,ron Torfwiesen bei Grimma" ! und von Groitsch ! (H. Lpz.) in der Flora von Leipzig; ich kann sie jedoch nicht höher bewerthen, als die Becker'sche Var. subsericea, trotzdem sie riel stärker behaart sind als diese.

Ich sehe mit Lehmann und Focke keinen Grund, diese Species aus der Gattung Potentilla auszuscheiden und zur besonderen Gattung „Coma- 
mu" zu erheben. Auch Schinz und Keller reihen sie in ilner neuesten "Flora der Schweiz" (1900) wieder bei l'otentilla neben der l'. rtuestris ein*). Das llauptmerkmal des schwammigen Bliithenbodens ist zu unwescntlich für einen Gattungscharakter und ilır nicht eimmal eigenthümlich. Ich halte es für angezeigt, wieder an die Worte Lehmann's (Rev. Pot. S. 74) zu erimnern:

. Wenn man die Beschaffenheit des Fruchtbodens bei mehreren Potentillen aus der Gruppe, Glandulosae und insbesondere bei $P$. arguta beriicksichtigen will, die Hooker (l'l. Boreal. Americ. I, tab. 63) trefflich abbildete und woron er sagt: , receptaculum carnosum fere ut in P.palustri'!, wenn man zugleich beruicksichtigen will, dass wir jetzt bei $I$. polyphylla und Kleiniana ein , carpophorum in fructu spongiosum kemnen, welches von I'. polyphylla häufig gegessen wird, dass endlich Turezaninow eine Potentilla aus der chinesischen Mongolei beschrieb, woron er bemerkt (Bullet. de la soc. des natur. de Moscou XVI, p. 621): petala in acumen prolongantur et sic transitum petalorum L'otentillarum in illa Comari demonstrant', so dïrfte die Vereinigung von Comarum mit Potentilla nicht wohl länger beanstandet werden können."

Dem füge ich bei, dass die P'. palustris an den blïthenstielen und Kelchen sehr reich an grossen mehrzelligen Drüsenharen ist (ähnlich wie P. recta und I'. opaca f. glandulosa); ferner dass anch bei der I'. supina der Fruchtboden sehwammig ansehwillt, wenn auch weniger stark. Letztere führt gewöhnlich ebenfalls Driisen, wie ich bei ihrer Besprechung bereits angab. Beide gehören zu den Potentillen, deren untere Blätter unregelmässig gefiedert sind und in obere dreizählige iibergehen. Allerdings hat P. palustris einen fadenförmigen (gleichdicken) Griffel, während der von P. supina spindeltörmig (in der Mitte verdickt) ist. Nach Focke bedingt die Griffelform ein wichtiges Mlerkmal für die Unterscheidung der Gruppen; aber wir wissen doch noch nicht genau, inwieweit und ob in allen Fällen eine Versehiedenlneit in dieser Beziehung eine nahe genealogische Verwandtschaft ausschliesst oder eine Ueberemstimmung eine solche einschliesst. Ich erimere nur daran, dass z. B. die P. rupestris denselben spindelförmigen Griffel besitzt wie die I'. supina, und trotzdem ist es noch Niemanden eingefallen, nur aus diesem Cirunde beide in nahe genetische Beziehung zu einander zu bringen. - Auch die Acephalie dürfte kein llinderniss sein, die R. supina mit Species multicipites in eine Gruppe zu rereinigen, wem wichtige Grinde dafür vorliegen. Wie oft kommt es bei anderen Pflanzengattungen vor, dass die nächstrerwandten Species theils einjährig, theils vieljährig sind, die man nur kïnstlich in zwei verschiedenen Gruppen untérbringen kïmte.

Ich rede hier der directen Einberielınng der P. supina in die Gruppe (ler l'alustres durehans nicht das Wort, aber man darf an gewisse Uebereinstimmungen erinnern und seine Gedanken darüber haben. Wenn Alefeld die I'. supina .Comarum supinum" namte, so war diese Zusammenstellung mit dem Comarum palustre kaum unnatiirlicher, als die der P. supina mit der P'. norregica.

*) Auch Koch zog in einem nachgelassenen Januscript die Gattung Comarum ein und zog sie zu Potentilla. 


\section{Potentilla argentea $\mathrm{L}$.}

Ueber die Verbreitung der P. argentea L. (im weiteren Sinne) braucht man kein Wort zu verlieren; Allen ist bekannt, dass sie, wie in ganz Deutschland, so auch in Sachsen zu den verbreitetsten Species gehört, die vielleicht nur dem höchsten Erzgebirge fehlt (\%). Ihr grösster Formenreichthum aber fällt wiederum in das Elbhügelland.

Das Characteristicum der ganzen Canescentes-Gruppe, in welche wir mit der P. argentea eintreten, und die man in drei Untergruppen: Can. argenteae, Can. collinas, Can. verae, abtheilen kann, bestelit darin, dass sie ausser den längeren und liürzeren Haaren, wie wir sie bei allen Potentillen kennen, am Stengel und besonders auf der Unterseite der Blätter noch einen aus sehr feinen, gekräuselten Ifaren bestehenden Filz tragen, welcher bei den Canescentes argenteae am dichtesten, bei den Canescentes verae und collinae weniger dicht auftritt.

Die Unterscheidung der Canescentes argenteae oder der Gesammtspecies P. argentea L. von den Canescentes verae oder der Gesammtspecies P. canescens Bess. wird dem geibten Botaniker in praxi meistens nicht schwer fallen, er erkennt beide gewöhnlich schon auf den ersten Blick und aus der Ferne, nichtsdestoweniger ist es gar nicht leicht, die Unterschiede in eine präcise, sichere Diagnose zu fassen. Es ist mehr der Gesammteindruck der Pflanze, welcher uns die Unterscheidung erleichtert, als die wenigen wirklich constanten Unterschiede, auf die man meistens nicht einmal achtet, wie z. B. dass bei P. canescens die reifen Früchtchen faltig runzelig und gekielt, bei P. argentea aber feinrunzelig und nicht gekielt sein sollen. Die meisten Unterscheidungsmerkmale, die noch angegeben werden, sind ungemein elastisch, immer nur + zutreffend, Ausnahmen erleidend, so z. B. bei P. canescens der Stengel aufrecht, bei P. argentea aufsteigend; dort die Blüthen bis mittelgross, hier meistens kleiner, die Blättchen dort flach, hier am Rande umgerollt, dort weichzottig, hier filzig u. s. w. - Wenn diese Schwierigkeit schon bei der Diagnostik zweier guter Species auftritt, so steigert sie sich bei der Unterscheidung der Varietäten und Formen der P. argentea fast bis zur Unmöglichkeit. Wir treten hier in eine für Viele recht unsympathische Formengruppe éin, deren Glieder sich keiner Subordination fügen wollen und mehr als in irgend einer anderen unter sich verschwimmen. Wir fühlen recht wohl, dass verschiedene Formen vorliegen, aber präcis abgrenzen lassen sie sich nicht, wir können nur einige extreme Formen mit besonderen Yarietätsnamen bezeichnen und es wird in vielen Fällen dem subjectiven Empfinden des Floristen anheimgestellt sein, welcher derselben er eine gegebene Pflanze anreihen will. Diese Unzulänglichkeit hat natürlich für denjenigen, welcher die Formen eben für das nimmt, was sie sind, d. h. für unbeständige Varietäten, weniger zn bedenten, als für jenen, der sich ängstlich - aber vergebens - abmüht, ihnen ihre Stellung als „Species" zu vindiciren. Es mögen meinetwegen in der Entricklung begriffene und in einer fernen Zukunft constant werdende Species sein, rorläufig sind sie es aber nicht und dürfen auch keine binären Speciesnamen tragen. Gerade in einem so complicirten und schwierigen Formenkreis ist es von Wichtigkeit, dass die Tarietäten möglichst bezeichnende Namen (statt der nichtssagenden Personen- und Localnamen) erhalten. Glücklicherweise ist dieses Princip bei der P. argentea bisher besser durch- 
gefïlut worlen als in den Gruppen der P'. canescens, I'. collina und anderen. Selbst 'Limmeter hat sich hier im wesentlichen darauf beschränkt, die alten Lehmann'schen Varietäten zu Species zu erheben und sie in seiner Art ordnungslos nebeneinander zu stellen, nur ein paar neue hat er beigefügt. Von diesen, ,Species" kommen in unserem Gebiet folgende 7 oder $S$ in Betracht: I. arjentea Zimm. (d. h. sensu strictissimo), P. decumbens Jord., $P$. septemsecta (Meyer) Zimm., P. tenuiloba Jord., P. demissa Jord., $P$. incanescens Opiz, und $I$. dissecta Wall.

Wenn wir nun diese Varietäten und Formen auf ihren Werth prüfen und nach diesem orlnen wollen, so fragt es sich zuerst, auf welche Unterscheidungsmerkmale wir das Hauptgewicht zu legen haben, und da stossen wir sofort auf hedeutende Schwieriglieiten. Sollen wir die Varietäten auf die Behaarungsverhältuisse der Blattoberflïche gründen und ihnen auf Grund der Gestalt der Theilblättchen "Formen" unterordnen, oder umgekchrt?*) Beide Motive - und es sind fast die einzigen greifbaren scheinen mir ziemlich gleichwerthig (oder gleich geringwerthig) zu sein. Sodann wiederholen sich bei den oberseits stark beharten Varietäten dieselben Blattformen wie bei den kahlen, und umgekehrt treten bei allen auf den Blattschnitt gegriindeten Varietäten dieselben versehiedenen Behaarungsformen auf. Wir werden also wohl beicle Motive combinirt zur Aufstellung der Varietäten verwenden miissen, wenn sich auch auf diese Weise deren Zahl etwas rergrössert. - Eine grosse Schwierigkeit für die Absonderung der Varietäten liegt darin, dass die I'. argentea eine Art Saison-Dimorphismus nicht uur bezüglich der Blattformen, sondern auch bezüglich der Behaarung zeigt, auf den meines Wissens noch nicht genügend hingewiesen wurde, obwohl seine Bedeutung in der Verna-Gruppe schon vielfach gewiudigt worden ist. Wir werden eine Pflanze öfters in ganz verschiedene Varietäten stellen müssen, je nachdem uns nur die unteren und mittleren bis Juli sich entwickelten Stengelblätter - die Wurzelblätter sind hier ganz ungeeignet - bei der Bestimmung zur Verfügung stehen, oder eine im llochsommer und bis in den Spätherbst hinein weiter ausgewachsene Pflanze vorliegt, an der vielleicht die unteren Stengelblätter schon ganz rertrocknet sind; eine P. arg. dissecta kann zur incanescens, eine tenuiloba zur argentea typica, oler diese zur incanescens (respective subincanescens) werden u. s. w.

Alle diese Beobaehtungen und Bemerkungen tragen dazu bei, uns eine Einsicht in das unstäte Treiben, sozusagen in den Gährungsprozess einer polymorplien Art, wie es die P. argentea ist, zu versehaffen, und uns mehr und mehr davon zu überzeugen, dass in diesem Formengewir rou, guten"Species keine Rede sein kann, sie dürfen uns aber nicht abhalten, die Varietiten und Formen zu sammeln, zu vergleichen und auf's eifrigste zu studiren.

Es sei mir gestattet, an dieser Stelle einen T'assus aus Poeverlein's Abhandlung (p. 5) einzuschalten: "Bei der Benutaumg des Materiales habe ich vor allem darauf grossen Werth gelegt, die Formen nicht einfach nach einigen besonders charakterisirten Merkmalen einem Typus unterznordnen, mit anderen Worten, mit einem Namen zu belegen, soudern auch etwaige Abweichungen von len bereits beschriebenen Typen,

*) Den ersteren Weg schlïgt A. Schwarz in seiner kïrzlich erschienenen Flora ron Nïrnberg-Erlangen (1899) ein; allerdings nicht ganz conseruent, denn er müsste eigentlich die Tar. $\gamma$ dissecta der Var. 3 . incanescens subordiniren, wie er die kahleren Blattformen alle der Tar. typica suborlinirt hat. 
wie sie ja an fast allen Exemplaren sich finden, zu constatiren. Wie rerderblich das erstere Verfahren ist, geht schon daraus herrol, dass ljei seiner Anwendung die einzelnen Formen in der Litteratur stets durch gut ansgerrägte Merkmale streng' von einander unterschieden erscheinen. während in Wirklichkeit zahllose Uebergänge zwischen denselben existiren, ja sogar oft Formen, welche die charakteristischen Nerkmale ron drei oder mehreren Formen in sich rereinigen."

Das ron Herrn Poeverlein angewandte nud empfohlene Verfahren ist gewiss das einzig richtige, das den Specialisten in der Erkeuntuiss seiner Gattung fördert. Es fragt sich nur, ob und wie dasselbe in der Litteratur praktisch rerwendet werden kaun. In einer ausfïhrlichen Specialarbeit, welche sich zur Aufgabe macht, die Potentillen-Formen eines begreuzten Landes aufzuführen, macht ja die Beschreiloung auch einzelner, namenloser Zwischenformen keine Schwierigkeiten. wie die Arbeit Poeverlein's beweist, aber in einer allgemeinen MIonographie und auch in den gewölnnlichen Floren geht das nicht an, und ich sehe nicht ein. wie wir an dem "verderblichen" Verfahren rorbeikommen könuen, in der Litteratur die Formen ,durch g'ut ausgeprägte Nerkmale* roll einander zu unterscheiden. Das Einzige, was man thun kanu und sollte, ist, zu betonen, dass und in welcher Richtung Zwischenformen und Uebergänge vorkommen, ohne diese im einzelnen zu beschreiben. Alver die Typen mitssen beibehalten und gut unterschieden werden, wenn wir nicht zu einer unendlichen Zersplitterung in Subvarietäten und Subformen kommen wollen. die zuletzt in eine Individuenbeschreibung ausarten würde (siehe Peter-Naegelis Hieracien!). und nicht eimmal mehr theoretisches Interesse böte, abgesehen daron, dass sie für gewöhnliche Sterbliche unbrauchbar würde. Letztere werden sich immer an genau unterschiedene und nach der Beschreibung unterscheidbare Typen halten und wemn sie theissig sind, etwaige Abreichungen daron auf den Etiquetten ihrer Herbar-Exemplare bemerken. Eins aber ist nothwendig und erleichtert die Sache wesentlich, dass man den Tarietäten, die man aufstellt, auch in der Diagnostik einen gewissen. nicht zu engen Spielraum gönut - das Abändern liegt $j a$ in der Natur derselben - und sie nicht immer in sensu strictissimo nimmt, in dem sie die Auctoren zuerst aufgestellt und durch die kleinlichste Individuenbeschreibung gekeunzeichnet haben. So wird es z. B. schwer halten, eine P. argentea Trar. tenuiloba (Jord.) zu finden, wenn man von ihr verlangt, dass sie in den kleinsten Kleinigkeiten mit dem ron Jordan in einer seitenlangen Diagnose beschriebenen Individum stimme, während sie in einem rernüuftig erweiterten Sinn aufgefasst allenthalben nicht selten ist. Es wäre daher das Beste, bei solchen Varietäten, luesonders bei denen, die schon durch ihre Namen das Charakteristische ausdriicken, den Anctormamen wegzulassen oder wenigstens demsęlben ...im erweiterten Siun" beizufügen.

Zur Besprechung unserer Varietäten übergehend, möchte ich nun ror allem aus der Zahl der weiter oben mit binärer Bezeichnung angeführten die P. septemsecta Zimm. ausscheiden und sie als Forma septenata (Lehm.) hinstellen, welche bei allen Varietäten vorkommen liann und in der That bei rerschiedenen derselben beobachtet worden ist. Ich weiss wohl, dass ich mich damit nicht nur mit Zimmeter, sondern auch mit Lehmann und mit Poeverlein in Gegensatz stelle, welch' Letzterer die P. septemsecta eine ",ausgezeichnete Form" nennt und behauptet: "Das Torkommen siebenzähliger Blätter bei den Argenteae erscheint als Seltenheit und deshalb wohl geeignet, die mit siebenzähligen Blättern rersehenen Formen ron den anderen zu trennen" (1. c. S. 52). Merkwürdig, dass ich gerade durch die relative Seltenheit dieser Form zum entgegengesetzten Schluss kim. Nach meinen Beobachtungen ist die septenata - wenigstens hier in Sachsen und besonder's im Elbthal - gar nicht so selten wie man annimmt, man hat nur nicht auf sie geachtet, aber sie kommt nicht truppweise, sondern vereinzelt, d. h. in einzelnen Stöcken zwischen vielen Stöcken, die nur fünfählige Blätter besitzen, ror, und zwar in der Varietät, die gerade an der Localität herrscht. Diese Art des Auftretens macht auf mich den Ëindruck, als ob wir es nur mit einer individuellen Abänderung zu thun haben, wenn ich auch nicht anzugeben wiisste, welche Ursache derselben zu Grunde liegt (dies kömnen wir ja überhaupt in den allerwenigsten Fïlen). Ich beobachtete und sammelte 
P. argentea typica $f$. septenata hei Wehlen und bei Döltzschen iuber dem Plauen'sehen Grund, sah sie anch von Frauenhain bei Grossenhain (leg. IIofn.), Tur. temuiloba f. septenatu bei Dresden-P'lauen und Alt-Coschüitz, Tur. dissecta $f$. septenata besitze ich ron Wahnitz in Lommatzschthale (leg. llfm.) und beobachtete sie bei Prositz. Ganz besonders gern scheint sie sich bei den schlitzblätterigen Varietäten tenuiloba und dissecta ein. zustellen, durch Theilung der heiden äusseren Theilblättchen in je zwei. Die ron Plauen bei Dresilen cultirirte ich mehrere Jalne im Garten. Im ersten Jahr nach dem Versetzen kamen fast nu fünfzählige, in den folgenden aber wieder vorwiegend sechs - und siebenzälılige Wurzelbläitter und untere Stengelblätter zum Vorschein. Wollte ich nun die PHanzen der angegebenen Standorte alle in die Var. septemsecta vereinigen, so miisste ich die Varietäten typica, tenuiloba, dissecta zu Formen degradiren und als solche her septemsecti anhängen; oder sollte ich etwa drei neno Varietaten mit besonderen Namen machen? Das mag ein Anterer thun, ich bleibe dabei, dass die septenata oder septemsecta, wenn man lieber will, nur als Form verschiedener Varietäten mitzuführen ist, gerate wie wir hei der l'. verna eine typica f. septenata, eine Var. incisa f, septenata ete. haben. Ueberall da. wo bei einer septenata-Form gegenüber einer quinataForm gar kein anderes Unterscheidungsmerkmal als die Zahl der Theilblättchen vorliegrt (wie in unserem lall) wird man mit Aufstellung von "Yarietäten" - geschweige denn von Species - vorsichtig sein müssen und sich am besten mit, Eormen" begnügen. Etwas ganz anderes ist es ja, wem die septenata-Form einer quinata-Species oder ungekelurt constint und wie unzertremulich ron noch auderen Unterscheidungsmerkmalen begleitet wird, wie z. B. bei P'. verna Var. Neumamiara.

Von den folgenden sechs Varietäten sind, weun sie typisch auftreten, die ersten vier (typica, decumlens, demissa und tenuiloba) auf ler Oberseite der Blätter kalıl oder schwach behaart, dagegen die beiden letzten (incanescens und dissecta) stark bis filzig behaart und daher von grauem Ausselien.

\section{Tarietäten mit oberseits kahlen bis schwach behaarten Blättern.}

Var. typica (= P. argentea Kimm.). Zimmeter bezeichnet nur diese Form als die 1'. argentea I., olowolıl es zweifellos ist, dass Linné unter diesen Namen verschiedene der folgenden von \%. als Species hingestellten Varietiiten, die ihm nicht unbekamnt sein konnten, mit inbegriffen hat*). Poeverlein stiegen zwar - von seinem bis jetzt noch festgelnaltenen standpunkt aus mit vollem Recht - Bedenken iiber dieses Verfahren auf, aher er billigt und arloptirt es schliesslich, schon a us Opportunitätsrücksichten", weil doch diese Form das grösste Verbreitungsgebiet besitze und den Typus der ,Gattung' (?) am besten reprisentire. Iel bin der Letzte, der etwas gegen eine Namengebung, aus Opportunitätsriicksichten" einzuwenden luat, besonders wenn sie anch, wie in diesem Fall, nit dem von $\mathbf{A}$. de Candolle 1853 emendirten Pariser Codex $\$ 56$ luarmonirt - ich wiinschte nur, dass die Opportunität häufiger berücksichtigt

*) Ganz analog geht er ïhrigens auch hei anderen Species, die er zerlegt hat, vor, 7. B. bei canescens Bess, recta I., thuringiaca Bernh., anserina L. etc, hei allen liesen miisste er streng genommen als Anctor "Zimmeter" setzen. 
würde - aber ich werde gelegentlich der Nomenclatur der P. opaca und $P$. verna meine Consequenzen aus Zimmeter's und Poeverlein's Verfahren ziehen.

Den folgenden Varietäten gegenïber kann man die typische argentea also charakterisiren: Stengel bogig aufrecht, Blätter derb, meist dunkelgrïn, oberseits kahl oder schwach behaart, unterseits weissfilzig; Theilblättchen aus schmaler, keilförmiger, zahnloser Basis, verkehrt eiförmig und vorn verbreitert, sich gewöhnlich mit den Rändern berührend (doch auch nicht selten spreizend), und ron der Mitte ab mit wenigen (meist nur 1-3) + tief eingeschnittenen, ungleichen und abstehenden, am Rande umgerollten Zähnen versehen. (Fig. 1)*).

Diese gemeinste, überall vorkommende typische Varietät wird durch Annäherungen an alle folgenden ungemein formenreich, es dürfte aber genügen, ausser der forma septenata, die breit- und kurzzähnigen Individuen mit forma latisecta und die schmal- und langzähnigen, die sich oft der Var. tenuiloba nähern, mit forma angustisecta zu bezeichnen. Diese praktische Unterscheidung hat nach Zimmeter (Beiträge S. 23) Sauter für die Tyroler P. argentea eingeführt. sie ist aber viel älter, ich fund sie auf den Etiquetten des Rochel'schen Herbars (dem Herbarium Dresdense einverleibt) durchgeführt. Weitere Formen und die Uebergänge zu notiren, muss Jedem selbst iiberlassen bleiben.

Die P. grandiceps Zimm., die für die Gebirgstläler Tyrols charakteristisch sein soll, welche aber Poeverlein auch in Bayern fand und ich in Sachsen vermuthe, kann ich weder nach der Beschreibung, noch nach den von Zimmeter ansgegebenen Herbar-Exemplaren für mehr als eine etwas grossköpfige Form der P. argentea typica halten. Aehnlich ergeht es mir - freilich vorerst nur nach der Beschreibung - mit der neuen P. Wisliceni Poeverlein (l. c. S. 57). Bezüglich der ersteren ist interessant, dass Zimmeter (Beitr. 23) sagt, Sauter's P. argentea (latisecta und angustisecta) scheine, wenigstens soweit sie in Gebirgsthälern, namentlich auf Glimmerschiefer wachse, mit seiner P. grandiceps identisch zu sein. Danach kann man annehmen, dass jener bekanntlich sehr genaue PotentillenBeobachter in der Zimmeter'schen grandiceps auch uichts Auffallendes, wenigstens keinen Grund gefunden habe, sie von der argentea typica zu trennen.

Yar. decumbens (Jord). Eine grosse, ohne Zweifel zu dieser Varietät gehörige, ja sie ziemlich typisch darstellende Form beobachtete und sammelte ich im Plauen'schen Grunde bei Dresden zwischen Dorngestrüpp !!, Hofmann entleckte sie auf der Bosel bei Meissen!. Leipzig ! (Herb. Kuntze), Schönefeld bei Leipzig ! (Herb. Pet.). Ohne Zweifel ist sie verbreiteter, aber nicht beachtet; denn Formen der argentea typica, die sich der decumbens stark nähern, trifft man hin und wieder. Ich bin sehr geneigt zu glauben, dass die Var. decumbens nur eine üppige Standortsform der argentea typica ist, die man wahrscheinlich leicht aus dieser auf fettem Gartenlande, besonders an etwas feuchten und schattigen Stellen ziehen könnte. Lehmann hat sie nicht als Tarietät aufgenommen, sondern nur als Synonym der P. argentea L. aufgefuihrt, und selbst Zimmeter weiss von ihr nur zu bemerken: „Eine grosse, flachblätterige Form der P. argentea“.

*) Die Beschreibung der Blätter bezieht sich stets auf die unteren und mittleren Stengelblätter im Sommer. 
Sun lassen wir sie vorläufig weiter bestehen. Sie unterscheidet sich ron der Var. typica durch ilren robusten, aber schlaffen Wuchs, die grossen, am Rande nicht umgeschlagenen Blätter, die langen, umgebogenen und allmählich aufstrebenden Stengel, einen etwas flatterigen Blüthenstand und meist schwächere liehanung. Nach aussersächsischem Material, das ich eingeselıen habe, lässt sich auch bei dieser Varictät cine f. latisecta und cine $f$. angustisecta unterscheiden. (Fig. 2.)

Var. demissa (Jord.) (= P'. minuta Ser.). Diese zierliche, der P. argentea typica bezüglich des Blattschnittes ebenfalls nahestehende Varictät ist das gerade Gegenstiick der Var. decumbens und hat nit dieser nur gemein, lass sic ebenfalls auf den Borlen hingestreckt ist. 'Limmeter fïlnt sie als P. minuta Ser, auf, behauptend, dass diese mit I'. demissa Jord. identisch sei, und nennt sie, grleichsam eine Zwergform der l'. argentea auf granitischem Boden". Ich ziehe den Namen demissa vor, unter dem sie auch Lehmamn als Varietät nennt, weil er für unsere Pflanze gerade das charakteristische und auffallendste Merkmal bezeichnet und diese durchaus nicht immer klein (minuta) ist. lch will die Varietät nach unsercn sächsischen Excmplaren, die mit solchen aus Frankreich, Bozen (!!), Ungarn und anderswoher genau iibereinstimmen, kurz beschreiben.

Die Stengel biegen sich ummittelbar ïber dem dicken Wurzelstock um und breiten sich, dicht dem Boden anliegend, im Kireise aus, wie etwa cine Corrigiola. Es sieht aus, als ob die Pflanzen auf den Boden festgetreten wären, woran aber nach den Standortsverhältnissen gar nicht zu denken ist, dies Wachsthum ist durchaus spontan. Erst von der Mitte an, oder noch weiter oben, erheben sich die '/weige und Bliithenstiele im Bogen etwas über die Erde. Mitten zwischen den niederliegenden Blüthenstengeln erheben sich schr häufig dichtbeblätterte, verkürzte, in diesem Jahre nicht zur Blüthe kommende 'Zweige (Blattrosetten), gerade wie bei P. collina auct, ein sehr merkwiirdiger Umstand, den Jordan in seiner Diagnose mit Recht ganz besonders hervorhebt*), denn die Pflanze nähert sich dadurch noch mehr als durch den liegenden Stengel den zweiachsigen Potentillen (l'. argentea wird zu den einachsigen gerechuet).

Die Blätter sind klein, oberseits dunkelgriin, ganz oder fast kall, unterseits schneeweiss filzig, dic Theilblättchen länglich, an der Basis schmal lang-keilig und zahnlos, ohen jederscits zwei- bis dreizähnig, im ganzen viel zierlicher als bei der Var. typica und stark ungerollt, meist in der forma angustisecta (Fig. 4). Der Blithenstand ist ausgebreitet flatterig, die Verzweigung der Stengel begimnt oft schon ganz unten nalie dem Wurzelstock, wodurch sie sich wieder gewissen Collina-Formen nähert, die Blïthen sind ziemlich klein.

I lh halte die Varictät demissa wegen ihres biologischen Verhaltens für eine der besten und empfehle sie selur der Beachtung unserer Floristen. Sic scheint wenig Neigung zu Uebergängen in andere Varietïten zu besitzen. bei uns wächst sic auf leichtem, sandigem, unfruchtbarem Boden, auf Heiden, besonders gern am Rande von Kiefernwiildern (ähnlich wie bei 1 '. collina). Ich fand sie mehrorts in der Tresdner Heide !!, bei Bühlan !!, Weisser Hirsch !!, zwischen Klein-Kadel und Dieshar !! (Ganz gleich traf ich sie auf Sandboden um Habichtstein bei Ilirschberg

*) . Caulibus mnlinue decumbentibus - candices crassi abbreviati surculis floriferis sterilibus intermixtis." 
in Böhmen), In anderen sächsischen Herbarien sah ich sie noch nicht; das will aber nichts besagen, denn da fehlen meistens auch die anderen Varietäten, weil man eben die P. argentea bei uns - wie anderwärts arg vernachlässigt hat.

Var. tenuiloba (Jord. erweitert), (= Var. perincisa Borb.). Da ich unter diesem Namen nicht nur die tenuiloba Jord. im allerengsten Sim des Auctors verstehe, sondern auch die ihr nahestehenden Formen mit einbeziehe, wäre es vielleicht besser, die Varietät einfach Var. incisa zu nennen. Um aber keinen neuen Namen einzuführen, wollen wir es, nach Vorgang ron Schwarz (Flora von Nürnberg-Erlangen 1899) sowie von Schinz und Keller (Flora der Schweiz 1900) bei Varietät tenuiloba bewenden lassen und sie folgendermassen charakterisiren: Grösse und Wuchs wie bei Var. typica; Blätter oberseits schwach behaart bis kahl, unterseits weissfilzig; Theilblättchen schmal, länglich oder rerkehrteiförmig-länglich, sich nicht berührend, spreizend, mit ganzrandiger keiliger Basis, jederseits mit zwei bis vier langen, schmalen und spitzen, nach vorn gerichteten Segmenten, oft doppelt fiederspaltig, besonders das mittlere (Fig. 3). Diese Varietät geht besonders leicht in die Var. typica f. angustisecta über; wenn die Blätter oberseits stärker behaart werden, ist sie von der Var. dissecta kaum mehr zu trennen. Sie ist besonders im Elbhügellande gar nicht selten und stellenweise fast so häufig als die Var. typica, weshalb ich keine besonderen Standorte aufführe.

\section{Varietäten mit oberseits filzigbehaarten, daher grauen Blättern.}

Var. incanescens (Opiz) (= var. impolita auct. var.). Jan kann kurzweg sagen, dass diese eine P'. argentea v. typica mit oberseits filzigbehaarten grauen Blättern ist; einen anderen wesentlichen Unterschied wird man kaum aufstellen können. Die forma latisecta ist die häufigere, die forma augustisecta geht leicht in die folgende Var. dissecta über. Poeverlein sagt mit Recht, dass die P. incanescens, wenn typisch ausgebildet, eine der schönsten Varietäten der Gruppe ist, macht aber auch darauf aufmerksam, dass sie bezüglich des Blattschnittes - ich füge hinzu, auch der Behaarung - zu den schwankendsten gehört. Es sei mir gestattet, einige hierauf bezügliche Beobachtungen anzuführen. An den Abhängen des Plauen'schen Grundes, in nächster Nähe meines Wohnortes, wächst die Var. incanescens zerstreut zwischen anderen Varietäten, und ich habe seit Jahren Gelegenleit, sie in ihrer Entwicklung zu beobachten. An den im Herbst und Frühjahr sich bildenden Wurzelblättern*) bemerkt man keine auffallend starke Behaarung auf der Oberfläche, sie erscheinen daher dunkelgrün. Auch die unteren Stengelblätter verhalten sich ähnlich, zeigen löchstens eine recht mässige Behaarung, und noch bis Mitte Mai, ja oft fast bis zur Zeit des ersten Aufblïhens, würde Niemand in unseren Pflanzen die Var. incanescens erblicken, der sich die Stöcke nicht schon vom Vorjahre her notirt hat. Erst im Juni und Juli beginnen die Blätter an den oberen Theilen der Pflanze und an

*) Diese lassen sich anch zur Erkennung anderer Tarietäten nicht beniitzen, sie sind bei allen fast gleich gestaltet. 
den später nachwachsenden Stengeln und '/weigen oberseits filzig zu werden. und gegen den Herbst - die Pflanzen treiben und blihen oft bis in den Spätherbst hinein -, wenn Wurzel- und untere Stengelblätter abgestorben sind, steht die incanescens fertig da. Wenn es, was oft der Fall ist, zu keiner sehr dichten Filzbildung auf der Blattoberfläche kommt, bleiben die I'tanzen auf der Stufe der forma subincunescens (Sat.) stehen. Ja, ich habe Individuen beobachtet, an denen nur cinzelne Stengel zur subincanescens wurden, während andere als Var. typica angesprochen werden mussten. Solche Extravaganzen geben zu denken! Die Blätter zeigen also bezüglich der Behaarung eine Art Saison-Dimorphismus; aber dieser spricht sich auch in der Blattform aus, indem die später erscheinenden Blätter kleiner, breit, wenig-, kurz- und stmmpf-bezahnt werden und ausserordentlich an die likatter der echten I'. collina Wib. erinnern, wie sie Focke und Petumnikov abgebildet laben. Uebrigens zeigt sich diese letzte Art von Dimorphismus in gleicher Weise bei den Varietäten typica und tenuiloba. Diese Erfalnungen beziehen sich nur auf die ron mir in Sachsen beobachtete incanescens, und ich weiss nicht, ob sic sich anderwärts auf gleiche Art benimmt. So schön weiss- und dichtfilzig, wie ich sie aus südlichen und östlichen Ländern (besonders Ungarn) besitze, habe ich sie bei uns noch nicht gesehen; dort verdient sie den Namen absinthifolia, den inr Trattinick gegeben hat.

Der Filz der Blattoberseite besteht aus kurzen, stark gekräuselten Härchen ähnlich den längeren der Unterseite, und aus geraden oder nur geschlängelten anliegenden Striegelhärchen. Herrschen die ersteren vor, so bekommt die Oberseite ein mattes. der Unterseite ähnliches Ansehen und wird stark grau bis weissgrau, im gegentheiligen Fall, wenn die Kiraushärchen spärlich und die Striegelhärchen überwiegend werden, bleibt die ()berseite grimer und bekommt ein seidigschimmerndes Aussehen. Ganz dasselbe gilt für die folgende Tar. dissecta.

Fïr das Torkommen der Tar. incanescens habe ich ausser dem Plauen'schen Grund !! noch zu nemnen: Abhänge ron Meissen bis Zadel !!, Lommatzschthal zwischen Var. dissecta und in Uebergängen zu dieser !!, Abtnaundorf bei Leipzig! (1I. Pet. als Var. tephrodes Rchb.). Sie ist jedenfalls ziemlich verbreitet und nur übersehen.

Var. dissecta (Wallr. p. p.?) Der ganze Unterschied dieser Varietät von der vorigen bestelit nu im Blattschnitt; man könnte sagen, dass sie die Tur.tenuiloba mit der Beharung der incanescens ist. Zimmeter und alle Neneren bestehen auf dem Charakter der starken Behaarung der Blattoberseite, die allerdings selten so stark wie bei der incanescens hervortritt; ob aber auch Wallroth dieses Kennzeichen für wesentlich gelialten hat, möchte ich bezweifeln - leider stelit mir seine Original-Diagnose nicht zur V'erfügung. Lehmann stellt nur zwei oberseits filzig beharte Varietäten auf, die Var. cinerea (= tephrodes Richb.) und (lie Tar. impolita (= unsere incanescens), sagt dagegen bei der Var. dissceta kein Wort von der Belraarung. Da er ancl keine Var. tenuiloba oder incisa nennt (obgleich er diese Formen ohne Zweifel kannte), so müssen wir annehmen, dass er entweder unter seiner dissecta alle schlitzblätterigen Formen, auch die kahlen, verstand, oder aber unsere stark beharite dissecta in seine Tar. impolita (= incanescens) nit einbezog. Es ist also nicht exact, wenn Zimmeter zu seiner (resp. unserer) dissecta als synonym I'. argentea $\varepsilon$ dissecta Lehm. citirt. Focke steht mit seinen 
Varietäten der P. argentea ganz auf Lelımann's Standpunkt. Petermann theilt die auf der Blattoberseite stark behaarten Formen also ein: $\beta)$ tephrodes Richb., $\alpha \alpha$ ) serrata, $\beta \beta$ ) dissecta Wallr., $\gamma$ ) impolita Richb. (= incanescens Op.). Jeder fasst also diese Formen auf andere Art auf. Wenn wir einmal neben der Var. tenuiloba (in unserem erweiterten Sinn) eine Var. dissecta zulassen, dann müssen wir auf der starken Behaarung auf der Blattoberseite bestehen, denn einen anderen greifbaren Unter-
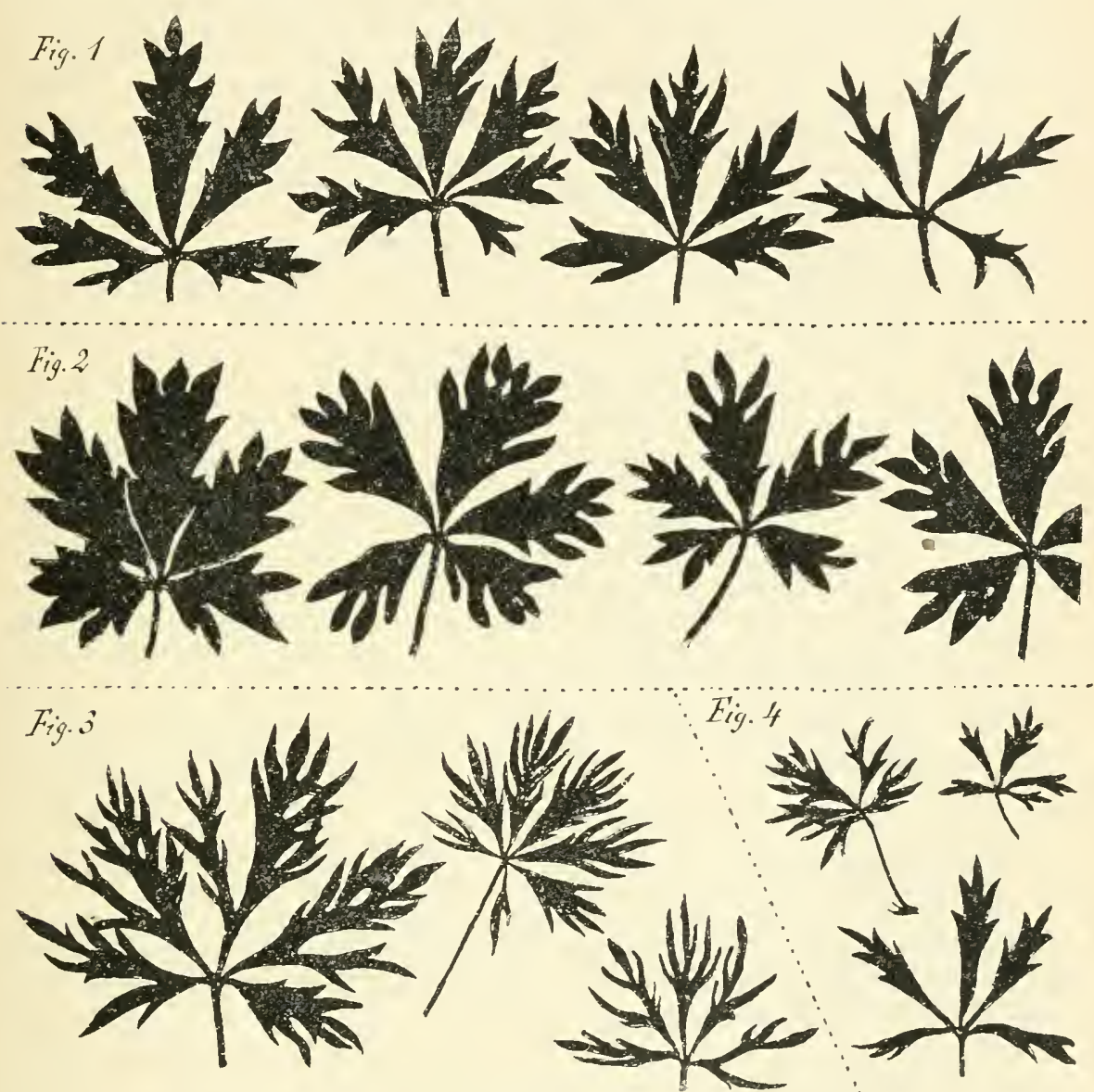

Fig. $1-4$.

Untere Stengelblätter der P. argentea $L$. Nat. Crr. nach Blattabdritcken. Fig 1. Var. typica, Fig. 2. Var. decumbens, Fig. 3. Var. tenuiloba, Fig. 4. Var. demissa.

schied zwischen beiden giebt es schlechterdings nicht. Den, welchen Poeverlein allen anderen Varietäten gegenüber geltend machen will, dass sich nämlich die P. dissecta, , vor allen durch die doppelt fiederspaltigen Blättchen auszeichne", kann ich nach meinen Erfahrungen nicht gelten lassen, ganz derselbe (doppelt fiederspaltige) Blattschnitt tritt oft genug bei den kahlen oder wenig behaarten Formen der Tar. tenuiloba 
auf. - Nebenlei sei bemerkt, dass eine von Siegfried (sul, No. 165) als „P. disseeta Wallr." ausgegebene Culturform anf der Oberseite der Blätter fast ganz verkahlt, also zur tenuiloba geworden ist.

Die Var. dissecta seheint bei uns in Sachsen hïufiger als die Var. ineanescens $z u$ sein, und kommt wie diese hauptsächlich im klbhügelland vor. Planen'scher Grund !!, Zadel !!, Lommatzschthal: bei Piskowitz! (Fr.) und Wahnitz (f. septenata)! (Hfm.), Naundorf bei Leipzig! (Fr.).

liecapitulation. In einer etwa zukünftigen Flora von Sachsen wären unsere Varietiiten der ['. argentea I. ungefähr also zn ordnen:

I. Bläter oberseits sehwach behaart bis kahl.

A. Theilblättehen (der unteren und mittleren Stengelblätter) keilig verkehrt-eiförmig, nach vorn verbreitert unı jederseits mit $1-3$ tief eingeschnittenen ungleichen abstehenden Zähnen versehen.

1. Stengel bogig aufrecht, Pflanze mittelgross .

2. Stengel niederliegend.

Trar. typica (Fig. 1).

a) Pflanze sehr gross, schlaff niedergestreckt, grossblätterig mit flachen (nicht umgerollten) Theilblättchen

Var. decumbens (Fig. 2).

b) Pflanze meist klein, Stengel vom Grund an dem Boden anliegend, meist sterile Blattrosetten vorhanden, Blïtter klein mit stark umgerollten Theilblättchen . .

Trar. demissa (Fig. 4).

B. Theilblättchen länglich, schmal, jederseits mit 2-4 langen, linearen, nach vorn gerichteten Segmenten, oft doppelt fieder'spaltig

II. Blätter oberseits stark behart bis filzig.

A. Theilblättchen wie bei I.A. . . . Iar. incanescens.

13. Theilblättehen wie bei I. B. . . . Var. dissecta.

Bei allen Varietäten kann die forma septenata vorkommen; bei der Var. typica und der Var. incanescens kann man eine f. latisecta und eine f. angustisecta unterscheiden.

\section{\%. Potentilla collina anct. (Sammelspecies).}

* Subspecies P. thyrsiflora Hïlsen.

$$
\text { (P. argentea -- rerua?) }
$$

Die Species ist für Sachsen neu. In keiner bisherigen Flora unseres engeren Vaterlandes wurde bis jetzt eine Form der P. collina erwähnt. Vor einigen Jahren sandte mir Herr F. Fritzsche in der Niederlössnitz aus seinem IIerbar unter anderen P'otentillen zur Revision auch ein paar, schon 1892 und 1894 gesammelte Pflänzchen zu, in denen ich 
zwar alsbald eine P. collina erkannte, aber bei dem geringen und dazu unvollständigen Material war es mir nicht möglich zu entscheiden, zu welcher der vielen Formen dieser schwierigen Gruppe es zu stellen sei. Natïrlich suchte ich im nächsten Frühjahr auf's eifrigste an den von Herrn Fritzsche angegebenen Fiundorten nach P. collina, - lange Zeit vergebens, bis ich Ende Mai 1898 die Freude hatte, sie in schönèn Exemplaren im lichten Föhrenwald zwischen Coswig und der Spitzgrund-lliuhle!! zerstreut anfzufinden und zu sammeln. Wie es zu gelien pflegt, stellte sie sich, einmal erkannt, bald an mehreren Stellen der Lössnitz ein, und zwar truppweisc an einem Eisenbahndamm bei Neu-Coswig!! und auf tem Himmelsbusch bei Kötzschenbroda!!, vereinzelt hinter der Friedensburg !! „Im Kies des Elbufers bei Köttitz, 1894" (Fritzsche) ist sie wahrscheinlich verschwunden (vielleicht war sie dort nur zufällig einmal angeschwemmt); am dritten Standort Her'rn Fritzsche's, ,unter Pflaumenbäumen bei Klein-Zadel"!! fand ich sie erst im Mai 1900 wieder, wenige Tage, nachdem sie Herr Hofmann auf einer Weinbergsmauer bei der Kinorre unterhalb Meissen! entdeckt hatte. Endlich sammelte sie Herr Hofmann noch im Juni 1900 ,am Kieferwäldchen $z$ wischen Klein-Zadel und Nieschiitz"! und Herr Fritzsche im selben Jahr bei Weinböhla! Hiermit sind nun alle bis jetzt mir bekannt gewordenen Standorte der P. thyrsiflora - wie man sieht, alle im Elbhügelland unterhalb Dresdens gelegen - aufgezählt. Im Jahre 1899 sammelte sie Herr Ilofmann in meiner Gesellschaft in der Lössnitz und gab sie in seinen Plant. crit. Sax. (1900) unter No. 112 aus.

Da wir es nur mit einer einzigen Form der vielgestaltigen und räthselvollen Collina-Gruppe zu thun haben, bin ich für jetzt glïcklicher'weise der heiklen Aufgabe überhoben, tiefer in dieses Wespennest zu stossen jeder Potentillen-Forscher wird mich verstehen! - und werde mich zunächst damit begnügen können, die P. thyr'siflora für unsere sammelnden Botaniker kemntlich zu machen. Construiren Sie sich eine Potentilla, die die Mitte zwischen $P$. verna und $P$. argentea hält, und sie werden sich ein ziemlich richtiges Bild unserer Pflanze machen. Im Frühjahr, vor dem Aufblïhen, ist sie von der P. verna, die mit ilır z. B. auf dem Himmelsbusch dicht vermengt wächst, schwer zu unterscheiden, so sehr ähneln dann ihre fünf- bis siebenzähligen Wurzelblätter denen von dieser. Die Theilblättchen haben bei beiden fast dieselbe Gestalt und Bezahnung (nur bei ïppigen Exemplaren werden die Blätter grösser und etwas reichlicher bezahnt, was aber auch bei gewissen verna-Formen zutrifft) und erst wenn man sie umkehrt, bemerkt man bei der P. thyrsiflora auf der Unterseite einen schwachen zarten Filz von langen wollig gekräuselten Haaren, ähnlich wie bei P. canescens, der aber von anliegenden Striegelhaaren bedeckt wird, so dass diese Seite, besonders auf den Nerven, seidigschimmernd wird. Ende Nai, wenn die P. verna der Hauptsache nach abgebliiht hat und die $\mathrm{P}$. argentea kaum die ersten vereinzelten Blüthen öffnet, steht die P. thyrsitlora in schönster Blüthe und zeigt dann einen veränderten Habitus: die niedergestreckten Stengel rerlängern sich weit über die Wurzelblätter hinaus, die oberen Stengelblätter werden denen der P. argentea ähnlich und auch die Inflorescenz erinnert an diese, kurz, sie erscheint jetzt im Habitus wie eine kleine, liegende $\mathrm{P}$. argentea. Was sie aber immerhin von dieser leicht unterscheiden lässt, ist 1. die schwache Filzbehaarung der Blattunterseite, 
welche diese noch immer stark grïn erscheinen lässt, ¿. die den Filz bedeckenden Striegelhare (ein wichtiges Merkmal der meisten Collinate den Argenteae gegenüber), 3. die stets reichlich vorhandenen sterilen Aestchen und Blattrosetten; die P. thyrsiflora ist, wie die meisten Collinae, entschieden zweiachsig. Die Stengel verzweigen sich oft schon weit unten, so dass der Bliithenstand weitschweifig und flatterig wird; dieser bildet also durchaus nicht immer — wemn auch oft amähernd - einen thyrsus (Strauss), was doch der Name der l'flanze besagen soll. Die lilüthe ist stenopetal, von der Grösse wie bei der gewölnhlichen P. verna, aber heller gelb, wie bei l'. argentea, so dass man die I'flanze, wo sie im Verein mit der ersteren vorkommt, schon von Ferne an der Blumenfarbe erkennt. In meinen Garten verptlanzt, blüht die P. thyrsiflora seit drei Jahren von Mitte Nai bis Mitte November fast munterbrochen. Ob sie auch im Freien bis in len Herbst oler im Herbst zum zweitenmale blüht, darüber luabe ich bis jetzt noch keine Beobachtungen machen kömmen.

Unsere I'flanze stimmt in allen makroskopischen liennzeichen durchaus mit zahlreichen Ilerbar-Exemplaren, die ich aus verschiedenen Lündern Centraleuropas besitze, so dass über ihre richtige Bestimmung kaum ein Zweifel auf'kommen kann. 'Trotzden muss ich auf einen freilich nur mit dem Mikroskop zu findenden Unterschied aufmerksan machen, der aber seine theoretische Bedentung hat.

l'etunnikov hat in seiner wichtigen Arbeit über die Potentillen Central-Russlands, deren Schwerpunkt gerade im Studium der CollinaGruppe liegt, nachzuweisen gesucht, dass alle Collinae Wisch-oder Zí ischenformen $\mathrm{z}$ wischen $P$. aryentea und $P$. arenaria darstellen. Er stuitzt sich auf die Thatsache, dass sich bei ihnen auf der Blattoberseite ,halbbüschelformige" Haare - ich nenne sie Zackenhaare und werde bei den I'. arenaria × verna-Pastarden anf sie zurïckkommen - finden, welche auf eine Beeinflussung der l'. arenaria hinweisen. Ich bin ganz derselben Ansicht wie I'etunnikov, dass die Anwesenheit ron Stern- und Zackenhaaren stets eine mehr oder weniger starke Betheiligung der l'. arenaria (in weitesten Sinne gefasst, also irgend einer Form der ganzen Arenaria(iruppe) bei der Bildung einer Potentilla anzeigt, ferner sehe ich mit vielen Kennern unserer Gattung die meisten Collinae als eine Mischgruppe zwischen den Argenteae und den Vernales an, aber ich glaube, dass P'etunnikov zu weit geht, wenn er alle nur für $P$. aregentea - arenaria erklären will, da es in der 'That Formen giebt, welche jene Zackenhaare nicht besitzen, und zu diesen gelı̈̈rt unsere $P$. collina aus dem Elblïgelland, trotzdem sie innerhall, des Gebietes der P. arenariu vorkommt. Eine solche P. collina ohne Kackenhaare darf man - wemn man überliaupt an eine Mischform glaubt - für P.argentea - verna (oder canescens - verna?) lialten. - Ich zweifle durchaus nicht, dass I'etunnikov richtig beobachtet, und bei allen von ihm mikroskopisch untersuchten Collinae die \%ackenhare gefunden hat, aber die Verallgemeinerung des Resultats wäre voreilig. Ascherson macht bei Erwähmung der Ansicht über die Bastardnatm der P. collina (in Flora d. nordostd. Flachl. S. 409) mit Recht eine entsprechende Reserve: ,ob diese P'flanze eine eigene Art, eine Abart der vorigen (P. argentea), oder, wofür Blüthezeit und gemeinsames Vorkommen an den meisten Standorten spricht, ein Bastard von P. argentea und incana (bez. im Westen Tabernaemontani" - 1. h. verna -), ,sei, ist noch nicht genügend festgestellt". 
Ich habe bereits angedeutet, dass ich bei einigen Collina-Formen und zu diesen gehört gerade unsere P. thyrsiflora - die Combination $P$. canescens - verna nicht für ausgeschlossen halte. Theoretisch steht ihr gewiss so wenig etwas entgegen, als der von argentea - verna, und in praxi erinnern mich gewisse Formen durch den sehr schwachen Filz auf der Blattunterseite, iiberhanpt durch die ganze Behaarungsart. und selbst durch Form und Bezahnung der Theilblättchen, mehr an P. canescens als an P. argentea. Die Frage iber die Abstammung der Mischgruppe der Collinae bleibt eine offene, und ich wollte mit vorstehender Bemerkung nur darauf hinweisen, dass man bei ibrer Discussion nicht in jedem Einzelfalle nothwendig an der P. argentea, als an einer der beiden Stammarten, festhalten müsse.

\section{Potentilla canescens Bess.}

(P. inclinata auct. var.)

Die P. canescens findet sich an sonnigen, bebuschten Felsabhängen und Hügeln, theils truppweise, theils vereinzelt, ist aber in Sachsen selten und auf wenige Standorte beschränkt. Es sind zu nennen: Im Elbli ügellande die Abhänge von der Knorre bei Meissen bis Zadel !!, hier am läufigsten und schönsten, (sonderbarerweise fehlt dieser reichste Standort in Richb. und Heyhold, ob damals noch nicht vorhanden:); Berggiesshübel ! (H. Dr.); in der sächsischen Schweiz auf der Ruine Wehlen a. d. Elbe!! spärlich; im Gebiet der Mulde: am Schlossherg von Schwarzenberg ! (H. Dr.), Zschocken und Wildenfels bei Zwickau (lichb.); im Vogtlande im Gebiet der Elster: nach Artzt um Plauen und Oelsnitz, bei Chrieschwitz, Weischlitz! (zusammen mit P. recta), Rosenberg, Pirk! (Fr.) und Uröla. - Früher am Kírchberg ron Panitzsch bei Leipzig, nach Petermann wenigstens von 1827-1846 (, auf dem Gottesacker und im Grasgarten der Pfarrwohnung", Herb. Petermanu!). In neuerer Zeit nach Mittheilungen des Herm Missbach nicht mehr gefunden. Nach den eingesehenen Original-Exemplaren war es eine forma oligodonta mit nur 3-4 Zähnen an jeder Seite der Theilblättchen der Stengelblätter.

Zimmeter hat aus der P. canescens $\gamma$, Species" herausgeschlagen und Blocki hat in rascher Folge noch 8 .,Species novae", die meisten aus Galizien, dazu gestiftet; dazu kommt theils ron demselben, theils ron anderen Auctoren noch eine ganze Reihe von "Varietäten" (d. h. leichtester Spielformen) und recht fragwiirdigen Bastarden, welche sich schliesslich zum grossen Theil wohl auch nur als Canescens-Formen herausstellen dürften. - Dass es sich bei jenen 15-20 Species - von den Varietäten gar nicht zu reden - nur um Formen einer und derselben guten Art, der Besser'schen P. canescens, handelt. daron wird sich Jeler, der einem brauchbaren Speciesbegriff huldigt, schon aus den gegebenen Diagnosen und Beschreibungen überzeugen*). Das Meiste läuft auf eine kleinliche Beschreibung der Form und Bezahnung der'Theilblättchen sowie der Quantität der Behaarung hinaus; ebenso unbedeutend und oft geradezu nichtssagend

*) Vergl. besonders auch den - nebenbei gesagt so gut wie nubrauchbaren "Schliissel zur Bestimmung der Potentillen-Arten". welchen Zimmeter im BotanikerKalender 1887 anfstellte. 
sind andere herangezogene Unterscheidungsmerkmale in der Diagnose, welche, je länger sie wird, desto cher in eine Individuenbeschreibung ausartet. Wemn man dam vorutheilsfrei die mit binären Speciesnamen beehrten Formen - ich besitze die allermeisten in Original-, d. h. von den Auctoren selbst ausgegebenen lixemplaren - untereinander vergleicht, dann wird man erst recht den Werth oder besser gesagt Unwerth solcher Species begreifen: iiberall Uebergänge und Unsicherheit, iberall Ansuahmen, ibberall blosse Annäherungen an das beschriebene Ideal; lauter Anzejchen, dass wir es höchstens mit sehr unhestäucligen Varietäten und wahrscheinlich of nur mit Standortsformen zu thun haben. die wohl schwerlich höher zu bewerthen sein werden als die Varietäten mo Formen der P'. argentea. Die Unterschiede sind oft nicht hedentender, als die zwischen Exemplaren, welche Cimmeter in seinen Rerisionen anstandslos als ,Formen" seiner P. canescens (sensu stricto) erklïrte.

Da ich num durchaus nichts gegen die Aufstellung von Varietäten und Formen habe, sonderı im Gegentheil ilu Studium fuir nuitzlich und nothwendig halte, wenn sie nur an ler rechten Stelle den Species subordinirt werden und wo möglich einen wirklich bezeichnenden Varietätsnancn erhialten (statt der nach Beräncherung duftenden Personen- oder der neist beengenden. daher" unrichtigen Localnamen)*), so ist die Frage berechtigt: zu welcher Form oder Varictät gehört unsere sächsische P. canescens? Die meisten ron mir eingesehenen Exemplare gehören zur P'. canesceus Zim n. (im engeren Sinne), welche man als die typische und häufigste Form der P. canescens Bess, betrachten kann. Aber wir besitzen auch die P. polyodonta (Borb.) Zimm., welche sich von jener im wesentlichen durch eine reichere und bis zur Basis der 'Theilblättchen reichende Bezahnung (jederseits $6-10$ \%ähne statt $5-\%$ bei canescens \%.) unterscheidet (Fig. 5 b); und zwa kommt diese Form an den heiden llanptstandorten Sachsens zusammen mit der typischen canescens ror. So liegt die durch Hofmann (Plantae crit. Sax.) rom Zadeler Abhang ausgegebene P'. cancscens im Dresdner Herhar mit einer richtigen P. polyodonta in einem und demselben Bogen. Auch ich fand die polyodonta bei Zadel. Mein Exemplar der canescens von Weischlitz im logtlande (leg. Artzt) ist polyodonta, dagegen das im H. Dr. von ebendort ist typische canescens; bei Herrn Artzt ju Plauen sah ich Uebergänge zwischen den beiden. Dadurch, dass sich bei beiden Formen läufig Zähne einstellen, die wiederholl sezähnt sind, kommen auch Annäherungen an die $P$. fissidens Borb. vor, welche ührigens, wie schon Poeverlein mit Recht hervorhelst, von der polyoulonta kaum zu trennen ist. Beide formen verschwimmen untereinander und auch mit der typischen canescens. Es genïgt vollständig, wenn wir den reichbezahnten Individuen unserer 1'. canescens Bess. beifügen: Forma polyodonta (Borb). - Wer es darauf absieht, die Flora von Sachsen zu bereichem (?) und die gehörigen Anlagen zur Haarspalterei mitbringt, wird an den Zadeler Abhängen unschwer Individuen finden, die er (wenn er nicht etwa eine P. Zadelensis sibi! stiften will) auch mit anderen Namen belegen kann, z. B. P. Dichtlianc Blocki. Ich mache mich anheischig, einzelne l'Hanzen vou dieser localität auszusuchen, die man, mit Dichtlischen Original-kxemplaren vermischt, nicht mehr herausfinden wird; demn sie stimmen mit diesen genau

*) P. Dichtliana, Buschakii, Skofitzii, Sapiehae, Woloscczakii, Hoelzlii, Klukii, Herbichii ete. lauter Blochi'sche neue Species! 
iiberein, ebenso wie die gauze Blocki'sche Diaguose selbst in unwesentlichen Dingen auf sie passt; andererseits aber finden auch Uebergänge zur gewöhnlichen canescens und von dieser zu polyodonta statt. Ich kamn, ,diese ausgezeichnete Art", wie sie Blocki nennt, nicht im geringsten höher einschätzen, als die polyodonta und andere Borbas'sche Formen, auch die Ansicht Poeverlein's nicht theilen, der in ihr einen ,Bastard zwischen einer' Rectae- und Argenteaeform" vermuthet, und zwar aus gleichen Gründen, aus denen ich weiter unten derselben Ansicht beziiglich der P. Arthuriana Ifm. entgegentreten werde. In der langen Diagnose, welche Blocki fiir seine P. Dichtliana giebt*), ist des Pudels Kern (wie auch Poeverlein l. c. ganz richtig hervorhebt), dass die Theilblättchen der unteren und mittleren Stengelblätter aus langkeiligem und stets ganzrandigem Grunde verkehrt-eilänglich, ungefähr aus der Mitte gezähnt, beiderseits fünfbis sechszähnig (niemals achtzähnig) ..." sind. (Fig. 5c.) Alles Uebrige der Diagnose ist unwesentlich und passt auch + auf andere CanescensFormen und die P. canescens Zimm. In einer Anmerkung hebt Blocki nochmals ganz besonders jenes wesentliche Unterscheidungsmerkmal hervor: "Yon allen übrigen Arten der Sectio Canescentes orientales" (d. h. der P. canescens Bess.), ,unterscheidet sich P. Dichtliand mihi selı auffallend durch die langkeilige, ganzrandige Basis der Theilblättchen, sowie durch ganz spitze Blattzähne". Nun, sehr spitze Blattzähne finden sich bei verschiedenen Formen (polyodonta, fissidens, incrassata, Uechtritzii, podolica, Sadleri etc.) und oft auch bei der typischen P. canescens (Zimm.); und Jeder, dem ein bedentendes Herbarmaterial zum Studium der CanescensGruppe zur Verfügung steht, wird finden, dass eine langkeilige, ganzrandige Basis der Theilblättchen keineswegs eir Privileg der P. Dichtliana ist. Man trifft sie 'z. B. - und zwar nicht nur an den oberen, sondern auch an den mittleren und unteren Stengelblättern - ebenso stark ausgeprägt bei der P'. pololica Blocki (die zugleich auch spitzzähnig ist), mehr oder weniger bei incrassata, Uechritzii, Sapiehae, bohemica und canescens (Zimm.). Poeverlein sagt zwar, dass bei der typischen canescens im Gegensatz zu der P. Dichtliana der Blättchenrand bis zum Grunde gezähnt sei. (also wie bei polyodonta). Aber ' L. weiss davon nichts, er sagte in der Definition seiner typischen canescens nur: „Die Blättchen sind verkehrt eifölmig-lanzettlich, keilig, grob gesägt". Man möchte daraus eher schliessen, dass ihre keilige Basis zahnlos sein soll und dies würde nicht nur sehr oft der Wirklichkeit entsprechen, sondern auch durch sehr viele von Z. selbst als canescens bestimmte Herbarptlanzen bestätigt. Allerdings nimmt die zahnlose keilige Basis bei den angeführten Formen meistens nur das untere Drittel des Theilblättchens ein (- es ist immer von den mittleren uud unteren Stengelblättern die Rede -), während dieses bei P. Dichtliana, ,ungefähr aus der Nitte gezähnt" sein soll. Aber an den Originalpflanzen Dichtl's finde ich die Bezahnung auch stets bedeutend unter der Mitte beginnend, und die Seitenblättchen sind an ihrer Aussenseite bis zum Grunde gezähnt (nicht keilig), genau wie bei canescens Z. und anderen Formen (Fig. 5c). Also von einem wesentlichen specifischen Unterschiede kann hier gar keine Rede sein, es handelt sich nur um ein mehr oder weniger. P. canescens typica steht in der Mitte mit + keiliger Basis der beiderseits sechs- bis achtzähnigen Theil-

*) Allgem. bot Zeitschr. 1897 S. 23. 
blättchen (F̈ig. $5 \mathrm{a})$, links ron ihr steht, durch Uebergänge verbunden, die forma polyodontu (Fig. 5 b) mit länglichen, bis zur Basis beiderseits sieben- bis zehmzihhnigen Bliittchen, rechts ron ihr, ebenfalls durch Uebergänge verhunden, die forma oligorlonta $(=\mathrm{P}$. Dichtliana Blocki) mit langkeiliger ganzrandiger Basis der beiderseits fünf- bis sechszïhnigen Theilblïttchen (Fig. $5 \mathrm{c}$ )*). Ganz analoge Formen mit Uebergïngen liessen sich auch in anderen I'otentillen-(iruppen aufstellen, z. B. bei den vielgestaltigen Argenteae oder hei den Vernae. Ich erinnere nur an die lieihe verna incisa - verna typica - verna longifolia. Die Form und Bezahmung der Blättchen ist wohl das ungeeignctste Mittel zur Aufstellung und Abgrenzung der Species. Es giebt nichts Veränderlicheres, nichts

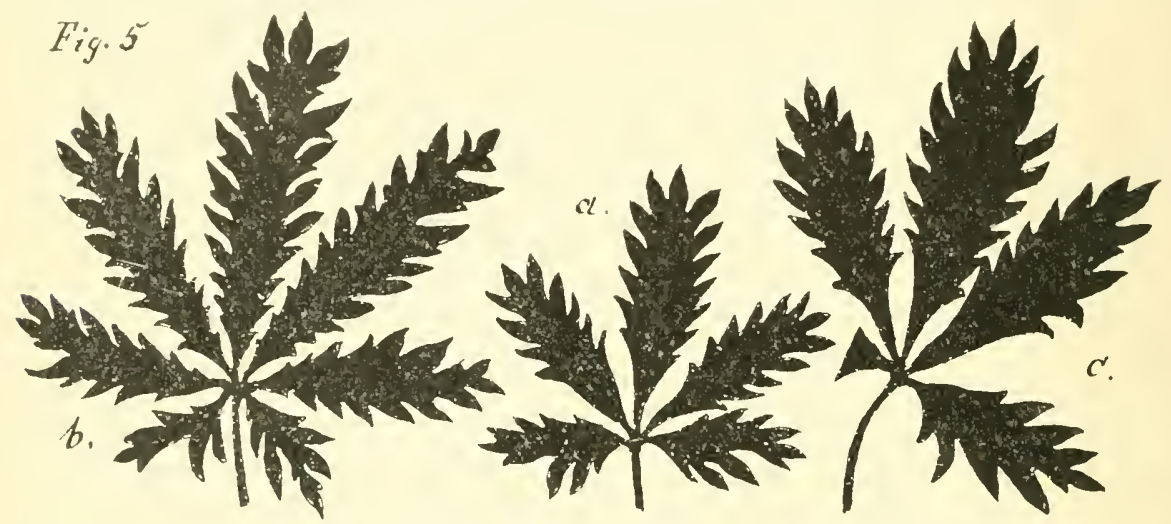

Fig. 5.

Untere Stengelblätter der $P$. canescens Bess. Nat. Gr. nach Blattabdrïcken. a) Forma typica, b) f. polyodonta, c) f. oligodonta (= P. Dichtliana) ron Kalksburg bei WVien.

Unbeständigeres als das Potentillenblatt! Und auf dieses unbeständigste aller unbeständigen Merkmale griindete Zimmeter grossentheils seine Species und im wesentlichen auch seinen Schlüssel zur Bestimmung der Potentillen im Botanikerkalender, wenigstens bezïglich der Species in den einzelnen

*) Wer diese „ansgezeichnete Art“, welche Blocki seinem „hochgepriesenen Freund zu Ehren" benannt hat und von der er behamptet, sie in der Cultur als constant befunden zn haben, etwas höher als blosse Form bewerthen will, mag sie immer als Tar. Dichtliana (Blocki) weiterfiihren. Cultur-Exemplare ans dem Siegfried'schen Potentillarium, noch mehr die von C. Schol\% ans Samen gezogenen, haben mit den wildgewachsenen Original-Exemplaren ron Kalksburg bei Wien (abgesehen daron, dass sie eben anch oligorlont sind) so wenig Aehnlichkeit, lass sie kein Jensch als P. Dichtliana bestimmen wiide, der ihre Abstammung nicht kennt (was ïbrigens anch für andere cnltivirte Tarietäten gilt). Der Standort scheint also doch eine wichtige Rolle zn spielen. - Die $P$. bohemica Blocki und $P$. podolicu Blocki kamn man sowoht in wilden als anch in cultivirten Exemplaren von einander nnd von den entsprechenden der $P$. Dichtliana nicht eimmal als Varietäten, höchstens als leichte Spielformen unterscheiden, beide sind ebenfalls formae oligodontae mit langkeiliger, zahnloser Basis der Theilblïttchen. - Wenn man mit derselben "Grïndlichkeit", wie die P. canescens, die noch formenreichere P. argentea verarbeiten wollte, könnte man aus ihr unschwer einige zwanzig nene Species anf Grund der Abweichungen in Blattschnitt und -bezahnmng prägen. Die vielen "Species" der P. canescens werten sich anf wenige Hanptrarietäten zuriickfiihren lassen, ganz analog denen der P. argentea. 
Gruppen. Kein Wunder, dass man nach diesem Schlüssel kaum eine Potentillen-Form bestimmen kann.

„Potentilla Arthuriana $\mathrm{H} \mathrm{fm.6.} \mathrm{Herr} \mathrm{H.} \mathrm{Hofmann} \mathrm{hat} \mathrm{unter} \mathrm{diesem}$ Namen im Jahre 1897 in den ,Plantae criticae Saxoniae“ eine Potentilla von der Ruine Wehlen an der Elbe unter No. 40 ausgegeben und sie als , nova forma (hybrida?) inter P. algenteam et canescentem. non P. superargentea Waisb." bezeichnet (cfr. Allgem. bot. Zeitschr. 189\%, S. 35). Herr H. hat meines Erachtens wohl daran gethan, zu "hybrida" ein Fragezeichen zu setzen, und noch besser wäre es gewesen, dieses linter das Ganze zu stellen, denn ich fürchte, dass wir es nur mit kleinen, etwas kümmerlichen Exemplaren der P. canescens Bess. zu thun haben. Da die Pflanze auch in Poeverlein's Arbeit über die bayerischen Potentillen zur Sprache kam, muss ich anf sie etwas nüher eingehen.

Nach Hofmanu's mündlichen Nittheilungen hat zuerst Dr. Arthur Schulz diese Potentilla auf der Ruine Wehlen aufgefunden und an Zimmeter zur Begutachtung geschickt. Dieser soll zuerst eine $P$. canescens $>$ argentea in ihr vermuthet haben, und so gab sie damn Hofmann, unter der Suggestion Z.'s stehend, als solche aus und zwar als ,forma nova", offenbar weil sie mit anderen bis jetzt unter can, $x$ arg. aufgestellten Formen nicht stimmen wollte. Als ich sie zuerst in dem Exemplar des Dresdener Herbariums aus den Plantae crit. Sax, kennen lernte, zweifelte ich sofort an der Richtigkeit der Bestimmung als P. canescens $x$ argentea, denn ich konnte nichts entdecken, was auf eine Betheiligung der letzteren hinwiese. Aber auch ich stand damals noch unter der Suggestion Zimmeter's mein Respect vor seinen Revisionen ist erst allmählich auf das heutige tiefe Niveau gesunken - und meinte, wenn Z. was Besonderes daran sah, dann müsse doch etwas Besonderes daran sein. Ich dachte an gewisse Formen der Collina-Gruppe, an die mich die sehr kleinen, fast krüppelhaften Pfänzchen des Dresdener Herbars erinnerten (kräftige hatte ich noch nicht gesehen), allein ich liess diese Gedanken als unhaltbar bald wieder fallen und vertröstete mich auf die Autopsie an lebendem Material auf der Ruine Wehten im folgenden Sommer. Und was fand ich? zwar keine P. Arthuriana, aber die echte und gerechte $P$. canescens Bess. in wenigen aber ziemlich kräftigen Exemplaren*), die sich von der Ptlanze an den Zadeler Abhängen in nichts Wesentlichem unterscheiden! Dasselbe war in diesem Jahre (1900) der Fall. Ich glaube kaum, dass ein vorurtheilsfreier Botaniker, der nichts von Zimmeter's Termuthung weiss, etwas gegen meine Bestimmung einzuwenden hat, wemn er meine Herbar-Exemplare sieht. Nun machte ich mich von neuem an die Untersuchung der ansgegebenen P. Arthuriana und Freund Hofmann hatte die Liebenswirdigkeit, mir all sein Material, das ihm von Wehlen noch geblieben war und das er nachträglich gesammelt hat, vorzulegen. Darunter waren neben kümmerlichen auch kräftige Exemplare, allein ich konnte Alles, was ich gesehen und eingehend mikroskopisch untersucht. nur für P. canescens erklären.

Unterdessen hatte aber auch Dr. Poeverlein die Hofmann'schen Potentillen revidirt und sich (1. c. S. 46) ïber die P. Arthuriana geäussert. Er

*) Leider war die Ruine wenige Tage vor meinem Besuch abgegrast worden. Aber auch dieses . Tahr (1900), in dem ich dem Abgrasen zuvorkam, beobachtete ich nm wenige Stöcke. Die meisten scheinen doch an diesem sehr beschränkten Standorte den Plantae crit. Sax. 1897 und einigen eifrigen Sammlern zum Opfer gefallen zu sein. 
hält die P. Arthuriana fiir , einen ziemlich zweifellosen bastard zwischen $P$. recta und $P$. aryenteu". Wemn Herm l'oeverlein ähnliches, vielleicht zum 'Theil dasselbe Material rorgelegen hat, wie mir, so kanm ich seiner Ansicht nicht beiptlichten. Sollte nicht auch er unter der \%.'schen Suggestion gestanden und geglaubt haben, an dieser Pflanze m üsse etwas Besonderes sein! Geren eine Combination canescens $\chi$ argentea spricht anch er sich aus, aber wie es scheint. hauptsäichlich ans dem Grunde, weil ,nach Hofmann der Originalstandort vom nächsten Standort (ler P. canescens 50-60 km entfernt ist, wïlrend die P'. recta nach lieichenbach ca. $3^{1} . \mathrm{km}$ clbaufwärts rorkommt" (l. l. vor 60 Jahren vorkam!). Dieser Grund ist hinfällig, nachdem ich die echte P. canescens auf Ruine Wehlen nachgewiesen habe. Offen gestanden, wäre, wenn die l'. Arthuriana doch einmal ein bastard sein müste, die Combination canescens $>$ argentea nach dem ganzen Habitus und allen Merkmalen der Pflanze noch weit plausibler, als die von recta $>$ argentea; dem bei jener wïrden die bei beiden Arten so ähulichen Trichome (weiche gekräuselte Filzhaare) so verschmelzen, dass aus der Qualität der Haare kaun etwas gegen den angeblichen Bastard vorzubringen wäre, höchstens aus der Quantität derselben*). - Ganz anders liegt die Sache bei der Combination recta × arcentea (oder auch recta $>$ canescens), bei der die total verscliciclene kurzborstige Stengelbehaarung der $P$. recta mit Sicherlueit sich mit lem weichen Filz der $P$. argentea auf irgend eine Weise comhiniren wïrde, wie ich bei allen echten Recta-Bastarden nachweisen kann. Bei der P. Arthuriana findet sich nicht die entfernteste Andeutung an die Beharung der P. recta. Noch etwas: unsere sächsische P. recta ist, wie ich später zeigen werde, seln drüsenreich; es ist mir unwahrschemlich, dass diesellye einen so ganz drüsemeinen Bastard bilden wïrde, wie es die P. Arthuriana ist. Ich schliesse dies aus Anologie, da unsere zahlreichen Arenaria > verna- und Opaca > verna-Bastarle meistens ebenso drüis sind, wie die reine arenaria und opaca, während die reine verna drüsenlos ist. Aus später zu entwickelnden Gründen — ich werde sehr ausführlich auf den Gegenstind zurückkommen — will ich dieses Argument nicht als ausschlaggebend, sondern nur als bekräftigend hinstellen.

Ich besitze zwei schöne. von Holulyy , arl vias in valle Bošácensi, C'omit. 'Treněin Hungariae" gesammelte und als .' '. inclinata Vill." (Il. h. P. canescens Bess.) ausgegebene Potentillen Das eine, im Juli 1887 eingelegte Exemplar ist nach allen Anzeichen und dem mikroskopischen Befmond des Stengelfilzes die echte P. canescens; dagegen fält das im. Juli 1888 an derselben Stelle gesammelte Exemplar schon bei oberflächlicher Retrachtnng durch seinen Hahitus, die schwache Filzbehaarnng, die grossen Bliithenköpfe ete. anf. Die mikroskopische Untersuchumg ergal, sofort am Stengel nud an den Bliithenstielen die Ilischung stejfer Borstenhärehen der P. recta mit den weichen Filzlıaren der $P$. canescens; zum Ueberfluss, aber zn meiner Frende, erschienen dam an den obersten Theilen der Bliithenstiele und an den Kelchbliittern gar nicht seltene S'tieldriisen. wie sie die $P$. recta gewöhnlich, die $P$. canescens aber nnd die $P$. argenten - soweit meine Beobarhtungen reichen - niemals trägt. Ich suehte die P. Wolffiana siegfr ans Sielrenbüroen hervor und fand, dass sich tieselbe in nichts von der Holnhyschen l'flanze unterscheilet. In beilen Fällen liegt ein unzweifelhafter Bastard P. recta (resp. obscura) $\times$ canescens vor. - Von den vielen Blocki'schen "Species" (meist aus (ializien), welche Zimmeter in der ('anescens Gruppe unterbringt, und die anf mich zmm grössten Theil den Eindruck von Standortsfornen machen, ist die $P$. Sko/itzii Blocki

*) So ist es in der That $z$ B. bei der P. superargentea $\times$ canescens Waisl,. I'. superargentea $\times$ bohemica Blocki und einigen anderen fragwirdigen Bastarlen des letztgellannten Alletors. 
ans Ostgalizien ein Recta $\times$ canescens-Bastard, ler aber der P. canescens etwas näher steht, als die P. Wolffiana. Die Behaarung rles Stengels ist der der letzteren sehr ähnlich, die spärlichen Stieldrïsen sind schlecht ausgebildet, was beides anch an den Siegfried'schen, allerdings sehr abgeänderten (verkablten) Cultur-Exemplaren wahrzunehmen ist. Der Filz auf der Blattunterseite ist spärlich, dagegen erimnern Blattform und kleinere Blïthen wieder mehr an P. canescens. - Die P. Sadlerinna Richb., die ich leider nur in Cultur-Exemplaren der Siegfried schen Exsiccaten besitze, in welcher Reichenbach eine P. recta $r$. laciniosa $\times$ canescens vermuthete, die Lehmann $\mathrm{zn}$ den Hybriden unbekannter Abstammung stellte, nnd die Schlosser und Tukotinoric sogar als Varietät zu P. hirta ziehen, ist nach der mikroskopischen Untersuchung des Stengelfilzes wahrscheinlich mur eine Form der P. canescens, lässt jedenfalls keinen Ein. fluss der Recta-Gruppe erkennen.

Was nun sonst noch in der Form und Bezahnung der Blätter, in der mit blossem Auge sichtbaren Behaarung, in Grösse und Form der Blüthentheile, im ganzen Habitus der P. Arthuriana auf eine Betheiligung der P. recta schliessen lassen soll, ist mir unerfindlich. Freilich, wenn man (ler von mir nicht getheilten Ansicht huldigt - auch Poeverlein scheint ihr zuzuneigen - dass die Gesammtart P. canescens oder die ganze Canescens-Gruppe als, intermediäre Art" zwischen P. argentea und P. recta erscheine, ,deren Formen viclleicht urspriinglich einer Bastardirung ihren Ursprung verdanken", die also mit P. argentea - recta bezeichnet werden könnte, dann ist es leicht, auch einmal eine etwas al,weichende Form der $P$. canescens als P. argentea hinzustellen, denn wer will sich vermessen, eine sichere Grenze zwischen primären und secundären Bastarden - jenen intermediären Formen - zu ziehen? Man kann ja zugeben, dass nach dem äusseren Habitus und dem Blattschnitt die P. canescens zwischen der P. recta und der P. argentea eine Art Vittelstellung einnimmt, aber nach dem wichtigen Merkmal der Behaarungsart entfernt sie sich weit von der $P$. recta, während sie mit der $P$. argentea recht wohl in eine Gruppe, die der Canescentes rereinigt und diese der Recta-Gruppe gegenübergestellt werden kann.

Ohne über die $P$. Arthuriana Hofm. apodiktisch den Stab zu brechen, kann ich zum Schluss nur erklären: auf der liuine Wehlen ist seit 1898 weder ein Canescens- noch ein Recta-Bastard zu finden; ob ein solcher unter den dort 1897 oder friher gesammelten und ausgegebenen Pflanzen versteckt liegt, kann ich nicht wissen, es wären alle ausgegebenen Exemplare zu untersuchen, was kaum angeht; das ron mir durchgesehene Arthuriana-Naterial ist $P$. canescens Bess., zum Theil in einer kleinen Kummerform.

\section{Potentilla recta L.}

Diese stattlichste und grossblïthigste unserer heimischen Potentillen hat wiederun ihre Hauptverbreitung im Elbhügellande ron Pirna bis Riesa und ist ausserhalb desselben sehr selten. Sie liebt, wie die P. canescens, sonnige, bebuschte Felsabhänge und Hügel, und kommt theils truppweise, theils vereinzelt vor.

Im Planen'schen Grunde bei Dresden mehrorts !!, Lockwitzgrund ! (H. Dr.), zwischen Lockwitz und Kreischa! (H. Dr.), Berggiesshübel! (H. Dr.). Nach Rchb, bei Hosterwitz, Pillnitz, Posta, Nenntmannsdorf, Dohna, Niederrathen und nach Hippe bei Krippen unweit Schandau. Von diesen Orten habe ich noch kein Exemplar gesehen und empfehle dieselben der Nach- 
prüfung. - Unterhalb Dresdens: Lössnitzgrund ! (H. Dr.), Weinberge der Lössnitz! (Herb. A. Kuntze), am Eisenbahntumel bei Oberau! (Fr.), Weinböhla ! (H. Dr.), Proschwitz bei Meissen! (H. Mäller), Abhänge run der Lnorre bei Meissen bis Zadel !!, Seusslitz! (IIfm.) (scheint in den letzten Jahren verschwunden zu sein)*), Wachtnitz im Lommatzschthal ! (Stf.). Rehb. nennt auch die Bosel und Sparrberge, ron wo ieh aber noch kein Exemplar gesehen habe. Ein recht isolirtes, wem auch nicht gar zu weit rom Elhhügellande entferntes Vorkommen ist das bei Zabeltitz zwischen Grossenlain und Elsterwerda! (leg. A. Artzt 18;1). - Ausserhalb des Elbgebietes findet sie sich am Lichtenwalder Schlossberge bei Chemnitz! (H. Dr.), sowie zwisehen Alt-Chemnitz und Erfensehlag (S̈̈ur.). Im Vogtlande entdeckte sie A. Artzt in der Gegend von Oelsnitz bei Weischlitz! (11. Dr.. 1I. Artzt), Planschwitz und Burgstein (Gutenfürst). Endlich tritt sie in der Oberlausitz im Mandauthal bei Zittau! (IIfm.), bei Herrnlnut! (Hfm., Fiegel in H. Artzt) und im benachbarten Berthelsdorf anf einer Gartenmaner (IIfm.) (ob nur verwildert?), nach Rehb. auch bei Haynewalde, am Orbin und an der Lausehe auf, an welchen Orten sie aber in neuerer Zeit nicht mehr beobachtet wurde, wie mir Ilerr Oberlehrer B. Lorenz aus Zittau selneibt. Aus dem Plauen'schen Grunde in meinen Garten verptlanzt blieb die I'. recta seit 7 Jahren durchaus constant, so dass sie ron den wildwehsenden in nichts zu unterseheiden ist. - Wo sie in Menge mit P. argentea dicht beisammen wäichst, wie in einem alten Steinbruch des Planen'schen Grundes, oder mit der P. canescens in Berührung kommt, wie an den Zadler Abhängen, habe ich, trotz eifrigen Suchens, niemals etwas gefunden, das an Uebergänge zu den genannten Arten oder an Bastarde mit denselben erimerte.

Wenu wir nach dem Yorgang der älteren Botaniker die P. obscura Willd. als Varietät der P. recta und nicht mit Zimmeter und manchen Neueren als besondere Species aufstellen, so miissen wir unsere sächsische P'Hanze als Iar. pallida Lehm. forma glandulosa bezeichnen. Die Var. obscura (Willd.) Lehm. fehlt uns, wic alle anderen zahlreichen Formen der liecta-Giruppe, die man besonders aus den südlichen und östlichen Iändern kennt.

Ich habe mich nun daräber zu erlilären, warum ich unserer Pflanze .forma glandulosa" beifügte. - A. l'etunnikov sagt in seiner werthyollen Abhandlung ïber, ,die P'otentillen Central-Russlands" (S. 12): "In der" Diagnose von P. recta legt Koch besonderen Nachdruck auf die kurzen, den Stengel bedeckenden Dris enhare. Dieses Unterscheidungsmerkmal erwïhnen weder L,elmann noch Zimmeter, und doch ist das Vorhandensein dieser llaare auf den Bliithenstielen, Kelchblättern und selbst auf den Blättern nach meiner Beobachtung ein bestänliges". In diesen P'unkte kann ich dem sonst so genanen Beobachter nicht unbedingt beipflichten und muss deshalb auch die zweite seiner allgemeinen Schlussfolgermugen einschränken: ...Merkmale, die dem Charakter der Behaarung der Stengel, Blattstiele und der Blätter entnommen sind, zeigen sich sehr beständig

*) Diese typische, reichlrïsige P. reeta wnde von Zimmeter für Herm H. Hofmann revidirt und unbegreiflicherweise als „Forn der P. canescens Bess." bestimmt! Poererlein (l. c. S. 亏0) erzählt einen analogen, aber umgekehrten Fall, in welchem Zimmeter fine bayrische unzweifelhafte Canescens-Form als P. obscura, also zu P. recta gehörend, bestimmte. Z. scheint also in der Unterscheidung zwischen Recta- mul Canescens-Formen nicht sieher gewesen zu sein. 
und kömmen als Beweis der Selbständigkeit und Reinheit der Art gelten". Dieses im allgemeinen richtige Princip findet auf die Drüsenhaare keine Anwendung. Ihr Vorhandensein oder Fehlen bedingt bei verschiedenen Potentillen-Arten (ich will nicht behaupten bei allen) nicht einmal gute Varietäten, sondern höchstens veränderliche Formen (f. glandulosa, f. eglandulosa), wie ich auch in der Gruppe der Potentillae vernales zeigen werde. - Schon lange vor Erscheinen der Abhandlung Petunnikov's - der sich übrigens hauptsächlich mit den Stern- und Zacken-, weniger mit den Drüsenhaaren befasste - hatten mich unsere sächsischen drüsenreichen Formen der P. opaca und arenaria sowie deren Bastarde gezwungen, dem Studium der Drüsenhaare dieser Arten eine besondere Anfmerksankeit zu schenken, besonders da ich in der Litteratur sehr wenig darïber fand. Durch die beiden citirten Aussprüche Petunnikov's angeregt. habe ich dann auch eine grosse Anzahl von Exemplaren der P. recta aus verschiedenen Gegenden Europas, ferner möglichst viele Varietäten und Formen aus ihrem engeren und weiteren Verwandtschaftskreise unter dem Mikroskop — das einzig sichere Mittel - auf Drüsenhaare untersucht und dabei gefunden, dass die echte P. recta var. pallida allerdings in den meisten Fällen mehr oder weniger drüsenhaarig ist, dass aber die Drüsen an Stengeln, Blüthenstielen und Kielchen bald sehr reichlich, bald sehr spärlich sind und hin und wieder ganz fehlen. Am öftesten fehlen sie am Stengel und an den Blättern, ziemlich oft auch an den Blüthenstielen, so dass man sie nur mehr an den Kelchzipfehn (spärlich) findet, schliesslich verschwinden sie ganz.

Unsere sächsischen Pflanzen fand ich reichdrüsig, mit Ausnahme eines von Herrn Hofmann bei Zittau und eines anderen von Herrn A. Kuntze in einem Weinberge der Lössnitz gesammelten Exemplars, welche beide an den Stielen schwach und nur an den Kelchen etwas reichlicher drüsig waren. Von Striegau in Schlesien besitze ich mehrere reichdrüsige Exemplare, aber eines (leg. Callier) ist vollständig drüsenlos. Ein schönes, ebenfalls ganz drüsenreines Exemplar stammt aus der Dauphiné (leg. A. Faure). Die am Stengel drüsenlosen und nur an den Kelchzipfeln schwach drüsigen Pflanzen stammen besonders aus süllichen Ländern und mögen zum Theil schon zur Var. obscura gehören. Letztere rerhält sich ïbrigens gauz ähnlich, wie die Var. pallida und ist noch läufiger selır drüsenarm. Eine am Strieganer Berg in Schlesien von C. Scholz als „P. recta $\beta$, obscura Willd.“ bestimmte Pflanze - scheint ïbrigens dieselbe Form zu sein, die Callier von dort als Var. pallida einlegte - ist vollständig drüsenlos. Aus der nächsten Verwandtschaft der Varietäten pallida und obscura führe ich noch folgende von mir untersuchte Formen an, die als besondere „Species" aufgestellt wurden: $P$. tuberosa J. Wolff aus Siebenbirgen ist drüsenhaarig; P. leucotricha Borb.: Original-Exemplare von Borbás am Blocksberg bei Ofen gesammelt, sind drüsenlos, ebenso eine von W. Steinitz 1879 an derselben Localität gesammelte und als P. recta rar. obscura ausgegebene Pflanze (Herb. A. Kuntze), dagegen die von Dichtl bei Kalksburg (Wien) gesammelten und als I'. leucotricha Borb. ausgegebenen Exemplare drïsig. - Ton den ron Blocki in Galizien gesammelten und benannten "Species" ist die $P$. fallacina, einschliesslich der V'arietäten hirsutior und calcicola, spärlich drïsig (Stengel drüsenlos), die P. Herbichio theils ganz drïsenlos, theils mit vereinzelten Drüsen an den Kelchzipfeln. die P. Pseudo-Herlichii an Stengel und Blüthenstielen ohne, an den 
Kelchzipfeln mit sehr spärlichen Drüsen; ebenso rerhalten sich seine $P$. subobicura und $P$. Relmanni; dagegen ist die $P$. thyraica theils reich-, theils schwachdrüsig.

Etwas weiter als die bisher genannten Varietïten der I'. recta L. entfernt sich ron deren Typus die P. pilosa Willd, die zwar l.ehmann nur als eine Form der Var. obsenra ansieht, aber schon Koch als Species hinstellte, welche sich ron der P. recta unter anderem durch das Fehlen der Drüsenhaare unterscheiclen soll. lch will nicht iiber den systematischen Werth dieser Form, die im Königreich Sachsen bis jetzt noch nicht aufgefunden ist, streiten - für mich ist sie vorläufig eine sich eng der Var. obscura anschliessende Subspecies der P. recta - sondern nur darauf hinweisen, dass das Unterscheidungsmerkmal bezïglich der Drïsenhaare hinfällig ist, 1 . weil es drüsenlose Formen der P. recta gieht, und 2. weil anch die P. pilosa wenigstens oft Drüsenhare besitzt. Gerade die als typisch geltenden Exemplare von Erfurt und Gotha besitzen am kelch Drüsenhaare (nur eines vom Seeberg hei Gotha fand ich ganz driiseulos), desgleichen die ron Borbás und lloluly aus Ungarn ausgegebenen. Ein ron Schlickum aus Samen aus dem botanischen Garten in Berlin 1866 gezogenes Exemplar, das mir vorliegt, ist sogar an Stengeln und Bliithenstielen reichdriisig; doch scheint hier eine Verwechslung mit der P. recta und pallida nicht ausgeschlossen, da auch der Blattschnitt nicht recht auf die $P$. pilosa passt. Auch die $P$. Roemeri Siegfr., die wohl identisch mit der auriflora Borb. sein und eine Varietät der P. pilosa darstellen dürfte, ist nicht drüsenfrei, wenigstens an den Kelchen. So verhält sich also die P. pilosa ganz wie die schwachdrïsigen Formen der Var. obscura.

Was endlich die der I'. recta L. fernerstehenden Speeies und Varietäten aus der Gruppe der Potentillae rectae anbelangt, so fand ich, so weit mein Untersuchungsmaterial reicht, die $P$. taurica Willd. aus der Krim (leg. Callier) starkdrüsig, die $P$. Detommasii 'len. ans Serbien drïsenlos, ebenso die I'. hivta L. aus Sïlfrankreich und Syanien. die P. laeta Richb. aus dem österreichischen Littorale, Herzegowina, Serbien und hrim, die P. pedata Nestl. aus dem Littorale und Dalmatien - welche alle drei als Rassen oder Subspecies in eine Gesammtspecies zu vereinigen sind - durchaus drüsentos.

Ich schliesse diese Digression resumirend: Im nächsten Verwandtschaftskreise der P. recta L. darf das Fehlen oder Torhandensein von Drïsenhaaren nicht in die Diagnostik der Species und Varietäten aufgenommen werden, man kann nur eine forma glandulosa und eine forma cglandulosa aufstellen, welche beide sich bei jeder Species oder Varietät wiederholen können und sich z. B. bei den Varietäten pallida, olsscura, pilosa, leucotricha und Herbichii in der That wiederholen. Wo die forma glandulosa bei weitem rorzuherrschen scheint, wie bei pallida und obscura, brancht man ja ,f. glandulosa" nicht besonders anzugeben, sondern nur bei den drüsenlosen Exemplaren ,f. eglandulosa" beizufügen. Sollten sich ungekehrt bei den, wie es scheint, gewölnlich drüsenlosen I'. hirta, laeta und pedata auch drüsige Formen finden, dann wäre es angezeigt, sie mit ,f. glandulosa" zu bezeichnen.

Da ich noch mehrfach auf die Drüsenhare der Potentillen zu sprechen kommen werde, will ich an dieser Stelle über die Natur derselben 
Einiges vorbringen, denn es scheint noch vielfach Unklarheit darüber zu herrschen. - Vor allem sei bemerkt, dass in der Potentillen-Forschung das Mikroskop ein wichtiges Hilfsmittel ist. das bis jetzt noch viel zu wenig angewendet wurde. Zum Studium der Potentillen-Trichome ist es geradezu unerlässlich. Ueberzeugend geht dies aus der schönen Abhandlung Petun. nikov's über die Potentillen Central-Russlands hervor, der sich aber, abgesehen ron seinen schon citirten Bemerkungen über die P. recta, nicht mit den Drüsenhaaren beschäftigte (vielleicht weil ihm sein Arbeitsfeld keine Veranlassung dazu bot) ebenso wenig wie Waisbecker in einem kleineren, älteren Aufsatz ïber die Stern- und Büschelhaare in der Oestr. bot. Zeitschr. 1892, S. 263.

Nur das Miskroskop ermöglichte es mir, in dem berlentenden von Zimmeter theils selbst gesammelten und ausgegebenen. theils revidirten und eigenhändig mit Bemerkungen versehenen Potentillen-Material, das sich allmählich in meinem Herbar angehänft liat, eine so grosse Zahl un lichtiger Bestimnungen nachzuweisen, dass ich gregen diese Auctorität ganz misstrauisch geworden bin. Seine Revisionen bediirfen einer grïndlichen Nach-Revision!

Die mikroskopische Untersuchung ist durchans nicht so schwierig, als sich Mancher vorstellen mag. Ein einfaches Instrument im Preis von 40-50 Mark, mit einer 50, 150 und 300 maligen Linearrergrösserung geniigt für unsere Zwecke, ja in den allermeisten Fïllen wird die erstere, d. h. 50malige Vergrösserung ansreichen und die geeignetste sein, weil man dabei grössere Theile des Stengels oder der Blätter übersehen und die Ptlanzentheile viel besser anf dem Jikroskoptischchen handhaben kann, wobei sellsst die Unterlage einer Glasplatte (des Objectträgers) ïberflïssig wirl. Die Untersmchung der Haare auf der Blattfläche bei durchfallendem Licht erfordert allerdings die vorhergehende Iaceration des Blattes durch verdiinnte Salpetersäure, dlas Abziehen der Epidermis etc nach einer Methode, die Petmnikor in seiner Abhandung heschrieben hat. Allein diese zeitraubende Nethode ist nnr da anzuempfehlen, wo es sich um sehr feine Untersuchungen, bei denen auch stärkere Vergrösserungen in Anwenlung kommen, hanctelt. Füir gewöhnlich wird man ein genïgend klares Bild der Behaarung bekommen, wenn man bei 50 maliger Vergrössermug die Pflanzentheile (Stengel, Blïthenstiele, Kelche, Blätter) ohne weitere V'orbereitung unter das llikrosliop liringt und deren Ränder bei durchtallendem Licht betrachtet. Am natiulichen Blattrand zeigen sich fast immer dieselben Haare. welche die Oberfläche bedecken, zun Theil auch die der Unterseite; sodam bieten die nach oben oder nach unten ungebogenen und gefalteten Blätter, wie sie ja an getrockneten Pflanzen so häufig sich finden, eine vortreffliche Gelegenheit, am Faltenrande die Ober- oder Unterseite des Blattes zn studiren; die Brnchränder, die man jederzeit herstellen kamu, leisten ebenfalls gute Dienste, und endlich gelingt es anch bei günstiger Belenchtung nicht selten, die Blattoberfläche bei anffallendem Licht sehr genan kennen zu lernen. Ein Bedecken des Gegenstandes mit einem Deckgläschen und ein Eintanchen in Wasser ist bei dieser Methorle nicht nothwendig, nicht einmal angebracht Während man mit der linken Hand das Object hin- und herschiebt, um verschiedene Theile dessellen zu betrachten. bewegt man mit der rechten den Objecttisch (oder das Rohr) mit der Mikrometerschraube auf mond nieder, nm die höher und tiefer gelegenen Theile in die richtige Sehweite $\mathrm{zu}$ bringen. Bald erlangt man eine grosse Fertigkeit im Beobachten und kann in einer Stmule ein paar Dutzend Pflanzen unter dem Mikroskop Rerue passiren lassen, selbst olne Theile von getrockneten Herbarpflanzen abzunehmen, wenn man sie anf einen erhöhten Gegenstand neben den Mikroskoptisch legt und nur die zu untersuchenden Theile auf diesen hinüberschiebt. Um einzelne Haare, z. B. Sternhaare, genaner zu betrachten, emptiehlt es sich oft, etwas von der Behaarung des Stengels oder der Blätter vorsichtig abzuschaben und anf einen gläsernen Objectträger zu bringen. - Der geringe Zeitaufwand, den die mikroskopische Untersuchung forilert, lohnt sich reichlich durch die Sicherheit, welche man fïr die richtige Beurtheilung der Pflanze erlangt. Sodann wird der, welcher durch zahlreiche Beobachtungen unter dem Mikroskop sich ein richtiges Bild der Behaarungsart gewisser Formen verschafft und eingeprägt hat, bald dahin gelangen, dass er schon mit einer guten Lupe viel mehr sieht, als ein anderer, der keine Ahnung rom mikroskopischen Bilde besitzt, er wird schon auf der botanischen Excursion diejenigen Pflanzen bezeichnen kömen, welche sich nnter dem Jikroskop als dieses ouler jenes erreisen werden, also Vieles beachten, was ein anderer granz unbeachtet lässt. 
In der Kochischen ron Petunnikov angezogenen Diagnose heisst es: ,P. recta (L.) caulilus erectis foliisque hirsutis, pitis elongatis tubereulo insidentibus brevibusque glunduliferis" . . Dies ist niclit gan\% richtig, mindestens unvollständig ansgedriickt, mind ebenso mngenan ist es, wenn Petumikor von ., diesen kurzen den Stengel bedeckenden Drïsenharen" spricht. Die lirren, steifen, den oberen Theil des Stengels und die Blïthenstiele dicht bedeckenden Ilaare sind allerdings für die l'. recta und ihne Varietäten sehr charakteristisch, besomlers den weichen geschlängelten Filzharen der Argentea- und Canescens-Formen gegenüber

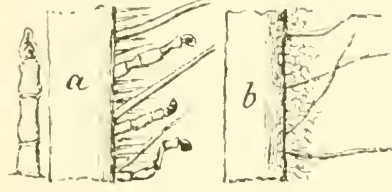

Fig. 6 .

a) Stengelbeharmoder $P$.recta

L. b) Stengelbehaarung der $P$. canescens Bess. (Vergr.) (Fig. 6), aber gerade sie sind lieme brüsenhaare, sondern zwischen ihnen stehen, sie meist überragend, Drïsenhaare von gainz anderer beschaffenheit und an Kahl, selbst hei stark druisigen Formen, immer weit hinter den dichtgedrängten kurzen Borstenhaaren zurückibleibend. Koch's Diagnose müsse etwa so ergänzt werden: P. recta . . . caulibus pilis mollibus elongatis brevibusque valde rigidis, plerumque intermixtis glanduliferis articulatis paulo longioribus.

Die kurzen, steifen und geraden Borstenhaare, welche besonders am oberen Theil des Stengels und der Blüthenstiele meist dicht gedrängt stehen, sehen unter der Lupe fast aus wie der Sternfilz auf den Blätter'n der P. arenaria, nur dass sie nicht sternförmig gruppirt, sondern einzeln auf der Oberhaut stehen. Sie fehlen nie und gehören in die Diagnostik der ganzen Recta-Gruppe, besonders wo diese gegen die der $P$. canescens und argentea alggegrenzt werden soll. lhre Alowescnheit hei der $P$. delphinensis Godr. und Gren., die in mancher Beziehung so sehr an die P. recta erinnert mud von Lehmann in der That in ihre Nähe gestellt wurde, hestimmte mich weit mehr, als die Grïnde Zimmeter's, dieselbe aus der Recta- in die Chrysantha-Gruppe zu versetzen. Die kurzen Borstenhatre, welche bei den reinen Canescens- und Argentea-Formen ganz fehlen, geben anch den besten Anhalt für die Beurtheilung der Bastarde der beiden letztgenannten Arten, bei denen eine Betheiligung der P. recta vermuthet wird. So finden sich z. B. - wie ich schon bei Besprechung der ,I'. Arthuriana" angab - an den Original-Exemplaren (ler P. canescens $\times$ recta v. obscura (Wolffiana Siegfr.) aus Siebenbürgen zwischen den gekräuselten Filzhaten der I'. canescens noch iiberwiegend die steifen Borstenhärchen der P. recta. Dagegen fehlen diese geraden Borstenhärchen bei einer von Oborny bei Znaim in Mlihren gesammelten und als l'. Wolffiana Siegfr. ausgegelenen Pflanze vollständig, sie besitzt reinen Canescens-Filz, und hauptsächlich aus diesem Grund - abgesehen diuvon, dass auch sonst uichts an P. recta erimert, muss ich ihr den Charakter und Namen einer P. canescens $>$ obscura alssprechen. - Soweit meine Erfalırungen bis jetzt reichen, muss ich annehmen, dass die charakteristischen Borstenhärchen der P. recta so sicher auf deren Bastarde, wenn auch in abgeschwächter Form, ihergehen wie die Stern- oder Zackenhaare auf die der P. arenaria und P. Gaudini.

Während die gewöhnlichen Haare der P'otentillen (bei Sternhaaren deren Aeste) lange und kurze, steife und gekräuselte, einzellig und riemlich starkwandig sind, bestehen die Drüscnhare aus einer lieihe läng- 
licher, äusserst dünnwandiger, wasserheller Zellen mit einer kieinen runden oder kurz-conischen, gewöhnlich rothgefärbten Endzelle, der Drüse an der Spitze. Diese zarten Drüsenhaare sind sehr hinfällig, man findet sie oft schon an der lebenden, stets aber an der getrockneten Pflanze stark eingeschrumpft, gekrümmt und geknickt, doch fallen sie nicht leicht ganz ab. Die Zahl ihrer Zellglieder ist unbeständig an einer und derselben Pflanze und schwankt von 3-6 (selten noch mehr), wodurch das Driisenhaar bald zwischen dem steifen Borstenfilz versteckt bleibt, bald weit iiber denselben hervorragt, aber sehr selten die Länge der langen, weichen, einzelligen Haare erreicht. Während zwischen den letzteren und den kurzen Borstenhaaren Uebergänge beobachtet werden, sind jene Drüsenhaare durch ihren mehrzelligen Bau scharf von allen anderen Haaren geschieden. (Vergl. Fig. 6 a.)

Solche Drïsenhaare fand ich bei unseren mitteleuropäischen Rosaceen, ansser der Gattung Potentilla nur noch bei Geum rivale L. und Geum (Sieversia) reptans L. - Die Drüsenhaare bei Rosa und Rubus sind ganz verschieden vou denen der Potentillen, es sind Drüsenstacheln in Miniatur, gehen bekanntlich in diese iber und theilen mit ihnen den anatomischen Bau. Dagegen finden sich die beschriebenen zarten Drüsenhaare in anderen weit entfernten Familien wieder, so z. B. in überraschender Aehnlichkeit, auch beziiglich ihres Auftretens zwischen der iibrigen Behaarung, in der Gattung Euphrasia.

Der Vollständigkeit halber muss ich erwähnen, dass bei den Potentillen ausser den mehrzelligen zarten Stieldrüsen auch eine zweite Art von Drüsenhaaren vorkommt, die man zu den Sitzdrïsen zu rechnen pflegt, - nicht sehr correct, dem sie sind kurzgestielt: auf einer einzigen, kurzen, ziemlich starkwandigen Zelle sitzt ein meist abgeplattetes Drüsenköpfchen, welches eine klebrige Flüssigkeit absondert. Mitunter besteht der Drïsenstiel aus 2, selten aus 3 Zellen, wodurch Uebergänge zu den langen Stieldriisen entstehen. Solche kurzstielige Drüsen finden sich nur sporadisch an einigen unserer heimischen Potentillen und werden uns hier nicht weiter bescläftigen, sie sind aber von Wichtigkeit und charakteristisch für andere uns fehlende Arten, welche durch sie oft starkdrüsig werden, so z. B. die hochalpine $P$. frigida Vill. Die langen Stieldriisen sondern viel weniger stark ab, und die damit reichlich behafteten Ptlanzen, wie unsere P. arenaria und P. opaca fühlen sich selten und dann nur schwach klebrig an.

Die ,Viscosität" einiger Potentillen wird iibrigens auch anf eine andere Weise, als durch lang- oder kurzgestielte Drüsenhaare, hergestellt, indem nämlich die Oberhautzellen des Blattes oder der ganzen Pflanze selbst eine klebrige Flüssigkeit ausscheiden. Die kleinen Tröpfchen erhärten später zu harzähnlichen Kügelchen und geben der Oberhaut des Blattes unter dem Mikroskop oder einer scharfen Lupe ein gekömeltes Ansehen. Diese Art der Secretion kam sich mit der durch Drüsenhare rerbinden, wie z. B. bei $P$. frigida Vill., oder sie besteht für sich allein, wie bei der asiatischen $P$. viscosa Don., ja sie kommt selbst bei mehreren Canescentes vor, bei welchen Driisenhaare ausgeschlossen scheinen, so z. B. bei einigen (ob allen?) Varietäten der P. pensylvanica L. und bei P. tanacetifolia Willd., welche beide, trotz ihrer gefiederten Blätter, unștreitig in die Canescentes-Gruppe (seusu lato) gehören. 


\section{$\uparrow$ ? Potentilla thuringiacal Bernh.}

Die P. thuringiaca, welche in nicht sehr grosser Entfernung von Sachsen ans Thüringen, Bölmmen und Bayern bekamt ist, wurde für Sachsen selbst bis jetzt in keiner Flora angegeben, und doch besassen wir sie bis vor nicht allzu langer 'Leit, und zwar in der Leipziger Gegend bei Panitzsch an der Parthe unweit Taucha. Ich machite die Entuleckung ganz zufïllig. Bei einem Besuch des Herrn O. l'. Säurich in Chenmitz im Spätherbst 1900 iibergab mir dieser unter anderem P'otentillen-Naterial anch ein pair aufgeklebte Ptlanzen, welche vom verstorbenen Herrn Büirgerschullehrer 11. P'ause herriihren, und von denen eine sofort meine Aufmerksamkeit fesselte. Die Etiquette besagt: "Potentilla obscura W. Panitz bei Leipzig 1850". I)as Wort obscura ist aber an Stelle eines ausradirten Wortes geschrielien, von dem man noch den Anfangs- und Endbuchstaben c und s crkennen kann und welches unzweifelhaft canescens geheissen hatte. Wie ich schon an einer frihheren Stelle gesagt, haben Ileynhold und Reichenbach anno 1840 für die letztere den Standort "l'anitzsch bei Leipzig" nach Gïttner angegeben, und nach Herb. L'etermann existirte sie dort thatsïchlich. Pause hat nun ganz richtig gefüllt, dass seine Pffanze von P'anitzsch keine P. canescens sein kann, da ihr der charakteristische Filz auf der Blattunterseite vollständig fehlt, und bestinmte sie als P. obscura W. las ist sie aber ebenso wenig, und die genaueste makroskopische und mikroskop ische Untersuchung erwies sie als $P$. thuringiaca Bernh. Die bekannte Gewissenlaftigkeit des Her'n Pause bürgt dafür, dass die vorliegende von ihm etiruettirte Pflanze wirklich von Panitzsch stammt und dort 1850 gesammelt wurde*). Es fragt sich nun, war sie clort nur ein voribergehend auftretender Gartenflüchtling oder einheimisch:? und im letzteren Falle: ist sie, vielleicht durch fortschreitende Cultur an den Abhängen lïngs der Parthe, ganz verschwunden, oder in den letzten Decennien nur nicht beachtet worden? Trotz eifrigster Bemühung, weiteres Material aus alten Herbarien, sowie Nachrichten über diese Potentilla zu bekommen, bin ich doch noch zu keinem befriedigenden Endurtheil gelangt. 1)ass sie nur als Gartenfliichtling auftrat, ist nicht wahrscheinlich, denn l'ause hïtte dies sicher notirt und zudem wird diese Art wohl kaun irgendwo, an wenigsten in Panitzsch als Gartenpflanze cultivirt worden sein. Herr R. Wissbach, der die Gegend kennt, versichert nur, dass er bei Panitzsch weder eine P'. recta noch eine P. canescens gefunden habe deshalb blicb ja auch der Reichenbach'sche Standort für dic letztere in nenesten .,Wünsche" weg —, allein er will, nach seiner gefälligen nündlichen Vittheihung, nicht mit derselben Sicherheit behaupten, dass dort auch die P. thuringiaca felle. Weiteren Aufschluss erhoffe ich von einer gründlichen Durchforschung jener Gegend, die ich für den nächsten Sommer in Aussiclıt nehme. Vorläufig nelıme ich an, dass die l'. thuringiaca dem geübten Scharfblick des Herrn Missbacl w wohl schwerlich entgangen sein wiirde, dass sie wenigstens bis zum Jahre 1850 als spontaner Bürger der

*) H. Panse hinterliess ein sorgfältig ausgearbeitetes, fast vollendetes II a u script einer Flora der Chemnitzer (iegend. das aber auch of über die Grenzen dieser hinansgreift. Einen bleibenden Werth verleihen dieser mïhevollen Arbeit die sehr zahlreichen und gewissenhaften Staudortsangaben, die einst bei der Herausgabe einer guten Flora saxonica nicht mbericksichtigt bleiben diirfen. Das Pause'sche Herbar ist im Besitze des Chemnitzer Realgymnasiums. 
Leipziger Flora rorhanden war, später aber - wie ja so viele andere ausgerottet worden ist.

Leider ist das Material, das mir zu Gebote steht - ein einziger Blüthenstengel ohne Wurzelblätter - so gering, dass ich danach nicht zu entscheiden wage, ob unsere Pflanze der typischen P. thuringiaca angehört oder einer Varietät derselben.

Bei dieser Gelegenheit möchte ich eine Beobachtung anführen, welche ich zwar schon früher an Potentillen der Thuringiaca-Gruppe gemacht habe, deren Bestätigung an unserer Pflanze ron Panitzsch mir aber um so mehr auffiel, als ich wenige Tage zuvor in Poeverlein's Arbeit eine Behauptung gelesen hatte, die meinen Beobachtungen direct widerspricht. Ich würde die Sache nicht berühren, wemn sie nicht ron einiger Wichtigkeit für die systematische Stellung der P. thuringiaca wäre. Poeverlein fülırt (l. c. S. r0) als dritten Grund, warum er die P. opaca aus der ChrysanthaeGruppe, wohin sie Zinmeter gezogen, wieder in die Aureae-Gruppe zurückversetzt (was übrigens schon vor ilhm Ascherson und Andere gethan haben) an: ,3. P. rubens" (d. h. unsere opaca), ,besitzt die für die Aureae (Campestres) so charakteristischen Drusenhaare, während dieselben den Chrysanthae sämmtlich felıle11." Dies ist nicht richtig, und ich muss annehmen, dass Herr Poeverlein entweder die Chrysanthae nur mit blossem Auge oder höchstens mit einer schwachen Lupe betrachtet, oder dass er zufällig nur drüsenlose Formen untersucht hat. Mit dem Mikroskop wird er - und Jeder, der sich davon überzeugen will - gerade wie ich, wenn nicht an allen, so doch an den meisten Chrysanthae dieselben Drüsenhaare finden wie an der P. opaca forma glandulosa. Allerdings sind sie an der letzten of triel häufiger, daher leichter bemerkbar, aber es giebt bekanntlich auch sehr viele opacae mit spärlichen Drüsenhaaren sowie ganz drüsenreine. Die deutlichsten Stieldrüsen in der bekamnten Form habe ich gefunden:

1. an der $P$. thuringiaca von Panitzsch bei Leipzig, sehr spärlich am Kelch, häufiger an den Blattstielen;

2. an der als typisch geltenden von Suhl in Thüringen (leg. Rudolph, Sagorski, Scharlock): sehr spärlich und vereinzelt am Kelch, etwas häufiger an den untereu Pflanzentheilen, besonders an den Stielen der unteren Blätter;

3. an der P. thur. von Windsheim in Bayern (leg. Kessler): am Kelch fehlend, aber sehr deutliche und lange Stieldrüsen an den Stielen ron Stengelblättern;

4. an der $P$. th. var. jurassica Siegfr. vom Col du Marchairuz im Schweizer Jura (leg. Favrat): an Kelch und den oberen Stengeltheilen zerstreut, weiter abwïrts am Stengel und an Blattstielen immer häufiger werdend. - Ganz gleich verhält sich ein ron Siegfried (No. 169) ausgegebenes Cultur-Exemplar;

5. an der P. th. var. Buquoyana (Knaf) rom Eichbusch bei Komotau in Böhmen (leg. Wolf !!): ähnlich wie bei der Var. jurassica, Drüsenhaare in idealer Schönheit! am Kelch spärlich, an den nnteren Pflanzentheilen an Zahl rasch zunehmend; 
6. an Subspec. P. Goldbarhii Rupr. aus Siidostgalizien verschiedene Exemplare (leg. Blocki): genan wie die vorige (Buquoyana), zum Theil sehr drïsenreich;

7. an der Subspec. P. Nestleriana Tratt.: zwei von Siegfried ausgegehenen Culturformen, an der einen (No. 173) fehlen die Drüsen an Kelch und treten an den unteren Stengeltheilen und Blattstielen vereinzelt anf; die andere (No. 175) ist reichdrusig bis hoch hinauf, auch an keleh finden sich zahlreiche lange stieldrüsen;

8. an der P. Nestl. tar. coronensis (Schur.): an einem Siegfried'schen

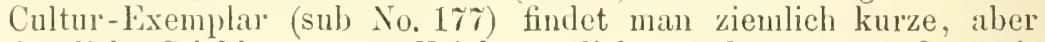
deutliche Stieldrüsen, am Kelch spärlich, an den unteren Stengeltheilen und Blattstielen häufiger;

9. an der P. Nestl. var. parviflora (Gaud.) von Samaden im Engadin (Siegfr. Exssice. No. 179 a, leg. Candrian): nur ein palar sporadische Driisen an den untersten Pflanzentheilen. Dagegen ist eine von Siegfried sub No. 179 alusgegebene Culturform (ler Var. parviflora (vom locus elassicus , Jonx brulés" im Unter-Wallis herstammend) mit sehr reichlichen I) rïsen bis an die obersten Blithenstiele und und die Kelchzipfel hinauf besetzt;

10. an der P. chrysantha Trev. von Langenthal in Siebenbürgen (leg. Barth): ausserordentlich drüsenreich wie No. 1\%;

11. an der $P$. clnysantlua ,bei den St. Georgs-Sauerquellen" in Siebenbürgen (leg. Dr. Alexi): nur vereinzelte Drüsen;

12. an der P. chrysuntha var. pseudochrysantha (Borb.) aus dem Banat (leg. Heuffel, E. Fiek): ausserordentlicher Drüsenreichthum wie bei einer P. opaca glandulosissima!

13. an der P. chrys. var. leiocurpa (Vis. und Panč. als Art) aus Serbien (leg. Hlic.): in Drüsenreichthum mit der vorigen Var. pseudoclurysantha wetteifernd, was die Vermuthung von Zimmeter und Borbás bestätigt, dass sie nur eine kleinblüthige Form von dieser ist;

14. an der P. delphinensis Godr. und Gren. vom Col du Lantaret im Departement Hautes-Alpes (leg. Nlme. 'True.): spärliche kurzgestielte Driisen am Kelch und den obersten Stengelblättern.

An der P. patula W. K. sowie an der kaum von ihr zu tremnenden P. Schurii Fuss. habe ich bis jetzt noch keine Drüsen entleckt, freilich stand mir ein nur sehr kleines Untersuchungsmaterial zur Verfügung. Mit Ansnalume dieser zwei, die mir ibrigens der l'. opaca viel nülher zn stehen scheinen als der I'. thuringiaca, ist mir keine einzige Form (auch nicht einmal cin einzelnes Exemplar) der gamzen Chrysanthae-Gruppe in die Hände gekommen, an welchem ich unter dem Mikroskop keine I)rüsenhaare gefunden hätte, und meine bisherigen Erfahrungen haben mich zur Ansicht geführt, dass die Drüsenhare bei den Chrysanthue bestiundiger auftreten als bei der $P$. opaca, unserer drisenreichsten Species der Aureae vernales. Meistens sind sie allerdings, besonders an Kielch, spärlicher vorhanden, aber an ter schönen I'. chrysantha stehen sie so dicht, dass sie schon mit blossem Auge oder einer schwachen Lupe gar nicht ühersehen werden können und ich mich nur wundere, wie dies dennoch geschehen ist. Bei den schwachdrisigen Formen nehmen die 
Drïsenhare allgemein gegen den unteren Theil der Pflanzen hin an Zahl zu, im Gegensatz zu der P. opaca, bei der sie gegen oben zuzunehmen pflegen.

Erst nach Abschluss meiner Beobachtungen an den Chrysanthae bemerkte ich, dass ich nicht der Erste sei, der auf ihre Drüsenhaare aufmerksam macht; ich fand bei Karsten (Flora ron Deutschland etc., 2. Aufl., S. 325) bei der P. thuringiaca Var. Nestleriana die Bemerkung: "wenig drüsig", und bei der Var. Buquoyana: .reichdrïsig".

Meine Untersuchungen bestätigen von neuem, dass die P. thuringiaca (und ihr ganzer Formenkreis) der P. opaca ausserordentlich nahesteht - ich könnte auch noch Belege aus der Uebereinstimmung in der anderweitigen Behaarung beider beibringen - aber ich ziehe daraus nicht etwa mit Ledebour, Celakorsky und Zimmeter den Schluss, dass die P. opaca in die Chrysanthae-Gruppe hinübergeschoben werden müsse, sondern behaupte gerade ungekehrt: der ganze Formenkreis der Chrysanthae muss in die Gruppe der Aureae herübergezogen werden.

Der dritte Grund, aus welchem Poeverlein die P. thuringiaca und die P. opaca in zwei ganz verschiedenen Abtheilungen unterbringt, ist also, wie wir gesehen haben, hinfällig; aber selbst wenn die Chrysanthae wirklich drüsenlos wären. brauchten sie noch nicht von den Aureae abgetrennt zu werden, denn wie viele Formen bei diesen letzteren, selbst unter den "Campestres", sind in der That drüsenlos, und hat nicht Poeverlein selbst eine angeblich ganz drüsenlose Gruppe derselben in seinen ,Aureae alpinae“ geschaffen? ( - wo bleibt dann die drüsenreiche $P$. frigida Vill.? -)

Wie steht es nun mit den beiden anderen Grïnden für die Abtrennung?

„1. Der Stengel ron P. rubens (resp. opaca) ist niemals aufstrebend wie bei den Chrysanthae, sondern stets niederliegend wie bei den Aureae." Der Satz, wie er steht, ist nicht richtig; höchstens könnte man ihn gelten lassen, wenn es statt niemals ", selten so" und statt stets „meistens" hiesse, aber dann wäre er eben nicht mehr, ,beweisend". Jeder der die P. opaca viel im Freien zu beobachten Gelegenheit hatte, wird wissen, wie sehr verschieden ihr Habitus von dem der P. rerna oder der $\mathrm{P}$. arenaria ist, gerade dadurch, dass sie, wie die $\mathrm{P}$. thuringiaca, vereinzelte compacte Stöcke ( - jene dagegen ausgebreitete wurzelnde Rasen - ) bildet, deren Aeste am Grunde wenig oder gar nicht wurzeln und dass sie sehr häufig aufrechte, oft hoch über die Wurzelblätter hinausreichende Stengel treibt, welche freilich wegen ihrer Schwäche sich sehr leicht umbiegen, und ,aufstrebend" (adscendentes) oder anch niederliegend werden. Wie oft hat mich früher dieser thuringiaca-artige Habitus in Verlegenheit gesetzt! Mehrmals fand ich in Herbarien grosse aufrechte Opaca-Formen, besonders aus Böhmen, als P. thuringiaca bestimmt. Umgekehrt findet man kleine Thuringiaca-Formen, z. B. bei der P. parviflora, auch bei der P. chrysantha, die nach ihrem Habitus ron grösseren Opaca-Formen kaum zu unterscheiden sind. Von der kleinen P. patula und der P. Schurii mit ihren kurzen, niederliegenden, ausgebreiteten Stengeln will ich gar nicht sprechen; wenn sie die abstehende Behaarung der P. opaca hätten, wären sie nur Varietäten von dieser! Wenn man die P. thuringiaca wegen ihres aufstrebenden Stengels in eine andere Hauptabtheilung, in die der "Assurgentes“ (Yoev.) verweisen will, dann darf man auch die P.grandi- 
flor mit einem ganz entschieden aufstrebenden Stengel nicht mehr bei den Aureae belassen, zu denen sie doch sicherlich atuch nach Ilerrn l'oeverlein gelıört, da sie so leicht mit den anderen Aureae alpinae Bastarde bildet*). - Die letzte Bemerkung fülnrt mich zur Prüfung des zweiten Grundes, aus dem Poeverlein die I'. thuringiaca weit von der P.opaca entfernen will:

2. „P. rubens (resp. opaca) bildet mit den Formen der Aureae-Gruppe namentlich den Stelligerae und Veruales gar nicht selten Bastarde, während Bastarde zwischen ihr und Chrysanthae-Formen meines Wissens noch nicht bekannt sind." Dies ist richtig, es folgt aber nichts daraus, denn die Species einer Gruppe müsen nicht immer Bastarde unter sich bilden und dadurch sich gleichsam als nahe Verwandte legitimiren, wenn sie es anch oft thum. IItan kennt ja anch z. 13. noch keinen Bastard zwischen P. thuringiaca und P'. patula, die man doch immer zusammenstellt! Wenn man noch keine Bastarde zwischen den Chrysanthae- und AureaeFormen kennt - Brïgger will iibrigens eine P. aurea $x$ thuringiaca beobachtet haben (Zimm. I. p. 24) — so kann dies claher rühren, dass die P. thuringiaca (sensu lato) gerade in den wenigen Ländern, wo bis jetzt eingehende Beobachtungen an Potentillen gemacht wurden, äberall spärlich, wohl auch sehr selten zusammen mit ilı'er nächsten Verwandten, der P. opaca aufzutreten scheint; wir wollten einmal sehen, ob sie sich so rein hielte, wenn sie so massenhaft mit der l'. opaca vorkïme, wie diese bei uns mit iler I'. verna? Es wäre vorerst zu untersuchen, ob denn die P. opaca in jenen Gegenden, wo die Chrysanthae-Formen häufiger auftreten, auch wirklich vorkommt, und wem das der Fall ist, ob die Bastarde vielleicht nur übersehen sind. - Andererseits beweisen Bastarde auch nicht immer eine sehr nahe Verwandtschaft der Eltern. Es wird wohl jeder Potentillen-Kenner zugeben, dass der Formenkreis der Argentae dem der Vernales ferner steht, als der der Chrysanthae, und doch kennen wir gerade zwischen den beiden ersteren zahlreiche Bastarde, selhst wemn nicht alle Collinae als Argenteae - Vernales zu betrachten sein werden.

Wenn man die Abtheilung der Chrysanthae nicht ganz einziehen und mit der der Amreae vernales vereinigen will, kann man sie allenfalls, wie die A, alpestres, als eine Unterabtheilung der Aureae gelten lassen, also: Aureae: a) chrysunthue, b) vernales, c) alpestres, welche Dreitheilung freilich ebenso küustlich ist, wie die Zweitheilung der Aureae in ,.campestres" und ,alpinae". Dic ganze grosse Abtheilung der Aureae bedarf einer griindlichen Neubearbeitung, welche wohl ganz andere Unterabtheilungen aufstellen wird, als die zwei oder drei eben genannten, die aber nicht möglich ist ohne Heranziehung der verwandten ausländischen Species zum vergleichenden Studium.

Da ich nun doch eimmal anlässlich der Potentilla thuringiaca auf das System zu sprechen gekommen bin, will ich an dieser Stelle noch einige

*) Bei Lehmamn (Rev. P.) heisst es in der Diagnose ron P. thuringiaca: „caulibus in orbem patentibus"; in der von P. opaca: "caulibus adscendentibus gracilibus" ; in der ron P. grandiflora: „canlibus $c$ basi adscendente erectis". 
Bemerkungen darïber machen, und zwar nur über die grösste und für uns wichtigste Section "Quinquefolium" (Focke)*).

Weil in seinem ,Fünfblatt" unglücklicherweise eine fiederblätterige Potentilla vorkommt, die er sonst nicht unterzubringen weiss, sieht sich Focke veranlasst, die Section in zwei sehr ungleiche Theile zu zerlegen:

I. ,Blätter gefiedert": (bei uns) nur P. multifida L.

II. ,Blätter 3-7zählig gefingert": alle ïbrigen. - Für diese wird nun als wichtigstes und oberstes Eintheilungsmotiv das Wachsthumsverhältniss der Achsen und die Richtung der Blüthenstengel gewählt:

A. „Stengel aufrecht, die seitlichen aus kurzem bogigem Grunde; vorwiegend einachsige Arten. (Eine natürliche scharfe Abgrenzung von den zweiachsigen Arten ist nicht vorhanden.)" - Dahin kommen nun: a) mit dreizähligen Blättern P. nivea L. und P. grandiflora L. - b) mit fünf- bis siebenzähligen Grundblättern: «) Stengel und Blattunterseite ohne gekräuselte Haare: P. recta L., P. pedata Nestl. - $\beta$ ) Stengel und Blattunterseite mit gekräuselten Haaren: P. intermedia L., P. canescens Bess., P. argentea L., Collina-Formen.

B. „Z Weiachsig; Stengel niederliegend oder aufstrebend, nach allen Seiten ausgebreitet." - a) Unfruchtb. Stengel rundlich, unterwärts ohne trockenhäutige Nebenblätter: $\alpha$ ) Unfruchtb. Stengel kurz, gleichmässig um die Blattrosette ausgebreitet, Grundblätter fünf- bis elfzählig: P. Nestleriana Tratt. P. thuringiaca Bernh. - P. patula W. K., P. rubens Zimm. (= opaca L.). - $\beta$ ) Unfruchtb. Stengel unregehmässig verlängert, mit gestreckten Achsentheilen vielfach wurzehd. Blattrosette nur im Frühjahr deutlich: P. arenaria Borkh., P. Gaudini Grml., P. verna L., P. dubia Zimm. (= minima Hall. f.) - b) Unfruchtb. Stengel kurz, mit trockenhäutigen alten Nebenblättern dicht bedeckt: P. villosa Zimm. (= alpestris Hall. fil.), P. aurea L. - P. frigida Vill.

Poeverlein's System für "Quinquefolium" weicht insofern wenig von dem Focke'schen ab, als auch er die Stengelrichtung und das Wachsthumsverhältniss der Nebenachsen als Haupteintheilungsmotiv annimmt und nur statt zwei drei Abtheilungen aufstellt:

*) System Focke's.

(I. Leucotricha.)

1. Trichothalamus (= Comocarpa Poev.)

2. Fragariastrum

(II. Atricha.)

3. Pentaphyllastrum (= Pimuatae Poer.)

4. Potentillastrum (= Acephalae P.)

5. Comarum (bei Poev. eigenes Genus)

6. Quinquefolium

7. Tormentilla

8. Chenopotentilla.
System Poeverlein's.

I. Comocarpa (= Trichothalamus Focke)

II. Acephalue (= Potentillastrum F.)

III. Pimatce (dazu Pentaphyllastrum F.)

IV. Chenopotentilla.

V. Tormentilla

VI. Quinquefolinm

VII. Fragariastrum. 
A. Elatae: Einachsig; Stengel aufrecht oler aufstrebend.

B. Assurgentes: Zweiachsig; Stengel aufstrebend.

C. Aureae: Zweiachsig; Stengel niederliegend.

Die Elatae zerfallen dann nach ihrer Behaarung in Rectae, Canescentes und Argenteae; die Assurgentes, ebenfalls nach der Behaarung in Collinae und C'hrysanthae; die Aureae werden nach ihren Standorten in Campestres und Alpinae geschieden.

Zimmeter theilt das "Quinquefolium" (seme "L'almatisectae") ohne eingehendere liegrïndung in: a) Rectae, b) Argenteal (incl. Canescentes und Collinae), c) Chrysanthae (incl. P. opaca), und d) Awreae. - Die Reihenfolge der (iruppen ist genau wie bei Poeverlein, nur dass dieser das System einigermassen zu begründen suchte.

Icl habe nun an beiden (reş). an den drei) Systemen auszusetzen, dass die Haupteintheilungsmotive viel zu unsicher und schwankend sind, und daher nicht eimmal zu einem guten Schlüssel, geschweige denn zı einem phylogenctischen System verwendbar erscheinen. Focke selbst hebt hervor, dass eine natüliche scharfe Abgrenzung der einachsigen von den zweiachsigen Arten nicht rorhanden ist. In der That giebt es einerseits zweiachsige Argenteae und selbst lectae, andererseits einachsige Collinae, Chrysanthae und selbst mitunter Aureae, indem alle Triebe zum Blïhen kommen und keine sterilen Blattrosetten zuriickbleiben. Icl kann den Unterschied, ob die im nächsten Jahr blühenden Wurzelknospen sich schon im Frühjahr oder erst im Spätsommer zn Blattrosetten ausbilden, nicht für so wesentlich halten, um auf ihn eineu Gruppenunterschied von phylogenetischer Bedeutung zu gründen, selbst wenn er beständiger wäre.

Was das zweite leitmotiv anbelangt, nämlich die Richtung und Höhe des Blïthenstengels, welche den IIabitus der Pflanze bestimmen, so steht es womöglich noch misslicher damit, es scheint mir noch unsicherer und unbranchbarer zu sein als das erste. Ich erinnere nur an die liegenden Argentea-Formen z. B. Var. demissa, an verschiedene Collinae rom aufrechten llabitus der P. argentea, an die opaca-artigen Chrysanthae-Formen, an die P. nivea und P. grandifiora (beide sicher elatae!) unter den Aureae alpinae. Focke scheint mir noch immer besser zu fahren, indem er seine Zweiachsigen nicht weiter nach Höhe und Richtung des Stengels trennt, als Poeverlein mit der Abtheilung derselben in Assurgentes und Aureae, mit welcher er die an und für sich schon bestehenden Schwierigkeiten nur vermehrt.

In beiden Systemen werden bei consequenter Durchführung der Leitmotive offenbar nahestehende Formen zu weit von einander getrennt und zudem in einer Reihenfolge aufgeführt, die sich bei einer genetischen Anordnung, die wir doch anstreben sollen, nach meiner Ansicht nicht halten lassen wird. - Wo in beiden Systemen bei den Unterabtheilungen die Behaarungsart als Eintheilungsprincip eintritt, werden die Gruppen natürlicher. Es ist eine alte und immer mehr anerkannte Erfahrung, dass bei den Potentillen die Behaarungsverhältnisse sehr constante Merkmale abgeben und dass sie eine ausserordentlich wichtige Rolle spielen, wenn es sich darum handelt, Verwandtschaftsgrade zwischen den Species aufzudecken, also ihrem Stammbaum nachzuspüren.

Ich frage nun: wie wïre es, wenn man den Versuch machte, die Behaarung als erstes und höchstes Abtheilungsmotiv in der 
Section "Quinquefolium" zu benützen? Sollten wir damit einem natürlichen, d. h. einem phylogenetischen System nicht näher kommen? Ich habe den Versuch längst gemacht und bin zu folgendem Resultat gelangt, welches ich zum Vergleich neben die zwei anderen Systeme hinstellen will, wobei ich aber die Focke'schen Species der Kürze halber in Gruppen zusammenfasse:

Nach Focke.

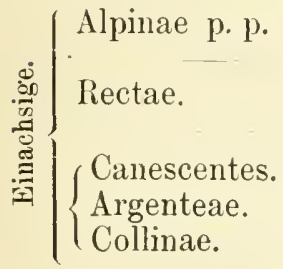

Chrysanthae.
Aureae
a) vernales.
b) alpinae.
Nach Poeverlein.

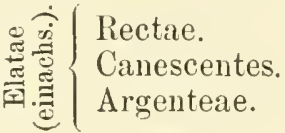

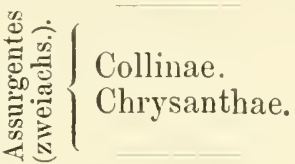

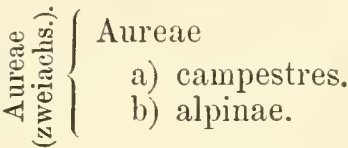

Nach mir.

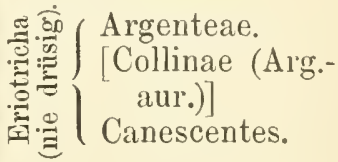

Rectae.
Aureae
a) chrysanthae.
b) vernales.
c) alpestres
(provis.).

Die Collinae habe ich nur vorläufig und in Klammern eingereiht, sie bilden eine Mischgruppe, die zunächst nicht in's System hineingehört und mit der Zeit aufgelöst werden muss, wenn wir erst über ihre Abstammung mehr im klaren sein werden. Sie sind später als primäre und secundäre Bastarde (argenteae $\times$ vernae und argenteae - vernae) bei den betreffenden Argenteae- und Vernales-Formen unterzubringen, denen sie am nächsten stehen, wie es mit anderen offenkundigen Bastarden schon längst geschieht, die im allgemeinen System auch nicht in bestimmte Gruppen zusammengefasst werden. Deshalb brauchen sie auch nicht in der allgemeinen Diagnose der Kraushaarigen (Eriotricha) berïcksichtigt zu werden; einige derselben besitzen z. B. spärliche Drüsenhaare - die den echten Kraushaarigen oder Canescentes gänzlich fehlen - welche von einer betheiligten P. arenaria forma glandulosa abgeleitet werden können.

Mein System, das ich nur als einen Versuch vorlege, scheint mir den Vortheil zu haben, dass nun die erste Hauptabtheilung ausnahmslos kraushaarig und - abgesehen von der nur provisorisch eingereihten Collinae - soweit meine Beobachtungen reichen, drüsenlos ist, und die zweite Hauptabtheilung ausnahmslos auf den Blättern nur schlichte, höchsteus geschlängelte, aber niemals wollig-geliräuselte Haare trägt. Ferner werden die Rectae an eine bessere Stelle geriickt, von den Canescentes zwar scharf geschieden, aber nicht weit entfernt von ihnen, und den Chrysanthae, denen sie in einigen Beziehungen nahestehen, unmittelbar angeschlossen. - Ueber die Stellung, welche meines Erachtens die Chrysanthae einnehmen müssen, habe ich mich schon weiter oben geäussert. Ihre nahe Vereinigung mit den Collinae in eine Abtheilung "Assurgentes" scheint mir unnatürlich zu sein, schon aus dem Grunde, weil die letztere uicht eine mit den anderen gleichwerthige Gruppe ron reinen Arten. sondern nur eine solche ron Bastard- und Mischformen darstellen. Um die Amnäherung der Collinae an die Chrysanthae zu recht- 
fertigen, sagt I'oeverlein (1. c. S. 63): ,Die scharfe Scheidung zwischen Chrysanthae und Collinae, der wir bei unseren einheimischen Arten begegnen, kann aber nicht iiberall aufrecht erhalten werden. So führt z. B. Ruprecht in sciner lora ingrica eine lar. tomentosa seiner P. Goldbachii an, die - wie anch Petunnikor mit Recht hervorhebt - die Merkmale von P. Goldbachii und P. argentea in sich vereinigt". Ganz richtig! aber es muss beigefügt werden, dass Petumikor in seinen Schlussfolgerungen No. 12 von jener Var. tomentosa Rupr. ausilrücklich sagt, dass sie für cinen Bastard P. Foldbachii > argentea gehalten werden könne, gerade wie die P. Heidenreichii für eine 1 '. intermedia $>$ argentea. Daraus folgt doch nicht, dass keine scharfe Scheidung zwischen den Chrysanthae und Collinae aufrecht erhalten werden kann, demn sonst könnte man mit demselben Reeht sagen, dass keine solche zwischen den Vernae und Collinae hestehe, weil die letzteren Vernae - argenteae sind. Die Collinae sind eben Wischformen zwischen scharf geschiedenen (iruppen, und können als solche zur Ermittelung der systematischen Stellung dieser nicht direct herangezogen werden. Fin Chrysantha $x$ argentea-Bastark beweist gar nichts dagegen, dass die reinen Chrysanthae den reinen Canescentes durchaus fern stehen, sich dagegen eng den Aureae anschliessen, und zwar nicht durch Bastarde und Mischformen, sondern durch ihre eigene Natur. ITenn wir die Sache nicht so auffassen, dann giebt es iiberhaupt im ganzen „Quinquefolium" keine scharf getrennten Gruppen mehr.

Bei Focke haben P. multifida, nivea und yrandiflora ganz isolirte unnaturliche Stellungen in Folge der Durchführung des Systems erhalten. Bei Poeverlein kommen sie - nicht in Uebereinstinmung mit den Eintheilungsprincip - am Ende zu den Aureae alpinae. Bei mir hat ihr Unterbringen keine Schwierigkeit: ich stelle ganz consequent die P. multifida und P'. nivea zu den Krausharigen (Eriotricha) und zwar in die Nähe der 1'. argentea*), von der sie die hochalpinen (und hochnordischen) V'ertreter sind, die P. grandiflora kann ich, unbekümmert um ihren aufrechten Stengel. bei den Aureae alpestres lassen. - Dass die P. multificla (mvollkommen-) gefiederte Blätter besitzt, kümmert mich wenig, deun ich setze das Behaarungsmoment auch über den Unterschied von gefiederten und gefingerten Blättern. Mit Recht hat man das alte (Lehmann'sche) Abtheilungsmotiv für höhere Gruppen oder Sectionen, Ternatae (foliis ternatis" und ,.Digitatae (foliis $5-7$ natis)" als unnatiolich fallen lassen; aber mit einer Abtremung von, "Pinnatue" und ,Digitatae (Palmatisectae)" steht es nicht viel besser, anch sie ist mmatiirlich und wird auf-

*) Ieh sage nur, dass sie in die Hauptabtheilung der Eriotricha gehören, welche ansser den Argenteae und Canescentes noch andere Gruplen umfasst, die aber in Hitteleuropa nicht, in Asien dagegen reichlich rertreten sind. Dass die P. nivea nud P. multifida mit den Amreae alpinae bastardiren. beweist noch nicht. dass sie mit diesen in diesellhe Gruppe gehören, dies thun ja anch die Argenteae mit den A mreae vernales. Jene beiden Arten entfalten in den nordischen Gegenden einen ausserordentlichen Formenreichthm, und manche ihrer dortigen Tarietäten stehen anch habitnell unserer P. argentea viel näher, als unsere zwei alpinen Pflänzchen. To giebt es $z$. B. eine P. nivea var. pentaphylla und eine var: pimnatifida. Die P. multifida var. tenella gleicht mit ihren über 3 Decimeter lingen stengeln einer P. argentea var. demissa. In die Gruppe der Canescentes horeales. wie ich sie vorläutig nennen will, gehört eine bedentende Anzahl muter sich nahe rerwandter Arten, welche theils ciremmolar, theils anf den Hochgebirgen Mittelasiens, theils in der Mandschurei auftreten, und ron denen die einen gefingerte, die anderen aber getiederte Blätter besitzen. 
gegeben werden müssen, besonders wenn wir unser PotentillenSystem nicht mehr auf die europäischen Arten beschränkeu wollen. - Wem kein reichliches aussereuropäisches Material zur Verfïgung steht, der blättere nur in Lehmann's Rev. Pot. die Abbildungen durch, um sich zunächst zu überzeugen, dass es keine scharfe Grenze, sondern viele Uebergänge rom folium pinnatum zum folium digitatum giebt, wie bei einigen Arten beide Blattformen, selbst unter den Wurzelblättern, nebeneinander rorkommen, wie durch jene Abtrennung oft das Nächstrerwandte weit auseinander gerissen und sehr Heterogenes nahe zusammengerückt wird. Wer Gelegenheit hat, besonders asiatische Potentillen an Herbar-Exemplaren zu studiren, wird finden, dass man nach allen Merkmalen und besonders nach dem mikroskopischen Befund der Behaarungsart, gewisse fiederblätterige Formen von der Gruppe unserer Argenteae, andere von der unserer Rectae gar nicht trennen kann, wenn man nicht rein künstlich verfahren will. - Ein weiteres Eingehen auf die Sache ist hier nicht am Platz, vielleicht bietet sich mir ein andermal Gelegenheit, darauf ausführlicher zurückzukommen. Für jetzt möchte ich nur nochmals die Ansicht aussprechen, dass die "Pinnatae" in Zimmeter's Simn, als eine grosse, den Digitatae gleichwerthige oder gegenüberstehende Section aufgefasst, nicht weiter bestehen können, und dass das folinm pinnatum nur noch zur Bildung kleinerer Abtheilungen innerhailb rerschiedener Gruppen dienen dürfe. Die Section "Quinquefolium" wird späterhin durch Aufnahme vieler „Pinnatae“" wohl einen anderen bezeichnenderen Namen erhalten müssen.

Zur Aufstellung eines rationellen, möglichst phylogenetischen Systems aller Potentillen der Welt reicht das Studium unserer europäischen Arten durchaus nicht hin. Man wird mehr und mehr einsehen, dass die Hauptzüge desselben sich auf die Beha arungsverhältnisse der Arten gründen lassen, daher kann das eingehende Studium dieser nicht oft und dringend genug empfohlen werden.

\section{Potentilla opaca L.}

(P. rubens Zimm.)

Da ich mit Focke, Petunnikor und Anderen fest davon überzeugt bin, dass das, was Koch, Lehmann und die allermeisten Botaniker seit mehr als hundert Jahren P. opaca genannt haben, dasselbe ist, was Linné darunter verstand, so sehe ich keinen Grund, aus Opportunitätsrücksichten, wie Focke leider gethan (- nachdem er doch die P. verna L. für Zimmeter's P. opaca beibehalten hat -) den gut gewählteu Namen fallen zu lassen, auch nicht einmal als Auctor Roth statt L. zu setzen, was neuerdings Einige, die den Namen „opaca" nicht aufgeben wollen, aus übergrosser Vorsicht eingeführt haben. Also meine P. opaca, ron der ich hier zu sprechen habe, ist die P. opaca Linnés, Roth's, Ehrhardt's, Jacquin's, Nestler's, Lehmann's, Koch's, Petunnikov's*) et auct. plurim., non Zimm.,

*) Vergl. Petunnikov, 1. c. p. 26 ff. - Er stellt den Satz: „P. opaca L. ist identisch mit P. npaca Koch und mit (Fragaria) rubens Crtz." sogar zu den hauptsåchlichsten Resultaten (unter No.17) seiner Potentillenforschungen. 
und, was ich gleich beifügen möchte, meine P. verna ist die Linnés, Koch's et anct. plurin., non Zimm.

Bevor ich anf die Charakteristik der P. opaca und ilırer Formen näher eingehe, will ich über ihr Torkommen in Sachsen vorausschicken, dass sie nur im Elbhïgellande ziemlich verbreitet ist; man wird hier an geeigneten Stellen (sonnige Abhänge, Hügel, Gebüsche, Waldwiesen), besonders an solchen, wo die Pflanzenassociation viele pontische Elemente aufweist, nicht oft rergebens nach ihr suchen, wenn sie auch selten so gesellig und in solcher Alenge anftritt. wie die Verna-tormen, ja sogar in dieser bezichung häufig von ihren Bastarden (mit l'. verna) ïbertrofłen wird. - Ganz fehlt sie im Vogtland und im oberen Erzgebirge (nach Vlittheilungen von Artzt und Säurich), ferner in der sächsischen OberLausitz (nach Hofmann und Lorenz, - doch sah ich sie aus der böhmischen Lausitz: an Tollenstein, also ganz nahe der sächsischen Grenze). Aus der Nieder-Lausitz habe ich sie noch nicht gesehen. - Für die sächsische Schweiz nennt Hippe in seinem Verzeichniss als einzigen Standort Hinter-Ottendorf bei Sebuitz. Säurich sammelte sie am Landsherge bei Spechtshausen! (Herb. Säur.) oberhalb Tharandt. Panse nennt in seinem MS als standorte: Penig beim Zeisig; Rochlitz bei den Schemen; Mittweida; Hainiehen; Glösa bei Chemnitz (bis 1858) und Chemnitzer Sehlossberg (hier nach Säurich längst rerschwunden). Flora von Leipzig: Altranstädt! und Grimma! (H. Lips.). Anf die Standorte im Elbhïgelland komme ich zuriek.

Ich halte es nicht für iiberflïssig, bei dieser Species sowie bei den beiden folgenden (verna und arenaria) die wesentlichen Unterscheidungsmerkmale genau anzugeben, weil wir sie nur mit Hilfe von diesen aus dem Chaos ihrer Nischformen heransschälen und die letzteren selbst richtig beurtheilen können. Die Yernachlässigmng der Bastarde bei den älteren Botanikern und selbst noch bei vielen jetzigen Floristen trägt die Hauptschuld daran, dass jene die Definition der Species zu schwankend und zum Theil mrichtig aufgestellt haben, und dass diese bei der Bestimmung der Potentillie vernales oft in die grössten Schwierigkeiten kommen. (Beweise dafür liefern fast alle öffentlichen und Privat-Herbarien in Menge.)

Abgesehen vom Fehlen der Sternhare (auch der unvollkommenen Sternhaare oder Zackenhaare), welche die P. arenaria von der P. opaca und der P. verna tremnen, kenne ich nur drei sichere Merkmale, welche alle Formen der I'. opaca von allen Formen der l'. verna scheiden: 1. die P. opaca treibt ans der Hauptwurzel kurze, anfrechte oder bogig aufsteigende, niemals wurzelnde Stämmchen, welche einen compacten Stock bilden; 2. ilıre Wurzelblätter besitzen eilanzettförmige Vebenblättchen; 3. ihre Stengel und Blattstiele sind von langen, wagreeht abstehenden Haren raharig und ihre Blätter abstehend behaart. Alles andere, wis oft in den Floren an erster Stelle hervorgehoben wird und wodurch die $\mathrm{l}$. opaca von der P. verna ,.leicht zu unterseheiden“" sein soll, wie roth äberlaufener Stengel, schmälere Theilblättchen, kleinere und dunklere Blïthen, zuriickgekrümmte Fruchtstielchen, siebenzählige Blätter I. S. w. ist unzuverlïssig, findet sich wohl in den recht typischen Pflanzen gewöhnlich beisammen, fehlt.aber oft an anderen Formen grossentheils und tritt auch an manchen Varietäten der P. verna einzeln oder grossentheils wieder auf. 
A d 1. Ich bin geneigt, das erste Kennzeichen, das Wachsthumsverhältniss der Grund- und Nebenachsen, für das wichtigste zu halten, und muss nach meinen an hunderten und tausenden von lebenden Pflanzen gemachten Erfahrungen die Diagnose von Lehmann, Koch und Allen, welche diesen gefolgt sind, in diesem Punkte als unrichtig bezeichnen. Diese geben nämlich der P. opaca ,hingestreckte, oft wurzelnde Aestchen" („caudiculis prostratis saepe radicantibus"), was falsch ist. Ich kann nur annehmen, dass sie auch gewisse der $\mathrm{P}$. opaca nahestehende Opaca $\times$ vernaBastarde zu jener gezogen haben, was um so wahrscheinlicher erscheint, als sie solche Bastarde nicht erwähnen und dieselben doch zu ihrer Zeit ebenso liäufig gewesen sein müssen, als heutzutage. Die neueren Potentillen-Forscher (Zimmeter, Poeverlein, auch Ascherson und selbst Petunnikor in seiner so ausführlichen Beschreibung der P. opaca) gehen iiber diesen wie mir scheint doch sehr wichtigen Punkt stillschweigend hinweg, vielleicht weil sie die Angaben Lehmann's und Koch's anzweifelten, andererseits aber in Ermangelung ausreichender Erfahrung das Gegentheil auch nicht $\mathrm{zu}$ behaupten wagten. Nun, eine vieljährige und ansgedehnte Erfahrung hat mich zur Ueberzeugung gebracht, dass eine reine P. opaca niemals wurzelnde Aestchen treibt. Wenn man einen Stock ausgräbt, sieht man allerdings, dass sich am Grunde derselben, nahe der Stelle, wo sie aus der Hauptachse entspringen, neue Wurzeln bilden, dies ist aber auch der Fall z. B. bei P. argentea, P. recta und vielen anderen Potentillen, denen man noch nie „,caudiculi radicantes“ zugeschrieben hat; an den oberirdischen Theilen der Triebe, selbst wenn sie sich einmal etwas stärker verlängern und niederlegen, habe ich niemals Turzeln beobachtet. Auf den Feldmauern hinter Döltzschen über dem Plauen'schen Grunde, wo die P. verna und ihre Bastarde so schöne Gelegenheit haben und auch benützen, sich weit auszubreiten und an allen Aestchen zu wurzeln, steht die typische P. opaca zwischen ihnen stets in einzelnen compacten Stöcken ohne die geringste Tendenz ihrer Triebe zum Wurzeln. In meinem Garten, wo ich die P. opaca seit Jahren neben verschiedenen Verna-Varietäten und -Bastarden cultivire, ist sie stets compact in einem Stock beisammen geblieben, während alle anderen $1 / 2 \square$ Meter grosse verzweigte und allenthalben wurzelnde Rasen gebildet haben, die jedes Frühjabr ringsum abgestochen werden miissen, um nicht noch melı Terrain zu überwnchern. Allerdings wurzeln die Verna $>$ opaca-Bastarde weniger als die reine verna und zwar um so weniger stark, je näher sie der P. opaca stehen. Das Anwurzeln der Aestchen ist für nich manchmal ausschlaggebend gewesen, wenu mich andere Nerkmale noch zweifeln liessen, ob ich eine gegebene Form einfach zu P. opaca stellen, oder sie als $\mathrm{P}$. superopaca $\times$ verna bezeichnen sollte. Die P. opaca zeigt genau die Wachsthumsverhältnisse der P. thuringiaca, die auch keine wurzelnden Seitenachsen treibt.

Ad 2. Das zweite Kennzeichen (gegenüber der P. verna und P. arenaria), nämlich die breitlanzettförmigen bis eilanzettförmigen Nebenblättchen der Wurzelblätter, ist ebenso sicher und untrüglich als das erste, wemn man es richtig zu beobachten versteht. Koch und verschiedene Neuere haben es leider über viel unwichtigeren Merkmalen übersehen und in ihren Diagnosen ibbergangen, Lehmann dagegen, Ascherson mud Andere heben es mit Recht ausdrücklich hervor. - Es ist hier nur von dem freien, nicht dem Blattstiel angewachsenen Theil der Nebenblättchen die Rede; dieser ist bei P. opaca breit dreieckig- oder eilanzettförnig und 
kurz zugespitzt (Fig. \%al), dagegen bei P. verna (und arenaria) schmal lineal und sehr lang ausgezogen (Fig. $\gamma$ b); bei den Bastarden beider - wir wollen es hier gleich beifügen - liält er dic Mitte zwischen den zwei typischen Formen, ist zwar häutig fast so schmal wie bei P. verna, aber dann stets viel kiilzer (Fig. 7c). Die typische l', opaca steht auch in dieser Beziehung wiclerum der P. thuringiaca ganz nahe, doch scheinen mir die sehr breiten lanzettlichen Nebenblättchen der letzteren meistens in cine längere Spitze auszulaufen, als bei P. opaca.

Um nun bei der Untersuchung keinen Fehlgriff zu thun, ist wohl zu bachten, dass die $P$. verna an ihren Stengelblättern dieselben breiten Nebenblättchen besitzt, wie die P. opaca an allen Blättern, und nur an den Wurzel-, höchstens noch an den untersten Stengelblättern die lang ausgezogenen schmalen Zipfel zeigt. Ich habe bemerkt, dass sich die Nebenblättchen bei $P$. verna oft schon an den alleruntersten Stengelblättern (scheinbaren Wurzelblättcrn) fruchtbarer 'Triebe sehr verbreitern und verkïrzen, und möchte daher schr empfehlen, nur echte Wurzelblätter, womöglich ron nicht blühenden Trieben zur Untersuchung zu benutzen. Vorzüglich eignen sich dazu die im Spätsommer und Herbst erscheinenden Wurzelblätter.

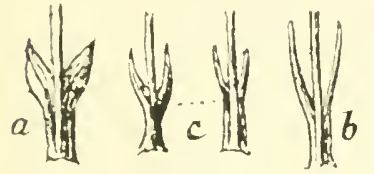

Fin. $\%$

Tebenblättchen der Wnrzelblätter a) von P.opaca L., b) von $P$. verna $L$. e) von $P$. opaca $\times$ everne. - Nat. lir.

Ad 3. Das Kennzeichen ker dichten, langen, horizontal abstehenden Behaarung an Stengel und den Blattstielen wird stets als das erste und wichtigste hingestellt, und doch lässt es uns gar nicht selten im Stich. An einer reinen P. opaca wird es wohl im Frühjahr nie fehlen, aber bei Schattenformen und an den im Herbst oft sehr stark verkahlenden Pflanzen fehlt es mitunter fast ganz, und dann können nur die beiden zuerst angefühı'ten Merkmale zu einer sicheren Entscheidung führen. Noch schlimmer ist es, dass die $P$. austrulis Kraš., die man allgemein für eine sülliche Rasse der P. opaca oder doch für deren nächste V'crwandte hält, eine zwar starke und lange, aber a ufrcht abstehende und sogar oft anliegende Behaarung zeigt**).

Dass nun die anderen fiur die P. opaca als wichtig angeführten Merkmale viel weniger Bedentung haben, als die drei besprochenen, habe ich bereits angeführt. Anf ihrer Ahwesenheit oder Modification beruhen cben die verschiedenen Formen unserer Species, die man kaum als gute Varietïten, sondern nur als Standortsformen und individuelle Abweichungen, wohl anch als l'roducte des Saison-Dimorphismus auffassen kann. Natürlich haben wil an dieser Stelle von allen Bastard-Formen (mit l'. verna) abzusehen und nur die reine P. opaca in Auge zu bchalten, und fü diese

*) Mir sind ïbrigens ïber die Dentung der P. australis als liasse der P. opara starke \%weifel anfrestiegen, denn die von Raap bei Porim in der Herzegovina 1895 gresammelten, von Halásy als P. anstralis Kraś. bestimnten und von Callier ausgegehenen Pflanzen hahen nicht nur die angegebene Behaarung, sondern anch die linealen Nebenhättchen der P. verna mul die starkverzweigten, liegenden und wurzelnden Triebe der letzteren. Wemn die Original-Exemplare Krašans ans dem Karst und anderen Gelieten diesen ans der Herzegovina gleichen - leiller steht mir kein anderes Intersuchungsmaterial zur Verfïgung - damn behaupte ich, dass wir es iiberhaupt nit keiner (opaca-Form, sondern mit einer Varietit der P'. rerna, oder höehstens mit einer P. opaca $\times$ verna zil thun haben. 
bleibt 'Zimmeter's Ausspruch zu Recht bestehen, dass sie „nur sehr wenig varirt". - Dass die $P$. opaca meistens siebentheilige Wurzel- und untere Stengelblätter besitzt (darunter aber auch fünf- bis neun-, ja selbst dreizählige), ist richtig, aber dasselbe ist auch bei einigen ausgezeichneten Verna-Varietäten der Fall. Ihre Theilblättchen sind meistens abstehend behaart, schmal verkehrt-eiförmig mit einer geringen Zahl schmaler Zähne nach oben hin; aber wie ganz anders sieht das grosse Herbstblatt aus, das mit seiner reichen Bezahnung und in seiner form vom Blatt der P. thuringiaca kaum mehr zu unterscheiden ist! Sodann wird die Form der Blätter bei Schattenexemplaren oft breitkeilförmig und der der VernaBlätter vollständig gleich und wenn dabei noch eine starke Verkahlung und ein ganz grüner Stengel dazu komnt, was sehr häufig der Fall ist, kann es Jedem passiren, dass er solche Herbar-Pflanzen als I. verna oder höchstens P. opaca $\times$ verna bestimmt, es sei denn, dass er auf die Form der Nebenblättchen achte. Andererseits giebt es wiederum Verna-Blätter, die besonders in Herbst im Schnitt durchaus mit den typischen OpacaBlättern übereinstimmen. Auf den Saison-Dimorphismus bei P. opaca hat besonders Petunnikov eindringlich aufmerksam gemacht: „Im Sommer oder Herbst ändert sich das Ansehen der Pflanze bedeutend, ebenso die Behaarung, so dass naan dann leicht verführt wird, sie für eine andere Art zu halten. Daun wachsen die Blätter über den vertrockneten Blüthenstengel hinans, die Behaarung wird dümner, die horizontale Behaarung der Blattstiele und die langen weichen Haare der Blattränder sieht man kanm mehr. Besonders stark verändert sich der Umriss und die Bezahnung der Blättchen: die keilförmige Gestalt der Frühlingsblätter mit wenigen nach vorn gerichteten Zähnen, verändert sich in eine fast längliche mit meist breiten oft dreieckigen Zähnen, 7-8 jederseits." Dies ist Alles wahr, aber ich füge hinzu, dass man auch in diesem Zustande die P. opaca noch immer mit Sicherheit von der P. verna - die übrigens einen ganz ähnlichen Saison-Dimorphismus zeigt - durch die unter 1 und 2 angegebenen Nerkmale unterscheiden kann, welche leider Petunnikov in seiner ausführlichen Beschreibung der P. opaca gar nicht erwähnt. Das Kennzeichen der zurückgebogenen Fruchtköpfchen bei P. opaca ist nicht constant und findet sich oft auch an schwach- und dünnstengeligen Verna-Formen. Es hat seinen einfachen Grund darin, dass die Bliithenstiele der P. opaca meistens dümner und zarter sind, als die der P. verna und daher die immer schwerer werdenden Fruchtköpfchen nicht mehr aufrecht halten können. Die Stiele der Blïthen, die keine Früchte ansetzen, bleiben stets aufrecht. So erklärt auch Petunnikov dieselbe Erscheinung bei den Potentillae collinae, welche den dickstieligen argenteae und canescentes gegenïber dünmere Blüthenstiele haben.

Die Drüsenhaare der P. opaca. Die reiche Drüsenbehaarung unserer sächsischen Potentillen der Vernales-Gruppe hat mich seit vielen Jahren eingehend beschäftigt, ja sie war die erste Veranlassung dazı, dass ich diese zu meinem Specialstudium erkor und meine Untersuchnngen bald auf die ganze Gattung Potentilla ansdehnte. Unglücklicherweise entdeckte ich den Drüsenreichthum zuerst zufällig an allerlei Bastard-Formen zwischen P. opaca und verna und zwischen dieser und arenaria, welche ja in unserer Gegend so ïberaus häufig sind, die ich aber damals noch nicht mit Sicherheit als solche zu deuten wusste; Alles verschwamm vor meinen Augen zu einem unauflöslichen von Drüsen durch und durch verpesteten 
Potentillen-Chaos, ich gerieth in eine heillose Verwirrung, zu der die ,l'otentilla glandulifera lirasan" nicht wonig beitrug und aus der mich weder dic ältere noch die neuere Potentillen-Litteratur befreite; denn die spärlich eingestreuten, ganz ungenïgcnden und oft unrichtigen Notizen über drüsentragende Potentillen komnten mich nicht aufklären, und so war ich fast gan\% auf meine eigenen Beobachtungen angewiesen, fiir die ich allerdings wohl in ganz Deutschland kein günstigeres Feld hätte auffinden können, als gerarle unser Elbhïigelland. Erst Poeverlein luat in seiner Arbeit den Driisenharen der I'otentillae rernales einc eingehendere Beachtung geschenkt, und es gereicht mir zur besonderen Genugthumng und Beruhigung, dass meine Beobachtungen fast durchgehends mit den seinigen iibereinstimmen und dass wir auch in manchen I'unkten dieselben Schlussfolgerungen daraus gezogen haben.

Die Form der Drïsenhare bei P. opaca ist ganz dieselbe, wie ich sie gelegentlich der Besprechnng der l'. recta beschrieben und wie wir sie auch an verschiedenen anderen Species beobachtet haben. Ich will nur noch einmal daran erimnern, dass die Driisen sich nicht an den gewölnlichen einzelligen, sondern an der Spitze von mehrzelligen, äusserst zartwandigen Haaren befinden, welche zwischen der gewöhnlichen Behaarung mehr oder weniger zahlreich zerstreut stehen (cfr. Fig. 6 a S. 44). Man erkennt die meist dunkelroth gefärbten Drüsenköpfchen gewöhnlich schon unit dem blossen Auge oder einer gewöhnlichen Lupe, und nur selten (bei schwachdrüsigen Formen) muss bei der P. opaca das Mikuoskop zu Hilfe genommen werden, obgleich dessen Anwendung bei sehr genauen Untersuchungen stets zu cmpfehlen ist. - Die Drüsenhaare finden sich bei den Ternales nicht nur an den Blüthenstielen und Kelchen, wie gewöhnlich angegeben wird, sondern auch an den unteren Theilen der Stengel, an den Blattstielen und selbst an den Blättern, jecloch an den beiden zuerst genannten I'flanzentheilen am häufigsten und gelrängtesten, und dies ist ein merkwürliger, aber nach meinen Erfahrungen recht constanter Unterschied von den Chrysanthae, bei denen gerade das Ungekehrte der Fall ist, indem die unteren Pflanzentheile durchgehends drüsenreicher sind als die oberen.

Lange Zeit fand ich in Sachsen nur die starkdrüsige P. opaca, die ich cinfach als forma glandulosa bezeichnete, da sie selbst Zimmeter, der doch gewiss mit Aufstellung neuer Species und Varietäten nicht kargte, nur , forma petiolis glanduliferis" namnte. Erst später mol allmählich entleckte ich auch die forma eglandulosa an mehreren Localitïten und zwar merkwürdigerweise spärlich und fast immermit der forma glandulosa beisammen auftretend. Von der zuerst gehegten Ansicht, dass die letztere eine gnte Varictit sei, kam ich besonders durch die Beobachtung zurück, dass zwischen beiden ausser dem Vorhandensein oder Fehlen der Drüsen auch nicht der geringste Unterschied zu entrlecken ist und dass das Fehlen der Drusen bei uns wie ein reiner Zufall bei gewissen Individuen erscheint. Das ist es nun natirlich nicht, denn Alles hat seinen Grund, aber alles Nachsinmen und Nachforschen über denselhen ist bis jetzt crgebuisslos geblieben.

Wix stehen hier vor einem schwer zu lösenden Rätlısel, das sich iil)rigens in derselben Weise bei P. arenaria und bei P. recta aufdrängt. Es wäre zunächst expcrimentell festzustellen, ob aus den Samen einer driisenlosen L'. opaca anch die forma eglandulosa oder eine f, parce glan- 
dulosa auflaufen kann und umgekehrt, oder ol, sich beide Formen rein und ständig nebeneinander fortptlanzen und die schwachdrüsigen nur Blendlinge beider seien. Nach ihrem Vorkommen in Sachsen bin ich geneigt, vorläufig das erstere anzunehmen, wenn auch der Grund dieser individuellen Abänderung, die sich nur auf die Drüsen bezieht, durchaus dunkel bleibt. Einer ähnlichen Frage werden wir bei den Opaca $\times$ verna-Bastarden begegnen, die bei uns ebenfalls meistens drüsemreich, in seltenen Fällen aber auch völlig drüsenlos auftreten. Wie die Sachen jetzt liegen, kann ich nur der Behauptung Poeverlein's, welcher ganz ähnliche Beobachtungen an der P. opaca machte, beipflichten, dass die Drüsenhaare kein geeignetes Merkmal zur Abgrenzung von Species, nicht einmal von guten Varietäten abgeben und nur drüsige und drüsenlose Formen bedingen, die sich bei den verschiedensten Species und Varietäten wiederholen können und in der That wiederholen. Dennoch dürften sie für die Beurtheilung gewisser Bastarde immerhin von einer nicht zu unterschätzenden Wichtigkeit sein.

Nach dem soeben Ausgeführten halte ich es durchaus nicht für angemessen, mit Poeverlein die von G. Beck*) eingeführte Eintheilung der P. opaca in eine Tar. a) typica (drïsenlos) und eine $V_{a r}$. $\beta$ ) gadensis (drïig) beizubehalten, 1. weil bei uns (vielleicht auch anderwärts?) gerade die gadensis die typische wäre, und 2. weil ,gadensis" ein nichtssagender ungeschickt gewählter Localname für eine blosse, aber weitverbreitete Form ist. Es genügt vollständig und ist Jedermann sofort verständlich, wenn wir einfach eine forma glandulosa und eine forma eglandulosa der P. opaca unterscheiden. Es mögen nun die hauptsächlichsten mir bekannt gewordenen Standorte beider im Elbhïgellande folgen:

P. opaca L. forma glandulosa: Um Dresden, besonders an den Höhenzügen links der Elbe von Plauen, Räcknitz, Zschertnitz und weiterhin gegen Lockwitz !!. Auf den Höhen über dem Planen'schen Grunde bei Plauen und Coschütz!!, sowie zwischen Döltzschen und Potschappel sehr häufig !!. Auf den Höhen der Ober- und Niederlössnitz sehr verbreitet !!, besonders zwischen Kötzschenbroda und Lindenau!!. Im Lössnitzgrund am Todstein !!. Auf der Bosel !!, Waldränder und lichte Föhrenwälder bei Coswig !!, am Tunnel bei Oberau!(H), Gröbern bei Meissen! (H), Abhänge bei Zadel selten! (H), Skassa bei Grossenhain !!. Im Grunde von Blattersleben stellenweise massenhaft !!, Seusslitz !!, bei Lockwitz !!, durch das ganze Thal des Lommatzschwassers an den Gehängen von Schieritz!! bis Leuben!(H). - Grimma! (H. Lips. leg. Güttner).

P. opaca L. forma eglandulosa: Am Kirschberg bei Reisewitz!! Im Kroatenloch zwischen Kötzschenbroda und Lindenan !!, Grund von Blattersleben !!, Skassa bei Grossenhain!!, Seusslitz !(H), Schieritz!(H), Leuben ! (H); an allen diesen Orten zusammen mit der forma glandulosa, aber viel spärlicher als diese. Ich sah sie auch im Ilerbar Säurich vom Landsberge bei Tharandt!, kann aber nicht angeben, ob dort die forma glandulosa zugleich vorkommt; ferner von Altranstädt bei Leipzig! (H. Lips.).

G. Beck, Flora von Niederösterreich II, S. $\% 56$. - Beck hat für die P. opaca L. den Namen $P$. dubia Suter hervorgesucht. Zimmeter dagegen hat denselben Namen nur mit einem anderen Auctor am Ende wegen der ,Fragaria dubia Crtz." der P. minima Hall. fil. beigelegt. Es lebe das Prioritätsprincip! 


\section{Potentilla verila $I_{\text {. }}$}

(P. opaca Kimm.)

Auch bei dieser Species setze ich ohne Bedenken als Auctor L., wie noch neuerlich focke und frïher fast alle Botaniker gethan haben, bis $1 S 8+$ Kimmeter die P. alpestris val. firma loch zu P'. verna L. stempelte, die bisherige P'. verna I. zu P'. opaca L. machte und den unerquicklichen Streit ïber 1'. verna und opaca hervorief. Wenn man einmal annimmt, wie wir gethan, dass Linné unter seiner P'opaca nicht die P. verna Koch und auct, sondern wirklich die P. opaca Koch und auct. verstanden hat, so muss sich seine $P$. verna mindestens auch auf unsere P. verna (Ḱoch) bezogen haben, mag er damit auch die P. alpestris Hall. fil. (und nicht bloss deren Varietät firma Kioch) mit einbezogen haben. Denn dass er unsere l'. verna nicht grekannt, ist schlechterdings nicht anzunehmen, nicht einmal, dass er sie für die seltenere Varietät der P. alpestris gegenüber gehalten habe (hat er doch nicht nur in Schweden botanisint oder nur schwedische PHanzen untersucht!). Das letztere ist übrigens gleichgiltig, denn wenn wir eimmal die Linuésche Gesammtart P'. verna in zwei trennen und einer diesen Namen belassen wollen, so fragt es sich nicht, welcho ron beiden Linné zufälliger (vielleicht irrthümlicher) Weise für die verbreitetere und bekanntere hielt, sondern welche es wirklich ist, und dann ist wohl keine Frage, dass dies die I'. verna auct. plur. und nicht die Tar. firma der P. alpestris ist, welche Zimmeter zur P. verna L. gemacht hat. Wir verfahren hier ganz gleich, wie Zimmeter (und neuerdings Poeverlein) bei P. argentea L., P. canescens Bess. und anderen Arten verfahren ist, bei denen er den Namen der Gesammtspecies des Auctors auf die nach seiner Ansicht rerbreitetste oder typischeste Form mit Belassung des alten Auctornamens ïbertring, und aus den anderen Formen neue Species machte. Dies kam Zimmeter und jeder Andere thun, der auf dem Boden des Pariser Codex und seiner Revision von 1883 steht, und nicht zu den Rigoristen gehört, welche im Falle der \%wei- oder 1reitheilung einer Gesammtspecies verlangen, dass nun der alte Name keiner der zwei oder drei neu abgegrenzten Species verbleibe. Hätte man doch diese vielfach geibte Praxis auch bei der I'. verua auf die rechte Weise geübt und nicht eine Nenerung eingeführt, die hunderten vou Botanikern so sehr gegen den Strich geht, dass sie sich nach 16 Jahren noch immer nicht danit ahfinden kömmen und mehr und mehr von der P. opaca Kimm. zur P. verna L. (oder Roth)**) zurückkehren. Die Iiückkehr zu P. verna L., die nich meiner Meinung noch inmer mehr nachgeahmt werden wirl (- denn diss der von Ascherson für sie empfohlene neue Name ,l'. Tabernaemontani" allgemeinen Anklang finden werde, möchte ich bezweifeln -) kömnte sich jetzt um so leichter vollziehen, als die I'. verna /imns, eigentlich ïberflüssig geworden ist, nachdem man mehr und mehr eingesehen, dass diese keine besondere Species, sondern ur eine Varictät der' I'. alpestris ist und von dieser gar nicht getrennt werden kann (cfr. Poeverlein l. c. S. 105. Auch meine eigenen Beobachtungen an cinem reichen Material aus der Zermatter Gegend bestätigen dies). Liesse man die $P$, alpestris oder, wer es für richtiger hält, die P. villosa (Crtz.)

*) so noch neulich Kirchner und Fichler in ihrer Excursionsflora von Württemberg (1900). 
Zimm.*) mit ihrer Var. firma Koch weiter bestehen und die P. verna Zimm. von der Bildfläche verschwinden, so wäre der Friede hergestellt. Aber Herr Poeverlein ist leider anderer Ansicht, die Zimmeter'sche P. verna muss um jeden Preis fortbestehen, er zieht deshalb die P. alpestris (resp. villosa) ein und schlägt diese als Synonym zu P. verna Zimm. Weniger radical verfahren Schinz und Keller in ihrer Flora der Schweiz (1899), indem sie die P. villosa als Species weiterführen und deren Var. firma nunmehr Var. verna nennen.

Der Name verna ist übrigens für die Species nur passend, wenn man darunter mit Linné hauptsächlich unsere $P$. verna versteht, sobald man ihn nur auf die im Hochsommer blühenden alpinen und nordischen Formen der P. alpestris bezieht, wird er unrichtig und ungeeignet. Dies nur nebenbei. Linné war im allgemeinen sehr glïcklich mit dem Namengeben und jedenfalls feinfühliger als unsere rücksichtslosen Prioritätsreiter; schon aus diesem Grunde glaube ich nicht, dass Linné jemals mit seiner $P$. opaca unsere gewöhnliche $P$. verna bezeichnet hat, eine Pflanze mit glänzenden oder wenigstens schimmernden Blättchen. Wollte er diese als dunkelgrün einer hellgrünen entgegenstellen, so hätte er eher das Wort obscura gewählt. "Opaca" ist als matt, trüb, nichtschimmernd dem glänzenden (nicht dem dunkelgefärbten) gegenübergesetzt, wie wir auch opakes Gold dem glänzenden entgegensetzen. Die Gegeniuberstellnng kommt in der Nineralogie häufig ror ohne Riiicksicht auf die helle oder dunkle Körperfarbe, und Linné wendet das Wort ganz im selben Sinn wie bei Potentilla auch z. B. bei Veronica opaca der glänzenden V. polita gegenüber an (beide sind dunkelgrün). Die Potentilla opaca verdankt ihr opakes, trübes und mattes Aussehen bekanntlich der stark abstehenden Behaarung ihrer Blätter; die P. verna hat meist spärlichere und stets mehr anliegende Behaarung, daher sind ihre Blättchen schimmernd. Kein Botaniker, der lebende typische Pflanzen der P. opaca mit solchen der P. verna zusammenhält, und das Wort opak im Linnéschen Sinn versteht, wird einen Augenblick darüber im Zweifel sein, welche ron beiden dieser P. opaca genannt haben wird. Dass auch die meist rothe bis dunkelviolette Färbung der Stengel bei P. opaca auct. noch zur Opacität beiträgt, ist nebensächlich, denn diese Färbung kommt auch oft bei glänzenden vernae vor und fehlt mitunter bei Schattenpflanzen der P. opaca.

Wenn wir nun wieder zuerst die $P$. verna den zwei nächstverwandten Species (opaca und arenaria) gegenüber abgrenzen und charakterisiren wollen, so können wir uns kurz fassen, dem die Hauptunter'schiede zwischen ihr und der P. opaca haben wir bereits bei der letzteren besprochen, und der zwischen ihr und der $\mathrm{P}$. arenaria besteht im wesentlichen und fast ausschliesslich im Fehlen der Stern- und Zackenhare auf den Blättern bei P. verna. Sobald wir mit Uechtritz annehmen wollen, dass eine P. verna Var. stellipila, also eine eigentliche P. verna mit Sternharen

*) Diese gewöhnlichste der Alpen-Potentillen, die schon so viele Namen getragen hat, ist gewiss nicht "rillosa", d. h. zottig, sie ist sogar weniger behaart als manche andere und rerkahlt oft fast ganz (die P. frigida verdiente den Namen viel besser). Den passendsten Namen (alpestris) gab ihr jedenfalls Haller fil., denn sie ist die verbreitetste

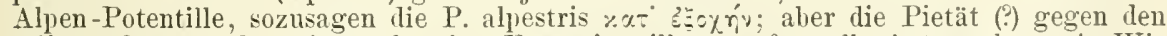
seligen Crantz, der einstmals eine Fragaria villosa aufgestellt hat, geht vor! Wir' haben iibrigens schon längst eine nordische P. villosa Pall., die diesen Namen mit rollem Recht verdient, denn sie ist "villosissima" (Lehm. Rev. P. s. 171). 
existire, lie nicht (primärer oder secundïrer) Bastard ist, so liätten wir gar keinen festen dnhalt mehr, beide Species zu unterscheiden, wir müssten beicle vereinigen, denn alle anderen Merkmale zur Unterscheidung der P. verna und P. arenaria, ausser den Sternhatren, sind un wesentlich, höchst veränderlich und durchaus ungenïgend, um zwei Species anfzustellen. Alle meine lirfahrungen, die ich zuneist im Fieien und an lebendem Naterial sammelte, drängen mich dazu, jede der P. verna ähnliche lorm. welche an den Blättern wenn auch nur veremzelte Sternhate oder unvollkommene Zackenhaare (,halbbüschelförmige“ Haare) aufweist, als ron der P'. arenaria (resp. in südlichen Gegenden von der P. Gandini) beeinflusst zu betrachten. 'Zu' selben Anschanung scheint auch Petunnikov (Schlussfolgerung No.5) gelangt zu sein, während Zimmeter der Ansicht war, dass es ungeschlechtliche Nittelformen zwischen P'. verna und P. arenaria gebe (I. sub No. 141, P'. subarenaria, und II. sub No. 141 a, P. vindebonensis 2. ., ,der I'. subarenaria ähnlich, aber kein Bastard") und P'oeverlein (S. 88, 90) die lrage vorläufig noch offen lïsst. lch werde bei den Verna $>$ arenaria-Bastarden auf den Gegenstand zurückkommen.

Wie an einem anderen Ort hervorgehoben wurde, zeichnet sich die P. verna der l'. opaca gegenüber durch drei llauptkenmzeichen aus: 1. besitzt sie stark verlängerte, liegende und wurzelnde Triebe (Nebenachsen, wodurch sie reichrerzweigte und sich weit ausdehnende niedrige liasen billet; 2. sind die Nebenblättchen ihrer Wurzelblätter stets schmal lineal und lang ausgezogen; 3. ist die Beharung ihrer Stengel und Blattstiele aufrecht abstehend bis anliegend. Alles Uebrige, was man sonst noch zu ihrer Charakteristik beizufïigen pflegt, ist unwesentlich für die Species und trifft immer nur zum Theil bei gewissen larietäten zu, wird daher besser bei der Besprechung dieser erwïhnt. - bezüglich des ersten Hauptmerkmals muss aber gesagt werden, dass es nur da typisch auftreten kamn, wo es das Terrain zulässt; an Stöcken, welche durch ihre nächste Umgebung, durch Steine, zu hohes und dichtes Gras oder sonstwie in ihrem Wachsthum gehemmt werden, kann es fehlen, doch tritt es sofort auf, wenn man solche Pflanzen an einen anderen geeigneten Ort, z. B. auf freies Gartenland, versetzt. Das zweite Merkmal versagt nie, das dritte kaum jemals, denn es giebt wohl keine ganz verkahlenden Formen, und ich habe allen Grund anzunehmen, diss angebliche Verna-Varietäten mit horizontal absteheuden Haaren stets auch andere Merkmale eines Opaca $>$ verna-Bastardes anfweisen werden.

Ein sehr gutes, zu wenig beachtetes Merkmal der P. verna, das aber leider nur an lebenden P'flanzen deutlich hervortritt, ist der Glanz oder Schimmer auf der Oberfläche ihrer Blätter (oft anch auf der Lnterseite). Er wird durch die anliegende, meist schwache Behaarung derselben bedingt, zeigt sich aber auch bei stärker behaarten Formen, wo er dann oft seidenartig erscheint. Bei der P. opaca und den meisten ihrer bastarde ist die Blattbehaarung bekantlich stark abstehend und hringt deren opakes Aussehen herror.

Bei dieser Gelegenheit möchte ich auf die Filzkrankheit der P. verna aufmerksan machen, die schon zu Verwechshungen Aulass gegeben hat. Sie zeigt sich nicht nur bei P. verna, sontern auch - vielleicht noch häufiger - bei allen ihren Bastarden, sowie bei l'. arenaria und (selten) bei I'. opaca, und besteht darin, dass an den Stengeln, Blättern und Blüthenköpfen grössere und kleinere Stellen mit einem dichten, weissen 
Filz überzogen sind. Gewöhnlich bleiben noch genügend viele und grosse Stellen frei von dieser abnormen Behaarung, so dass man deren Natur als Krankheitssymptom leicht erkennt; aber in selteneren Fällen erscheint die ganze Pflanze dicht weissfilzig, und solche Exemplare findet man mitunter in den Herbarien als P. albescens Opiz (Var. der verna), selbst als P. arenaria Borkh. bestimmt. Dieser krankhafte Filz unterscheidet sich von der gewöhnlichen Behaarung auch dadurch, dass er unter dem Vikroskop neben dichtstehenden runden Striegelhaaren eine Menge schmallanzettlicher oder bandartiger Trichome erkennen lässt, die mehr Aehnlichkeit mit Schuppen haben. Ich habe der Ursache der Filzkrankheit noch nicht nachgeforscht, glaube aber, dass sie ähnlich den Rosengallen, auf Insektenstiche zurückzuführen sein wird.

Von neuem muss hier auf den Saison-Dimorphismus hingewiesen werden, der bei allen Varietäten der P. verna dieselbe grosse Rolle spielt, wie bei der P. opaca, und welcher die Auseinanderhaltung der Varietäten oft so sehr erschwert, ja unter Umständen unmöglich macht. Fast immer sehen die HerbstpHanzen, besonders bezüglich des Blattschnittes und der Höhe der Blattstiele sehr verschieden aus von den Frühlingspflanzen. Nun, auf diese Unterschiede ist ja gerade bei P. verna am frühesten und häufigsten aufmerksam gemacht worden.

Bevor wir zu den V'arietäten übergehen, möchte ich noch die Frage aufwerfen: Giebt es Formen der P. verna mit Drüsenhaaren? Die Frage könnte Manchem recht überflüssig erscheinen, nachdem Krašan eine P. glandulifera (aus dem Formenkreis der P. verna) aufgestellt, nachdem Zimmeter behauptet hat, dass die P. longifrons Borb. (Var. der verna) ,häufig Drüsenhaare an den Blüthenstielen" trägt, nachdem noch neuerdings Poeverlein dasselbe behauptet hat, freilich beifügend, dass bei den Verna-Formen ,das Vorkommen von Drüsenhaaren zu den Seltenheiten gehört". "Trotzdem glaube ich, dass die Frage nicht überflüssig und keineswegs entschieden ist. Sie hat aber auch ihre praktische Bedeutung: denn wenn die echte P. verna in allen ihren Varietäten stets drüsenlos ist, so haben wir bei zweifelhaften, der P. verna sehr nahestehendeı Formen mit Drüsenhaaren - und solcher giebt es gerade bei uns so viele! - in diesen Drüsen ein vorzïgliches Mittel, zu entscheiden, $o b$ ein Bastard, etwa eine P. superverna $\times$ opaca glandulosa, oder, wenn zugleich Zackenhaare auftreten, eine P. superverna $x$ arenaria glandulosa vorliege; wem aber eine echte $P$. verna in irgend einer Varietät mit Drüsenhaaren auftritt, dann wird das durch diese bedingte Unterscheidungsmerkmal hinfätlig. - Znnächst nun meine Zweifel bezüglich der $P$. glandulifera Kraš.! Gleich am Anfange meiner Potentillen-Studien fand ich in der Lössnitz (im Kroatenloch) eine drüsenreiche Potentilla, auf welche ganz genau und in allen Einzelheiten die Beschreibung der Kŕašan'schen P. glandulifera (Oestr. bot. Zeitschr. 1867, S. 303) passte. Ich zweifelte nicht im geringsten daran, dass ich diese für Sachsen entdeckt habe und glaube es auch jetzt noch, nachdem ich sie jahrelang in meinem Garten cultivirt und beobachtet habe, musste aber bald die Beobachtung machen, dass sie ein unzweifelhafter Bastard der $P$. opaca und $P$. verna sei, welche beide an derselben Stelle vorkommen. Später fand ich sie an verschiedenen Orten, zum Theil truppweise und von den nächsten Standorten der Eltern ziemlich weit entfernt. Wenn ich jetzt die Diagnose Krašan's wiedor aufmerksam lese, so finde ich, dass er genau einen 
Opaca $>$ verna-Bastard mit fünf- bis elftheiligen Blättern und riemlich starker, aber weicher und aufrecht-abstehender Beharung beschreibt, wio er bei uns so häufig ist. Sehr interessant ist, dass lirašan ausclrücklich bemerkt, seine P'. glandulifera untèrscheide sich (unter anderem) ron der l'. verna besonders dadurch, dass die letzterc sich, durch an der Oberfläche etwas glänzende Blätter auszeichne"6, und dass er dann fortfïlnt: "Dieser Glanz (noch in keinem botanischen Werke hervorgehohen) ist als diagnostisches Merkmal von grösstem Werthe". Durchaus einverstanden! aber gerade deshalb hatte Krašan nach meiner Ansicht keine Verna-Form, sonder'n einen Verna > opaca-Bastard vor sich. Leider stehen nir keine Uriginal-Exemplare Kraśan's zur Verfügung; ich besitze nur ein von Zimmeter am Spitzbiihel bei Mühlau (Innsbruck) gesammeltes und als $P$. glandulifer $a$ ausgegebenes Exemplar, das aber schon makroskopisch gar nicht zu Krašan's Beschreibung passt und unter dem Mikroskop) (lurch die deutlichsten Zackenha are sich als cinen Gaudini-Bastard documentirt, wodurch sich die Anwesenleit der Driisenhaare ganz natürlich erklärt, denn die I'. Gaudini pflegt hochgradig damit behaftet zu sein*). Eine zweite, $P$. glandulifera Ǩraš." meines Herbars ist ein Cultur-Exemplar (der Same soll aus den Alpen des Kanton Waadt stammen) aus Siegfried’s Exsiccaten (No. 201), welches nur spärliche J)rüsen, aber unter dem Nikroskop die schönsten Gaudini-llaare (Kackenhaare) an den Blätter'n anfweist, also wielerum keine P'. glandnlifera Kraš. sein kann, was auch aus dem übrigen makroskopischen Befunde hevorgeht, nach weleliem sie eher zu P. longifrons Kimm. non Borb. gehört. Ich fürchte, dass noch manche andere, $\mathrm{P}$. glandulifera" der Herbarien einer gründlichen Nachrevision unter dem Mikroskop nicht Stand halten wird,

*) Diese Potentilla von Mühlan hat die grösste Aehnlichkeit mit der, welche Siegfried als P. Gaudini var. ossulana von Agueda bei Bormio ansgab. Anch diese ossulana halte ich für eine $P$. Gandini $\times$ verua. Uebrigens besitze ich eine ganz typische ron $\%$. selbst gesammelte und richtig bestimmte P. Gandini von Mühlan. - Die P. Gandini $\times$ verna scheint in allen Abstufungen in der ganzen subalpinen Region, von der Schweiz bis nach Oesterreich und bis in die Ebenen längs des Nordrandes der Alpen hinab, sehr rerbreitet zn sein; ich besitze sie ron vielen Localitäten (aber unter sehr verschiedenen Namen erhalten). Es gieht darunter anch driisenlose Formen, z. B. im IVallis, wie es denn auch ganz drüsenlose Formen der echten P. Gaudini giebt, obwohl selten. Die P. Gandini beträgt sich in allem, besonders anch in ihrer Neigung zur Bastardbildung und in der Art derselben, ganz analog unserer P. arenaria, von der sie sich abel meiner Jleinung nach specifisch unterscheidet, mindestens muss man sie als eine gute Rasse oder subspecies ansehen. Es ist hier nicht der Ort, dies weitläufiger zu begrïnden; ich will mur anf die Verschiedenheit ihrer Sternhare hinweisen, welche zuerst Waishecker in seiner citirten Abhandlung mit Recht hervorgehohen hat, und die sich anch bei den Gaulini-Bastarden gegeniiber den Arenaria-Bastarden nachweisen lässt. Bei den Sternhaaren der P. Gaudini ist dis in der Mitte des sternes sich erhebende striegelhitar länger als hei P. arenaria, die Strahlen sind kiurzer und diunner, weniger zahlreich und bilden oft mur eine Zackenkrone un den Fuss des Striegelhares. Sie sind of't nur nit dem Mikjoskop zn finden. - Morphologisch kïnnte man die P. Gandini mit ihrer meist langen und ziemlich stark abstehenden liehaarung sowie ihren langen schmalen Theilbliattchen als eine $P$. arenaria $x$ opaca anffassen, doch ist jedenfalls an primäre bastarle dieser Combination nicht zu denken, wenn anch der Gedanke nicht ohne weiteres zurïckzuweisen ist, dass sie möglicherweise einstens aus einer solchen hervorgegangen und sich mit der \%eit modificirt habe, dass sie also einen secundären. längst zur species gewordenen Bastard darstelle. Die P. Gaudini und ihre Formen (P. bolsanensis, P. tiroliensis, P. Murrii '/imm. etc.), sowie ihre zahlreichen Bastarde (darunter wahrscheinlich anch $P^{\prime}$. vindehonensis Zimm.) bediurfen noch einer griundlichen Rerision und liearbeitung; es werden sich eine Anzahl vou "Species", Varietäten mul Formen als synonym und iiberflïssig herausstellen. 
und empfehle eine solche dringend für jeden einzelnen Fall. Auch Poeverlein (S. 99) gesteht, dass er unter jenem ominösen Namen verschiedene Formen zusammengestellt habe, die - ausser der drüsigen Behaarung - wenig A ehnlichkeit unter sich besitzen; bei einer derselben vermuthet er selbst einen Opaca-Bastard, eine andere soll der P. aestiva (auch eine sehr fragliche Verna - Varietät!) ähneln, wieder andere durch die Blattform an longifrons (ob nicht eher an Gaudini?) gemahnen. Vielleicht wird auch hier das Mikroskop mehr Licht schaffen! Es ist sehr leicht möglich und mir sogar wahrscheinlich, dass wir schliesslich die $P$. glandulifera Kra... nicht nur als Species, sondern auch als Varietät der verna ganz streichen m ïssen, - wie so manche andere Errungenschaft der modernen Potentillenforschung und voreiligen Speciesmacherei.

Ich komme nun zur , drüsentragenden" P. longifrons Borb., die nicht weniger der Aufklärung bedarf, als die P.glandulifera Kraš. Borbás hat diese Form zuerst in schedis als P. verna var. longifolia aufgestellt, und dabei bätte er es bewenden lassen sollen. Zimmeter musste sie natürlich zur "Species" erheben, und da es schon eine P. longifolia Willd. (allgemein aber P. viscosa Don. genannt) gab, so hat Borbás den Namen in ,lungifrons" umgeändert und sie nach Zimmeter"s Vorgang als "Species" hingestellt (Oestr. bot. Zeitschr. 1887 S. 404), damit die späteren Botaniker das Vergnügen haben, sie wieder zur Varietät zu degradiren! Ob Borbás seine P. verna var. longifolia ,in schedis" genau beschrieben und gesagt hat, dass sie häufig Drïsenhaare trage, weiss ich nicht; als er sie in der Oestr. bot. Zeitschrift in P. longifrons umtaufte, gab er keine Beschreibung von ihr. Nach allem Anschein rühren die Diagnosen in Zimmeter I, S. 18 und in Kerner's Schedae No. 838, wo von ,pedunculis pler'umque glanduligeris" die Rede ist, von Zimmeter selbst her. Ihm war es vorbehalten, diese Drüsenhaare zu entdecken und nun behauptet alle Welt auf seine Auctorität hin: „Die P. longifrons besitzt häufig Drüsenhaare“, obne auch nur daran zu denken, die Zimmeter'schen Belegexemplare sich unter dem Mikroskop einmal gründlich anzusehen! Wir besitzen in Sachsen die P. verna var. longifolia Borb. sehr schön, aber ohne Drüsen. Ich gab mir viele, aber vergebliche Mühe, in den Besitz eines Borbás'schen OriginalExemplars zu kommen, um es mit den unsrigen zu vergleichen; dagegen gelang es mir allmählich $\gamma$ reichlich aufgelegte Bogen von angeblicher „P. longifrons Borb." zu erwerben, welche nach den beiliegenden Zetteln alle von Zimmeter revidirt sind, und zwar: 1. von Steyr, von Zimmeter selbst gesammelt und ausgegeben; 2. von Garsten, von Z. selbst gesammelt und ausgegeben; 3. von Reichraming, von Steininger gesammelt und ausgegeben; 4. wie No. 3, aber von Siegfried (No. 204) ausgegeben; 5. Lasensteiner Strasse, von Steininger gesammelt; 6. Garsten bei Steyr, von Anna Pehersdorfer gesammelt; $\%$. von Neftenbach bei Winterthur, von Appel gesammelt. Nun gut: No. 7 ist eine zarte schmächtige Form der P. verna, die man am besten zu Var. incisa Tsch. oder zu einer dieser verwandten Form, die Zimmeter P. Siegfriedii getauft hat, stellen wird; sie ist drü senlos; aber No. 1-6 sind sämmtlich Formen der P. Gaudini! wie ein Blick auf sie unter dem Mikroskop oder auch schon mit einer scharfen Lupe beweist. Sie sind sämmtlich von den für P. Gandini charakteristischen Sternharen (- diese sind etwas ander's gestaltet als bei P. arenaria -) dicht besetzt, tragen natürlich auch deren Drüsen, haben aber von P. longifrons Borb. absolut nichts als einige Aehnlichkeit in den 
länglichen Theilblättchen. Da Exemplare von den oben genamnten Standorten und Sammlern in den Herbarien ziemlich verbreitet sein dürften, so fordere ich die Herren Collegen auf, selbst eine Nachrevision dieser P. longifrons Zimm. non Borb. zu unternehmen*). - Der Einzige, der bis jetzt die Sternhaare an der sogenannten P. longifrons beachtet zu haben scheint, ist Waisbecker, wie ich neulich zufällig entdeckte. Auch Andere haben wohl den einzigen darauf beziiglichen Satz in seiner Abhandlung**) übersehen, er sagt nämlich nur: ..Auch die P. longifrons Borb. besitzt (wenigstens zum Theil) auf der Unterseite Büschelhare". Ohne Zweifel lagen auch ihm Zimmeter'sche Exemplare vor. Ich begreife nur nicht, warum er nach dieser Beobachtung die I'. longifrons (Zimm.) nicht sofort in den Kreis der P. Gaudini, wenigstens als Bastard derselben, verwiesen hat.

Ich zweifle nicht im geringsten, dass sich noch manche Potentilla, die man einfach wegen der länglichen Form ihrer Blättchen zu P. longjfrons Borb. gezogen hat, neben den Drüsen auch Zackenhaare (oder auch nur die letzteren ohne Drüsen) aufweisen wird, und empfehle daher, wie bei der P. glandulifera geschehen, alle verdächtigen Herbar-Exemplare einer genanen Nachprüfung. Selbst wo Zackenhaare fehlen, ist nachzuweisen, dass ein Einfluss der P. opaca ausgeschlossen ist. (Vergl. auch Poeverlein über diese ,Art" l. c. S. 99.) Vorläufig muss ich ammehmen, dass die echte $\mathrm{P}$. longifrons Borb. stets drüsenlos ist.

Wenn es nun keine P. verna var. glandulifera und keine P. longifrons f. glandulosa gäbe - wie es mir sehr wahrscheinlich ist - was berechtigte uns dann noch zur Amnahme, dass überhaupt eine drüsentragende Form der P. verna existirt? Etwa der ('Trug-) Schluss: weil es eine P. opaca f. glandulosa und eine I'. arenaria f. glandulosa giebt, muss auch die dritte Species der Vernales-Gruppe eine forma glandulosa besitzen? Gewiss nicht, dem möglich ist Vieles, aber nur was ist, das muss anch sein! Es fragt sich nicht was möglich, sondern was wirlilich ist.

Ich verkenne durchaus nicht, dass es Potentillen-Formen mit spärlichen Drüsenhaaren giebt, welche der $P$. verna ausserordentlich nahestehen. Gerade wir in Sachsen besitzen sie zahlreich, und sie beschäftigen mich seit Jahren vielfach, haben sogar diese Erörterungen hervorgerufen. Das Erste, was ich betonen muss, ist, dass dieselben nur im Elbhügellande, also in Gebiet, wo die drüsemreiche P. opaca und die ebenso drüsenreiche P. arenaria mit ilıren drüsigen Bastarden eine so grosse Rolle spielen, vorkommen. Niemals ist mir eine driisentragende Form der $P$. verna aus einer anderen Gegend Sachsens, in der

*) Ich könnte eine sehr lange Reihe von sicher falsahen Bestimnungen Zimmeter's nur ans meinem eigenen Herbar nachweisen, aber sie betreffen grossentheils species, die hier nicht zur sprache kommen. theils sind sie ron weniger Belang. Die Aufdeckung solcher Dinge gehört nicht zn den Annehmlichkeiten der Potentillenforschung, demn sle liann leicht den Verdacht gehässiger Gesinnung erwecken, aber sie ist nothwendig. nm zn zeigen, wie sehr in manchen Punkten die Potentillenforschung noch im argen liegt. trot\% der Zimmeter'schen Revisionen, vielleicht zum Theil gerade durch sic, weil sie Nanchen veranlasst haben, in rerba magistri zu schwören, statt so viel wie nüglich selbst zu prïfen und fleissig las Mikroskop zu handhaben. Nichts ist in der Naturwissenschaft schädlicher, als der blinde Anctoritätsglanbe; mit inm kommen wir keinen sichritt weiter.

**) V. Waisbecker, Ueber die Biischelbaare der Potentillen. Oestr. bot. Zeitschr. 1892. s. 265. 
$P$. opaca und $P$. arenaria fehlen, zu Händen gekommen, trotzdem ich in meinem bedeutenden Herbarmaterial und in fremden Sammlungen eifrigst danach suchte. Dies ist gewiss eine auffallende und kaum zufällige Thatsache. An unseren massenhaften Opaca $<$ verna-Bastarden können wir eine fortlaufende Reihe von superopaca $\times$ verna bis superverna $>$ opaca in allen Abstufungen nachweisen und dabei die Beobachtung machen, dass eine Form, je weiter sie ron der P. opaca ab- und der P. rerna zurückt, desto ärmer an Drüsen wird; die P. superverna × opaca, die sich aber durch verschiedene Kennzeichen noch deutlich als Bastard documentirt, zeigt sie nur mehr spärlich, und dann kommen wir zu Formen, welche wir ruhig zu P. verna stellen würden, wenn sie nicht -_ nach meiner Ansicht - durch einzelne Drüsen noch eine entfernte Beeinflussung der P. opaca bekundeten. Ich erkläre mir ihre Anwesenheit durch die Rückbastardirung zu P. verna. Wenn schon die reine P. opaca und die reine $\mathrm{P}$. verna so leicht und liäufig Bastarde, die die Mitte zwischen beiden halten, erzeugen, um wie viel leichter und häufiger wird nicht eine Termischung von opaca $>$ verna mit einer verna und dann wieder die einer solchen superverna $\chi$ opaca mit einer verna u. s. f. stattfinden? (Wir werden später sehen, dass alle diese Bastarde fruchtbar sind). Auf diese Weise entstehen, unreine" Verna-Formen, die den Anschein erwecken köunten, dass es echte Verna-Varietäten mit Drüsen gebe. - Genau derselbe Fall tritt bei den Arenaria-Bastarden bezüglich der Zackenhaare ein, die allmählich (durch Rückbastardirung) bis auf einen minimalen Rest verschwinden, so dass man sie nur mehr mit Nühe unter dem Mikroskop finden kann. Ich habe eine ganze Peile solcher verna-ähnlicher Formen mit spärlichen Drüsen und unvollkommenen 'Zackenhaaren als, „unreine P. velna" zusammengestellt. Niemals habe ich unter denselben eine auch nur halbwegs reichdrüsige gefunden, was doch sehr auffallend wäre, wenn es eine von P. opaca (oder arenaria) unbeeinflusste P. verna var. glandulifera gäbe.

Ich will noch einen amalogen Fall vorbringen. wenn el mich anch wieder ïber die Grenzen unseres Gebietes hinausführt. Die P. alpestris Hall. f. (villosa Zimm.), eine sehr nahe Terwandte unserer P. verna, ist (auch nach Poeverlein) ganz driisenlos, und doch tragen Formen, die sich ron ihr makroskopisch gar nicht unterscheiden lassen, Driisen, und zwar im Gebiet der P. frigida, dieser drüsenreichsten Art der Aureae alpinae.

Die Unterscheidung der Potentillae aureae rernales (..campestres") ron den P. aureae alpestres („alpinae") durch das Fehlen der Driisenhaare bei den letzteren. welche Poeverlein begriinden will (1. c. S. 72, 74 ), wird durch die P. frigida und ihre zahlreichen Bastarde hinfällig. Auch die P. grandiflora hesitzt häufig, wenn anch meist spärliche Driisen. Sodann gehört die meist driisenreiche P. Gandini nach ihrem Vorkommen mehr zu den ...alpinae" als zu den "campestres". sie ist wenigstens subalpin mnd steigt hoch in die Region der P. alpestris hinanf, mit dieser Bastarde erzengend. Ich besitze aus der Gegend über Zermatt (iiber $1700 \mathrm{~m}$ ) eine driisentragende P. Gandini und eine drïsentragende $P$. Gaudini $\times$ alpestris (Schroeteri siegfr.), gesammelt ron meinem Freund Prof. Chr. Bötzkes, dem ich ein höchst reichhaltiges und prachtroll präparirtes Potentillen-Material aus der Umgegend des Natterhornes verdanke.

Die P. frigida $\times$ alpestris (Hegetschweileri Brigg.), die ich sehr zahlreich ans der Gegend res Matterhorns besitze, ist fast noch so dritisenreich wie die P. frigidla selbst. aher an Formen, die sich stark der P. alpestris nähern und schon riel weniger zottig. sind, die man also mit superalpestris $x$ frigida bezeichnen könnte, werden die Irüsen immer spärlicher. l,is sie endlich nur mehr vereinzelt an solchen Individuen auftreten, die man kaum mehr als Bastard zu bezeichnen wagt, so sehr nähern sie sich der $P$. alpestris (var. firna). Natiirlich sind hier stets die kurzgestielten. breitköpfigen Drïisen der frigida auf die P. alpestris übertragen, wie bei uns die langen stieldrisen der opaca 
auf tie P. vema. Diese Erscheinung kann man nur anf dieselbe Weise, wie hei der P. verna, durch Riickbastardirung zur P. alpestris erklären. Die echte P. alpestris mnd ihre Formen bleiben deshalb doeh stets drïsenlos. - Aehnliche Beobachtungen kamn man an P. frigida $\times$ grandiflora (vallesiuca Huet.) anstellen. Aber vor dem Bastard frigida $\times$ multifida (pennina (rml. = ambigua Gaud.) möchte ich an dieser Stelle wamen. Das wats nuter diesen Namen in den Herharien allgemein verhreitet ist unl was anch ich in Menge rom sichwarzsee bei Zermatt besitze, ist eine $P$ alpestris $\times$ multifida (Schleicheri Zimm.). die Zimmeter in seinen . Beitrïgen" (sub No. 169) mit Unrecht wieder gestrichen hat. Vor allem fiel mir daran anf, flass anf diese angebliche P. frigila $x$ multitida nichts von len lorisen der $P$. fivigida ïbergegangen ist, aber anch sonstige Anzeichen sprechen zu (iunsten einer Combination alpestris $x$ multitida. Herr siegfried in Winterthm hestïtigte mich in meiner Ansicht mul theilte mir anf eine hierauf beziigliche Anfrage brieflich mit: .Die $P$. penmina Greml. befand sieh nieht unter Ihren Potentillen. was ich begreife, denn diese hochseltene Hybride rom Schwarzsee ist seit Jahren nicht mehr anfgefunden worden! sie ist ansgerottet und muss frisch entstehen, ilamit vie der. Wissenschaft nenerdings zu Angen komme. Von diesem kleinen, silberweiss gliinzenden, ïber nud ïber feinhaarigen PHänzchen besitze ich leiler nur wenige Brmehstiucke" ete. Ueher die P.alpestris $\times$ multifida (Achleicheri Zimm.) schreiht er: „Jein Freund Zimmeter hat höchst Unrecht gethan, dass er in seinem supplement diese werthrolle Bastard-Comlination ammllirte. Diese prächtige Hybrile ist unseren Botanikeru bekannt und findet sich in alten und nenen Herbarien Leider hat Zimmeter seine rermutheten Thahnehmmgen und die hieranf gegrindete sicherheit eben zu frii h publicirt und ist nicht nur hierans. sondern auch durch seine vorher mul nachher ergangenen Determinationen etc. ein Wirrwarr entstanden, der lediglich nur dureh grosse Arbeit zu heben ist.

Ich will hier die lange Discussion ïber die Drüsenhaare bei P. verna schliessen. Fïr mich ist das Resultat folgendes: bis jetzt sind bei keiner Varietät der $P$. verna Stieldrüsen mit Sicherheit nachgewiesen worden; so lange dieses nicht geschieht, glaube ich, dass mus die Anwesenheit ron Drïsenharen an scheimbaren Formen derselben dazu berechtigt, diese als ron einer driisigen $\mathrm{P}$. opaca (resp. arenaria bei gleichzeitiger Anwesenheit von unvollkommenen Zackenharen) beeinflusst anzuseben. - Jedenfalls wird man zugeben, dass meine oben gestellte Frage nicht unberechtigt war, und wenn sie auch nur zu weiteren genauen Beobachtungen Anlass gieht, so bin ich zufrieden, selbst im Falle, dass ich meine Ansicht später anf Grund besserer Belehrung ändern müsste. *)

Varietaiten der $\mathbf{P}$. verna $\mathbf{I}_{\text {。 }}$ Die $\mathrm{P}$. verna ist eine der veränderlichsten Species, anch sind die Varietäten derselben durch so viele Uebergänge untereinander verbunden, dass deren Diagnosen imner nur für typisch ausgebildete Individuen ganz zutreffen werden, während es bei den meisten heissen wird: ,nähert sich dieser oder jener Varietät". Sic gleicht in dieser Hinsicht der P, argentea, und wie bei jener, dürfen wir auch hier die Diagnosen nicht zu engherzig ziehen, sondern müssen die aufgestellten Parietäten oft in einem etwas weiteren Sinn anfassen, als der Auctor, der sie zuerst besehrieben hat, was wir um so eher kömnen, als wir wiederum die Formen nicht nit Zimmeter als Arten, sondern einfach als höchst unbeständige Varietäten ansehen. So lange wir uns nicht über das gar zu ängstliche Zühlen der Theilblättchen oder ihrer Zïhne, iiber das Abmessen ron Länge und Breite der Blättchen nach Millimetern und Aehnliches hinwegsetzen kömnen, werden wir auch nicht über die Aufstellung von immer neuen, ,Species", Varietäten und l'ormen linauskommen, sondern die Zersplitter'ung der Art nur immer weiter fortsetzen. Leider miissen wir ja jene Dinge, die für die Species als solche ziemlich gleichgiltig sind, für die Unterscheidung der Varietäten heranziehen und genau

*) Ich habe sie bereits geándert; ich selbet fand jetrt-obvohl selten-einige 
beachten, aber nicht von einem kleinlichen Gesichtspunkt aus; denn ausschlaggebend wird hier immer das Gesammtbild der Pflanze sein, wie es sich besonders an ihren natürlichen Standorten und in ihrem Verhalten den anderen Varietäten gegenüber bietet. Zur Kenntniss eines solchen Gesammtbildes aber gelangt man nur schwer durch das Studium der HerbarMumien, man muss sie vor allem erwerben durch langjährige kritische Beobachtungen im Freien an Ort und Stelle. „Nur dadurch kann es noch gelingen, die Gattung aus dem Chaos, das eine von kleinlichen Gesichtspunkten ausgehende Bearbeitung zustande gebracht hat, herauszureissen und einer freieren, einsichtsvolleren Specialforschung die Bahnen zu ebnen" (Poeverlein, S. 5). - Gar Nanches, was als gute Varietät oder selbst Species ausgegeben worden ist, dürfte sich nur als Standortsform höher zu stellender Varietäten ergeben.

Es hätte wenig Zweck, hier eingehend abzuwägen und zu untersuchen, in wie weit jedes einzelne Merkmal zur Aufstellung und Abgrenzung der Varietäten sich eigne. Es würde sich herausstellen, dass meistens ein Merkmal allein dazu nicht genügt, dass dasselbe Kennzeichen, welches im Verein mit anderen ständig auftritt, für eine Varietät sehr wichtig werden kann und zu deren Constituirung gehört, während es bei anderen Varietäten, an denen es nur mitunter rorkommt, eine blosse Form derselben bedingt. So z. B. gehören die siebentheiligen Wurzelblätter der Var. Neumanniana zu deren Begriindung und in ihre Diagnose, bei der Var. typica dagegen veranlassen sie nur deren forma septenata. Bei der Var. Amansiana gehören die grossen platypetalen Blüthen zu ihrem Wesen, bei anderen Varietäten treten sie selten neben kleinen und stenopetalen Blüthen auf. Da sich vorläufig noch gar nicht feststellen lässt, welche der beobachteten Kennzeichen der Varietäten den grössten phylogenetischen Werth haben und bei einer Weiterentwickelung zu etwaigen sich später abzweigenden Arten die Hauptsache spielen, ist es für jetzt ziemlich gleichgiltig, in welcher Reihenfolge wir dieselben aufstellen. Wir beginnen mit der läufigsten und verbreitesten.

Var typica (P. opaca Zimm.). Ausser den für die ganze Species angegebenen Hauptkennzeichen fügen wir für die typische Varietät noch hinzu: Pflanze ziemlich schwach behaart, Haare am Stengel und den Blattstielen anliegend oder aufrecht abstehend, auf der Blattoberseite spärlich und kurz, anf der Unterseite an den Nerven zahlreicher, länger, anliegend. Blätter klein bis mässig gross, meist fünfzählig (ausser forma septenata), dick, oft von lederartiger Consistenz, dunkelgrïn, schimmernd; Theilblättchen verkehrteiförmig bis vorn keilförmig verbreitert (besonders an Frühlingsblättern), jederseits bis zur Mitte oder fást bis zum Grunde mit 3-4 (an Herbstblättern mehr) mässig tief einschneidenden stumpflichen Sägezähnen (Fig. 8); Kronblätter verkehrt herzförmig bis schwach ausgerandet, den Kelch meistens wenig überragend, breit und sich berührend, oder schmal und weit auseinanderstehend. Die Stengel, Bliithenstiele und Kelche der Pflanze sind an sonnigen Stellen oft ganz roth iiberlaufen.

Die typische P. verna ist durch ganz Sachsen verbreitet und ich fübre für sie keine besonderen Standorte an, doch will ich bemerken, dass sie durchaus nicht überall häufig ist, wie in den Floren gewöhnlich angegeben wird, ja sie fehlt oft, besonders im höheren Gebirge, auf weite Streckeı. Selbst im Elbhügelland ist sie nicht so gemein, wie es den Anschein haben könnte, denn sie wird hier zum Theil von den folgenden Varietäten ersetzt 
und geht in diese über, sodann hat man im Bereich der P. opaca und der $P$. arenaria oft Miihe, eine ganz reine $P$. verna (ohne alle Drüsenund Zackenliare) aufzufinden. Die $P$. verna kommt desto reiner und typischer ror, je weiter wir uns rom lilbhügelland entfernen.

Die Formen dieser Varietait bezeichnen wir mit selbstverständlichen Namen, die keiner weiteren Erklärung bediirfen: Bei der forma septenata sind die Wurzelblätter vorherrschend seehs- bis siebenzählig statt fünfzählig, im übrigen kann sie durchaus typiseh sein. Naeh der Bliithe unterselieiden wir eine $f$. grandiflora und eine $f$. parvitlora, je nachdem die Kronblätter weit über den Kelch hinausreichen oder kiirzer sind als dieser; ferner eine forma platypetala und eine f. stenopetala. Selbstverständlich können sich diese Formen combiniren und werden dann am besten mit einem combinirten Namen bezeichnet, z. B. kommt eine schöne forma grandiflora stenopetala über den ganzen Rücken der Bosel von Sörnewitz bis Meissen vor; denn wenn wir für alle lormen und deren mögliche oder auch nur wirklich vorkommende Combinationen neue binäre Speciesnamen erfinden wollten, welche meist nichts besagen oder irgend einen Freund verewigen sollen - wie ja leider so vielfach im Brauch ist - so würden wir nie zu Lnde kommen und den Potentillen einen schlechten Dienst erweisen. Der Name der Form soll möglichst das ausdrieken, was sie rom Typus unterseheidet und charakterisirt. - Zu den blossen Formen der Var. typica zähle ich auch die forma pusilla (Koch als Var., Huet als Species = P. verna var. nana Lehm.), deren Name alles besagt. Selbst die neuerlich von Poeverlein als ,nova forma" (aber doch mit binärem Namen!) aufgestellte Potentilla Schuarzi möehte ich nach der Beschreibung hierher ziehen; dem wenn ihr Hauptuntersehied, wie es scheint, darin bestehen soll, dass, die langen Blattstiele den Blüthenstand nach dem Verblühen überragen" (also im Sommer), so ist das eine Eigenthimlichkeit, welche sich im Sommer bei versehiedenen Varietäten der P. verna (ebenso wie bei P. opaca) gar nicht selten zeigt.

Var. hirsuta DC. (erweitert). Ich halte es für zweckmässig, diese zuerst ron De Candolle aufgestellte und von Lehmamn adoptirte Tarietät, die Zimmeter merkwürdigerweise und wie mir scheint, ohne Grund zu seiner $P$. explanata (einem Opaca $\propto$ verna-Bastard) zieht, anfrecht zu halten, und zwar für sehr stark beharte Formen, welehe sich aber, abgesehen von der dichten aufrechten Behaarung, in allem Uebrigen der Var. typica eng anschliessen. Lehmann definirt sie kurz: „multo minor, hirsutissima, pilis densis longissimis incana". IVenn wir sie in nicht zu engem Sinn auffassen, so gehört dahin auch die P. adpressu Opiz ( $P$. albescens Zimm.), die iibrigens noch der Aufklïrung berlarf (sie scheint bis jetzt nur im böhmischen Herbar zu liegen, wenigstens in der der P. serotina ähnlichen Form, wie sie Zimmeter haben will). Die kurz- aber doch dichtbehaarten Exemplare bezeichne ich als formu brevipila, und $7 u$ dieser gehört auch die I. mulbrula Kras̀. (als Art). l)ie P. verna var. pilosa Döll. wird ebenfalls wenigstens zum Theil zu muserer Var. liirsuta gehören: ,Blätter beiderseits ausser den längreren Haaren der Hauptnerven dicht mit kurzen angedriekten Haaren besetzt" (Celak.). *)

Wenn auch diese. mur auf die Belaarung gegründete Varietät vielleicht etwas weit aufgefasst erscheint, so haben wir in ihr doeh einen 
Platz, wo wir die stark behaarten Formen, welche sich gewöhnlich nicht genau mit der P. albescens Zimm. oder der P. puberula Kraš. decken, sondern sich nur + diesen nähern, die aber überall - auch in Sachsen - mitunter vorkommen, unterbringen können, ohne mit Aengstlichkeit die oft unmögliche Entscheidung treffen zu müssen, ob sie in allen Punkten genau mit dieser oder jener übereinstimmen. Vielleicht werden sich nach weiteren Beobachtungen später andere Anhaltspunkte entweder zu einer weiteren Trennung der Formen oder zu einer engeren Zusammenziehung derselben bieten.

Die Var. hirsuta beobachtete ich z. B. in der Gegend von. Weisstropp und Constappel !!, in der Lössnitz !!, in der Dresdner Heide !!; in einer grossen forma septenata sah ich sie ron Lindenthal bei Leipzig! (H. Lips.). Formen der Var. typica, die sich der Var. hirsuta ungemein nähern - die Grenze zu ziehen wird in jedem Fall dem Ermessen des Beobachters anheimgestellt bleiben - sind an vielen Orten zu treffen; man muss sich nur hüten, gewisse zottige Opaca $\times$ verna-Bastarde damit zu verwechseln, oder gar eine stark filzkranke Pflanze als Tar. hirsuta einzulegen!

Var. Amansiana F. Schultz. (Zimm. als Art; P. Chaubardiana Tymb.Lagr., P. verna Var. grandiflora Lehm. p. p.). Ich wiirde gern den bezeichnenden Namen grandiflora für diese grossbliithigste unserer Verna-Varietäten dem Schultz'schen Personennamen .,Amansiana" vorziehen, wenn wir jenen nicht gebrauchten, um eine grossblüthige Form mehrerer Varietäten bezeichnen zu können, und wenn nicht Lehmann sehr wahrscheinlich alle grossblüthigen Formen in seiner Varietät vereinigt lätte, was jetzt nach meiner Ueberzeugung nicht mehr statthaft wäre.

Die Var. Amansiana unterscheidet sich von der Var. typica besonders durch die stets sehr grossen, den Kelch fast um's Doppelte überragenden, goldgelben, stets platypetalen Blumenkronen und durch die kleinen, eikeilförmigen Theilblättchen (der Wurzel- und unteren Stengelblätter), welche nur an vorderen Theil $2-3$ kurze und stumpfe Zähne tragen (Fig. 9). Andere brauchbare Unterscheidungsmerkmale gegenüber der Var. typica giebt es nicht, obwohl sie von dieser auffallend absticht. Ihre Behaarung ist gewöhnlich sehr spärlich und stark angedrückt. Tom Standort hängt es $a b$, ob sie (auf magerem felsigen Grund) klein und niedrig bleibt, oder ob sich ihre Stengel (im hohen Gras und Gebüsch) schlank zu einer Höhe erheben, zu der die Var. typica selten gelangt. Ihre Abänderungen sind so unbedeutend, dass sie keinen Anlass zur Aufstellung besonders benamster Formen geben.

Die Var. Amansiana habe ich bis jetzt in Saclisen nur aus dem Elbhügelland gesehen, am häufigsten in der Lössnitz !!, um Lindenau mehrfach!! (Fr.), auf dem Himmelsbusch !! und hinter der Friedensburg bei Kötzschenbroda!! (Fr.), an der Elbbrücke bei Niederwartha !!, Gröbern bei Meissen!(Fr.), im Plauenschen Grunde! (Stf.). Sehr schön und typisch sammelte sie Herr Hofmann zwischen Diera und Kmehlen! in der Gegend von Zadel bis Diesbar. Man muss sich hüten, diese Varietät mit der P. aurulenta zu verwechsehn, welche älnnliche grosse platypetale Blumen zeigt, sich aber ausser der starken und abstehenden Behaarung schon durch viel grössere, fast immer sechs- bis siebentheilige Blätter unterscheidet. Nach Zimmeter hat schon F. Schultz seine P. Amansiana, ,irrigerweise" mit der P. aurulenta zusammengestellt (Z. I, S. 19). Lei uns ist 
eine Verweclislung $u m$ so leichter, als beide in demselben Gebiet enge beisammen vorkonmen.

Var. incisa T'sch. (P. serotina Vill., Zimm. ete.). Da wir es nicht mit einer Species, sonclern nur mit einer Varietät der P. verna zu thun haben und zudem der Name, serotina" für sie ganz unpassend ist - sie blïht durchaus nicht später als die Var. typica - so lasse jch ihr den von Lehmann acceptirten sehr bezeichnenden Namen "incisa“, welcher ihr Hanptunterscheilungsmerkmal der Var, typica gegenïber ansdrückt. Dieses besteht nïmlich darin, dass die lang-keilförmigen, algestutzten Theilblättchen vorne tief eingeschmitten sind und jederseits ein paar lange, schmale, nach vorn gerichtete Zälne tragen (Fig. 10). Im ganzen ist diese Varietät zarter und schmächtiges als die Var. typica, die Blätter sind weicher, die Stengel und Triebe diinn (,filiformes"), ihre Behaarumg ist schwach und angedriiekt. Die Bliithen sind mittelgross und fast immer stenopetal; es giebt auch eine forma grandiflora stenopetula. Ihre Blätter sind sehr häufig, an manchen P'tlanzen fast aussehliesslich siebenzïhlig. Zimmeter irrt, wenn er ihr nur fünfählige Blätter zuschreibt und da die Zahl der Theilblättchen in seinem Schliissel im Botanikerkalender von $188 \%$ eine so grosse Rolle spielen, wird man bei Benutzung von diesem niemals auf unsere Varietät (lie P. serotina) stossen. In meinem Herbar liegt übrigens eine .P. verna von der alten Oder bei Breslau" (leg. Kabath), zu der Zimmeter mit eigener IIand sehrieb: „P. serotina Vill. typisch!“ Nun diese typische serotina hat durchgehends siebenzählige Blätter! Auch Siegfried gab P'. serotina mit seehs- bis siebenzähligen Blïttern aus. Wenn man will, kann man ja eine forma quinata und eine $f$. septenata unterscheiden oder nur die letztere hervorheben wie bei der Var. typica. So charakteristisch die Var. incisa in typischer Ausbildung durch ihre Blattform und ihren ganzen Habitus anch ist, so schwer ist sie von den anderen Varietäten, besonders der typica, zu trennen, wegen der vielstufigen Uebergänge (Zwischenformen oder Blendlinge?) in diese. In unseren Elbhügellande ist die Var. incisa stellenweise ebenso häufig oder sellost häufiger als die typica - ich fülıre deshalb keine besonderen Standorte für sie auf - und auch bei unseren Opaca $\times$ verna-Bastarden zeigt es sich in Blattschnitt, dass sehr lıäufig bei ihrer Bildung die P. verna v. incisar in Spiele war. Aus anderen Gegenden Sachsens besitze ich sie von mehreren Stellen der Ober-Lausitz! (leg. Hofm.).

Wahrscheinlich ist die P.porrigens Zimm. (Rehb. als Var. der verna), welche Reichenbach von Marienbad in Böhmen heschrieb (Fl. germ. exc. p. 591) nur eine kleine schmächtige Form der Var. incisa, "foliolis parvis, oblongo-cuneatis, apice truncatis, acute et tenue serratis". In der Flora saxonica p. 331 sagt Reichenbach von ihr nur: "hat mehr Stengelblätter und sehr lange diinne Bliithenstiele". Nun, das trifft bei Var. incisa gar niclit selten $\mathrm{zu}$, und so dürften wir diese forma porrigens auch in Sachsen besitzen, was ja auch Reichenhach anzudeuten scheint, indem er sie in die Flora von Sachsen aufnahm. - Etwas anders als Rchb. fasste Petermann die P. porrigens auf. Er bringt sie in seiner Flora lips. als $P$. verna $\gamma$, porrigens Richb. und sagt von ihr nur: ,canles pedicellique valde elongati". Nach den Original Exemplaren in seinem Herbar! (Lindenthal und Riückersdorf bei Leipzig) ist es nur eine langstielige Form der Irar. typica, die allem Anschein nach zwischen hohem Gras gewachsen ist. Wurzelb)ätter sind reichlich vorhanden; einige Theilblättchen sind 
ziemlich tief eingeschnitten-gezähnt und nähern sich dadurch denen der Var. incisa. Mehr lässt sich über sie nicht sagen.

Zimmeter hat „eine der $P$. serotina nahestehende Form als $P$. monticola bezeichnet" (Beitr. S. 31). Ich besitze sie von Z. selbst gesammelt (12. Mai 18\%(j) und ansgegeben von "oberhalb der Quellen des Müblauer Baches bei Imsbruck", und was ist es? Eine reichdrïige (unter den Mikroskop) mit der schönsten Gaudini-Behaarung versehene Pflanze mit langkeiligen, vorn klein- und kurzzähnigen Blättchen! Sie hat nicht das Geringste mit der P. serotina Vill. zu thun und gehört ohne Zweifel zu den schon früher besprochenen Gandini-Formen oder-Bastarlen, welche um Mühlan recht häntig zu sein scheinen und welche Zimmeter unter allerlei Namen in die Welt geschickt hat. Wenn die P. monticola Zimm. auch von anderen angeblichen Standorten die Priifung so schlecht besteht, so muss sie einfach gestrichen werden.

Var. Neumanniana (Richb. als Art). Für diese Varietät besitzen wir in Sachsen den locus classicus, ,Schlossberg von Dohna", an dessen felsigen Abhängen sie in Menge wächst. Ich will zunächst die Diagnose Reichenbach's in der Flora saxonica (S. 331) hersetzen: „Blättchen siebenund fünfählig, lang keilförmig, umgekehrt eirund, nach der Spitze hin eingeschnitten, die fadenförmigen niederliegenden Stengel, Blatt- und Blïthenstiele angedriickt behaart. . . Wuchs und Ansehen der P. opaca, geringe Bekleidung der P. verna und patula." Die Beschreibung ist gut und es ist ihr wenig beizufügen; nur begreife ich nicht, wie Reichenbach und Andere (die sie aber wahrscheinlich an Ort und Stelle gar nicht beobachtet haben) durch ihren Wuchs und ihr Ansehen an P. opaca erinnert werden konnten, von der sie absolut nichts besitzt, als die vorherrschende Siebenzahl der Theilblättchen, die sich aber bekanntlich auch an anderen Varietäten der P. verna findet. Gerade ihr Wuchs, die langen hingestreckten, stark wurzelnden Triebe documentiren sie nebst der spärlichen enganliegenden Behaarung, sowie den sehr langen linealen Nebenblättchen der Wurzelblätter (besonders im Sommer und Herbst) als echte verna. Sie als Tarietät bei der P. opaca unterzubringen, wie noch neulich Wünsche in seiner letzten Auflage gethan, ist ganz unstatthaft, ebenso unbegründet wäre es, sie für eine $P$. opaca $\chi$ verna oder gar opaca $\times$ patula zu halten. Letzteres soll nach Zimmeter Reichenbach gethan haben, allein da muss ich doch diesen in Schutz nehmen: das hat er nirgends gethan. In der objgen Diagnose vergleicht er nur ihr Ansehen mit dem der P. opaca und ihre Behaarung mit der der patula und der verna; und in der Fl. germ. excurs. fügt er seiner lateinischen Diagnose nur bescheiden bei ,forte luybrida inter vicinas", ohne zu sagen, zwischen welchen.

Die Var. Neumanniana gehört zu den grossen und grossblättrigen Formen der P. verna. was sich besonders an den Sommer- und Herbstblättern zeigt, die sich im länglichen Schnitt und durch die reichlichere Bezahnung etwas denen der Var. longifolia nähern (nit der sie in mancher Beziehung die nächste Terwandtschaft zeigt), doch sind die letzteren vorwiegend fünfzählig und die der Neumanniana meistens siebenzählig. Im Frühjahr gleichen die Theilblättchen durch ihre starkkeilige Gestalt und den nur in der vorderen Hälfte eingeschnittenen Rand etwas denen der Var. incisa, doch sind sie (wie die ganze Pflanze) viel derber, vorn viel mehr verbreitert, so dass sie sich berïlıren und das ganze Blatt fast kreisrund erscheint; ferner sind ihre Zähne weit weniger tief eingeschnitten und erscheinen daher breiter (Fig. 11). Die Stengel und besonders die Kelche sind oft stark roth überlaufen, was aber durchaus nicht an 
P. opaca zu mahneı braucht, denn es kommt sehr häufig auch bei der rerna typica und bei der Var. Amansiana vor. Die Blüthenkrone ist mittelgross und ziemlich stenopetal (die Kronblätter berühren sich in der geöffreten Blume nicht), ihre Farbe ist ein helles Goldgelb. - In meinem Garten bliiht diese Varietät an einzelnen Zweigen bis zum Ilerbst, im Freien fand ich nach dem Juni keine Blüthen mehr. Typisch kommt die Neumannima, wie es scheint, in Sachsen nur am Dohnaer Schlossberg (auf (iranit) vor !! Wo sie dort aus dem Gebüsch und ron den stark mit Humus bedeckten Abhängen auf dïrre, sandige Stellen oder auf den fast nackten Felsen heraustritt, wird sie klein, ihre Blätter sind dann oft fünfzählig und sie scheint mir da Uebergänge zur Var. typica zu zeigen, welche ganz in der Nähe vorkommt. Solche Mittelformen finden sich auch dem Schlossberg gegenüber an den linken Gehängen des Müglitzthales und in der Nähe des Bahnhofes von Dohna: Ob wir es hier nur mit Standortsformen der Var. Neumanniana, oder mit Blendlingen zwisehen dieser und der Var. typica zu thu haben, wage ich derzeit noch nicht zu entscheiden. Eine zwischen Var. Amansiana und Var. Neumanniana stehende Form fand ich bei Lindenau in der Lössnitz!!, andere Formen nehmen eine Mittelstellung zwischen der Neumanniana und der Var. incisa ein.

Die Var. Neumanniana scheint anch ansserhalb Sachsens iiberall selten zu sein. Dass in den Herlarien unter diesem Namen gar Verschiedenes liegt, darauf hat schou Zimmeter (I. . . 18) aufmerksam gemacht; auch Kerner (Schedae 1246) sagt, (lass er ofters in den Herbarien die P. serotina als Nemmanniana bezeichnet fand. Von dem, was ich als P. Neumanniana bekam, kann ich nur die ron Siegfried und ron Appel ausgegehenen Exemplare von Neftenbach bei Winterthur dafïr annehmen, sie stimmen recht gut mit denen ron Dohna. Am unglïcklichsten war E. Hippe, welcher eine typische kleine $P$ avenaria $\times$ verna .,vom Teplitzer Schlossberg" als P. Nemmamiana Richb. ansqab. Später, 1895. wollte er sich verbessern und gab von lerselben Localität wieler als P. Nenmanniana eine sich der P. serotina nähemde Form der P. verna Tar. typica ans!*)

Var. longifolia Borb. (P. longifrons id., Zimm.). Auch diese gehört zu den grossen, starken Varietäten der P. verna, was sich besonders wieder an den langgestielten Sommer- und Herbstblättern zeigt. Ihre langen und starken Triebe wurzeln sehr lejcht und stark, so dass sich ein Stock gar bald zu einem breiten flachen Rasen ausdehnt, wie ich in meinem Garten beobachtete. Die Theilblättchen ihrer meist fünfzähligen Blätter bilden ihr Characteristicum: sie sind derb, an den Frïhlingsblättern ahgestumpft und vorn breit, aber reichzähnig, an den Sommerund Herbstblättern sind sie länglichlanzettlich, scharfgezähnt und (wenigstens die drei inneren) deutlich gestielt; sie besitzen jederseits $6-8$ spitze $Z$ ähne bis zu dem sich allmählich versehmälernden Grund, dazwischen kommen aber auch solche mit wenigen Zähnen nur an der vorderen IIälfte und mit einer sehr langkeiligen in das Stielchen sich verlierenden Basis vor, welche an die Blätter der V'ar. incisa erinnern. Auch die Blättchen der oberen Blätter am sehr robusten Stengel sind

* Am 3. Mai 1Rgs suchte ich selbst den Teplitzer Schlossherg auf Potentillen ab. Ich fand solelie mur an den grasigen stellen. Weg- und Waldrändern zwischen der von Teplitz-Schönan herant- und am Nordfuss hinführenden strasse und dem bewaldeten steilen Kegel. Dort sammelte ich die P. opuca l.f. eglandulosa (elienso am IIilleschaner!!), die $P$. rema l'ar. typiea eine $P$. opaca $\times$ verna und lie $P$. arenaria $\times$ verna in melureren Abstufungen. Etwas anderes knmmt dort nicht vor. lie reine P. arenaria fehlt derzeit, diüfte aber friher vorhanden gewesen scin. 
auffallend lang und schmal, wenn auch weniger reich gezähnt (Fig. 12). Die Behaarıng dieser Varietät ist spärlich, angedrückt, der der Var. Neumanniana ähnlich; Drüsen habe ich an ihr nicht beobachtet*); ihre Blüthenköpfe sind verhältnissmässig gross, die Kronen den Kelch wenig überragend, ziemlich hellgelb und meist stenopetal.

Ich fand diese schöne Varietät zuerst auf sandig-kiesigem Boden hinter dem Weissen Hirsch bei Dresden!!, wo sie Ende Juli reichlich bliihte und schon dadurch, noch mehr aber durch ihre grossen merkwürdigen Blätter mich höchlich überraschte. Dass hier eine ausgezeichnete Varietät vorlag, war mir sofort klar und die vollkommene Uebereinstimmung mit der Diagnose der P. longifrons Borb. liess keinen Zweifel aufkommen, dass wir es mit dieser zu thun haben. Seitdem cultivire ich sie im Garten, wo sie sich unverändert erhält und fast den ganzen Sommer blïht; auch im Freien finde ich sie jeden Herbst bis in den November hinein in schöner Blüthe. Die obige Beschreibung habe ich nach unserer sächsischen Pflanze gemacht.

Ausser dem angegebenen Standort fand ich die Var. Iongifolia, aber nicht so ganz typisch, in einem Steinbruch unweit Skassa bei Grossenhain !! Die Pflanze ist hier etwas schmächtiger und zarter, die Blattform ist zwar die der longifolia, aber die länglichen Theilblättchen sind tiefer und unregelmässiger eingeschnitten, sie erinnern unwillkürlich an eine Combination incisa $\times$ longifolia und ich halte eine genetische Beinflussung durch die Var. incisa durchaus nicht für ausgeschlossen. Immerhin steht sie der Var. longifolia bedeutend näher und wir können sie einfach als Var. longifolia forma incisa bezeichnen**).

Eine echte Var. longifolia, welche mit der vom Weissen Hirsch sehr gut übereinstimmt, erhielt ich neulich von Herrn Ingenieur Artzt, welcher sie Ende Mai 1887 bei Plauen i. V. sammelte (!). Ferner sah ich eine longifolia forma septenata von Connewitz bei Leipzig! (H. Lips.).

Petermann hat in Flora lips. p. 378 eine P. verna $\beta$ ) oblongifolia aufgestellt: ,foliola obovato-oblonga, plurima non truncata, superne lateribus pectinato-serrata". Er citirt dazu als Synonym P. aestiva Richb. Nach den Original-Exemplaren von lieuschberg bei Leipzig!, die ich im Herb. Pet. einsah, ist es nur eine kräftige Form der Var, typica mit 3 bis 4 Zähnen jederseits an den Theilblättchen. An unsere Var. longifolia erinnert sie nur schwach, und mit P. aestiva Hall. f, oder Gaud. darf sie jedenfalls nicht zusammengeworfen werden.

Andere als die aufgeführten Varietäten der $P$. verna habe ich in Sachsen noch nicht angetroffen*/Die Besprechung der Var. aestiva (Hall. f.) Gaud. incl. der P. autumnalis Opiz muss ich in den Formenkreis der P. opaca $\times$ verna hiniberziehen, zu dem wir sofort übergehen werden, nachdem ich erst noch für unsere sächsischen Floristen einen Schlïssel für die Bestimmung der Verna-Varietäten hergesetzt. Es muss natürlich feststehen, dass die Pflanze eine echte verna und kein Opaca $\times$ remaBastard ist.

*) Ueber die von Zimmeter angegehenen Drüsenhaare der P. longifrons und den Missbrauch, der mit diesem Namen getrieben wurde, vergl. S. 67.

**) Ein rechter Potentillenmam aus der Zimmeter'schen Schule wiurde das Ding wohl so bezeichnen: Potentilla serotina Vill. $\times$ P. longifrons Borl. $=$ P. Grossenhainensis oder P. Pr ..... pumskii, Nova hybrida mihi, was freilich pompöser klänge!

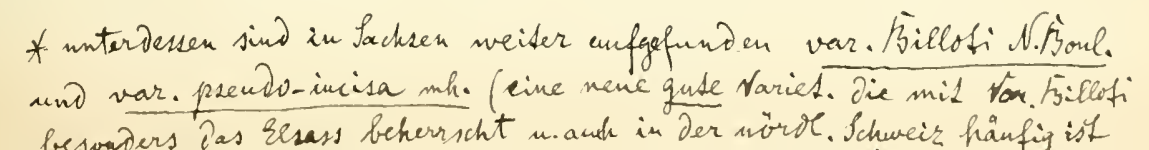




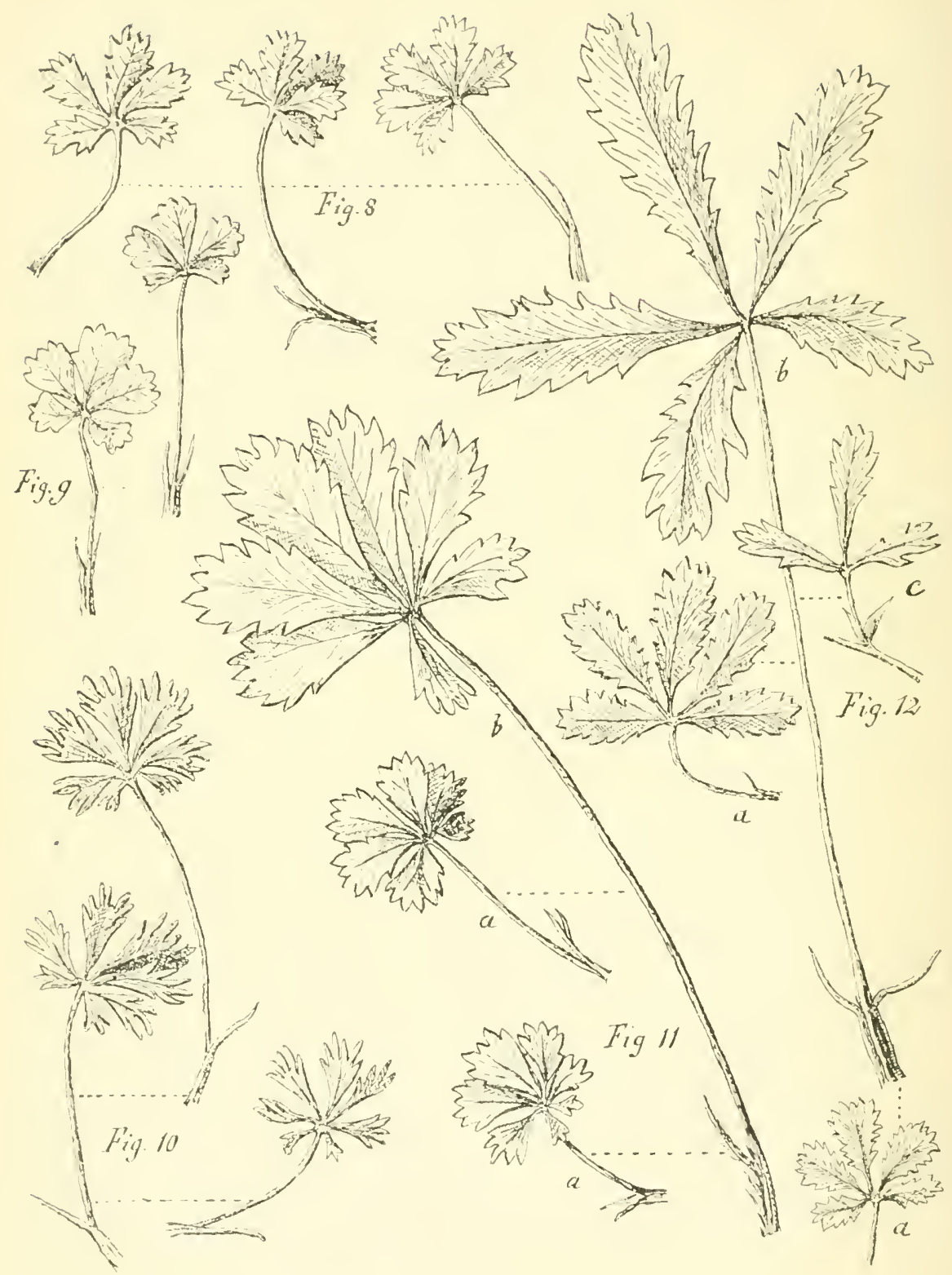

Fig. 8-12.

Wurzelblätter der P. verna L. Nat. Gr. nach Blattabdrïcken. Mig. 8. Frühlingsblättex der Var. typica, Fig.9. Frühlingsblätter dex Var. Amansianı, Fig. 10. Frïhlingsblätter der Var. incisa. Fig. 11. Var. Yeumanniana, a) Friihlingsblätter, 1) Sommerblatt, Fig. 1\%. Var. Iongifolia, a) Érühlingsblätter, b) Sommerblatt, c) oberes Stengelblatt. 
I. Pflanze, besonders die Blätter stark aufrecht-abstehend oder anliegend behaart . . . . Var. hirsuta DC. (erweit.),

II. Ganze Pflanze schwach aufrecht-abstehend oder anliegend behaart.

A. Ganze Pflanze klein bis mittelgross, Theilblättchen klein, derb, oboval-keilig, meist zu 5 am Blatt, jederseits mit 2-4 kurzen stumpfen Zähnen.

1. Theilblättchen vorn und seitlich jederseits mit 3-.4 mässig eingeschnittenen spitzlichen Zähnen. Krone den Kelch wenig überragend, wenn grösser dann gewöhnlich stenopetal Var.typica (Fig. 8).

2. Theilblättchen nur vorn jederseits mit $2-3$ sehr stumpfen und breiten Zähnchen. Krone stets gross (fast doppelt so lang als der Kelch), und platypetal. .Var. Amansiana F. Schltz. (Fig. 9).

B. Pflanze mittelgross, zart; Blätter düm, häufig sechs- bis siebenzählig, Theilblättchen abgestumpftlangkeilig, fast gestielt, nur vorn jederseits mit 2-3 langen, schmalen, vorgestreckten stumpfen Zähnen . . . . . . . Tar. incisa Tsch. (Fig. 10).

C. Pflanze meist gross und robust. Blätter gross, derb, reichzähnig, Theilblättchen mit $3-9$ Zähnen jederseits.

1. Blätter meist siebenzählig. Theilblättchen oboval-keilig, vorn stark verbreitert und an der vorderen Hälfte jederseits mit $3-\mathbf{5}$ stumpfen Zähnen . Var. Neumanniana Relıb. (Fig. 11).

2. Blätter meist fünfzählig. Theilblättchen an den Sommerblättern länglich-lanzettlich, zum Theil deutlich gestielt, bis 9 spitze Sägezäbne jederseits . . . Var. longifolia Borb. (Fig. 12).

\section{Potentilla opaca $\mathrm{L}_{.} \times$verna $\mathbf{L}$.}

$$
\text { (P. rubens Zimm. } \times \text { opaca Zimm.) }
$$

Dahin gehört eine ganze Reilıe von Formen, welche man theils mit binären Speciesnamen bezeichnet, theils als Varietäten der P. verna und der P. opaca aufgefasst hat, so unter anderen die P. vitodurensis Siegfr. P. tariensis Siegfr., P. explanata Zimm., P. intricata (Grml.) Zimm., P. aurulenta Grml., P.opacata Jord., P. vivariensis Jord., P. agrivaga Timb.-Lagr. (?), P. fagincicola M. Lamotte (?), P. subopaca Zimm., P. pilosa Döll. p. p. (?), $P$. aestiva (Hall. f.?) auct. p. p., P. antumnalis (Opiz?) auct. p. p., P. verna var. crocea Koch und Lehm. p. p. etc. etc. In den Herbarien begegnet man oft den Opaca $>$ verna-Bastarden unter den verschiedensten Namen, unter denen sie der Kenner derselben sicher nie gesucht hätte. - Die grosse Unklarheit und Unsicherheit in der Beurtheilung dieser Bastardformen 
crklärt sich besonders daraus, dass zu dieser das meist geringe Herbarmaterial oft recht unzulänglich ist und dass, wemn irgendwo so hier, ein längeres Studiun der Formen im Freien an ihren natürlichen Standorten fast zur Nothwendigkeit wird, wozu aber nur wenige Forscher Gelegenheit finden. Wegen dieses Mangels an Erfahrung am lebenden Material hat auch Mancher noch keine Ahnung von der grossen und häufigen Rolle, welche die Kreuzung bei den Arten der Vernales-Gruppe spielt. Kanm eine andere Gegend Deutschlands dïrfte eine so giinstige Gelegenheit zum Studium der Opaca $>$ verna- (und Arenaria $\times$ verna-) Bastarde bieten, wie die schöne Umgebung Dresdens, iiberhaupt unser Ethhügelland. Was ich also hier über sie vorbringen werde, grïndet sich vor allem auf jahrelang fortgesetzte Beobachtungen im l'reien und das von mir selbst an Urt und Stelle gesammelte Material.

Eine allgemeine, d. h. für alle Bastardformen der P. opaca $>$ verna zutreffende Diagnose zu geben ist kaum möglich, denn sie variren zu sehr, was ja schon in ihrer Bastardnatur und sodann auch darin begründet ist, dass sich verschiedene Varietäten der Eltern an der Kreuzung betheiligen. Man kann nur im allgemeinen sagen, dass sie in den wichtigsten Merkma!en zwischen beiden Eltern stehen: die Stämmchen und Triebe der Pflanze pflegen kürzer zu sein und weniger zu wurzeln als bei der P. verna; die Nebenblättchen der Wurzelblätter sind lang lanzettlich oder lineal, aber dam kürzer als bei dieser, die behaarung weicher, dichter und länger, als bei der verna nnd sehr stark abstehend, wenn auch selten ganz horizontal wie bei der P. opaca. Durch diese Behaarungsart wird ïbrigens ein ähnliches opakes Aussehen der Pflanze hervorgebracht wie bei der letzteren. Die Blätter sind vorherrschend sechs- bis siebenzählig. Drüsenhaare sind (bei uns) in den meisten Fällen rorhanden, fehlen aber auch mitunter; in diesem Punkt verhalten sich die Bastarde ganz wie die I'. opaca. V'egetatir sind sie oft kräftiger, schöner und grossblüthiger als die Eltern, auch scheinen sie meistens ziemlich fruchtbar zu sein. - An Mischformen, welche ungefähr die Mitte zwischen beiden Eltern halten, wird man gewöhnlich alle die hier angegebenen Merkmale heisammen finden; aber hei den extremen Formen der stufenreihe werden diese mehr und mehr denen der reinen P. verna oder der reinen P. opaca ähnlich sein.

Die Neigung der P. opaca zu der P. verna muss ungemein stark sein, demn wo immer beide Species beisammen stehen, kann man sicher sein. deren Bastarde zu finden. Diese kommen aber nicht etwa nur vereinzelt zwischen den Eltern vor, sondern sie überwiegren stellenweise die letzteren an Zahl und verdrängen sie mitunter vollständig, so dass man im weiten Umkreis weder eine reine Verna noch eine reine Opaca antrifft, was man sich nui durch ihre vegetative Ueberlegenlieit über die Eltern und ihr wenig geschwächtes geschlechtliches Reproductionsvermögen erklären kann. Ich will lier gleieh hemerken, dass wir ganz ähnlichen Bastard-Colonien bei der P. arenaria $>$ verna begegnen werden, und zwar an Orten, an denen die P. arenaria schon lange verschwmnden ist, aber nach der Pflanzen-Association (pontische Flora) höchst wahrscheinlich in nicht zu ferner Vergangenheit vorhanden war. Bei solchen Colonien kann nicht mehr von primären Bastarden die Rede sein. Diese haben sich seit Generationen auf geschlechtlichem Wege fortgepflanzt und köunen sich unter Umständen so weit festigen und vielleicht auch etwas modificiren, 
dass sie sich durchaus als selbständige Species benehmen. Ich sage unter günstigen Umständen, zu denen ich auch das Verschwinden der Eltern aus irgend einem Grunde in der nächsten Umgebung, also eine gewisse Isolirung auf längere Zeit, rechne. Demn wo diese mit den Bastarden rermischt weiter wachsen, können wir auch gewöhnlich eine weitgehende Rückbastardirung der letzteren beobachten, welche danı natürlich das Entstehen einer neuen gefestigten Species erschwert.

Dass es Pflanzenarten giebt, welche sich aus ursprünglich primären und dann secundären Bastarden entwickelt und im Laufe der Zeit so gefestigt lıaben, dass sie sich von den Eltern längst vollständig unabhängig erweisen und daher von den Floristen als ,gute Species" aufgeführt werden, ist die Ansicht vieler Forscher: auch Ascherson macht mehrmals, z. B. bei Circaea intermedia, Naturtimn anceps und Naturtium armoracioides, auf solche gleichsam zu Species gewordene Bastarde aufmerksam. Theoretisch scheint mir nichts im W'ege zu stehen, dass durch Kreuzung nahe verwandter Arten neue, fruchtbare und constant bleibende (Mittel-) Species entstehen können, und glaube ich. dass diese Art der Speciesbildung in allen Entwicklungsperioden des Pflanzenreiches, auch in der heutigen, in der 'That viel häufiger eintrat und noch eintritt, als man bisher anzunehmen geneigt ist, gegenwärtig besonders in polymorphen Familien, welche wie die Rosaceen (Rubus, Rosa, Potentilla, Alchimilla) gerade in unserer Erdperiode in ihrer Hauptentwicklung begriffen zu sein scheinen; (- auch Hieracium, wenigstens das Subgenus Pilosella, ist in diesem Fall -).*) Unter den Potentillen halte jch für solche zu Species gewordene Bastarde die P. collina auct, die P. procumbens Sibth., die P. Gaudini Grml. Wir werden unter den P. opaca $>$ verna-Bastarden eine Form kennen lernen, die auf dem besten Wege ist, sich den Speciesrang zu erwerben, wenn es nicht schon geschehen ist.

$\mathrm{Da}$ es einerseits äusserst schwierig wäre, die vielen Formen der P. opaca $\times$ rerna zu beschreiben und man damit kaum je zu Ende käme, indem immer wieder etwas abweichende Formen sich finden werden, da es ferner recht zwecklos wäre, alle diese Formen mit besonderen Namen zu beehren, andererseits aber sich eine gewisse Unterscheidung doch nothwendig macht, möchte ich vorschlager, sie einfach mit der selbstverständlichen Bastardformel in drei Abstufungen zu bezeichnen: 1. P. opaca $\times$ verna: der Bastard steht ungefälı in der Mitte zwischen beiden species; 2. P. superopaca $\times$ verna: er nähert sich sehr der P. opaca; 3 . P. superverna $×$ opaca: er steht der P. verna näher. Für lie letztere Bezeichnung könnte man ebenso gut subopaca $\times$ verna setzen; allein ich vermeide die Zusammensetzungen mit sub-, um keine Verwechslungen mit P. subopaca Zimm. (=P. opaca $\times$ verna) und $\mathrm{P}$. subarenaria $\mathrm{Borb}$. $(=\mathrm{P}$. arenaria $\times$ verna $) \mathrm{zu}$ veranlassen. Ich verbinde stets mit super-diejenige Art, zu der der Bastard entschieden hinneigt, wobei es dahingestellt bleibt, ob dies schon bei der erstmaligen Kreuzung oder durch eine Rückbastardirung stattfand.

*) Soeben lese ich in der im Erscheinen begriffenen Bearbeitung der Gattung Rosa ron R. Keller in Ascherson-Graebner's synopsis Bd. VI, S. 54 , eine sehr beherzigungswerthe Auslassung ron $\mathrm{Christ}$ ïber dieses hier beriuhte Thema. gelegentlich der Rosa Jundzillii Bess., die er für eine $R$. gallica-canina hält. Ich bin vollständig seiner Meinung über die Entstehung mancher constanter species aus urspriunglichen Bastarlen: auch R. Keller scheint diese Ansicht zu theilen, sonst hätte er wohl die Ausführungen Christ's nicht ohne irgend eine Bemerkung aufgenommen. 
Im letzteren Falle wäre also z. B. P. superverna $>$ opaca die abgekiirzte Formel fuir P'. (opaca $\times$ verna) $\times$ verna. lch lalte daran fest, dass ein Bastarl stets an erster Stelle mit der Bastarlformel ausgedrickt werden soll, und diese genügt vollständig, denn sie vertritt den binïren Speeiesnamen; ein zweiter binärer Aame, wenn auch nur in Klanmern, ist eine unnüte '/ugabe, die nur len Synonymenwust rermehrt. Dagegen kömen dann recht wohl Varrietäten und Formen des Bastards unterschieden werden, womöglich in bezeichnenden Ansdrücken.

Für die Rentheilung des Verwandtschaftsgrades mit der einen oder anderen Art wird bei den Opaca-Bastarden in den meisten Fïllen die dichtere oder dünnere, längere oder kürzere, stärker oder weniger abstehende Beharung den ersten und besten Anhalt geben, demn die übrigen Merkmale folgen erfalırungsgemäss im selben Verhältniss. - Bei allen drei Bastardstufen werden wir eine forma glandulosa und eine forma eglandulosa zu unterscheiden haben. Ferner wird der [ilattschnitt oft Veranlassung geben, die Betheiligung dieser oder jener Varietät der P'. verna zu vermuthen, dann kam man auch hinter der Bastardformel den Nanen der betreftenden Varietät oder Form beifügen, z. B. incisa, longifolia, grandiflora. stenopetala ete, und wenn auch eimmal zwei Formenbezeichnungen zusammentreffen, so macht das nichts aus, da damit das Gedächtniss nicht beschwert, sondern in Gegentheil erleichtert wird, indem die Gesammtformel zugleich eine kurze beschreibung der I'flanze giebt. Mir scheint es z. B. leichter verstänllich und sogar kiirzer zu sein, wemn ich sage P. superverna $>$ opaca, f'. incisa, glandulosa, als wenn ich dasselbe so ausdrückte: P. (verna var. serotina $x$ opaca var. gadensis) $\times$ l'. verna.

Die Frage, ob eine P. opaca $\times$ verna f. eglandulosa durch die Betheiligung einer P'. opaci glandulosa entstehen könne und umgekehrt, ist fast dieselhe, die wir bezïglich der reinen I. opaca gestellt haben, und ich heantworte sie in demselben Sinn wie dort, nämlich, dass die Möglichkeit gewiss nicht zu bestreiten ist. Für gewöhnlieh aber glaube ich, dass die drüsenlose opaca emen drüsenlosen Bastard und die drüsenreiche opaca einen drisenreichen Bastard erzeugen wird. Jedenfalls diirfen wir bei zweifelhaften Formen ans der. Anwesenheit von Driisen (ohme Sternund Zackenhare) auf die Betheiligung irgend einer P. opaca schliessen, demn von der P'. verma stammen sie nach meiner Insicht niemals her. Wie hei dem häufigen Auftreten der P. opaca f. ghlandulosa in Sachsen a priori zu vermuthen war, treten bei uns auch die Opaca $\times$ verna-Bastarde ïberwiegend in derselben forma glandulosa anf.

Die Aufzählung aller mir bekannt gewordenen Standorte aller Varietäten und Formen würde crmüdend sein, demn es wïrden sich dieselben Namen zu häufig wiederholen, da selten an einer Localität nur eine, gewöhnlich aber 2-4 verschiedene Stufen und Formen aufzutreten pflegen. Ich begnüge mich daher, zu wiederholen, dass man die Opaca-Bastarde überall finden wird, wo die P. opaca in der Näbe wächst (siehe deren Standorte). Ganz besonders reiche Ausbente wird man finden: bei Dresden um Plauen und liäcknitz, äber den Ablängen des I'lauen'schen Grundes bis P'otschappel, besonders hinter Iö̈ltzsehen, in der Lïssnitz zwischen Kätzschenbroda und Lindenau, am Eisenbahntunnel bei Oberau, anch noch bei Shassa unweit Grossenhain. Aus weiterer Entfernung vom Elbhïgelland, wo ja auch die P'. opaca selten wird, habe ich noch keinen Bastard derselben geselien. 


\section{Potentilla alurulenta Gremli (erweitert).}

(P. opaca - verna. P. aestiva und autumnalis auct. pp.)

Es giebt eine Vittelform zwischen P. verna und P. opaca, welche man nicht ohne weiteres zu den Opaca $>$ verna-Bastarden werfen kann, demn sie zeichnet sich durch Eigenthümlichkeiten aus, die ihr meines Erachtens einen höheren Rang anweisen und uns berechtigen, sie als besondere Species zu betrachten, mit demselben Recht, mit dem z. B. die P. procumbens Sibth. oder die P. Gandini Grml. als solche behandelt werden. Es fragt sich nur, ob der von mir für sie gewählte Name der richtige und passendste ist.

Diese schöne Potentilla ist für gewisse Theile unseres Elbh ̈̈gellandes geradezu eine Charakterpflanze und wird die Aufmerksamkeit jedes Floristen auf sich ziehen. Sie ist für mich seit mehreren Jahren das Object eingehendster Beobachtungen und ich darf mir wohl ein Urtheil ïber sie erlauben.

Die Pflanze, um die es sich handelt, kann man am kürzesten definiren, wenn man sagt, dass sie fast genau in der Mitte zwischen P. verna und P. opaca steht, dabei aber stets sehr grosse, sattgelbe, platypetale Bliithen besitzt. Der letztere Umstand unterscheidet sie besonders auffallend von den gewöhnlichen Opaca $>$ verna-Bastarden mit meist mittelgrossen und ziemlich stenopetaleu Bliuthen, welche ja im übrigen oft mit ihr so ziemlich übereinstimmen. - Die Behaarung ist viel dichter, länger und stärker abstehend als bei der P. verna (daher das opake Aussehen), an den Blattstielen und unteren Stengeltheilen oft ganz horizontal, wie bei P. opaca. Die Blätter sind meist sechs-bis siebenzählig, die Theilblättchen keilförmig, vorn verbreitert (sich berührend) und mässig tief gezähnt, in der Form an die der P. verna var. Neumanniana erinnernd, mitunter aber auch tiefer eingeschnitten, fast wie bei der Var. incisa. Die ganze Pflanze ist robust, ziemlich gross und hat einen compacten Wuchs, d. l. die Triebe bleiben kürzer als bei der P. verna und wurzeln wenig, sie entspricht in dieser Hinsicht mehr der P. opaca. Die Sommerblätter werden gross und langstielig. Der Pollenstaub ist grossentheils gut ausgebildet und die PHanze ist recht fruchtbar, wie die vielen Sämlinge in ihrem Gebiet beweisen. Bis jetzt kenne ich von ihr nur die forma eglandulosa, was in Anbetracht ihres massenhaften Auftretens in einer Gegend, wo die drüsigen Opaca $\times$ verna-Bastarde so häufig sind, sehr auffallend und auch ein Anzeichen ist, dass sie sich viel beständiger benimmt, als die letzteren. In der That treten bei ihr nur wenig abweichende Formen auf, sie bleibt sich gleich und zeigt nur selten allmähliche Uebergänge (Riückbastardirung) zu P. verna oder opaca, wie sie bei den Opaca $x$ verna-Bastarden so gewöhnlich sind. Ferner ist zu beachten, dass sie stellenweise in grossen Colonien auftritt, welche ganze Abhänge überziehen, während sich werler P. verna noch P. opaca in ihrer Nähe zeigen.

Als ich diese Pflanze zuerst von den Zadler Abhängen nach der neuen Litteratur zu bestimmen suchte, konnte ich sie nur für die $P$. aumlenta Grml. erklären, um so mehr, als die ron Siegfried vom ,Hard bei Winterthur" ausgegebenen und von Zimmeter revidirten Exemplare genau mit ihr übereinzustimmen schienen. Zimmeter verlangt zwar von der P. auru- 
lenta, dass sie stets „exquisit alsstehende Ilaare" besitze (- Gremli sagt nur ..Haare der Blattstiele fast wagrecht abstehend" -), aber da er andererseits sagt, (lass sie, die ausgesprochenste Mittelform beider Stammarten" sei, so sollte man meinen, dass sie anch beziiglich der Haarrichtung die Mitte halten dïrfte, und so ist es in der That nicht nur bei unseren sächsischen I'flanzen, sondern auch bei mehreren von Zimmeter für I'. aurulenta erklïrten Exemplaren. "Exquisit abstehend" sind die langen llaare gewöhnlich nur an den untersten Pflanzentheilen, oft anch an den Blattstielen, nach oben zu werden sie + schief abstehend. Oh es sich bei der von Gremli anfgestellten l'. aurulenta um einzelne primäre, oder ebenfalls um zu einer Nittelspecies gewordene secundäre Bastarde handelt, kamn ich nicht wissen*), aher dass unsere sächsischen Pthanen mit ihr morphologisch ïbereinstimmen, scheint mir sicher zu sein, und daher glaube ich den schönen und bezeichnenden Namen anf sie ausdehnen zu dürfen, wenigstens mit Beifügung von „erweitert" in Klammern, um mich nicht zu sklavisch an den Wortlaut der Diagnose zu binden.

IIan könnte in krwägmng ziehen, ob man die P'flanze, von der wir handeln, nicht lieher als $P$. aestiva 11 all tïl. (incl. $P$. autumalis Opiz) bezeichnen soll, denn ich bin zur Ueberzengung gekommen, dass gar Manches, was unter diesen Namen länft, zu unserer $P$ '. opaca - verna gehört, und es ist sehr fraglich, ob nicht Haller und Opiz selbst ähnliche aurulenta-artige Mittelformen ihren Benennungen zu Grunde gelegt haben. Da zu ihrer Zeit von primären und secundären l'otentillen-Bastarden wohl noch kaum die Rede war, haben sie dieselben als Tarietäten bei der P. verma untergebracht. Ebenso verfuhren Koch und Lehmann, denen die so lä̈ufigen Mittelformen unmöghich ganz unbekannt sein lionnten; hei ihnen haben wir sie zu suchen unter $P$. verna $\beta$ ) crocea, zu welcher beide als Synonym die P. verna aestiva Hall. fil. (resp. Gand.) eitiren.

Dass die P'. aestiva (mit autumnalis) nicht als Varietät bei der P. verna bleiben kann, wenigstens nicht in ihrem ganzen puäsumptiven Umfang. haben nenerlich Schwarz in seiner flora von Nürnberg, sowie Schinz und Keller in ihrer Flora der Schweiz ganz richtig empfunden; in beiden Werken finden wir die P. aestiva Ilall. fil. als eigene drt neben ler P. vema und der P. opaca anfgeführt. Wenn ich nun doch den Namen P. aurulentu Grml. vorziehe, so geschieht dies 1. weil heide Namen, aestiva und antumnalis ganz unpassend sind (ebenso wie serotina), da die PHanzen so gut vernales sind wie P. verna und opaca, wenn auch einzelne Nachzügler im Herbst noelımal blühen mögen, was ja bei verschiedenen anderen Formen auch vorkommt; 2. weil es einerseits nicht feststeht, ob Haller wirklich eine opaca — verna orler nur eine Varietät der letzteren beschieb (- man müsste die Original-Exemplare einsehen -), und andererseits die späteren Botaniker den Namen nicht nur auf aurnlenta-artige, sondern auch anf recht verschiedene andere Formen ausgedehnt zu haben scheinen; es wïrde also nur ein Theil der P'. aestiva auct. mit unserer erweiterten P. aurulenta zusammenfallen und von jenen zu trennen sein, wälnend ein anderer allenfalls als Varietät der i'. verna fortbestehen könnte oder sonstwo unterzubringen wäre; 3. weil der Name aurulenta wirklich zuerst für eine unzweifelhafte Nischform der l'. verna nnd opaca angewendet

*) Gremli sagt in seiner Excursionsflora, 8. Aufl., 1896: "Mittelform oder Bastar"i". 
wurde - ob für einen primären oder einen secundären zur Species gewordenen Bastard, ist unwesentlich -, und eine Haupteigenschaft der Pflanze, die grossen goldgelben Blumen, schön bezeichnet.

Dass unter P. aestiva recht Verschiedenes zusammengefasst wird, zeigt unter anderem auch die von Poeverlein gemachte Zusammenstellung der bayrischen Formen derselben (l. c. S. 102), ebenso die Durchsicht jeden grösseren Potentillen-Herbars. Ein genaueres Studium des in den Herbarien unter dem Namen P. aestiva zerstreuten Materials kann erst ergeben, unter welche bekannten Varietäten der P. verna oder ihrer Bastarde sich dasselbe vertheilen lässt und ob es überhaupt nothwendig sein wird, eine eigene Var. aestiva beizubehalten. Für unsere sächsischen ,aestiva-artigen" Formen konnte ich bis jetzt stets einen engen Anschluss theils an unsere P. aurulenta, theils an irgend eine Opaca $\times$ verna-Stufe finden. Ich habe solche Formen überhaupt nur im Elbhügelland, also im Verbreitungsbezirk der P. opaca beobachtet. Es wäre sehr zu wünschen, dass auch anderwärts, wo die sogenannte P. aestiva vorkommt, genau darauf geachtet würde, ob sich in ihrem Gebiet nicht die P. opaca und unzweifelhafte Bastarde von dieser finden. Solche Beobachtungen über ihre geographische Verbreitung würden vielleicht wesentlich zur Aufklärung ihrer Stellung beitragen; doch müsste man sich hüten, anzunehmen, dass ein vereinzeltes Vorkommen derselben sehr fern von jedem Opaca-Standort, ohne weiteres gegen ibre Opaca - verna-Natur spräche, da es sich ja nicht um einen vorübergehenden primären Bastard, sondern um eine bereits gefestigte Species handelt, der andere Verbreitungsmittel zu Gebote stehen können, als jenem.

Man könnte nun noch die Frage aufwerfen, warum ich die P. aurulenta (resp. aestiva) nicht einfach als eine ursprünglich ohne Kreuzung entstandene Mittelspecies auffasse, die sich also neben der P. verna und der P. opaca gleichzeitig mit diesen aus einer Ur-Vernalis-Potentille heraus entwickelt habe, oder gar diese selber vorstelle. Das morphologische Resultat wird für uns ziemlich dasselbe sein, ob sich in dieser Species die Charaktere der I'. verna und der P. opaca nie getrennt, oder ob sie sich erst später durch Kreuzung jener Arten vereinigt haben; beides lässt sich durch $\mathrm{P}$. opaca - verna ausdriicken. Die Frage ist also eine rein theoretische, es kommt nur auf die genetische Auffassung an. Ich stütze mich für meine Ansicht, dass die Species ursprünglich, vor nicht gar zu langer Zeit, durch Kreuzung entstanden ist, besonders auf ihr Vorkommen in Sachsen, wo sie, wie die unbeständigeren Opaca $\times$ vernaBastarde, sich nur im Gebiet der P. opaca findet; denn es wäre doch sonderbar, wenn sie, seit unvordenklichen Zeiten unabhängig neben der $P$. verna und $P$. opaca bestehend, hier nie über das Gebiet der letzteren hinausgriffe, wie es ja $P$. verna thut. Schon ihre verhältnissmässige Seltenheit in den meisten Ländern spricht für ursprüngliche Bastardnatur. Wie früher bemerkt, zeigt sie zwar eine grosse Unabhängigkeit und gewisse Stabilität, und es ist kein Zweifel, dass die überwiegende Mehrzahl von Pflanzen in unseren Aurulenta-Colonien keine prinä̈ren Bastarde sind, sondern sich durch viele Generationen selbst fortgeptlanzt haben, andererseits aber scheint es doch, dass sie sich an isolirten Standorten, fern von den geschlossenen Colonien, hin und wieder noch immer von neuem durch Ḱreuzung bildet, so dass also der Zusammenhang der P. opaca - verna mit der P. opaca $\times$ verna durchaus nicht ganz abgebrochen ist. Wenn sich 
die I'. aurulenta nicht stets durch ihre grossen, sattgelben Blumen auszeichnete, wäre eine Grenze iberhaupt nicht zu ziehen, besonders wo man es nur mit Herbar-Exemplaren zu thun hat, iber deren Verhalten an ihren natiulichen Standorten man keine Kemntniss hat.

Es eribrigt noch, die Verbreitung der P. aurulenta in Sachsen anzugeben. Ihr Hauptgebiet sind die sonnigen Abhänge zwischen MeissenCöln bis Diesbar an der Elbe, ganz besonders in der Nähe von Zadel, wo sie im Mai grosse Strecken gelb färbt!!. Bei Diesbar steht sie mehr vereinzelt !!, ebenso zwischen Leckwit\% und der Schwedenschanze !!. (Noch weiter abwärts an der Elbe sammelte sie Ilerr Stiefelhagen bei Weinberge unweit Mühlheim jenseits der sächsischen Grenze !.) Sehr sehön besitze ich sie von Naundörfel bei Seusslitz! (Fr.), ferner sah ich sie rom Tunnel bei Oherau! (Hfm.). Sehr rerbreitet ist sie in der Lössnitz zwisehen Köötzschenbroda und Lindenau !!, Himmelsbusch !!, Friedensburg !!, Lössnitzgrund !!, Niederwartha !!. In der Nähe der Spitzgrundmühle bei Coswig !! - Recht auffallend ist mir ihr Fehlen an den Hängen des Plauen'schen Grundes, die so reich an den gewöhnlichen kleinblüthigen Opaca $<$ verna-Bastarden (darunter auch drüsenlosen) sind.

\section{Potentilla arenaria Borklı.}

\section{(I'. incana Mnch. P. cinerea auct, non Chaix.)}

Die P.arenaria unterscheidet sich sowohl von P. opaca als auch ron 1'. verna bekanntlich leicht und sicher durch den dichten Filz von Sternhaaren auf der Unterseite der Bläter. In ihren übrigen Hauptmerkmalen, also im Wuchs und in der Gestalt der Nebenblättchen an den Wurzelblättern, kann sie kaum von der P. verna unterschieden werden, dagegen theilt sie mit der P. opaca die Eigenschaft, dass sie bald rlïisenlos, bald drüsenreich auftritt. Die forma eglandulosa soll die hänfigere sein. Da ist es nun gewiss interessant, zn erfahren, dass wir in Sachsen nur die forma glandulosa besitzen, und zwar glandulosissima! während z. B. Poeverlein für diese Form in ganz Bayern nur drei Standorte (einen bei Regensburg und zwei in der Pfalz) namhaft machen kann*). Die Drüsenhaare besitzen ganz dieselbe Form wie bei

*) Freilich sind noch nicht alle Herbar-Exemplare ron den vielen Standorten. die er für die forma eglandulosa anfzählt, mikroskopisch nutersucht, wie er selbst sagt, und es ist nicht ausgeschlossen, dass die f. glandulosa doch anch in Barern und sonstwo liäutiger auftritt als man glaubt. Bei der Untersuchung der P. arenaria ist das Mikroshop noch unentbehrlicher als bei der P. opaca, weil die kurzen Stieldriisen oft zwischen dem dichten Sterntilz verstecht sitzen. Ich entuahm meinem Herbar 15-20 Bogen der P. arenaria aus folgenden Lïndern: Brandenburg. Ostprenssen, Schlesien. Rheinland, Ober-(lesterreich, Polen, Galizien, mod die nikoskopische Revision ergab, dass ich mur von zwei Standorten die forma eglandulosa hesitze: von Warschan (leg. Karo) und ron steyr (leg. Zimmeter), aber hier zusammen in einem bogen mit f. crlandulosa! Sollten denin nur mir die driasigen Furmen zulaufen, oder sind sie in anderen Herbarien nicht beachtet worden? Hänfiger scheint die Far. Tommasiniana (F. Schml\%) jenseits der Alpen driisenlos vorzukommen; ihre f. glandulosa lesitze ich nur ron Porim in der Herzegorina nnd einem Punkt der französischen Seealpen, die f. eglandulosa dagegen ron mehreren Orten in Dalmatien (Karst). Triest, Travnik in Bosnien. Budapest. Die $P$. Clementi Jord. besitze ich sehr drïsenreich sowohl aus dem Dep. Drôme (loc. class.), als auch aus dem Dep. Isère. - Von der meist drüsenveichen P. Gaudini Grml. war schon frïher die Rede. 
der P. opaca, hie und da sind sie sehr lang, hie und da ziemlich kurz und dann schwerer zu sehen. Von anderen Formen kann man noch eine forma grandiflora und eine f. parviflora unterscheiden; die erstere besitzt schöne Blumen fast von der Grösse wie bei P. verna Amansiana, bei der zweiten bleiben sie klein und die Kronblätter ïberragen kaum den Kelch. In Sachsen besitzt die P. arenaria gewöhnlich plat y petale Blüthen, doch treten da, wo die Pflanze in Ilenge wächst (z. B. Abhänge bei Schieritz), zwischen den platypetalen auch vereinzelte sehr stenopetale Individuen auf.

Man hat bei der P. arenaria die Pflanzen mit vorherrschend dreizähligen Blättern als Var. trifoliata (Koch und Lehmann), trisecta (Scholz), oder f. triphylla und f. partula (Blocki in schedis) unterschieden. Aber ich glaube, dass man unter diesen Namen, wenigstens unter dem ersten, mit Unrecht Formen von verschiedenem Werthe zusammengefasst hat, nämlich theils blosse unbeständige Standortsformen theils eine höher einzuschätzende Varietät oder Rasse. Ob auch Koch und Lehmann ihre Var. trifoliata so verallgemeinert wissen wollten, scheint mir noch zweifelhaft $z u$ sein, denn sie sagen beide nur: ,foliis omnibus ternatis, raro quaternatis quinatisve" und geben keine besonderen Standorte für sie an. Ėrst Zimmeter (I, S. 24) beschränkt sie (als Synonym) auf die südliche, transalpine Varietät oder Rasse, welche F. Schulz P. Tommasiniana genannt hat, und giebt für sie die Standorte: „Oestr. Littorale, Karstgebiet bei Triest, Pola, Süd-Ungarn". Sie fand sich unterdessen auch weiter am Rande der Südalpen bis Ligurien, durch Bosnien und die Herzegovina verbreitet. Zimmeter bemerkt dann bei der P. arenaria, dass sich „mitten unter fünfblätterigen Exemplaren auch nur dreiblätterige finden", ohne für letztere einen besonderen Namen vorzuschlagen. Nach den Behaarungsverhältnissen zu urtheilen, scheint mir die durchgehends dreiblätterige P. Tommasiniana der P. arenaria Borkh. gegeniiber eine ähnliche Stellung als Rasse zu behaupten, wie im südwestlichen Europa die ebenfalls fast stets dreiblätterigen $P$. Clementi Jord., $P$. vestita Jord, und $P$. velutina Lehm. gegenüber der $P$. cinerea Chaix. (non auct.), wenn man die letztere mit Petunnikor als eigene, der $P$. arenaria Borkh. gleichwerthige Species betrachtet. - Jedenfalls empfiehlt es sich nun, den Namen Var. trifoliata Koch nicht für unsere hin und wieder auftretenden Pflanzen der P. arenaria mit vorherrschend dreizähligen Blättern anzuwenden, sondern diese als forma trisecta (Scholz) zu bezeichnen. So that auch Ascherson in Flora des norddeutschen Flachlandes, S. 409. Soweit ich diese Form im Freien beobachten konnte, und selbst in manchen Herbar-Exemplaren, macht sie auf mich den Eindruck einer Kummer- und Hungerform von sehr sterilen Orten. So findet man sie vereinzelt, von schönen, kräftigen Pflanzen der gewöhnlichen P. arenaria umgeben, am Schieritzer Abhang auf fast nacktem Felsgrunde, mit sehr kleinen, ober- und unterseits dichtfilzigen Blättern und zugleich sehr kleinen Blïthen.

Ian hat bis jetzt der Form, Bezahnung und Beharung der Theilblättchen bei P. arenaria wenig Beachtung geschenkt, wenigstens auf die darauf bezüglichen Unterschiede keine Varietäten gegründet, wie bei der P. verna, und doch sind diese Unterschiede oft recht bedentend und kaum weniger ausgebildet als bei der letztgenannten Species. Die Lnterseite ist wohl stets dicht mit Sternfilz bedeckt, aber die Oberseite kann ganz kahl (dann dunkelgrün) bis ebenfalls dicht sternfilzig (dann grau wie bei P. argentea var. incanescens) sein. Die Blättchenform ist äusserst variabel: entweder 
schwachlieilig-oboval, wie bei P. verna typical, oder stark-keilig und vorn verbreitert, wie bci P. verna Neumanniana, oder länglich und beiderseits allmïhlich verschmälert wie bei $P$. verua longifolia. Die Bezalmung ist entweder seicht und abgerundet (gekerbt), oder tiefer eingcschnitten und spitzlich; bald sitzen zahlreiche Zähne am ganzen Blättchenrand, bald nur wenige an der vorderen Ilälfte desselben. Von Danzig besitze ich eine P. alenalia. deren Blätter in Gestalt und Bezahnung vollständig denen einer typischen $P$. verna var. incisa gleichen. - lch will für jetzt keine Nenerung einführen durch Anfstellung analoger Varietäten wie bei P. verna, cinmal weil für unsere wenigen sächsischen Standorte auch nur wenige Formen zu verzeichnen wären, und dann weil ich den auf Blattschnitt und Bezahnung gegründeten Formen bei der P. arenaria ebenso wie bei der P. rerna, keinen hohen systematischen Werth beilege. Dies soll mich aber nicht hindern, den Specialisten dringend zu empfehlen, die angegebenen oder sonstige Abänderungen, ihr vereinzeltes oder massenhaftes Anftreten an gewissen Localitäten, ilıre Uebergänge ineinander u. s. w. scharf zu beobachten und Notizen darïber zu machen. Nit der Zeit wird es sich herausstellen, ob einige auffallende Abänderungen eine gewisse Stabilität oder eine bestimmte geographische Verbreitung zeigen und später mit besonderen Varietätsuamen hervorgeholsen zu werden verdienen. Vorläufig kann man sie ja in schedis als forma longifolia f. cuneifolia, f. crenulata, f. acutideus, f. incisa oder sonstwic passend (nur nicht mit Personen- oder Localnamen!) bezeichnen.

An dieser Stelle möchte ich einer Eigenschaft der l'. arenaria, wenigstens unserer forma glandulosa gedenken, die ich noch nirgends erwähnt fand. Es ist dies der eigenthuimliche streng-aromatische Geruch der lebenden Pflanze, besonder's während der Blithezeit, wie ich ihn von keiner anderen Potentille kenne. Auch die starkdrüsige P'. opaca riecht aromatisch, aber schwächer und milder. Dic P.arenaria glandulosa besitzt einen Geruch sui generis, der schwer zu beschreiben ist, den man aber nicht wieder vergisst und mit keinem anderen verwechselt. wemn man ihn cinmal empfunden hat. Er ist so stark, dass man ihn bei Schieritz in einer Entfernung ron 200-300 Metern von den von der P. arenaria ubberzogenen Abhängen noch sehr deutlich wahrummt, wenn an cinem warmen Mlaitag ein leise: Wind über das Blüthenmeer hinstreicht und das Parfüm in der Umgegend verhreitet. Dieser Geruch ïberträgt sich auch auf dic Arenaria-Bastarde, und es passirte mir melrmals, dass ich diese zuerst durch den Gernchssinn entdeckte, bevor ich sie gesehen. .. Hier riecht es nach Arenaria!" Ueber diesen Ausruf lächelten zwar hie und da meine Excursionsgenossen, wunderten sich aber doch über die Spürnase, wenn ich ihnen in kurzer Zeit den gefundenen Arenaria-Pastard vorführte. Es fragt sich nun, ob dieser Geruch der ganzen Species P. arenaria eigen ist, oder nur an der forma glandulosa haftet. also von den Drüsen ausgeht. Da wir hier die forma eglandulosa nicht besitzen, muss ich die Eutscheidung der Frage jenen Fachgenossen iiberlassen, welche Gelegenheit haben, diese auf ihren Geruch zu prüfen.

Die Verbreitung der $l$. arenaria beschränkt sich in Sachsen durchaus auf das Elbhïgelland ron Pirna his zur Landesgrenze bei Strehla, und anch in diesem schmalen Gebiet sind ihre Stanclorte nicht zahlreich. Der I)resden zunächst liegende bcfindet sich jun Lössnitzgrund an fast unzugänglichen Granitfelsen des Todsteins in der Nähe der Ncierei !!. 
Ilier sind ihre Tage gezählt, denn die fortschreitenden Steinbrucharbeiten dürften den wenigen Exemplaren dieser Localität bald ein jähes Ende bereiten. An anderen Orten der Lössnitz, z. B. bei Zitzschewig (Richb.) ist sie bereits verschwunden, ebenso bei Zadel, von wo ich sie im Leipziger Herbar in einem schönen grossblüthigen Exemplar sah (legit Römer, Apr. 1835 !). Es folgt in grossem Abstand unser Hauptstandort: die Abhänge zwischen Schieritz und Prositz im Thal des Lommatzschwasser's, wo sie in grösster Menge auftritt!! (gross- und kleinblüthig, mit oberseits graufilzigen bis ganz kahlen Blättern, auch in der forma trisecta). In einer kleinblüthigen und kleinblätterigen Form besitze ich sie von Priesa! bei Zehren, etwa 5 Kilometer südlich vom Schieritzer Standort (leg. F. Fritzsche). Der letzte linkselbische Standort befindet sich Diesbar gegenüber an den Felsen des Göhrisch!! (hier eine sehr schöne grossblätterige Form). Ob sie rechts der Elbe auch an den Felsen von Dieshar und Seusslitz noch jetzt vorkommt. bleibt festzustellen; mit Sicherheit habe ich sie erst etwas östlich von Diesbar, im Grunde von Blattersleben, spärlich nachweisen können!! (wahrscheintich der Heynhold'sche Standort, an Wegen zwischen Seusslitz und Grossenhain"). Unterhalb Seusslitz tritt sie an melireren Stellen an den Abhängen längs der Elbe auf, von Merschwitz!! bis zur Schwedenschanze!! und über das vom Fluss entfernter liegende Dorf Leckwitz hinaus!!. Herr Stiefelhagen sammelte sie bei Gohlis und Zeithain unweit Riesa am Rande von Kieferwäldern in der Nähe des MilitärSchiessplatzes! (zusanmen mit rerschiedenen Bastarden) und Herr Fritzsche bei Jakobsthal unweit Strehla hart an der sächsischen Grenze. - Jenseits der Grenze findet sie sich bei Weinherge unweit Mühlheim an der Elbe! (Stfg); ob sie noch weiterhin in nordwestlicher Richtung der Elbe entlang vordringt und dort vielleicht mit anderen Verbreitungsgebieten in Fühlung kommt, konnte ich bis jetzt nicht in Erfahrung bringen.

Es sind also in ganz Sachsen nur etwa neun sichere Standorte für die P. arenaria nachgewiesen; dass sie aber vor nicht gar zu langer Zeit im Elbgau weit verbreiteter war als jetzt, dürfen wir als sehr wahrscheintich annehmen in Anbetracht der Hüufigkeit ihrer Bastarde an Orten, wo jetzt die echte P. arenaria auf weite Entfernungen fehlt, z. B. auf dem Kohlberg bei Pirna, im Plauen'schen Grunde, auf der Bosel, an vielen Orten der Lössnitz, - aber stets an Localitäten nit zahlreichen pontischen Florenelementen, wie sie bekanntlich die genannten besitzen. An sandigen Wegen im Föhrenwald zwischen Coswig und Spitzgrundmiihle fand ich so stark sternfilzige Superarenaria-Bastarde, dass ich bis heute noch zweifelhaft bin, ob sie nicht besser als echte Arenaria-Form angesehen würden. Es wäre dann dieser neue Standort den obigen beizufügen. Doch legt die starke und lange, ziemlich abstehende Behaarung an Stengeln und Blattstielen den Gedanken an eine Beeinflussung ron Seite der P. opaca oder P. aurulenta nahe. Ganz in der Nähe finden sich nämlich P. opaca f. glandulosa, P. aurulenta und P. aurulenta $>$ arenaria.

\section{Bastarde der Potentilla arenaria Borkh.}

Wie schon früher bemerkt wurde, bin ich - wohl mit der IIehrzahl der Potentillen-Forscher - der Ansicht, dass die Sternhaare ein Characteristicum der P. arenaria und ihres Formenkreises sind und der P. verna 
und ihrer Sippsehaft vollständig abgehen. Sobald wir eine $P$. verna var. stellipila zugeben, vereinigen wir beide Speeies, denn es bleibt dann kein einziges greif bares Nerkmal mehr für ihre Unterscheidung.

Alle meine Beobachtungen in Sachsen haben mich in meiner Ansicht nur bestätigt: niemals habe iel ausserhalb des Verbreitungsgebietes der P. arenaria (Elbhiigelland) ein Sternhaar oder anch nur ein ,halbbüschelförmiges" Haar (Zackenhaar) an den Blättern einer P. verna oder I', opaca beobachtet, dagegen sind solche an unseren Vernales-Potentillen des Elbgaues eine ebenso gewöhnliche lirscheinung als die Drüsen, und zwar meistens unter Umstïnden, welehe kaum einen Zweifel zulassen, dass sie ihr Dasein einer Krenzung der I'. arenaria mit einer Verna- oder OpacaForm verdanken*). Man kam auf's dentlichste verfolgen, dass das Sternhaar der arenaria an den Bastarden nicht nur seltener, sondern anch in dem Grade zum Zackenhaar und schliesslich zum einfachen Striegelhaar umgeformt wird, als die PAlanzen sich mehr und mehr (durch Riickbastardirung) der $\mathrm{P}$. verna oder der $\mathrm{P}$. opaca nähern. An eine $\mathrm{P}$. verna stellipila kömnte man allenfalls denken, wenn plötzlich an einer P. verna vereinzelte vollkommene Sternhare aufträten ohne weitere Anzeichen eines Bastarls; dies ist aber - wenigstens soweit meine Untersuchungen reichen niemals der Fall. Ein weiteres Anzeichen, dass wir es mit Bastarlen und nicht mit Verna-Formen zu thun haben, ist der Umstand, dass fast immer die reichlichen Driisenhaare der P'. arenaria auf den Bastard ïbergehen (ïhnlich wie bei den Opaca $\times$ verna-Bastarden). Sodann müsste man mit demselben Recht auch eine P. opaca var. stellipila aufstellen, was noch Niemanden eingefallen ist; denn diese Art befindet sich der P. arenaria gegenüber genau in demselben Fall wie die P. verna. Wir besitzen also in den Stern- und Zackenhaaren einen ausgezeichneten, nie versagenden Anhalt zur Erkennung der Arenaria-Bastarde und der Beurtheilung ihres jedesmaligen Verwandtschaftsgrades mit P. opaca und P. rerna. Freilich muss ich gleich beifuigen, dass hier nur das Nikroskop sichere Aufschliisse giebt, und besonders die unvollkommenen, oft spärlichen Zackenhaare nur mit seiner Hilfe erkannt werden können.

Das typische Sternhaar ler P. arenaria ist ein zusammengesetztes Trichom und besteht aus einer zelligen halbkugelförmigen Warze, aus welcher nach allen freien Rielıtungen bis über 20 kurze steife Striegelhärchen ausstrahlen, so dass es die Gestalt eines Sternes oder eines halbirten Seeigels erhält. Sehr gewöhnlich combinirt es sich nit dem gewöhnlichen Striegelhaar, indem sich ans der Nitte der Warze ein viel

*) Man hat Anstoss daran genommen, dass verna-ähnliche Formen mit stern- oder Zackenharen an Orten vorkommen. an denen gegenwärtio die reine T'. verna und reine P. arenaria oler eine derselben fehlen. Erstens wirl fiur lie meisten solcher Standorte noch eine genauere I)urehforschumg zu empfehlen sein, sothan ist zu berlenken, dass die Stammeltern nicht inmer in numittelbarer Nähe strhen mïssen, besonder's wenn es sich nicht mu vereinzelte Bastarde. sondern un ganze colonicu bandelt, die sich auf mbestimmte Zeit selbstständig erhalten mu fort jthanzen kömen. und emllich ist zu mutersuchen, ob nicht vielleicht durch fortschreitende Kintur des Bodens die stammelterm in jiingster Zeit relulängt worden sind, wie es hei mus in Sachsen stellenweise fast mit Sicherheit angenommen werden kamu (- wie manchen standort sah ich in den letzten 10 Jahren zu meinem Bedanem verschwinden! -). In südlichen Gegenten spielt die $\mathrm{P}$. Gandini dieselbe Rolle, wie bei uns die I'. arenaria mol veranlasst eine ganz analoge Bastardreihe; dort ist also auf die Yerbreitung dieser Subspecies zu achten. 
längeres und stärkeres Haar erhebt, das meistens stark der Blattspitze zuneigt, so dass der kurze, sammetartige Sternfilz der Blattunterseite wie mit langen Striegelhaaren bedeckt erscheint (Fig. 13a). - Bei den ArenariaBastarden vereinfacht sich nun das Sternhar zum Zackenhaar*) dadurch, dass sich die Sternstrahlen auf $10-2$ reduciren, dann entweder pinselartig beisammenstehen, oder, was am häufigsten der Fall ist, eine kleine Zackenkrone um den Fuss eines starken Striegelhaares bilden (Fig. 13b). Beim einfachsten Zakkenhaar reducirt sich die Krone auf ein einziges Zäckchen. - Bei den Zackenhaaren der Bastarde variren die Aeste in Länge und Stärke viel mehr, als bei den eigentlichen Sternhaaren der ech-

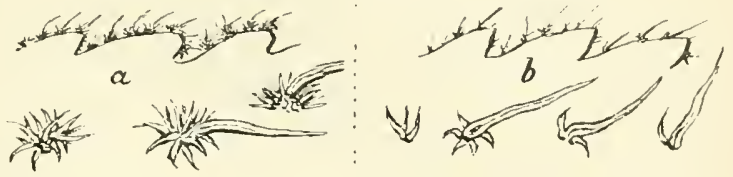

Fig. 13.

Stern- und Zackenhare (vergr.) a) bei $P$. arenaria Borkh., b) bei $P$. verna $\times$ arenaria.

ten P. arenaria. Je reichzackiger die Krone, desto dichter pflegen am Bastard die Zackenhaare zu stehen, man wird dann wenige ganz einfache Striegelhaare finden; umgekehrt tritt die Form mit nur 1 oder 2 Zacken spärlich zwischen der überwiegenden Mehrzahl einfacher Haare auf. Sie sind das letzte Zeichen, das uns einen entfernten ArenariaEinfluss bei einer verna- oder opaca-ähnlichen Form vermuthen lässt. Fehlen auch sie ganz, dann sind wir durch nichts mehr berechtigt, von Arenaria-Bastarden zu sprechen.

Ich möchte hier nur vor einem Beobachtungsfehler warnen. Auch die $P$. verna und opaca haben neben den langen Haaren gewölnnlich und oft recht dicht aber einzeln stehende kurze steife Härchen auf der BlattEpidermis. Betrachtet man nun den Blattrand, wie ich früher empfohlen, ohne Ablösung der Haare unter dem Mikroskop, so kann leicht die Täuschung entstehen, dass eines oder das andere der Härchen, welches einem grossen Striegelhaar sehr nahesteht, aus dessen Fuss entspringe. Man darf in solchen Fällen die Untersuchung nicht zu oberflächlich machen und muss sich durch eine stärkere Vergrösserung, eventuell durch eine complicirtere Untersuchungsmethode von der wahren Sachlage zu überzeugen suchen.

\section{Potentilla opaca L. $\times$ arenaria Borkh.}

\section{(P. rubens Zimm. $\times$ arenaria Borkh. P. subrubens Borb.)}

Bei der grossen Neigung der P. arenaria, sich mit der P. rerna und den Opaca $\times$ verna-Bastarden zu kreuzen, ist es auffallend, dass sie sich mit der reinen P. opaca nicht gern einzulassen scheint. Trotz eifrigen Nachforschens konnte ich bis jetzt in Sachsen nur eine einzige Localität

*) Ich gebrauche statt der jetzt üblich gewordenen Ausdriicke „bïschelförmige mud hallbbïschelförmige Haare" die kïrzeren Worte stern- und Zacken haare; das letztere. das sich mir unwillkïrlich beim häufigen Anblick der charakteristischen Zackenkronen anfdrängte, scheint mir mindestens ebenso hezeichnend zu sein, als das langathmige "halbbiischelförmige Haar" ( - wo bleibt dem iibrigens hei einem einzigen Zäckchen der Bïschel orler auch nur der halbe Biischel" -), und hat vor diesem jedenfalls dem Vorzug der Kürze. 
auftinden, an welcher (in unzweifelhafter Opaca $>$ arenaria-Bastard und zwar in schöner Mittelform auftritt, nämlich am oberen Theil des Ablianges von Schieritz, wo die P. opaca f. glandulosa in zienulich zahlreichen Stöcken von der P. arenaria dicht umdrängt wächst. Anch lier gelang es mir uur, ein par rereinzelte lixemplare des Bastards zu sammeln. Die lange, lichte, alstehende Jiehaarung der Stengel und Blattstiele, die Gestalt und Bezahnung der Blättchen, die kleinen dunkelgelben Bliithen, die zarten zurückgebogenen Blüthenstiele und der ganze Habitus der P'flanze lassen keinen Zweifel an der Betheiligung der P. opaca autkommen, wälnencl die dicht stehenden und schön ausgebildeten Zackenhaare auf Ober- und Unterseite der fünfzähligen Blätter eine starke Einwirkung der P. arenaria bekunden. Sehr merkwïrdig ist num, dass einer dieser jedenfalls primären Bastarde mitten zwischen nur sehr drüsenreichen Arenaria-l'flanzen vollständig driisenlos blieb, da doch zugleich auch die P. opaca von dort meistens stark drisig ist (ich fand in der Nibe nur ein drüsenloses Exemplar). Es scheint lier wirklich ein directer Beweis vorzuliegen, dass drïsen reiche Eltern ein drïsenloses Product liefern können. Die übrigen Bastarde der Localität sind drïsenreich. Wir haben also bei P. opaca $>$ arenaria eine forma glandulosa und eine forma eylandulosa zu verzeichnen, die letztere bis jetzt nur in einem Exemplar vertreten.

Ueber eine vermuthliche $P$. superarenaria $>$ opaca $f$. glandulosa in der Nähe von Coswig siehe am Schluss des Standortsverzeichnisses von P. arenaria, S. 89. Sie muss weiter beobachtet werden und wage ich noch kein endgiltiges Urtheil über sie abzugeben.

\section{Potentilla verma L. $\times$ arenaria Borkh.}

\section{(P. opaca Zimm. $>$ arenaria Borkh. P. subarenaria Borlo.)}

Der mit dieser Formel im allgemeinen bezeichnete Bastard ist im Elbhügellande - aber a uch nur in diesem Gau Sachsens - ebensu häufig und mannigfialtig als die P. opaca $>$ verna. Da unsere P. arenaria stets drisenreich ist, sind es auch ihre meisten Bastarle (nur selten ist eine f. eglandulosa zu verzeichnen); und da die Neigung der P. arenaria zu P. verua sehr stark ist und es auch an Riickbastardirungen nicht fehlt, finden wir alle möglichen Stufen oder Verwandtschaftsgrade zwisehen den beiden Stammarten. Wir erhalten also eine durchaus analoge Reilie von Bastarden wie bei der P. opaca $>$ verna und ich verweise auf das dort darüber Gesagte, um mich nicht zu wiederholen. Die Ausdrücke: P. verna $\propto$ arenaria, superarenaria $>$ verna, superverna $<$ arenaria, $f$. glandulosa oder $f$. eglandulosa bei jeder der Stufen, sowie var. oder $t$. incisa, longifolia etc. (je nuchdem sie in der Blattform anf diese oder jene Yarietät der I'. verna hinweisen) werden selbstvenständlich sein. Die längere Behaarung dieser Bastarde wird reine Verna- oder Arenaria-Behaarung, also angedrückt oder stark aufrecht-abstehend sein, die Nebenblätchen der Wurzelblätter sind lineal, lang ausgezogen. Der Verwandtsclaftsgrad oder die Stufe wird nach der Menge oder. Spärlichkeit der Stern- und Zackenhaare auf den Blättern, sowie nach der relativen Vollkommenheit oder Unvollkommenheit der letzteren zu beurtheilen sein. Eine P. superarenaria $>$ verna, auch die $P$. verna $>$ arenaria, wird selbst olne Mikroskop ziemlich leicht, eine P. 
superverna $>$ arenaria dagegen für gewöhnlich nur mit dessen Hilfe erkannt werden. - Auch bezüglich der Verbreitung der Verna $>$ arenaria-Bastarde finden wir die grösste Uebereinstimmung mit der der Opaca $\succ$ vernaBastarde: bald treten sie vereinzelt zwischen den Eltern auf, bald in kleinen Colonien, in deren unmittelbaren Nähe die P. arenaria gegenwärtig fehlt, aber nach allen Verhältnissen, besonders der ganzen Pflanzenassociation der Umgegend zu urtheilen, wohl sicher früher vorhanden war, wie z. B. auf der Bosel, im Plauen'schen Grunde, auf dem Kohlberg bei Pirna. Auch an den Zadler Abhängen, wo die P. aurulenta $x$ arenaria wächst, wurde die P. arenaria - längst ganz verschwunden - noch im Jahre 1838 gesammelt (H. Lips !). Die Existenz solcher isolirter Colonien und der Umstand, dass man in ihnen auch ganz junge Pflänzchen und Sämlinge antrifft, ist wohl ein sicheres Anzeichen, dass diese Bastarde sich lange Zeit selbständig erlhalten und fortpflanzen können, ähnlich wie die Opaca $\times$ verna-Bastarde unter gleichen V'erhältnissen.

Etwas sehr Auffallendes, das ich mir noch nicht genügend erklären kann, beobachtete ich im Wuchs und Habitus der Verna $x$ arenaria-Bastarde. $\mathrm{Nur}$ ausnahmsweise breiten sie sich durch lange, wurzelnde Triebe und Aeste rasen- und polsterförmig aus wie ihre Eltern (so fand ich sie am Hohen Stein über dem Plauen'schen Grunde, am Todstein im Lössnitzgrunde, am Abhange von Schieritz); gewöhnlich stehen ihre Stöckchen einzeln zwischen dem kurzen Gras umher, und ihre niederliegenden oder aufsteigenden Stengel zeigen kaum eine Tendenz zum Turzeln. Es erregt den Anschein, als ob man es meist mit jungen Pflanzen zu thun habe. Auch bleiben die Wurzelblätter gewöhnlich kurz und klein, so dass sich die spärlichen Stengel sehr weit über sie hinaus erheben (vergl. Hofmann, Pl. crit. Sax. fasc. VI, No. $\left.144[1901])^{*}\right)$. Diese kleine und auffallende Tracht bewalıren oft noch solche Formen, die sich (durch Rï̈ckbastardirung) der $P$. verna schon wieder so weit genähert haben, dass man den Arenaria-Einfluss nur noch an spärlichen, sehr unvollkommenen Zackenhaaren unter dem Mikroskop nachweisen kann (sie entsprechen morphologisch der Formel: P. (superverna $>$ arenaria) $>$ verna), so z. B. an mehreren Stellen bei Skassa unweit Grossenhain (ausgegeben von Hofmann, Pl. crit. Sax. fasc. V1, No. 146 [1901|). - Während die Blüthen der Opaca $\times$ verua-Bastarde die ihrer beiden Eltern sehr oft an Grösse übertreffen, finde ich sie umgekehrt bei der P. verna $\times$ arenaria meistens bedeutend kleiner, als bei den Stammarten. - Dass bei uns die P. verna $\times$ arenaria ebenso häufig als die $\mathrm{P}$. opaca $\times$ verna als forma incisa bezeichnet werden kann, erklärt sich leicht durch die starke Verbreitung der entsprechenden Verna-Varietät in unserem Gebiet.

Die hauptsächlichsten Standorte der Verna $>$ arenaria-Bastarde lassen sich folgendermassen zusammenstellen:

P. verna $\times$ arenaria, a) f. glandulosa: Kohlberg bei Pirna!! auf dem Rücken hin an verschiedenen Punkten zwischen der Wirthschaft und der grossen Sandgrube. Sauberg bei Coschütz!! und Hoher Stein bei Plauen !! unweit Dresden. Todstein im Lössnitzgrund !!, Friedensburg bei Kötzschen-

*) Dieser anffallende Wuchs ist auch bei Herbar-Exemplaren noch erkennbar und fiel z. B. Herrn Poeverlein in den Hofmann'schen Exsiccaten sofort auf (nach briefl. Mittheilung); er vergleicht ihn sehr zutreffend mit dem der P. alpestris Var. firma (P. verna Zimm.). 
broda !!, Coswig !!, Grund ron Blattersleben !!, Skassa bei Grossenlain ! (Ifm.), Zeithain bei Riesa! (Stf.), Jakobsthal und Burxdorf bei Strehla! (Fr.).

b) f. cglandulosa: Auf der Bosel, mehrorts gegen die Boselspitze zu!!, Friedensburg bei Közzschenbroda! (Hfm.), Sehieritzer Abhang !!, Zeithain ! (Stf.), ist zugleich var. hirsuta. - (Schlossberg bei Teplitz in Böhmen !!, Hippe's P. Neumanniana.)

P. superveru: > arenaria, a) f. glandulosa: Hoher Stein bei Plauen !!, Todstein im I „ossnitzgrund !!, Ilimmelsbusch bei Kötzsehenbroka !!, Grund von Blattersleben!(Hfm.). Skassa bei Grossenhain !!, Merschwitz an der Elbe !!.

b) f. eglandulosa: Kiohlberg bei Pirna!!, Himmelsbusch !!, Bosel !!, Cölln bei Meissen! (Hfm.), am Collmberg bei Oschatz! (Fr.)*).

P. superarenaria $>$ verna, $f$. septenata glandulosa. Unter dieser etwas langen Formel will ich einen höchst auffallenden Bastard erwähnen, der am Felsen des 'lodsteins im Lössnitzgrund liart neben der P. arenaria in einem grossen Rasen wuehs!! und ron Herrn Stiefelhagen mit Lebensgefahr von ihrem Standort herabgeholt wurde. Die kleinen goldgelben Blüthen und die häutig sechs- bis siebenzähligen Blätter liessen zunächst die Betheiligung der P. opaca vermuthen, allein die Behaarungsart, die Form der 'Theilblättchen, der ganze Wuehs und Auderes spricht entsehieden dagegen. Die längeren, stranm anliegenden Haare an Sitengel und Blattstielen lassen nur an P. rerna und arenaria denken; das ganze Blatt erimnert an kleine sechs- bis siebenzählige Blätter der I'. verna var. Neumanniana, während die einzelnen Theilblättchen mit ihren seichten, abrerundeten 'Z̈̈hnen auch der Var. Amansiana angehören könnten. Die Blattoberseite ist auffallend dunkelgriin und ziemlich dicht mit anliegenden, seidensehimmernden Striegelhärchen bedeckt, anch auf der Unterseite liegt der Filz von Zackenhaaren unter langen Striegellaaren verborgen. Die ganze Pflanze ist - auch an den liättern - ausserordentlich driisenreich und verbreitete lebend den stärksten Arenaria-Geruch. Die dichtstehenten, wohlausgebildeten Zackenhare der Blattunterseite beweisen eine sehr starke Betheiligung der P. arenaria, um so merkwürdiger ist das Vorherrschen sechs- his siebenzähliger Blätter, die bei letzterer bekanntlich ausserordentlich selten vorkommen, sowie ihr sehr abweichender Habitus von der unmittelbar neben ihr stehenden P. arenaria. Die P'llanze hatte an $\%$. Mai 1898 zahlreiche Frichte angesetzt. Seit 3 Jahren eultivire ich sie in Garten, leider olne sie bis jetzt wieder zur Blühe zu bringen, während die echte P. arenaria vom Todstein neben ihr jedes Jahr reichlich blïht.

\section{Potentilla opaca $\mathbf{L}_{\text {. }} \times$ verna $\mathbf{L}_{\text {. }} \times$ arenaria Borkh.}

Die Aufstellung ron Doppel- und Tripelbastarden ist meistens ein etwas gewagtes Unternehmen, besonders wenn man sich erkühnt, zugleich den Bildungsgang eines solchen bastardes genauer zu bezeichnen, also

*) Dieser Standort ist ler von der Elbe entfernteste, ron welchem ich bis jetzt in Sachsen einen Alenaria-Bastard beobachten konnte; er liegt ca. 17 Kilometer rom Elbstrom bei strehla, wo sich zugleich die ihm nächstliegenden bekannten ArenariaStandorte finden. Da aher lie Gegend ron Oschatz botanisch noch sehr wenig erforscht ist, so wissen wir nicht, wie weit sich dort die Verbreitungszone der echten P. arenaria dem Collmberg nähert. 
z. B. statt obiger Formel P. (opaca $\times$ verna) $<$ arenaria oder $\mathrm{P}$. opaca $\times$ (verna $\times$ arenaria) schreibt, was genetisch nicht dasselbe ist, obgleich das morphologische Endresultat in beiden Fällen kaum zu unterscheiden sein wird. Andererseits lässt sich gegen die Möglichkeit der Doppel- und Tripelbastardirung theoretisch kaum etwas vorbringen und in der Praxis drängen sich solche Gebilde unabweisbar auf. Entsteht nicht schon bei der Rückbastardirung, die kaum in Abrede gestellt werden kann, ein Doppelbastard? Was ist z. B. eine superverna $>$ arenaria anderes als eine $P$. verna $>$ (verna $\times$ arenaria $)$ ? Die Kreuzung des Bastards geschieht hier allerdings wieder mit einer der Stammarten, allein die mit opaca kann für uns kaum befremdender sein, nachdem wir deren häufige Vereinigung mit P. verna kennen gelernt haben. - Man könnte nun fragen, ob eine P. opaca $>$ arenaria oder eine opaca $>$ superarenaria nicht ebenso aussehen würde, als eine opaca $\times$ verna $>$ arenaria, da wir doch von der P. opaca nur die lange, austehende Behaarung und ron der P. arenaria die Stern- oder Zackenhaare mit Sicherheit ableiten können, die übrigen Merkmale aber ebenso gut durch opaca $\times$ arenaria als durch opaca $\times$ verna erklären könnten ( - P. verna und arenaria sind ja, abgesehen von den Sternhaaren, kaum zu unterscheiden -). Darauf antworte ich, dass man allerdings bei Herbar-Exemplaren, deren Standortsverhältnisse man nicht kennt, in vielen Fällen in Zweifel bleiben kann, ob eine P. opaca $>$ arenaria, oder eine $\mathrm{P}$. opaca $\times$ verna $>$ arenaria, vorliege, dass aber in den von mir aus Sachsen anzuführenden Fällen eine Mitbetheiligung der P. verna mehr als wahrscheinlich ist. Ich stiitze mich dabei auf folgende Beobachtungen: Die bei uns spärlich vorkommende unzweifelhafte P. opaca $\times$ arenaria (von Schieritz) zeigt einen ganz anderen Habitus als die Bastarde, von denen hier die Rede ist, und einen ganz verschiedenen, der P. opaca nahestehenden Blattschnitt. Bei unseren Opaca $\times$ verna $x$ arenaria-Bastarden herrscht die $\mathrm{P}$. opaca $\times$ verna so stark vor, dass man sie makroskopisch ohne Bedenken zu diesen stellen würde, wenn nicht das Mikroskop die Zackenhare auf der Blattunterseite nachwiese, und zwar kommen sie meistens in der ausgesprochenen forma incisa vor, die ich nur von einer $P$. verna var. incisa, durchaus nicht von einer P. opaca oder arenaria ableiten kann. Endlich bastardirt die P. arenaria sehr gern mit der P. aurulenta, wie wir noch sehen werden, und so dïrfen wir wohl anmehmen, dass dieselbe Neigung auch zu den der P. aurulenta genetisch so nahe verwandten Opaca $>$ verna-Bastarden bestehe, innerhalb des Gebietes von diesen, wo sie sich in der That finden.

Natürlich kommen auch bei den Doppel- und Tripelbastarden - und bei ihnen noch mehr als bei den einfachen - verschiedene Stufen oder Verwandtschaftsgrade vor, welche durch die entsprechenden Formeln ansgedrückt werden können, ebenso die f. glandulosa und eglandulosa, die f. incisa, longifolia u.s. w. - Dass die Formeln hier oft sehr lang werden können oder müssen, ist bedauerlich, aber unvermeidlich, wenn man sich präcis ausdrücken will; sie sind inmer noch besser, als ein nichtssagender binärer Name, der uns über die Stellung einer Pflanze ganz im Unklaren lässt. Nur müssen wir Eines bedenken: solche Formeln köonnen nur Anspruch auf morphologische Genauigkeit, in den wenigsten Fällen aber auf absolute genetische Richtigkeit machen; eine Pflanze könnte daher auf mehrere Weisen morphologisch richtig bezeichnet werden, genetisch 
nur alif eine, wenn uns diese eine Entstehungsart bekannt wäre. Un ein einfaches Beispiel zu wählen: eine $P$. superverna $\times$ arenaria macht den Eindruck, als ob eine P. verna $>$ arenaria sich mit einer P. verna gekreuzt hätte und man kann diesen Gedanken mit P. verna $>$ (verma $>$ arenaria) ausdruicken; es ist aber nicht ausgeschlossen. dass sich schon bei der ersten Kreuzung der P. verna mit der P. arenaria ein Bastard bildet, welcher der P. verna viel nïher steht als der P. arenaria und genau das Bild einer superverna $x$ arenaria hervorbringt, in welchem Fall also obige Formel nur morphologisch, nicht aber genetisch cinen richtigen Begriff der Pflanze gäbe. Da wir bei complicirten Bastarden in so vielen Fällen den Eutstchungsgang nur ahnen, alıer nicht sicher feststellen können, wäre es eigentlich richtiger, statt der $\times$-Zeichen - Zeichen einzuschalten; doch können wir meines Erachtens die Bastardzeichen vorläufig beibehalten, wenn wir uns nur bewusst blciben, dass wir damit wur dic morphologische Combination geben wollen. - Bei langen Formeln stellt sich hier auch noch die Unbequemlichkeit ein, durch Anwendung von super- das Vorherrschen des einen oder anderen Theiles hervorzuheben, und da wäre es angebracht, statt dessen das Zurücktreten der P. arenaria mit sub- zu bezeichnen, besonders da eine Verwechshung mit der P. subarenaria Borb. (= verna $>$ arenaria) morphologisch kaum ins Gewicht fiele. Wir haben z. B. eine P'. superverna $\times$ opaca, die ron $P$. arenaria nur wenig beeinflusst ist, statt nun zu sagen P. super-(superverna $>$ opaca) $X$ arenaria, scheint es mir besser zu schreiben: P. (superverna $>$ opaca) $>$ subarenaria; beides besagt ja dasselbe.

Es wäre zwecklos, hier alle möglichen Stufen und Formen der Opaca $x$ verna $x$ arenaria-Bastarde mit ihren Formeln herzusetzen, die letzteren lassen sich ja in jedem concreten Fall leicht und morphologisch richtig aufstellen. Ich will mich darauf beschränken, die mir in Sachsen bekannt gewordenen Formen anzuführen:

P. (opaca $\times$ verna) $>$ arenaria, $f$. glandulosa. Eine sehr sehöne und typische Form, in der die 3 Arten so ziemlich im Gleichgewicht stehen, in einem Steinbruch bei Skassa mweit Grossenhain!!

P. (opaca $\times$ verna) $\times$ subarenaria, f. incisa, glandulosa. Im Grund ron Blattersleben !!. An Felsabhïngen unterhalb Merschwitz an der Elbe!!.

P. (superverna $\times$ opaca) $\times$ subarenaria, f. parce glandulosa. Vereinzelt im Grund von Blattersleben!! mit der vorigen.

P. (superverna $\times$ opaca) $>$ arenaria, $f$. inciso-longifolia, parce glandulosa. An den Abhängen unterhalb Merschwitz an der Elbe!! ziemlich zahlreich.

P. (superverna $\times$ opaca) $>$ superarenaria, f. incisa, glandulosissima. Abhänge unterhalb Merschwitz an der Elbe! (Hfin.).

Der an erster Stelle aufgeführte, ziemlich grosshlüthige Bastard von Skassa hat schon eine grosse Aehnlichkeit mit der nun folgenden P. aurulenta $>$ arenaria. Andererseits kömnte man auch vielleicht einige $z u$ letzterer gezogene, wenig grossblïthige Formen noch zu der P. (opaca $\times$ verna) $>$ arenaria stellen, Eine scharfe Grenze ist hier ebenso wenig zu ziehen, als zwisehen P. aurulenta und P. opaca $>$ verna. 


\section{Potentilla aurulenta Grml. $\times$ arenaria Borkh.}

\section{(P. [opaca - verua $] \times$ arenaria. P. aestiva $>$ incana Poeverl. p. p.)}

Das Meiste, was im vorlergehenden Abschnitt über die P. opaca $x$ verna $x$ arenaria ansgeführt wurde, gilt auch für die $P$. aurulenta $x$ arenaria, so dass ich mich hier kurz fassen kann. Der Unterschied besteht darin, dass wir hier mit grosser Sicherheit die Verbindung der P. arenaria mit der vorhandenen, zur Species gewordenen P. opaca - verna behaupten können, dass also die Formel auch im genetischen Sinn richtig ist und z. B. der Ausdruck P. opaca $>$ (verna $>$ arenaria) falsch wäre. Ich kenne den Bastard bis jetzt nur von Standorten, an denen zugleich die P. aurulenta wächst, er scheint eng an diese gebunden zu sein. Die grossen Blüthen unterscheiden ihn sofort ron den Opaca $<$ verna $>$ arenaria-Bastarden. Die üblichen Abstnfungen bezüglich der Betheiligung der P. arenaria, sowie die Formen glandulosa und eglandulosa giebt es auch hier, im übrigen aber, in der Behaarung, im Blattschnitt, siebenzählige Blätter u. s. w. bleibt der ganze Aurulenta-Charakter und -Habitus, wie er frïher beschrieben wurde, gewahrt, was besonders bei den dicht mit Sternfilz bedeckten Formen auffält, welche nach diesem Kennzeichen als P. aurulenta $\times$ superarenaria bezeichnet werden müssten.

P. superaurulenta $\times$ arenaria, f. glandulosa, von der P. aurulenta nur durch das Mikroskop zu unterscheiden, sammelte Herr Fritzsche (!) in einem Grund zwischen Lindenau und Zitzschewig in der Lössnitz. Dieselbe, aber in der $f$. eglandulosa, fand sich am Abhang von Zadel! (Hfm.); und als $f$. parce glandulosa bei Coswig im Spitzgrund!!.

P. anrulenta $>$ arenaria, mit starkem und sehr starkem Sternfilz auf der Blattunterseite, fand sich in der $f$. glandulosa: auf dem Himmelsbusch bei Kötzschenbroda!! In der Nähe der Spitzgrundmühle bei Coswig!! (hier zum Theil parce glandulosi). - In der f. eglandulosa: vor allem an den von P. aurulenta bedeckten Abhängen bei Zadel!! bis zur Karpfenschänke in der Nähe von Meissen!!, wo sie Herr Hofmann an einem felsigen Abhang zu tausenden fand und ron wo er sie in Pl. crit. Sax. fasc. VI unter No. 147 (1901) ausgab. Ferner in der Lössnitz im Hohlweg zwischen Naundorf und Lindenau!! und bei der Spitzgrundmïhle unweit Coswig !!.

\section{Potentilla anserina $\mathrm{L}$.}

Diese jedem Anfünger bekannte Art gehört, wie in den meisten mitteleuropäischen Ländern, so auch in Sachsen, vielleicht mit Ausnahme des höchsten Erzgebirges, zu den verbreitetsten der Gattung und findet sich fast allenthalben anf Grasplätzen, Wiesen, Triften, an Wegrändern und Strassengräben, besonders häufig in und um Dörfer. Standortsangaben für die Species im allgemeinen sind hier überflüssig; allein sobald man solche für ihre verschiedenen Varietäten angeben soll, kommt man in Verlegenheit, weil dieselben fast gar nicht beachtet werden und deshalb in den meisten Herbarien fehlen. Wie Hancher giebt sich damit zufrieden, dass ein so ,gemeines" Ding in einem einzigen, dazu noch defecten Exemplar in seiner Kräutersammlung vertreten ist! Die P. anserina theilt dieses Loos mit vielen anderen, "gemeinen" Pflanzenarten, trotz ihrer schönen 
goldgelben Blïthen, welche zu den grössten dieser Gattung gehören. Ich will hier wenigstens auf ihre Hauptrarietäten aufmerksam machen.

Die typische, gemeine I'. anserina, die Lehmann mit Walhoth Var. discolor namnte, hat oberhalb grine, unterhalb weiss-seidig beharte Blätter.

Die Var. concolor Wallr. (Zimm. als Art, sericea Hayne) besitzt beiderseits weiss-seidig behtarte libitter. Typisch scheint sie bei uns selten vorzuliommen; ich sammelte sie nur am liande eines trockenen líeferwaldes bei Coswig!!, sodann sal ich sie aus dem (irossen Gehege bei Dresden! (leg. Dr. Rich. Schmidt 1879). Uebergänge zu der Var. discolor sind dagegen nicht selten, besonders auf trockenem Sandboden. Ich möchte unsere Floristen ersuchen, nach ihr auch auf Sumpfwiesen zu suchen. denn sie kommt merkwürligerweise nicht nur an sehr trockenen, sondern auch an sehr nassen Orten vor. So fand ich sie ror einigen Jahren sehr schön in einem Sumpf bei Nauheim in der Wetteran. Aus Sachsen ist sio mir von einem nassen Standort noch nicht bekannt.

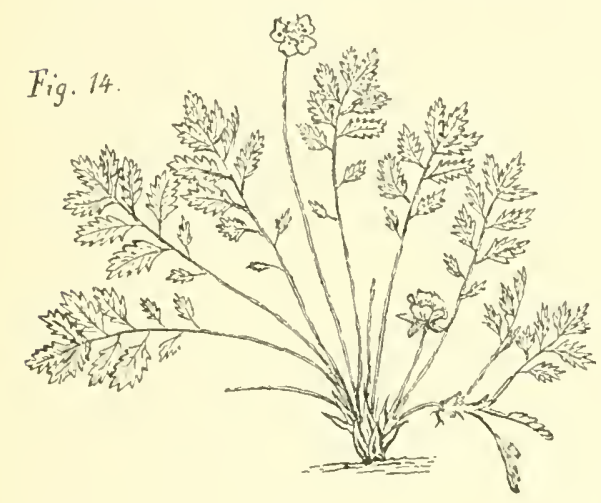

Fig. 14.

Die Var, virilis Koch ('/imm. als Art) ist schwach behaart und hat beiderseits grüne Blätter. Ich habe sie, trotz eifrigen Suchens in Sachsen noch nicht anfgefunden und sie ist wohl anch anderwärts selten(Poeverlein l. c. s. 14).

Eine lar. geminiflora Koch, in Sachsen ebenfalls noch nicht beobachtet -, scheint mir kanm als Varietät, sondern nur als eine vereinzelt vorkommende Form (Missbildung?) ,pedunculis nomnullis bifloris" (Lehm.) gelten zu dürfen. Zimmeter liess sich nicht abhalten, auch sie, wie die beiclen vorhergehenden Varietäten mit besonderen

P. anserina L. Tar. minima Peterm. Nat. Gr. nach Original- Exemplaren Petermann's.

Var. minima Peterm. (in sched.). Artemmanen und unter besonderer Nummer von der P'. anserina getrennt aufzustellen.

Yar. minima Peteme (in schen.). Diese ansserordentlich zierhelre, nur etwa 4 Centimeter holne Zwergform hat ausser ihrer Kleinheit noch andere Eigenthümlichkeiten, so dass sie mindestens mit demselben Recht wie die vorhergehenden als besondere Varietät aufgefiihnt zu werden verdient. Petermann beschreibt sie weder in seiner llora lipsiensis noch in seinem analytischen Schlïssel, denn er sammelte sie crst nach dem Erscheinen dieser Werke, im Jahre 1849 zwischen Kö̈tzschlitz und Dölkan an der Strasse Leipzig-Nerseburg. Der Standort liegt schon ca. 3 Kilometer jenseits der heutigen sïchsischen Grenze, ist also preussisch, aber wir besitzen vielleicht die cinzigen existirenden Original- Exemplare in Pet ermann's II erbar zu Leipzig. Ich finde die Varietät noch nirgends erwähnt, habe auch nie etwas Aehnliches gesehen. Sehr erstaunt wal ich, dass die Diagnose, welche Lehmann (Rev. P'ot. S. 100) ron der I. anserina r) groenlandica Torr. und (iray giebt, wörtlieh auf sie passt: ,foliis paucijugis multo minoribus, foliolis pinnatifido-incisis." Doch stimmen Ilerbar-Exemplare 
von dieser aus Labrador durchaus nicht mit unserer kleinen Varietät überein, und nähern sich im Habitus viel mehr der typischen P. anserina.

Es liegen mir 7 kleine Pflänzchen, möglicherweise Theile ein es grösseren Stockes vor; die Wurzeln fehlen, denn die Pflänzchen sind unmittelbar unter dem Wurzelkopt abgeschnitten, und jedes besitzt einen Schopf langgestielter Wurzelblätter. Es sind nur 2 kleine Blüthen vorhanden und diese scheinen direct aus dem Wurzelstock zu entspringen; von den kriechenden Stengeln bemerkt man erst ein paar kaum 2 Centimeter lange Anfäuge ınit ein em Internodium. Die ganze Pflanze ist sehr spärlich behart, auf der Oberseite der Blätter fast kahl, und nur auf deren Unterseite stehen die langen Haare etwas dichter. wodurch sie schwach graulich-schimmernd wird. - Das Auffallendste ist nun die Blattform selbst. Während sonst bei der P. anserina der Blattstiel kurz und die gefiederte Blattspreite viel länger als dieser zu sein pflegt, ist bei der Var. minima das Verhältniss umgekehrt: Die zarten Blattstiele sind im Durchschnitt 3 Centimeter hoch, die gefiederten Blattspreiten dagegen nur 1 bis höchstens 2 Centimeter lang und $1 / 2-{ }_{3}$ Centimeter breit. Das Blatt ist uur drei-bis fünfpaarig gefiedert (bei der gewöhnlichen P. anserina vielpaarig) und von den kleinen 2-4 Iillimeter langen, keilig-obovalen Fiederchen sind die unteren und mittleren deutlich gestielt (bei den anderen Varietäten sitzend) und nur die beiden obersten mit keilig zulaufeuder Basis sitzend. Die sonst vorhandenen kleinen Zwischenfiederchen fehlen hier ganz. Die Blïthenstiele sind so lang als das Blatt, aus dessen Achscl sie entspringen, die Blüthe selbst ist klein, etwa wie bei einer kleinblüthigen $\mathrm{P}$. verna; die Kronblätter überragen kaum die Kelchzipfel.

Leider hat Petermann keine Notiz über die Standortsrerliältnisse dieser hochinteressanten Varietät hinterlassen, nicht einmal die Zeit des Einsammelns ist notirt, doch dürfte diese eine verhältnissmässig frühe sein, da die verlängerten Achisen noch fehlen. Das weitere Nachforschen nach ihr oder ähnlichen Zwergformen sei unseren Botanikern dringend empfohlen!

Mit der P. anserina sind wir bereits in die Abtheilung der Potentillae axilliflorae eingetreten, welche sich von den früher besprochenen Arten weit entfermen. Sie wurden ron Focke in 2 Gruppen getheilt, die er Chenopotentilla und Tormentilla nannte. Während die erstere bei uns nur durch P. anserina repräsentirt ist, besitzen wir von der letzteren mehrere Species und Bastarde.

Der Formenkreis der Tormentilla-Gruppe wird auf der einen Seite von der typischen $P$. Tormentilla Sibth. (Tormentilla erecta L.) und auf der anderen von der typischen P. reptans L. begrenzt. Diese zwei guten alten Arten, welche morphologisch und biologisch scharf von einander getrennt erscheinen - Limé brachte sie sogar in zwei verschiedenen Gattungen unter - und in ihrer typischen Ausbildung auf den ersten Blick unterschieden werden, sind nichtsdestoweniger durch eine lange, ununterbrochene Reihe von Zwischenformen eng miteinander verbunden, deren Deutung and Charakterisirung den Floristen oft nicht geringe Schwierigkeiten bereitet, da ihre Unterscheidungsmerkmale ungemein variren und in weiten Grenzen hin- und herschwanken. So streng sich die Arten der ganzen Gruppe gegen eine Berührung oder Beeinflussung von Arten irgend einer anderen Potentillen-Gruppe abschliessen, so locker ist ihr Gebahren 
unter sich; sie bihlen Bastarde rerschiedener drt und diese vermehren nicht wenig den durch die Variabilität der Arten schon an und firr sich berlingten grossen Formenreichthum.

Fon 16 mittelenropäischen ,Arten" der Gruppe, d. h. Formen, welche Zimmeter in seinen beiden ersten Arbeiten mit binüren Speciesnamen und nutel besonderen Summern nebeneinander stellt - fast alle kommen auch in Sachsen ror - befinden sich nur drei, welehe den Namen Species verdienen: die zwei schon oben genannten $F$. Tormentilla Sibth. und P.reptans L., sowie die in der Mitte zwisehen ihnen stehende P. mocumbens Sibth., und drei zweifellose Bastarde: P. Tormentilla $<$ procumbens $(=\mathrm{P}$. suberecta Zimm.). P. procumbens $\times$ reptans (= I'. mixta Nolte) und I'. Tormentilla $\times$ reptans ( $=\mathrm{P}$. adseendens Grml.); alle iibrigen, also 10 , sind theils Varietäten oder unbedentende Formen der 3 Species und ihrer Bastarde, theils Riickbastardirungen der letzteren in irgend einer Richtung, also Doppelbastarde.

Es besteht eine grosse Wahrseheinlichkeit, dass die l'. procumbens ursprünglich ebenfalls aus einer Krenzung der P'. 'Tormentilla mit der P. reptans entstanden sei und sich im Laufe der Zeit unter gïnstigen Umständen und bei hinlänglicher Fruchtbarkeit so weit gefestigt und von den Stammarten unabhängig gemacht hahe, dass wir ihr den Rang einer (Vittel-) Speeies einräumen müssen und sie an erster Stelle nit einem binären Speciesnamen begrüssen dïrfen. Schon Grenier hïlt sie für eine P. supertormentilla $\times$ reptans; versehiedene Venere sind ähnlicher Ansicht und anch Poeverlein steht ihr sympatisch gegenüber (l. c. S. 31). Ich meinestheils zweifle nieht an der Entstehung dieser Art aus der P. Tormentilla und der P. reptans, nur wage ich den Verwandtschaftsgrad orter die Bastardirungsstufe zwischen beiden nicht so präcis festzustellen, wie Grenier. -- Wenn wir also die P. procumbens in genetische Verbindung mit den heiden extremen Arten setzen, so erhalten wir folgendes phylogenetisches Bild der Gruppe:

$$
\text { P. Torm. } x \text { procumb. }
$$

P. procumb. $\times$ reptans.

P. Tormentilla_- P. Torm. - reptans (mocumbens)_- P. reptans.

P. Torm. $\times$ reptans.

Leider ist mir eine wichtige Arbeit über die Bastarde dieser Gruppe von Swante Murbeck in der sehwedischen Zeitsehrift, ,Botaniska Notiser" 1890 his jetzt muzugänglich gebliehen, wie wohl manchem anderen Botaniker, der des Schwedischen nicht mïchtig ist. Im Vorhergehenden und Nachfolgenden gebe ich hauptsïchlich meine persönlichen Ansichten iiber clieselben, wie ich sie bis jetzt durch eigene Beobachtung gewomen habe.

Aus praktischer liücksicht werde ich hier zuerst lie 2 Hauptspecies, damn die Mittelspecies und schliesslich die Bastarde besprechen.

\section{Potentilla 'Tormentilla Sibth.}

\section{(I'. silvestris Neck., P. erecta Zimm. p. p.. Tormentilla erecta L.)}

Ich fincle es nit Focke angebracht, dass man ,aus I'ictät", wenn auch nicht gegen Linné, so doch gegen den schönen und wie es scheint uralten Vulgiinamen ,Tormentill" — Linné wollte ihn als Gattungsnamen 
verewigen -, denselben in der Potentilla Tormentilla Sibth. (Nestl., Hartm., Maly, Ledeb., Gaud., Ser., Koch, Lehm., Focke et auct. plur.) erhalte, statt sich immer weiter zu zanken, ob diese P. erecta (nach Zimmeter) oder P. silvestris Neck. (nach Ascherson), oder sonstwie heissen müsse. Der letztere scheint ja, wahrscheinlich auf Ascherson's Beispiel hin, neuerdings mehr in Aufnahme zu kommen, während eine Zeit lang der vorletzte in Mode war. Dieser, nämlich der Name P. erecta Zimm. ist jedenfalls der unpassendste ron allen. Wir verdanken ihn natürlich wieder dem ,strikt durchgeführten Prioritätsprincip" (siehe Zimm. II. S. 9). Linné's Tormentilla erecta, die ja der Tormentilla procumbens gegenüber recht gut benannt war, muss zur Potentilla erecta werden, so will es Herr Zimmeter! Wann wäre es Linné eingefallen, neben einer Potentilla recta noch eine P. erecta aufzustellen? Zimmeter meint (1. c.), „eine Gefahr der Verwechslung sei wohl anch nicht ernst zu nehmen". Nun, dann hat wohl Nyman im Consp. flor. enrop. nur einen schlechten Witz machen wollen, wenn er die P. sciaphila Zimm. und P. strictissima Zimm. (Varietäten der P. Tormentilla) zu P. recta L, stellte? Was einem Nyman passirte, kam auch Anderen passiren. Doch diese „Gefahr" wäre in der That nebensächlich.

Zimmeter beruft sich zu seiner Rechtfertigung (II. S. 9) auf Beispiele in der zoologischen Litteratur, in der eine llenge derartiger ähnlichlautender oder gleichbedeutender Namen unbeirrt nebeneinander existiren. Sonderbare Logik! Also, wenn die Zoologen irgend eine Ungereimtheit begehen, müssen sie die Botaniker gleich nachmachen? - Dasselbe „Argument" hat man mehrfach zu Gunsten der Einführung jener unschönen und geschmacklosen Tautologie in die binären Speciesnamen (Scolopendrium scolopendrium, Linaria linaria, Radiola radiola etc.) vorgebracht: die Zoologen thun ja dassellue! - Fritz hat einen leichtsinnigen Streich gemacht und beruft sich dem mit Strafe drohenden Vater gegenüber auf Kar]: der hat's zuerst gethan! Die einzig logische Consequenz zieht der Vater: dann verdient Karl eben auch Hiebe! - Siehe den soeben erschienenen beachtungswerthen Artikel von Dr. Hans Hallier: "Das proliferirende, persönliche und das sachliche, conservative Prioritätsprincip in der systematischen Ontologie", in Potonié's Naturwissenschaftl. Wochenschrift Bd. X VI. No. 12 (2t. März 1901). ,Das Prioritätsprincip hat nur insoweit eine Berechtigung, als es sich dem Endzweck und den leitenden Grundsätzen der Nomenclatur unterordnet."

Sohald die Botaniker einmal auf den rernïnftigen Gedanken kommen, dnrch eine internationale Commission, welche anch dem Opportunitätsprincip Rechnung* trägt, - das stricte Prioritätsprincip allein wird uns nie zur Ruhe bringen! - einen NormalCatalog, vorlänfig wenigstens der emropäischen Pflanzenarten, aufzustellen, und sich rerpflichten. mit Hintansetznng ihrer persönlichen nomenclatorisehen Bedenken die darin angenommenen Gattungs- und Speciesnamen fortan zu gebrauchen, so unterwerfe ich mich mit Frenden; so lange aber Jeder thnt, was ihm gut dünkt, darf ich dasselbe thun und halte mich, soweit immer möglich, am Alten, wenn man mir auch vorwirft, dass ich nicht modern gekleidet gehe. Ich bin daron überzengt, dass es einmal $\mathrm{zu}$ einem solchen Normal-Verzeichniss, das, nebenbei gesagt, die Auctor-Citation fïr gewöhnlich überflüssig machte*), kommen wird, aber erst damn, wenn man allge-

*) Das Weglassen der Auctor-Citation in den Floren, wie es Ascherson in seiner "Flora des norddeutschen Flachlandes" eingeführt und es Schinz und Keller in ihrer nenesten „Flora der' Schweiz" nachgeahmt haben, ist leider verfitht, so lange Ascherson's Nomenclatur nicht allgemein, wenigsteus in Europa, anerkannt ist. Wird 
meiner als bis jet\%t cinselıen wird, dass die Nomenclatur an erster Stelle dazu da ist, ein leichtes und sicheres Verständigmssmittel zwischen den Botanikern zu schaffen, nicht aber um einen Tummelplatz für antignarische, prioristische, philologische und orthographische Zänkereien abzugeben, oder gar nm gewissen Leuten eine bequeme Gelegenheit zu grosser "Beriihmtheit“ zu bieten dadnrch, lass sie ihr liebes Ego hinter recht vielen Namen glänzen lassen künnen. - Noch sieht es nicht danach ans, als ob das pium desiderimm (nach einem Normal-Catalog) sobald in Erfüllung gehen solle, wäre es doch anch eine nothwendige Vorbedingung dafür, sich ïber einen vernünftigen und praktischen Speciesbegriff zul einigen; denn nach der älteren Ungrenzung der Art, welcher $\%$ B. auch A scherson fulgt, wiirden wir nicht viel über 10000 , nach der ..modernen" Auffassmo aber, die jede Varietiit zur Art stempeln möchte, vielleicht fünfmal mehr europäische Speeies bekommell.

Die $P$. Tormentilla ist wieder eines der Sclmerzenskinder der Potentillenforscher, nicht nur wegen ihrer grossen Geneigtheit zum Abändern und Bastardiren, sondern anch, wie Poeverlein (l. c. S. 15) richtig bemerkt, wegen der grossen Gleichgiltigkeit, mit welcher bis vor kurzem ihr grosser Formenreichthum einfach ignorirt wurle. Sie wird als, gemeine Art"verachtet und man findet in den allerwenigsten Herbarien ein himreichendes und brauchbares Material zum Studium der Varietäten. Aus diesem Grunde bin ich wieder fast ausschliesslich auf las von mir selbst in Sachsen beobachtete und gesammelte Material beschränlit, und dieses ist leider noch nicht sehr umfangreich, beziehentlich noch ein zu lileines Gebiet umfassend.

Ich werle diese Art nicht minutiös beschreiben - sie ist ja jedem Botaniker bekannt -, sondern nur die wesentlichen Untersehiede hervorhehen, die sie besonders von ler zweiten llauptspecies, der T'. reptans trennt; nur mit Beachtung dieser werden wir die Mhttelformen und Bastarde zwischen beiden richtig beurtheilen können. Ich verstehe hier unter den wesentlichen Unterschierlen nicht nur die rein morphologischen, welche in den Floren meistens allein angegeben werden, sondern ganz besonders auch die biologisehen, welche trotz ilner grossen Bedeutung in dieser Gruppe von den Floristen gar sehr vernachläsigt worden sind. - Der Stengel der P. Tormentilla, welcher selten über 3 Decimeter lang wird, ist stets (meist reich-) rispig verzweigt, er hat ein hegrenztes Wachsthum und stirbt gewöhnlich schon gegen Hnde August ab, ohne jemals zu wurzeln und aus den Achseln der Stengelblätter neue l'fläinzchen zu entsenden. Niemals kommt aus diesen Achseln etwas anderes, als neue Stengelïste und Bliithenstiele zum Vorschein, und soloald man am Stengel einer, wenn auch der P. Tormentilla noch so ähnlich sehender Pflanze vereinzelte, langgestielte, den Wrurzelb] ïter"n ähnlich sehende B]ätter erscheinen sieht. kann man überzeugt sein, lass man es nicht mit einel echten 'Tormentilla-Form, sondern mit einem Bastard zu thun hat. Die Stengelblïtter sind bei 1'. 'Tormentilla bis zu den äussersten Spitzen der Verzweigungen stets entwickelt, wenn sie sich gegen oben auch sehr

diese Anerkennung von Seite der Franzosen, Engländer und anderer Ansländer jemals erfolgen, nachlem sie nicht einmal um ilnre Meinung gefragt worden sind" Ohne eine internationale Abmachnng ist die liefriedigende Lösmo ier Nomenclatmfrage hentzutage undenkbar. Deshalb zweifle ich anch sehr, dass Frust H. L. Kranse in Saarlouis allgemeine \%ustimmung finden wird, der uns nenlich in einem ..Reductio generum plantarum" ïberschriebenen Artikel in Potonic"s Naturwissenschaftlicher Wochenschrift (XY. 1900, No. 52) nit einem sehr eigenmächtigen radicalen Vorgehen droht: . Bei der Auswahl der Namen für die nenbegrenzten Gattmugen verfahre ich nach lintdïnken (disorio antokratica O. K.) und sage mit Limé (Gen. pl. Ratio \$ 23): Tomina mullum terreant nova, sell si ea non placerent, nova ipse fingas, vel synonyma allegata retineas, si tibis magis arrideat!" 
vereinfachen und schliesslich zu einem ungetheilten kleinen Blättchen werden; niemals reduciren sie sich auf die Nebenblätter allein (wie bei P. reptans). Die Wurzelblätter sind verhältnissmässig klein, meistens dreizählig, selten vier-, noch seltener fünfzählig, und bilden eine sehr lockere (wenigblätterige) Rosette ïber dem Wurzelstock; sie sterben gewöhnlich frübzeitig ab, was schon Lehmann mit Recht hervorhebt. Die Stengelblätter sind wohl stets dreizählig (mit Ausnahme der obersten einfachen) und bei der typischen Form sitzend, aber bei einigen Varietäten kurzgestielt. Auch die anderen in den Floren gegebenen Merkmale sind nicht ganz constant, so findet man neben den meist vierzähligen Blüthen nicht selten einige fünfählige; die meist drei- bis fünfspaltigen Nebenblätter werden an den oberen Zweigen und oft weit herab am Stengel einfach und ganzrandig; die meistens den Kelch nicht überragenden Kronblätter werden bei einigen Varietäten viel grösser. Die Behaarung, der Blattschnitt und die Bezahnung sind sehr veränderlich und dienen nur zur Unterscheidung der Formen oder Varietäten.

Ueber die Bewerthung der Formen dieser Art gehen die Ansichten der Botaniker noch weit auseinander; während ihmen die einen (darunter Zimmeter) einen übertriebenen Wertl beilegen und sogar selbstständige Species in ihnen erblicken, wollen sie andere (darunter selbst Blocki) nur als unbedeutende Standortsformen betrachtet wissen. Wenn einmal der ganze Formenkreis, besonders auch die geographische und standörtliche Verbreitung seiner Glieder, besser studirt sein wird, als bislang, wird es sich wohl herausstellen, dass es neben wenigen guten Varietäten auch unbedeutende Formen giebt, welche sich bei mehreren Varietäten wiederholen. Wie mir scheinen will, sind die bis jetzt aufgestellten Formen durch die Diagnosen recht nnsicher abgegrenzt — was ja bei den unmerklichen Uebergängen nach allen Richtungen erklärlich ist —, weshalb eine und dieselbe Pflanze von den besten Botanikern oft ganz verschieden bestimmt wird. Auch Zimmeter war über diesen Formenkreis offenbar noch sehır im unklaren, daher seine häufige Entscheidung bei den Revisionen: „P. erecta, nähert sich der $P$. strictissima"; ,nähert sich" dem oder jenem, oder "nicht typisch" etc. - Wir müssen auch hier wieder wie ich schon bezüglich der Varietäten der P. verna L. bemerkte - . den Grundsatz aufstellen, dass nicht ein oder das andere Merkmal allein, sondern nur das Zusammenvorkommen mehrerer, also das Gesammtbild der Pflanze, die Zugehörigkeit derselben zu einer Varietät entscheidet. Ich will nun die in Sachsen vorkommenden Varietäten (oder Formen, wenn man lieber will) kurz charakterisiren, um auf sie aufmerksam zu machen und zur Beobachtung ihrer Verbreitung anzuspornen.

Var. typica. Stengel aufrecht, aufsteigend, bis niederliegend, stark rispig verzweigt, Stengelblätter sitzend (sehr selten eines oller das andere kurzgestielt). Blättchen länglich lanzettlich, die unterèn oft verkehrteiförmig oder etwas keilig, an der Basis ganzrandig, nach oben eingeschnitten-gesägt mit spitzen Zähnen, angedrückt behaart; Nebenblättchen mässig gross, mit Ausnahme der obersten drei- bis fünfzipfelig. Kronblätter den Kelch nicht oder nur wenig überragend*).

*) Die Var. typica umfasst die P. erecta Zimm. (sensu stricto) mit, beschränkt sich aber nicht auf sie, denn sonst mïste sie stets niederliegende Stengel haben (daher P. erecta!!). Die P. erecta Zimm. scheint eine seltene Form zu sein. z. B. in Bavern, nach Poeverlein (S. 22). 
Dies ist die gewöhnliche Varietät mnserer Wälder, Meiden, Triften, Wald- und Sumpfwiesen; sie kommt auf dem trockensten wie auf sehr nassem Boden fort.

Stark beharte lormen, welche im iilurgen mit der Var. typica ïbereinstimmen, sollte man meines Erachtens als forma hirsuta zu dieser ziehen, statt damit neue Varietäten aufmstellen. Eine solche Var. typica forma hirsuta liegt im Ilerb. I'et. rom lienitz bei Leipzig unter dem Namen Tormentilla erecte $\delta$ ) sericea Peterm. - Dalin gelï̈t sehr wahrscheinlich auch die P. monacensis Zimm. (Woerl, als Varietä)*). - Analoge stark beharte Formen finden sich auch bei anderen Varietäten, z. B. bei Var. strictissima, und kömnen jedesmal als f. lirsuta beigefuigt werden. So scheint die P. pubsecens (Woerl, als Var., hirta Iloller als Var.) nach Poeverlein selbst (S. 21) eine stark behaarte Form (f. hirsuta) der Var. daciea zu sein.

Die $P$. divergens Richl). kann ich, gestützt auf die kurze Diagnose und auf ein von Reichenbach selbst ausgegehenes Exemplar ron Laibach in Krain! (11. lips., legit Fleischmann) nur für eine Form der Trar. typica halten, und es ist mir nicht recht verständlich, warum focke in Koch's neuester Auflage gerade sie als Varietait der P. Tormentilla auffiihrt, wälrend er die anteren, mit Ausualume der strictissima, iibergeht und nu fur , standörtliche Abänderungen" erklärt. ,Foliis sessilibus, foliolis obovatis, ramis divergentibus, bracteolis post anthesin ealycem aequantibus". Yon diesen vier Punkten der Diagnose ist der erste und dritte (sitzende Blätter und sparrige Aeste) von keiner Bedeutung, sie gelten anch fiir die Var. typica, der dritte wenigstens sehr häutig; es bleiben nur die obovalen Blättchen und die nach lem Terblïhen gleichlangen inneren und äusseren Kelchzipfel als Handhabe zur Abtrennung von ler typischen larietät. Geht man aber das Herbar-Material durch, so findet man bei Var. typica (sowie bei Var. dacica) läufig olovale Blättchen, besonders an den unteren Stengeltheilen, olne dass die Kelchzipfel gleichlang werden, und ungekehrt findet man gar nicht selten Formen mit gleichlangen Kelchzipfeln, ohne dass sie obovale Blättehen besitzen. Jedes der beiden Kenmeichen für sich ist inconstant an derselben Pflanze, besonders varirt die Länge ler äusseren líelchblättchen ausserordentlich. Wenn nun zufällig einmal beide an einem Individumm zusammentreffen, so ist es die P. divergens Relıb.! Ich kann in derselben beim besten Willen keine gute Varietät, geschweige denn eine Art erkennen, wie Reichenbach**). - Vine der Laibacher Pflanze durchaus ähuliche Form liegt mit ihr zusammen (auch als l'. divergens) im Leipziger Herbar von Carlsbad in Böhmen! (leg. Fleischmann); der einzige Unterschied ist, dass sie kurzgestielte Stengelblätter besitzt, weshalb ich sie einfach für Tar. dacica erklären möchte.

Ganz belanglos ist eine Fol'm, welche P'etermann in Flora lips. S. 374 als densifotia unterschieden hat. Sie ist nach den Original-Exemplaren von Schönfeld bei Leipzig ! und Iainichen bei Frankenberg ! (H. I'et.) nur eine kleine niedergestreckte Form der Tar.typica, bei der die kleinen Stengelblätter sehr gedrängt beisammenstehen.

*) Woerlein will diese auch aus der Gegend ron Dreslen gesehen hahen. Deutsch. bot. Monatsschr. 188!\%

**) Das Vorgehen Reichenhach's in diesem Punkt ist un so anffallender, als er viel prägnantere Formen dieser sipecies, sowie die Bastandformen der ganzen TormentillaGrupe, die loch mu Dresten so schön rorkmmen, ganz ïberschen oder verkannt hat. 
Var. strictissima (Zimm. als Art). Diese Varietät ist, wenn typisch ausgebildet, eine der besten und auffallendsten. Sie wird charakterisirt durch einen stramm-aufrechten, robusten Stengel, der sich nur oben wenig dichotom verzweigt und daher armblithig erscheint, durch grosse, grobgezähnte, sitzende Blätter und ebenfalls grosse, stark zerschlitzte Nebenblätter, endlich durch verhältnissmässig grosse, die Kelchblätter bedeutend überragende Kronblätter.

Die Var. strictissima scheint ursprünglich die alpine und subalpine Form der P. Tormentilla zu sein und findet sich ausser dem Alpengebiet auf allen höheren Gebirgen Dentschlands (z. B. über den ganzen líamm des Riesengebirges hin!!), sie steigt aber auch, wie manche andere Alpenpflanze, in die Ebenen hinab und kommt bis in's norddeutsche Flachland vor, doch erscheint sie dann gewöhnlich nicht mehr ganz typisch und zeigt viele Uebergänge zur Var. typica, noch mehr aber zu der folgenden Var. dacica. In typischer Ausbildung habe ich sie aus Sachsen zwar noch nicht gesehen, bin aber fest davon iberzeugt, dass sie sich in unserem höheren Erzgebirge finden wird, das ich leider in den letzten Jahren, seitden ich mich mit dieser Gruppe eingehender beschäftige, zu besuchen keine Gelegenheit fand. Voraussichtich wird sie sich aber anch in anderen, niedriger gelegenen 'Theilen Sachsens noch finden lassen. Eine der typischen sehr nahestehende Form der Var. strictissima, die sich aber durch zum Theil ganz kurzgestielte Blätter der Var. dacica etwas nähert, beobachtete ich an den Abhängen des Plauen'schen Grundes!! und am Windberg bei Deuben!!

Var. dacica Borb. (Zimm. als Art). Ihre Stengel sind robust, aufrecht oder aufsteigend, ziemlich reich sparrig-verzweigt und reichblüthig, wodurch sie sich von der Var. strictissima ebenso leicht unterscheiden lässt, als durch die kleinen, langgestielten Bliithen; dagegen stimmt sie mit dieser durch die grossen, tief zerschlitzten Nebenblätter und die grossen derben Stengelblätter ïberein, doch besitzen die Theilblättchen der letzteren im allgemeinen eine mehr ovale Form und stumpfere Bezahnung. Was sie aber sowolnl der Var. strictissima als auch der Var. typica gegenüber besonders kennzeichnet, sind die kurz gesticlten (1-3 Millimeter) Stengelblätter. - Durch Fehlen des einen oder anderen der gegebenen Nerkmale nähert sie sich häufig mehr oder weniger einer der beiden Varietäten, denen wir sie gegenübergestellt haben, sie scheint überhaupt sehr veränderlich zu sein.

Allem Anschein nach ist die Var, dacica in Deutschland recht verbreitet und bis jetzt nur übersehen, beziehentlich mit der Var, typica zusammengeworfen worden. Dies hat z. B. Poeverlein (S. 25) für Bayern nachgewiesen, und dies dürfte sich bei weiterem Nachforschen auch für Sachsen herausstellen. Ich beobachtete sie, wenn auch nicht gerade in ganz typischen Exemplaren, mehrorts in der Dresdener Heide !!.

Var. sciaphila (Zimm. als Art). Diese ,schattenliebende" Form, über welche ich nach mehrjähriger genauerer Beobachtung besser zu urtheilen im Stande bin, hat so viele nicht nur morphologische, sondern auch biologische Eigenthïmlichkeiten, dass sie mindestens mit demselben Recht, wie die vorhergehenden, als besondere Varietät hingestellt zu werden verdient. Sie ist die kleinste und zarteste der mir bekannt gewordenen Formen der P. Tormentilla; Zimmeter diagnosirt sie gut: „Stengel liegend. zart, niedrig, Stengelblätter verkehrt eiförmig-lanzettlich, klein, 
genähert, gsestielt (Stiel $2-3$ Millimeter), Nebenblättchen meist gauz. Blätter weichhaarigs. Nur die letzten Worte möehte ich weglassen, bei uns z. B. sind die Blätter selı spärlich behart his fast kahl; dagegen erlaube ich mir, gestïtat auf meine Beobachtungen in der Dresdener Heide, Folgendes beizufügen: Die Blüthen sind klein, wenigstens nicht grösser, als bei der gewöhnlichen Form der Var. typica. Die P'llänzchen gleichen im Habitus gar sehr kleinen Exemplaren der P. procumbens Sibth.. einmal durch die stets hingestreckten Stengel, damn durch die dunkelgrïnen, zahlreichen, eine Rosette bildenden Wurzelblätter, welche bis in den Ilerbst hinein grï zu bleiben pflegen, durch die obovale Form der 'Theilblättchen und besonders (biologisch) anch dadurch, dass sie, wie die I'. procumbens, ihre Blüthezeit gern weit in den Herbst hinein rerlängern. Die schömsten Exemplare fand ich stets in Spätherbst (bis November), wenn die Var. typica rings umher im Wald und auf der Heide längst abgel)lïht war und nur noch vereinzelte grüue Wurzelbliitter zeigte. Da nun an denselben Stellen die l'. procumbens, die I'. Tormentilla > procumbens (P. suberecta Zimm.) und deren Var. fallax mit der P. sciaphila durcheinander vorkommen, so kommt man in die grösste Verlegenheit, wenn man die letztere von jenen Bastarden in jeclem einzelnen Fall unterseheiden soll. Die besten Merkmale diesen gegenüber sind, neben der Kleinheit und Zartheit aller ihrer 'Theile, die sehr kurz gestielten Stengelblätter, die klemen, fast stets vierzähligen blüthen und durchgehends nur dreitheiligen Wurzelblätter, ferner, dass sie an den Internodien des liegenden Stengels weder wurzelt, noch langgestielte Wurzelblätter treibt zu einer Zeit, da die P. procumbens dies sehr ausgiebig thut, wo immer ihre Aeste den Boden zn berühren Gelegenheit haben. 'Trotz der Beachtung aller dieser Anzeichen bleiben immer noch zweifelhafte Formen, ïber deren Stellung ich bis liente noch nicht in's klare gekommen bin, und vor allem ist mir das biologische Verhaiten der Var. sciaphila - soweit ich sie in unserem Gebiet beobachtet habe - noch ganz räthselhaft, demu ich kamn mir es aus ihrem feuchten, schattigen Standort allein nicht erklären. Sie findet sich auf schattigen, etwas feuchten Waldwegen und an den Gräben und Dämmen längs derselben auf kalılen oder wenig bewachsenen Stellen (im hohen, dichtstehenlen Gras gedeiht sie nicht). Zu ihrem weiteren Stulium empfehle ich die Hresklener Heide, hesonders hinter dem Weissen Hirsch und Bühlau gegen Ullersdorf zu, wo sie stellenweise massenhaft zu finden ist!!. Es wäre aber von grosser Wichtigkeit, ihr Benehmen auch ausserhalb des Bereiches der l'. procumbens und deren Bastarde zu studiren.

\section{Potentilla reptams L.}

Auch diese Art gehört wieler, wemn anch nicht gerade zu den ,gemeinen", so doch zu den hänfigen, welche nur im liöchsten Erggebirge selten werden oder stellenweise auch ganz fehlen dïrfte. Besonderer standortsangaben für die gewölnliche Form bedarf es also nicht. I)agegen werde ich wieler ihre wesentlichen Merkmale, besonders die biologischen, der P'. Tormentilla gegenüber hervorheben, weil über einige derselben noch nicht bei allen Potanikern volle Lilarheit an herrschen scheint. 
Der Stengel der P. reptans ist unrerzweigt (oder scheinbar wenig verzweigt), kriechend, mitunter bis 1 Meter lang und von unbegrenztem Wachsthum, indem er erst im Spätherbst nach Eintreten der ersten Fröste abzusterben pflegt. Er bildet vom dritten oder vierten Internodium an in der Achsel eines jeden Stengelblattes eine Knospe, aus der sofort ein neues Pflänzchen entsteht, das nach oben ein bis mehrere langgestielte Wurzelblätter und nach unten Würzelchen entsendet (oft nur Luftwurzeln oder knotige Ansätze dazu, wenn der Stengel am Internodium den Boden nicht beriihrt). Neben diesen Knospen entspringen aus den Achseln der Stengelblätter oder ihrer Rudimente die langgestielten Blïthen, einzeln oder seltener zu zweien. Gewöhnlich bleibt es im ersten Jahr bei der Bildung einiger Wurzelblätter des neuen Pfänzchens, wenn es aber ausnahmsweise seine Achse noch im selben Jahr verlängert und einen Blïthenstengel treibt, damn entsteht der Anschein, als ob sich der Hauptstengel der Pflanze rerzweige. Eine eigentliche dichotome Verzweigung des Stengels, wie sie bei P'. 'Tormentilla so reichlich und bei den Bastarden spärlicher eintritt, konnte ich bei P. reptans noch nicht beobachten, stets stellten sich die scheinbaren Aeste als Hauptachsen der neuen Pflänzchen heraus. Wenn man die hier beschriebene Wachsthumsart nicht beachtet, fällt man in den Irrthum, die langgestielten Blätter dem ganzen Stengel entlang für Stengelblätter zu halten. In der That besitzt die Pflanze gewöhnlich nur zwei bis vier fünfzählige gestielte Stengelblätter an den ersteu (untersten) Internodien, dam folgen meist ein paar kleinere, dreizählige, und alle ïbrigen - der Stengel mag noch so lang werden reduciren sich auf ein kurzgestieltes, kleines, einfaches Blättchen oder ein lanzettliches sitzendes Läppchen zwischen den Nebenblättern, das man gewöhnlich übersieht. Die ganzrandigen oder nur wenig gespaltenen Sebenblätter sind ziemlich gross, breit lanzettlich, stark unter sich und mit dem Stengel verwachsen und bilden oft eine Art Hülle um diesen, an der man kaum noch eine Spur rom eigentlichen Stengelblatt unterscheiden kann; dazu kommt noch, dass sie leicht häutig und braun werden. Aus dieser Hülle, den Rudiment des Stengelblattes, treten nun die langgestielten neuen Wurzelblätter einzeln oder zu mehreren hervor, welche so oft fälschlich für Stengelblätter gehalten werden. Nur selten und ausnalımsweise tritt im meiteren Verlauf des kriechenden Stengels manchmal ein grösseres fünf- oder dreizähliges Stengelblatt auf, es sei demn an den Scheinzweigen, die aber, wie schon gesagt, vielmehr als unabhängige Hauptachsen betrachtet werden müssen, die nur noch zufällig mit der Mutterpflanze verbunden sind. Legt man also einen langen Stengel der P. reptans (ohne die untersten Internodien) ein, so besitzt man einen nur Blattrudimente und Blïthen tragenden Stamm, an dem aber eine ganze Colonie unabhängiger Pflänzchen sitzt, nämlich so viele als Internodien vorhanden sind*).

Die Wurzelblätter der P. reptans sind gewöhnlich gross, durchgehends fünfzählig, selten sieben- bis nemzählig oder nur dreizählig, und stets (mit Ausnahme der dreizähligen) fussförmig, was nenerdings Ascherson (in Flora d. nordd. Flachlandes) mit Recht hervorhebt, nachdem sie schon

*) Die P. anserina L. zeigt ganz analoge Wachsthumsvernältnisse. Ich habe bei Besprechung derselben nicht darauf hingewiesen, weil sie uns dort weniger interessirten. als bei der P. reptans, bei welcher sie von Wichtigkeit sind zum Vergleich mit denen (ler Reptans-Bastarde. 
I.elmann in seiner Diagnose ..subpedata" genamnt hatte. Die wenigen ausgebilıleten Stengelblätter sind den WTrzelblättern ähnlich, nur kiirzer gestielt. Die Theilblättehen haben eine keilförmig rerkehrt-eiförmige bis lïngliche Gestalt und sind mit Ausnahme der Basis ringsum reichlich gekerbt-gesägt bis ziemlich spitz gezilhnt. Die Behaarung varirt ron dicht bis zerstreut angedrickt-behart. Die grossen, goldgelben libithen sind meistens fünfzählig, scehs- und siehenzählige sind an iippigen Exemplaren keine Seltenheit, dagegen fand ich bis jetzt nur zwei vierzählige 13liithen. Lehmann behauptet, dass ihm selbst bei dieser Art niemals solche vorgekommen seien und vermuthet, ,diss solche Blumen, deren hiu und wieder Eiwähnung geschieht, einer I'. procumbens angehört haben, welehe bereits Wmyeln aus den Gelenken der Stengel getrieben hatte". Ich möchte eher empfehlen, beim Vorliommen vierzähliger Bliithen genau zu untersuchen, ob man es nicht mit der der P'. reptans viel näher stehenden P'. mixta Nolte zu thum habe (siehe diese).

Der Formenkreis der Art ist nicht gross und es lassen sich kaum Varietäten aufstellen. Ich will diejenigen hersetzen, welche in Sachsen beobachtet wurden, bemerke aber gleich, dass ich ihnen keinen grossen systematischen Werth heilegen möchte.

Var. microphylla Tratt. (Kimm. als Art). Sie besitzt sehr kleine, meist nur an der vorderen Hälfte gezähnte, fast dreieckig-obovale, stark verkahlte Blätchen und soll purpurothe Stengel haben. Das letztere ist aber nur bei den der Sonne stark exponirten Exemplaren der Fall. Sie ist wahrscheinlich nur eine kleine Standortsform auf trockenem, unfruchtbarem Boden, und geht in die gewöhnliche Form über. Ich sammelte sic am Windberg bei Deuben!! und beobaclite sie nun schon seit 10 Jahren an einer mageren Stelle einer Rasenfläche meines Gartens in Planen bei Dresden, ohne zu wissen, von wo sie dahin gelangte!!. Nachdem ich ein paar Pfiänzchen in besseres Land verpflanzt hatte, wurden sic üppig und wucherten stark, schon nach zwei Jahren konnte ich sie nicht mehr von der gewöhnlichen P. reptans muterscheiden. Im Kies und auf den gepflasterten Dïmmen des Elbufer's findet man nicht selten kleine Pflanzen, die gut mit der microphylla ïbereinstimmen. Siehe auch über len Werth oder besser Unwerth dieser Varietät, Poeverlein 1. c. S. 35.

Var. pubescens Fiek. besitzt beiderseits stark seidin behaarte Blätter. Eine Pflanze, welche ich zu ilu ziche, hat Herr Fritzsche bei Leipzig (!) gesammelt. Ausser der langen, dichten Behaarung unterscheidet sie sich nicht von der gewöhnlichen Form. - Eine ganz ähnliche, sogar etwas weniger stark beharte, aber ebenfalls schr grossb]ätterige Pflanze hat ()Jorny aus Znaim in Mälnen als I. lanata Lag. ansgegeben. Ich zweifle sehr, dass sie mit der spanischen P'. lanata (, undique dense canovillosa v. lanata, foliis minutis, pedunculis brevibus") i(lentificint werien dürfe, da sie, wie die unserige, unter andelem grosse libitter und lange blattstiele hat und bei weitem nicht grau-zottig genamnt werlen kann. Ob beide Pflanzen, die sächsische und lie mïhrische, vielleicht besser mit der I'. reptans var. mollis Borl). - die ïbrigens Kimmeter auch zu P. lanata zu ziehen geneigt ist - iibereinstimmen, weiss ich aus Mangel an Vergleichsmaterial nicht zu sagen, jedenfalls verdienen sie den Yamen pubescens viel besser als den der lanata ${ }^{* *}$ ).

*) Callier hat in Flora siles. exsicc. Ed. 1894 No. 1040 eine merkwürlige Pflanze als P. reptens vur. pubescens Fiek, von "Breslan: Dämme bei Klein-Ischansch" aus- 
Was es für eine Bewandtniss mit der Var. sulpedata Lehm. (C. Koch als Art, ebenso Zimm.) hat, ist mir nie recht klar geworden; denn ,folia subpedata" - das Hauptkennzeichen - besitzt die P. reptans durchgehends, wie Lehmann und Ascherson in deren Diagnose hervorheben und auch ich weiter oben behauptet hahe; d. h. nur die drei mittleren Theilblättchen des fünfzähligen Blattes gehen direct rom gemeinsamen Blattstiel aus, während die zwei äusseren von dem Stielchen der zwei seitlichen des trifolium abgehen; bei dem siebenzähligen Blatt gehen sogar die vier äusseren von den Seitenblättchen und nicht vom gemeinsamen Blattstiel aus, wodurch das ,folium pedatum" noch deutlicher zum Vorschein kommt. - Auch die Blätter der P. procumbens und aller Reptansund Procumbens-Bastarde sind, sobald sie mehr als drei Theilblättchen besitzen, stets subpedata. - Die anderen Kennzeichen dieser angeblichen Varietät: „foliis inferioribus quinatis intermixtis ternatis, petiolis longissimis" sind ganz belanglos und kommen bei allen Formen vor. Lehmann selbst sagt (Rev. Pot. S. 185): „P. subpedata C. Koch ist nach OriginalExemplaren nur durch sehr lange Blattstiele und diinnere Blumenstiele -welche darauf hinweisen, dass die Pflanze an einem feuchten und schattigen Orte gewachsen - von der gewöhnlichen Form verschieden." Nun gut, warum damn eine Varietät oder gar Species daraus machen? Jeder kamn sie sich aus der gemeinen P. reptans in seinem Garten unter feuchtem Gebüsch ziehen; in dem meinigen wuchert sie - zum Theil aus der Var. microphylla entstanden! - nur gar zu sehr. Für mich ist sie eine ganz unbedeutende Standortsform, die noch weniger hoch als die Var. microphylla zu bewerthen ist.

Aehnlich ergeht es mir mit der Tar. anomala Lehm. (Ledeb. und Zimm. als Art), die sich besonders durch häufig siebenzählige fussförmige Wurzelblätter und sehr grosse, breite, äussere Kelchzipfel auszeichnen soll. Wenn man beachtet, dass siebenzählige Blätter bei Pflanzen, die auf einem sehr fetten Boden wachsen, oder im Garten in Cultur genommen werden, sehr häufig auftreten, dass an denselben Pflanzen die Länge der äusseren Kelchblätter nngemein veränderlich ist und an einzelnen Blüthen die der inneren um mehr als das Doppelte übertrifft, ferner, dass an ihnen sich zugleich nicht selten sechs- und siebenzählige Blüthen und allerlei sonstige Abnormitäten zeigen, so wird man wenigstens den Gedanken nicht ohne weiteres als absurd zurückweisen können, dass die P. anomala vielleicht nur auf hypertrophirte Exemplare der P. reptans gegründet sei, bei denen die Missbildungen an Blättern und Blïthenstielen besonders stark und allgemein auftreten. Die P. anomala wäre dann statt als Varietas eher als IIonstrositas aufzufiuhren. Ich will mich nicht vermessen, die Frage schon jetzt, olme hinreichendes Belegs- und Vergleichsmaterial, zu entscheiden, sondern nur zur weiteren Beobachtung dieser

gegeben. In der Behaarung stimmt sie mit der unserigen von Leipzig iberein, aber anch in nichts anderem. Ihre Stengel verzweigen sich vom zweiten oder dritten Intermodium an wiederholt dichotom, schon der ganze Habitus ist nicht der der $\mathrm{P}$. reptans und sie hat in allen Theilen die auffallendste Aehnlichkeit mit der Abbildung, die Lehmann in Rer. Pot., Tab. 58, von seiner P. italica giebt. Ich trage kein Bedenken, sie zu diesel, also zu den Tormentilla $\times$ reptans-Bastarden zu stellen. Hoffentlich haben die Exemplare, welche Fiek zur Aufstellung seiner Var. pubescens dienten, anders ausgesehen, als die von Callier gesammelten und ausgegebenen, deun sonst miissten wir seinen Namen hinter pubescens (als Tar. der P. reptans) streichen. 
Form und deren Uebergänge zur gewölnlichen P'. reptans auffordern. Solche Uebergangs- oder '/wischenformen, an denen nur ein 'lheil der Blätter und Blïthen mit denen ler Yar. anomala stimmen, sind gar nicht so selten, wie man glaubt. Ieh fand sie mehruals, z. B. bei Rathen in der saichsischen Schweiz !!. an der Strasse, die rom Plauen'schen Grund nach Döltzschen hinauffïhrt!!. Am letzten Ort machte ich die Beobachtung, dass sich die äusseren Kelchripfel an den fiinfrälligen Bliithen oft ganz enorm entwickelten, während sie an den liäufigen sechs- bis siebenzähligen normal oder sogar auffallend klein hlieben (Compensation?). An den Cultur-Exemplaren der P'. reptans in meinem Garten lionnte ich jährlich viele Anomali-Blätter und -Blïthen beobaehten.

\section{1\%. Potentilla procumbens Sibth.}

(P. 'T'ormentilla-reptans.)

Wir heginnen die Reihe der \%wischenformen zwischen der P. Tormentilla und der $\mathrm{P}$. reptans mit der (bei uns wenigstens) verbreitetsten derselben, welche mit Recht als eine eigene speeies angesehen wird, weil sie sich in der 'That in jeder Beziehung als solche benimmt, wenn sie auch höchst wahscheinlich ehemals aus einer Kreuzung der P. 'Tormentilla und der $\mathrm{P}$. reptans hervorgegangen ist. Ob sie noch immer hin und wieder aus den präsumptiven Stammarten ganz in der Form entsteht, in der wir sie als secundären oder zur Species gewordenen Bastard kennen, ist eine rein academische Frage, auf die wir uns nicht weiter einlassen wollen. Die Möglichkeit wird kamm bestritten werden können, aber die Entscheidung in jeden Einzelfall dürfte auf die grössten Schwierigkeiten stossen. Jedenfalls sind die allermeisten der gegenwirtig existirenden l'flanzen keine primären Bastarle, sondern die Nachkommen der sich seit ungezählten Generationen selbstständig dureh Samen ebenso stark als durch wurzelnde Stengelknospen fortptlanzenden P. procumbens. 1)aran wird Niemand zweifeln, der ihr Vorkommen in Freien beobachtet hat.

Die P. procumbens hïlt in ihren morphologisehen und biologischen Kennzeichen die Mitte zwischen der P. Tormentilla und reptans. Von jener hat sie den ziemlich stark sieh dichotom verzweigenden Stengel, der bis in die letzten Verzweigungen hinein mit ausgebildeten, wemn auch zu oberst bis auf ein kleines, aber stets gestieltes Blättehen reducirten Stengelblättern versehen ist. Die Stengel werden bis über 1/. Meter lang, sincl anfangs etwas aufstrebend, legen sich aber sehr friihzeitig um und breiten sieh mit ihren Aesten weitschweifig auf den Bocken oder ïber das Gras ler Lmgebmug aus. Gegen den Herlost hin bilden sich an vielen (niemals an allen) Internodien der bis in den Spätherbst fortblühenlen Aeste, wem sie den boden beriilnon, Wiirzelchen, wälıend sich in der Achsel des betreffenden Stengelblattes die Knospe eines neuen l'flänzchens bildet, das alsbald ein (oler zwei) langgestieltes Wurzelblatt entsendet, gerade so, wie wir es bei P'. reptans an allen Internodien beobachten. Sehr häufig kommt aus derselben Achsel sofort ein neuer Ast (oder eine Hauptachse?) hervor, der oft noeh im selben Jahre blïht. Wo die Steigel und Aeste der Pflanze den Boden nicht berühren, sonderu über dem hohen Gras der. Umgebung hingebreitet sind, 
bilden sich solche Adventivknospen dennoch in den meisten Fällen (etwas später und mit Luftwürzelchen), wenn auch nicht so zahlreich; aber hin und wieder bleiben sie ganz aus, so dass dann ein wichtiges Erkennungszeichen dieser Species wegfällt*). In diesem biologischen Verhalten nähert sich also die P. procumbens der P. reptans, sie hat ein scheinbar unbegrenztes Wachsthum, wie diese, blült bis in den November hinein und nur nach den ersten Frösten beginnen ihre Stengel abzusterben, ja, einige derselben, die sich spät entwickelten, überdauern an geschützten Stellen den Winter und blühen in folgenden Mai weiter, wie ich in der Dresdener Heide mit Sicherheit beobachtet habe.

Die Wurzelblätter sind d’ei- bis fünfzählig, sehr häufig vierzählig; bei den dreizähligen sind die Seitenblättchen oft gelappt (Ansatz zum fuss förmigen vier- oder fünfzähligen Blatt); sie bilden eine dichtere Rosette als bei $\mathrm{r}$. Tormentilla und sind viel dauernder als bei dieser, oft bilden sie gerade im Herbst die schönsten Rosetten. Die unteren und mittleren Stengelblätter sind drei- und vierzählig, seltener fünfzählig und im Durchschnitt etwa 1 Centimeter lang gestielt; an den Blüthenzweigen vereinfachen sie sich wie bei P. Tormentilla.

Die Nebenblättchen sind meist ganzrandig, höchstens an den unteren Stengelblättern zwei- bis dreizähnig oder -spaltig, an den obersten werden sie klein, schmal und häufig kurz gestielt, wie das zwischen ihnen hervortretende einfache Stengelblättchen. - Die Theilblättchen sind gross, keilförmig oboval, hinten ganzrandig und rorn grob eingeschnitten-gesägt mit spitzen Zähnen, gewöhnlich schwach angedrückt-behaart. Die Blüthen sind zwar kleiner als bei P. reptans, aber viel grösser als bei P. Tormentilla und die verkehrt-herzförmigen Kronblätter überragen die Kelchblätter fast um's Doppelte; sie sind vorwiegend vierzählig, doch sind fünfzählige keine Seltenheit**). Die Pflanze bringt reichlich fruchtbare Samen hervor nach Culturversuchen und der Beobachtung im Freien.

Ich hielt es nicht für überflüssig, die P. procumbens eingehender zu beschreiben, als es in den Floren gewöhnlich geschieht, demn sie wird, trotzdem sie bei uns gar nicht selten ist, doch noch vielfach verkannt, wie ich bei Durchsicht von Privat- und öffentlichen Herbarien erfuhr. Eine Verwechslung mit P. Tormentilla oder reptans wird bei Beachtung des soeben Angeführten kaum mehr möglich sein, dagegen ist ihre Unterscheidung von den weiterhin folgenden Bastarden nicht immer leicht.

Die P. procumbens liebt feuchte, schattige Waldungen, wo man sie zerstreut, aber gesellig besonders an Wegrändern, Strassengräben, oder an den aufgeworfenen Dämmen längs der Abzugscanäle in sumpfigem Terrain, seltener mitten in Gehölz (mit Ausnahme junger Schonungen), findet, sodann kommt sie ebenfalls gern auf moorigen Wriesen an den Teichrändern vor. Vereinzelt und vielleicht manchmal nur verschleppt, trifft man sie

*) Ton solchen Pflanzen nahm ich Ende October blïhende Zweige mit nach Hause und stellte sie in ein Glas mit IVasser neben einen Blumentopf; dann bog ich die Aestchen über diesen und heftete sie mit Klammern auf der fenchten Erde fest. Nach drei Wochen Waren sie an den Internodien fest angewnrzelt und trieben die bekannten langgestielten Wurzelblätter. Im folgenilen Jahr bliihten die kräftig herangewachsenen Ptlänzchen in meinem Garten und wurzelten ihre Stengel im Herbst ron selbst an.

**) Die Exemplare mit vorherrschend fünfzähligen Bliithen als Var. Neymeyeriana (Tratt. als Art, P. tormentilloides Iay.) von der P. prucumbens zu trennen, wie Pet ermann in Flora Lips. p. 374 gethan, ist nicht zu empfehlen. Mit Recht hat schon Lehmann die beiden Namen einfach als Synonyma der P. procumbens aufgefiihrt. 
auch an Wiesen- und Feldrindern nnd sellıst auf Sclıttplätzen. Ihr Hauptrerbreitungrsebiet liegrt in Sachsen rechts der Lilbe, in der sächsischen Schweiz, in der Drestener Heile und im ganzen (iebiet der oberen Spree, der schwarzen Elster, der Pulsuitz und (ler Röder. Im nördlichen Sachsen hängt es direct mit den angrenzenden Verbreitungsgehieten in Schlesien, l'rovinz Sachsen und Brandenburg zusammen. Limks der Elbe kommt sie hesonders im Erzgebirge ror. - In der sächsischen Sehweiz trifft man sie selır schön un und auf dem grossen Winterlyerg, so an der Strasse von Schmilka hinauf!!, hesonders aber an der basaltischen Kuppe !!. (In (ler angrenzenden bölnmischen Schweiz ist sie ausserordentlich liäufig un Dittersbach!! und an der ganzen strasse ron dort his nach Herruskretschen !!.) Hippe giebt füı die säiehsische Schweiz links der Elbe die Orte: 'Thürmslorf', Neidberg, Markershach, I'faffendorf und C'mmersdorf. Dresdener Heide: besonders die Gegend hinter dem Weissen Hirsel und

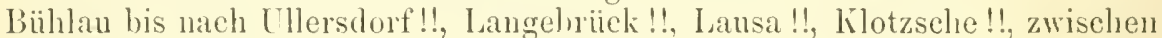
lïtzschenbrorla und Lindenan!!, zwisehen Spitzormulnülrle und Weinböhla !!. - In lev Teichlandschaft ron Moritzbulor und Radeberg !! bis Ortrand !!, Königsbrick ! (H. Dr.). - Um Grossenhain nach Hofmam: am Spitalteich!, bei Kabeltitz!, Seaup!, Blochwitz!, Frauenhain!. - Vereinzelt bei Gittersee iber dem Plamen'schen Grund bei Dresden !!. - A A dem Erzgebirge sah ich sie vom Geisingberg! (llfin.); doch giebt Rejehenbach sowohl für das obere als anch (las niedere Erzgrebirge eine ganze Reilse rou Standorten an: Gablenz (! Säurich) und Dittmannsclorf bei Chemnitz, Oederan, Bockau, Lanter, Sachsenfeld, Wildenau, Grünhain, Zwönitz, Jolnungeorgenstadt, Schneeberg, Hartenstein. -- Im Vogtlande ist sie nach Artzt selten: Eich, Holıe Kranz und Suissebach bei Oelsnitz. - Endlich werlen für den Leipziger Kreis genannt, von Wolfram: Eschfeld und Wendischleula bei Borna; von Petermann: Leipzig, Machern, Lindenthal ! (H. Pet.), Zschepa, Lauer und Düben. Alle ron Reichenbach (und von Hippe) angegebenen Standorte hediirfen der Bestätigung. da Rehb. offenbar die P'. 'Tormentilla $>$ reptans (adscendens) und andere Bastarde noch nicht zu unterselieiden wusste und selbst iiber I'. mixta Nolte im unklaren war, diese Formen also mit der P. procumbens nöglicherweise zusammengeworfen luat.

\section{Potentilla 'Tormentilla $\times$ reptans.}

(Dahin P. adscendens Grml. (= P. Gremlii Zimm.) nud P. italica Lehm.)

Der Bastard steht der P'. procumbens sehr nahe und kamn uur mit dieser verwechselt werlen; es genügt (laher, die Ilauptunterselicie dieser gegenüber hervorzuheben: Stengel robuster, daher besonders im Anfang mehr aufsteirend nud erst später liegend; unter den Wurgel- sowie den unteren und mittleren Stengelblättern herrsehen lie fiunf- und vierzähligen über die dreizähligen vor, sie sind meist stark seidig behaart, daher oft grauschimmernd, und ihre 'Theilblättchen besitzen meistens eine elliptische oder längliche Form und sind weiter gregen die lbasis zu gezilhnt als bei (ler l'. procumbens, hei der sie keilig und rorn verbreitert zu sein pflegen. Die bliithen sind etwa so gross wie l,ei l'. procumbens, aber häufiger fünf-als vierzïhlig. Die Behauptung Zimmeter's: , Siigezïlue 
in geringerer Zahl, weniger scharf und tief ", gilt nicht im allgemeinen, denn nach Herbar-Exemplaren aus der Schweiz, Frankreich, Scandinavien, Brandenburg, Sachsen, finden sich auch Formen, deren Blättchen sehr reichliche, tief eingeschnittene (zum Theil doppelt gesägte) und dabei auffallend spitze Zälıne besitzen. Auch die anderen oben angegebenen Merkmale sind nicht immer rollzählig, wenigstens nicht immer typisch rorhanden, überhaupt scheint die P. adscendens Grml. veränderlicher als die P. procumbens zu sein, und ich stiess gerade bei uns in Sachsen auf Pflanzen, die man fast mit gleichem Recht zu der einen wie zu der anderen stellen kann. Es gielst gross- und kleinblïthige. sehr stark- und schwachbehaarte Formen, und besonders der Blattschnitt ist recht inconstant. Ich stütze mich bei dieser Behauptung besonders auch auf die von Nurbeck, Zimmeter, Siegfried, Appell und anderen Potentillenkennern revidirten oder ausgegebenen Exemplare.

Die P. Tormentilla $\times$ reptans findet sich an ähnlichen Standorten wie die P. procumbens. In Sachsen scheint sie nur rereinzelt (nicht gesellig) vorzukommen; ich kenne sie bis jetzt ron: Niederrathen in der sächsischen Schweiz, am Weg nach dem Amselgrund!!, Grossenhain! (Hfm.), Hohenstein-Ernstthal bei Chemnitz! (Hfm.), Geisingberg im Erzgebirge! (Fr.), hier sich der P. procumbens nähernd; endlich von Sayda im Erzgebirge! (Artzt). Die Pflanze vom letztgenannten Standort, welche ich Herrn Ingenieur Artzt in l'lauen i. I. rerdanke, und welche dieser schon am 15. Juni 1870 sammelte, ist in mancher Beziehung ron den anderen sächsischen (und ausser-sächsischen meines Herbars) recht rerschieden. Leider liegt sie nicht in ihrer vollen Entwicklung ror, denn sie wurde zu einer für llie ganze Tormentilla-Gruppe besonder's im Gebirge seln frühen Zeit eingelegt; daher sind ihre Stengel ( 14 aus einem starken Wurzelstock entspringend !) erst 15 bis 20 Centimeter lang. Der erste Gesammteindruck, den die Pflanze macht, ist der einer dickstengeligen, a uf rechten oder stark aufsteigenden P. Tormentilla, wozu besonders auch die kurzgestielten, mit grossen drei- bis fünfspaltigen Nebenblättern versehenen unteren und mittleren Stengelblätter beitragen. Aber die Aehnlichkeit mit P. Tormentilla verschwindet sofort bei der genauen Untersuchung der übrigen Ierkmale, die sie der P. reptans und procumbens weit näher rücken, trotz ihres durchaus nicht reptans-artigen Habitus. Ton den kleinen und kurzgestielten Wurzelblättern sind an meinem Exemplar leider nur mehr wenige Reste vorhanden, nach diesen waren sie fussförmig fünf- und rierzählig. Auch die Stengelblätter sind kleiner als sie bei der P. procumbens und gewöhnlichen adscendens zu seiu pflegen; nur die untersten sind ca. 1 Centimeter, die ïbrigen nur $5-3$ Villimeter lang gestielt. In ihrer Mehrzahl sind sie fünfzählig und sehr deutlich fussförmig, weiter oben am Stengel werden sie sehr unregelmässig rier-bis dreizählig, indem die zwei äusseren Blättchen des dreizähligen Blattes mehr oder weniger stark einseitig gelappt erscheinen. Die Form der ziemlich kleinen oft recht deutlich gestielten Theilb]ättchen ist elliptisch (in der Mitte am breitesten) und die Pezahnung - jederseits 4- 7 lange und sehr spitze Sägezähne - reicht bis weit unter die Hälfte des Blattrandes. Ihre Behaarung ist sehr mässig, ähnlich wie bei P. procumbens. Natürlich waren bei dem schon Mitte Juni gesammelten Exemplar noch keine wurzelnden Internodien an Stengel und Zweigen, noch daraus entspringende langgestielte Wurzelblätter zu erwarten. Die Blithen, von denen erst wenige geöffnet waren, sind fünf-, einige sogar 
scehszählig und so gross wie hei P. procumhens, An vielen aufgeweichten Kinospen fand ich lieselben Lahlenverhältnisse.

Dass wir es bei dieser Ptlanze von Sayda mit einer Zwischenform zwischen P. Tormentilla und P', reptans zu thun haben, dariber kam kein Zweifel walten; es fragt sich nur, ob man sie als Varietät zu P'. procumbens, oder zum liastard P.' Tormentilla $<$ reptans stellen soll? In Habitus weicht sie ja ron beiden ab, aber nach der Mehrahl ilner Merkmale, besonders den fünfzälıligen blüthen und Blättern, der elliptischen lorm der Theilblättchen und den robusten Stengehn - ich möchte hin\%ufügen, auch nach ihrem selieinbar ganz vereinzelten Vorkommen - muss sie meines krachtens bei P'. Tormentilla > reptans untergebracht werden, womit nicht gesagt ist, dass sie ganz genau nit der P. adscendens Grml., wie sie der Auctor und 'Limmeter beschreiben, ibereinstimmen muss. Die allgemeine Bastarlbezeichnumg hat eben vor einen binären Nanen den grossen Vortheil, dass sie verseliedene Formen mul Varietäten umfasst, welche man, wenn sio genügend studirt sind, mit $Y$ arietätsnamen oder anch mit modificirten Bastariformeln (z. I). l'. supertormentilla > reptaus oler l'. sunerreptans ×'Tormentilla) ausdrüeken kann. Deshalb sind fül mich P', adscendens (irml. und I'. italica Lehn. nicht sehlechtweg synonyma zu l'.'Pormentila > reptans, sondern - wie auch unsere P'flanze ron Suyda — verschierlene Formen derselben, zu der sich mit der '/eit noch andere gesellen können. - Das Studim eines einzigen Herbar-Exemplars reicht natiolich bei weiten nicht aus, die lerwandtschaftsstufe unserer Sayda-Potentilla zu P'. 'Tormentilla oder P'. reptans genauer zu bestimmen, und ilı schon jetzt einen besonderen Varietaitsnamen beizulegen, lualte ich fuir zwecklos und rerfriiht. Dagegen möchte ich unsere Floristen dingend ersuchen, auf diese interessinte form - wie auf die I'. Tormentilla > reptans ïberhaupt - eifrig zu filnden und ihr etwaiges Auftreten genau zu notiren.

Zum Sehluss noch ein paar allgemeine Bemerkungen iiber das Verhältniss der l'. 'Lomentilla > reptans zu der l'. 'Tormentilla - reptans (procumbens). Ich fasse dasselbe ganz älnlich auf wie jenes zwischen l'. opaca < verna und l'. opaca-verna (aurulenta, resp. aestiva pp.), über das ich an einer anderen Stelle (S. só) ausfühlicher gesprochen habe. Es unterliegt keinem \%reifel, dass beide Mittelformen einander sehr nahe stelıen, was ja bei ihrer vorausgesetzten ähnlichen Entstehungsweise als ganz natürlich erscheint; ja, wenn es sich heransstellen sollte, dass sich die I'. adscendens, italica und ähnliehe Formen, ebenfalls wie dic P'. proeumbens nnabhängig von den stammarten nieht nur durch rein regetative Vermehrung (Adventivknospen), sondern auch duch reichliche fruehthare samen auf unbegrenzte Zeit fortptlanzen, also sich gleichfalls wie eine Species benehmen, so müsste man in ernstliche Lrwïgung riehen, ob sie nicht als Varictäten oder Rassen ler l'. proeumbens anzureilıen wären. In diesem fialle kïme damn ihnen die phylogenetische Bezeichnmng P'.Tormentilla - reptans und der P'. procumbens die von P'. supertormentilla - reptans zu, denn diese rüickt entschieden in ilıen morphologischen Merkmalen der l'. Tormentilla etwas näher, als jone. - Leider hatte ich noch lieine Gelegenheit, durch eigene Beobachtung ihres Verhaltens im Freien und ilner Lortpflanzungsart mir ein festes Urtheil ïber die 'Jormentilla < reptansBastarle zu billen. Wie sie sich in der Schweiz und in anderen südlichen Länder'n (ausserhalb des Geljietes der P. mocumbens) benehmen, wo sie häufiger zu sein scheinen, als bei uns, weiss ich nicht; aber ihr 
in den nördlichen Gegenden sporadisches, nicht geselliges Vorkommen, sowie ihre bedeutende Veränderlichkeit spricht allerdings für ilıre Natur als primäre Bastarde in den meisten Fällen, und da sie heutzutage von den meisten Potentillen-Kennern für solche gehalten werden, so wollen auch wir es vorlänfig dabei bewenden lassen. Bei der grossen Neigung der ganzen 'Tormentilla-Gruppe zur Bastardbildung liegt kein Grund vor, an der Wahrscheinlichkeit zu zweifeln, dass auch die extremsten Formen derselben, die P. Tormentilla und die P. reptans, sich noch immer hier und dort direct krenzen.

\section{Potentilla Tormentilla $\times$ procumbens.}

(Hierhin P. suberecta Zimm. und P. fallax [Mor.] Zimm.)

Die P. Tormentilla ist mit der P. procumbens durch eine lückenlose Reihe von Zwischenformen rerbunden, die unmerklich in einander übergehen und nach ihrem constanten Vorkommen zwischen den genannten Arten oder wenigstens ganz in deren Nähe, mit grosser Sicherheit als deren Bastarde angesehen werden können. Sie haben alle Platz unter der gegebenen allgemeinen Bastardformel, aber eine für alle giltige Diagnose lässt sich kaum aufstellen. Für einige passt so ziemlich die von Zimmeter für seine P. suberecta gegebene, für andere die der I'. fallax, für wieder andere keine von beiden, und wie unsicher Zimmeter selbst seiner Sache in diesem Punkte war, geht aus dem von ihm revidirten Herbarmaterial hervor, wo seine Bestimmungen mit den Diagnosen oft gar nicht stimmen wollen. Man kann sagen, dass sich die Bastarde von der P. Tormentilla besonders durch die häufig anftretenden vierzähligen (selten fünfähligen) Wurzelblätter und die oft ziemlich langgestielten Stengelblätter, durch die breiteren, oval-lanzettlichen Theilblättchen, die weniger stark geschlitzten bis ganzen Nebenblätter und die meist langen, hingestreckten, peitschenförmigen Stengel und Aeste unterscheiden, von der P. procumbens aber durch meist dreizählige (selten vierzählige), oft kürzer gestielte Stengelblätter, häufiger geschlitzte Nebenblätter, mehr elliptischen als keilförmigen und reicher bezahnten Theilblättchen, durch meist viel kleinere und fast durchgehends vierzählige Blïthen, endlich dadurch, dass ihre Stengel und Zweige im Herbst an den Internodien nicht wurzeln (ob niemals?).

Anstatt sich lange mit der minutiösen, nur zu oft resultatlosen Untersuchung zu quälen, ob eine vorliegende Pflanze zn der Definition der P. suberecta Zimm, oder der der P. fallax Mor. genau stimme, empfiehlt es sich in dieser Bastardreihe, ganz analog wie wir bei $P$. opaca $\times$ rema und $P$. arenaria $\times$ verna gethan, drei Stufen, beziehentlich drei Nodificationen der Bastardformel aufzustellen: Tormentilla $\times$ procumbens, supertormentilla $\times$ procumbens und superprocumbens $\times$ Tormentilla, die sich von selbst erklären. Oft wird es dem subjectiven Ermessen des Floristen anheimgegeben sein, in welche Stufe er eine Pflanze versetzen will, da die Natur durchaus keine scharfe Grenzen zieht.

P. Tormentilla $\times$ procumbens, zu der ich die P. suberecta Zimm. rechne, hält ziemlich genau die Mitte zwischen den beiden Stammarten, und dürtte überall im Gebiet der P. procumbens nicht selten sein. In 
Sachsen habe ich sie bis jetzt mu in der Dresdener lleide !! gefunden weil ich eben nur hier auf sie speciell achtete - , sie ist aber jeclenfalls verbreiteter; so fand sie rorigen Herbst Ilerr Hofmann bei Blochwitz ! unweit Grossenhain.

P. supertormentilla > procumbens, eine sich der 'Tormentilla stark nïluernole und in sie iblorgelsende lorm, finclet sich ebenfalls nicht selten in der Inesilener Heide !! Iler mus aber vor einer V'erwechselung mit der I'. Torm. var. dacica (nnit kurggestielten Stengelblättern) und ganz besonders mit der 'Torm. var', sciapluila gewarnt werden, iiber deren eigenthimbliches Verhalten iclı schon gelegenthich ihrer besprechung (S. 106) aufmerksam gemacht habe. - In diese Stufe diirfte auch eine ron Schwar\% aufgestellte „P. fallax $x$ silvestris" gehören.

P. superprocumbens × Tormentilla. Dass es diese Stufe giebt, auf der sich die PHanzen der P. procumbens viel mehr nähern, als der P'. Tormentilla, ist sicher; es fragt sich nur, ob ich liecht habe, wemn ich die P. fullax Mor. zu ilır ziehe. Ueber diese, ,trügerische" Form ist schon öfters gestritten worden. Moretti selhst stellte sie als Varietät der P. Tormentilla anf, ebenso Marsson, Uechtritz und in den neuesten Floren unter anderen Kirchner und Eichler, sowie Schinz und Keller. Zimmeter erhol, sie zur Art, und Callier vertheidigt sie ,als gute zur Gruppe der P. silvestris geliörigen Art" in del Allgem. bot. Zeitschr. 1895, S. 40. Dagegen betrachten sie Focke, Murbeck, Fiek und neuerdings noch Scliwarz als eine I'. Tormentilla $\times$ procumbens und dieser Ansicht schliesse ich mich ganz entschieden an. Callier heweist weit und breit, dass sich die I'. fallax nicht nur von P. Tormentilla, sondern auch von der I'. suberecta Zimm. unterscheide. Dies gebe ich gern zu, aber sie braucht auch nicht identisch mit der P. suberecta zu sein und kann dennoch eine P. Tormentilla $\times$ procumbens, nur auf einer anderen Stufe, vorstellen. Es wïre zu wünschen gewesen, dass Callier ebenso ausführlich ihre Unterschiede von P. procumbens hervorgehoben liätte, denn dieser scheint sie mir, trotz Callier's Ausfiulnungen, viel näher zu stehen, als der l'. Tormentilla. Ich stütze mich besonders auf die ron Callier selbst ausgegebenen Exemplare von Obernigk bei Breslau (leg. Hellmann) und ron Korsenz bei Trachenberg (leg. Schwarz), auf das ron Zimmeter revidirte von Hohenschönhansen bei Berlin (leg. Hirte), auf ron Siegfried ausgegehene Cultur-Exemplare (ron Originalpflanzen von Lorsenz, in Schlesien lierstammend), und entlich auf die von mir selbst in der Dresilener Heide gesammelten Pflanzen, die sich ron den schlesischen kaum unterscheilen lassen. Die Siegfried'schen Cultur-Exemplare besitzen bis zu den oberen 'Theilen des Stengels und der \%weige viele vierund selbst fünfzählige, deutlich fussfömige Stengellblätter; auch bei wildgewachsenen Pflanzen sind solche nicht selten, ein Tinstand, der allein schon deutlich fuir ihre Bastardnatur spricht. l,eider fehlen bei allen meinen fremden Ilerbar-lixemplareı die Wurelblätter, hei den säichsischen sind sie theils drei-, theils vierzählig. Die Sicgfried'schen I'flanzen und die aus der Gegend von Berlin sind grossblüthig wie P. procumbens, die sächsischen theils ebenso grosshliithig, theils kleinblüthig (es giebt auch kleinblïthige Formen der echten l'. procumbens!). Die langen, peitschenförnigen" Aeste und lihithenstiele, die nach Zimmeter besonders charakteristisch für die P. fallax sein sollen, funten sich oft fast ganz gleich bei P. procumbens, besonders an Schatten-Lxemplaren. Ilı ganzer Habitus ist ler der letzteren. 
Ich muss gestehen, dass ich noch jetzt grosse Schwierigkeit habe, die P. fallax von der P. procumbens zu unterscheiden, und wenn ich sie jetzt nicht mehr - wie noch vor wenigen Jahren - als blosse Form von dieser, sondern als eine P. superprocumbens $\times$ Tormentilla betrachte, so geschieht dies hauptsächlich wegen der nicht oder selten keilförmigen, sondern vorherrschend elliptischen oder länglich-lanzettlichen For'm ihrer Theilblättchen, und weil ich bei ihr bis jetzt nie Anzeichen fand, dass sie im Herbst an den Indernodien wurzle.

Pflanzen, welche nach meiner Ansicht entschieden eine P'. superprocumbens $\times$ Tormentilla vorstellen - mögen sie mit Zimmeter's oder Callier's P. fallax sensu strietissimo stimmen oder nicht - fand ich mehrfach in der Dresdener Heide: Weisser Hirsch !! und Bühlau !!, Langebrïick !!, Lausa an dem Waldteich !!, Klotzsche !!. Auch sah ich sie von Königsbriick! (leg. Hofm.).

\section{Potentilla procumbens $\times$ reptans.}

(Dahin P. mixta Nolte.)

Dieser um Dresden gar nicht seltene Bastard ist bis jetzt von den säehsischen Botanikern fast ganz ïbersehen worden. Reichenbach giebt allerdings für die P. mixta Nolte in seiner Flora saxonica die "Gegend von Pirna (nach Bater)6*) und Wünsche wiederholt dieses in allen seinen Auflagen. Es ist durchaus nicht unmöglich, dass sie irgendwo um Pirna wuchs oder noch wächst - ich habe sie bis jetzt dort nicht finden können und ein Beleg-Exemplar von dort scheint nicht zu existiren -, allein mir will scheinen, dass Reichenbach unsere sächsische P. mixta gar nicht liannte und unter diesem Namen etwas anderes (eine procumbens-Form?) verstand, denn seine kurze Beschreibung (Flora sax., S. 330) passt in wichtigen Punkten niclit auf sie und lässt einige Hauptmerkmale unberührt. Unter anderem sagt er: ,Achselblättchen gestielt, lanzettlich, zerschlitzt,... gänzlich verschieden" (das heisst von denen der P. reptans). Er lässt dies als etwas sehr. Wichtiges gesperrt drucken, und doch trifft es gerade bei der P. mixta nicht zu, wohl aber häufig bei P. procumbens. Die Nebenblättchen (Kchb. nennt sie Achselblättchen, wie aus seiner Beschreibung der P. Tormentilla hervorgeht) der P. mixta sind weder gestielt noch zerschlitzt, sondern sitzend, breit lanzettlich, meist ganzrandig (selten etwas gezähnt), ganz ähnlich wie bei P. reptans und nicht ,gänzlich verschieden“. Ihre Blätter sind selten ,,starkbehaart", die Frühlingsblätter bei uns sogar fast kahl, meist fünf- und vierzählig, nur wenige dreizählig, und nicht ,gleichförmig“ (wie bei reptans), sondern nur an der vorderen Hälfte gezähnt etc.

Es bleibt also dahingestellt, was Reichenbach für P. mixta ansah und ob diese bei Pirna vorkam. Er war übrigens nicht der einzige ältere Botaniker, der uiber diesen Bastard im unklaren war. Lehmann, der die P. mixta nur kurz als Anhang zu P. procumbens bespricht, hält sie zwar fuir ,eine aus der Vermischung von P. procumbens mit P. reptans hervorgegangene Form", die bald grössere Aehnlichkeit mit jener, bald mit dieser habe; allein er behauptet, dass sie ,sowohl im Kopenhagener als Ham-

*) Ausserdem nennt Rehb. nur noch "Niesky in der preuss. Lausitz (nach Burkhardt" . 
burger botanischen (iaten aus Samen angezogen, ganz in I'. procumbens zurücliging" (liev. l'ot., S. 18\%). lis ist fast gewiss, dass man beiderorts Samen ron I'. procumbens gesïet liatte, denn die $I$. mirtu ist merkw ïrligerweise gan\% steril. Stmolenlang habe ich anno 1898 und 1899 an einem ron l'. mixta dicht ibberzogenen lieldrain bei Dresden, wo man ihre abgewelkten Blïthenköpfchen zu tauscuden sammeln konnte, vergehens nach einem ausgebildeten Früchtchen gesucht, ebenso an anderen sächsischen Standorten, und anch an meinem Ilerbarmaterial von answärts kounte ich nie cinen Ansatz zur linchtbildumg tinden. Die I'ollenkörmer der P. mixta schlagen ebenfalls fast ausnahmslos fehl. Auch Koch sagt, dass er von ihr keine reifen Frijchte gesehen habe, und Ascherson in Flora des nordostdeutschen Flachlandes, S. 411: ,Frichte biklen sich nicht aus, so dass die Bastarlnatur der PHanze kamn zweifelhaft erscheint." lis ist dies bei der nahen V'erwand tschaft der Stammeltern sehr auffallend, da andere I'otentillenBastarde manchmal ziemlich viele Fröichtchen ausbilden. - Man kamn die Frage aufwerfen, ob die I'. mixta, deren unter sich bleibende Individuen unfruehthar sind, mit anderen Species der Gruppe neue bastarde bilden kam!? Unmöglich seheint es mir nicht, dass die Ovarien mit den l'ollen anderer Arten befruehtet werden, aber sicher (experimentell) nachgewiesen ist es auch noch nicht. Die drei von Figert aufgestellten und ausgegebenen (Doppel-) Bastarde P'. mixta <'Tormentilla, mixta $<$ procumbens, beide vom Hmmmeler Teich bei Liegnitz, und P. reptans $>$ mixta von der Heller '/iegelei bei Liegnitz - ich besitze alle drei in authentischen von Figert gesammelten Exemplaren - machen auf mich nicht den Eindruck von solchen. Den ersten und zweiten wiüde ich für Formen der P. procumbens und den dritten einfach für P. mixta halten.

Der Formenkreis der I'. procumbens $>$ l'eptans ist nicht so eng, wie der der P. mixta Nolte sensu stricto. Es gielst unstreitig Formen, die sich meln der l'. procumbens, und andere, die sich mehr der I'. reptans näher'n und deshalb schlage ich hier wieler die Anfstellung von drei Stufen wach morphologisehen Merkmalen ror: mocumbens $\times$ reptans, superprocumbens $x$ reptans und supereptans $<$ procumbens, wobei es nicht nothwendig ist, in allen Fällen eine Riuckbastardirung zu einem (ler Eltern als sicher vorauszusetzen; es soll mm die Amnäherung an diese ansgedrïckt werden und wir vermeiden eine streng phylogenetische Formel (z. B. I'. [procumbens $<$ reptans] $\times$ procmubens, oder P'. [procumbens $>$ reptans] < reptans), fïr deren Berechtigung wir gewöhnlich den Beweis schuldig bleiben miissten. Eine T'. on pocumbens $>$ reptans kimn möglieherweise ganz anders anssehen als cine pocmmbens $>$ o reptans, wir wissen experimentell noch gar nichts darüber. Die erste kömnen wir vielleicht dem äusseren Ansehen nach ganz richtig als l'. superprocumbens $>$ reptans und die zweite als $\mathrm{P}^{\prime}$. superreptans $>$ procumbens bereichnen, während die vorhin angeführten phylogenetischen formeln direct falsch wären.

Solange nan nur immer die zuerst ron Nolte aufgestellte und ausgegehene, kleinblätterige Form rom Einfelder See in llolstein, lie in den Herbarien sehr verbreitet ist, vor Augon batte und nach ihr die Beschreibungen der l'. mixta machte, war es nicht leicht, eine ähnliche wiederzufinden, denn sie stellt dnrchaus nicht den zwischen $P$. mocumbens und $P$. reptuns in der. Mitte stehenden Tymus des Bastards, sondern nur eine seltene, ziemlich abnorme, ler P. reptans var. microphyllu ähnliche Form desselben dar. Wenn man also die P. mixta 
als Synonym für P. procumbens $\times$ reptans beibehalten will, muss man ihr beifügen: Nolte (erweitert), denn die P. mixta Nolte (sensu stricto) passt sich den wenigsten Formen an. Es ist ja richtig, dass die P. procumbens $x$ reptans im allgemeinen etwas kleiner und schwächlicher ist als die P. reptans, sie gleicht in Stärke des Stengels und Grösse der Theilblättchen mehr der P. procumbens; aber ich kenne eine Form (von Rathen), die in Grösse der Bliithen (2-2 ${ }^{1}$. Centimeter breit) und Theilblättchen (4-5 Centimeter lang) der grössten mir bekannten P'. reptans mindestens gleichkommt, und ohne eingehende Untersuchung wïrde es wohl Niemand wagen, diese Riesenform mit der Einfelder Zwergform Nolte's zu vereinigen. In neuester Zeit scheinen sich aber die Botaniker nicht mehr so streng an das Nolte'sche Vorbild zu halten und erklären auch manche ron ihr recht abweichende Formen für P. mixta (besser wäre dafür P. procumbens $<$ reptans zu setzen). Mein Lerbarmaterial aus Brandenburg und Schlesien stimmt nit den in Sachsen gesammelten und von mir für typisch gehaltenen Exemplaren sehr gut überein. Zimmeter kannte, nach allerlei Bemerkungen in seinen Revisionen zu urtheilen, diesen Bastard schlecht.

Die Unterscheidung der P. procumbens $\times$ reptans von der P. reptans bietet keine Schwierigkeit. Die Hamptachse verzweigt sich wiederholt dichotom, wenn auch spärlicher als bei P. procumbens, die Theilblättchen sind schärfer und spärlicher (oft nur an der vorderen Ilälfte) bezahnt, als bei P. reptans und haben oft eine ausgesprochen keilige, vorn verbreiterte Gestalt. Ferner unterscheidet sie sich von der reptans durch die vielen drei- und besonders vierzähligen Wurzelblätter, die den fünfzähligen beigemischt sind, durch ein dunkleres Grün der Belaubung und clurch die ebenso häufig vier-als fünfzähligen, etwas kleineren und stets sterilen Blüthen. Sie beginnt früher zu bliihen als die P. reptans und behält zahlreichere wintergriine Wurzelblätter; nach ihrem Fortwachsen und Fortblïhen bis in den Spätherbst hinein besitzen ihre Stengel, wie die der letzteren, ein scheinlar unbegrenztes Wachsthum; habituell und biologisch stehen sich beide sehr mahe. Bei beiden wurzeln die Stengel sehr leicht und stark und zwar rom Frühjahr an; bei beiden sind nur die untersten Stengelblätter, an den ersten 3-5 Internodien, gut ausgebildet und werden weiterhin rasch rudimentär, wie ich dies bei $P$. reptans beschrieben habe, bei der $P$, procumbens $x$ reptans allerdings allmählicher und nicht so stark wie bei P. reptans, aber selten findet man am mittleren und oberen Theil des Stengels und an den Aesten noch ein ansgebildetes Stengelblatt, an ihre Stelle treten die Wurzelblätter der Adventivknospen und neuen Pflänzchen, die man so oft mit Stengelblättern verwechselt. Die Nebenb]ättchen zeigen läufiger als bei P. reptans zwei oder drei Einschnitte und das reducirte Stengelblättchen bleibt fast immer gestielt und mit ein paar Einschnitten versehen.

Eine Verwechslung mit der P. procumbens kann nur vorkommen, wenn man von der letzteren bloss die im Herlsst stark wurzelnden Stengeltheile und deren Verzweigungen vor sich hat, an denen die Stengelblätter ebenfalls (doch weniger stark) reducirt sind und viele neue, langgestielte Wurzelblätter erscheinen. In diesem Fall wird die reichere Verzweigung und das Vorhandensein ausgebildeter Früchtchen, sowie das Vorherrschen ron drei- und vierzähliger Blätter oft den Ausschlag zu Gunsten der P. procumbens geben, wenn uns Blattschnitt und andere morphologische Merkmale im Stiche lassen. Um ganz sicher zu gehen, muss man eben die 
ganze Pflanze vor sich haben oder noch besser im Freien bobachten, denn die biologischen Verlaältnisse geben den besten Aufschluss.

Dis Vorkommen ler P. procumbens $\times$ reptans ist durehaus nicht streng an das Zusammenvorkommen iher beiden stammarten oder anch nur an das von einer derselben gebunlen, obwohl sie sich am häufigsten im Gebiet der P. procumbens (in dem anch die P. Tormentilla wohl nie fehlt) findet. Lis erklärt sich dies bei ihrer gänzlichen Unfrnchtbarkeit leicht durch ihre ungeheure Vermehrung auf rein regetativem Weg (stiirker als bei P. reptans!), welche die Leichtigkeit ihrer Verbreitmng zur Folge hat; denn jedes Stengelglied wurzelt und lebt abgetrennt als selbstständige l'flanze weiter. lhre Verschleppung ist dadurel und bei ihrer grossen Lebenszähigkeit ansserordentlich leicht, und eimmal anf Culturland gelangt, ist sie fast mansrottbar, wie zn meinem Leidwesen mein Garten beweist. Im Freien findet sie sich an ähnlichen, meist etwas fenchten Oertlichkeiten, wie die P. reptans, aber auch, wie die P. proeumbens, an 'T'eichdämmen und auf Moorwiesen. Ich kenne sie aus Sachsen in ihrer Mlittelform, das heisst als

P. procumbens $>$ reptans, ron: Planen bei Dresden melirorts !!, so ïherzieht sie z. B. viele alte Gräiber anf dem alten aufgelassenen Friedhof um die Kirche von I'lauen!!. In dem aufgelassenen Theil der Gärtnerei von Mictseh, dureh den jetzt die ,.Münchener Strasse" geführt ist, ïberwucherte sie noch vor zwei Jahren grosse Strecken!!; Plauen'scher Grumd gegenüber dem Felsenkeller !!; in der Nähe des Alberthafens, Uebigan gerenüber!!; an Ufermamern bei Kötzschenbroda! ( $\mathrm{Fr}_{\text {. }}$ ); zwischen Weinböhla und der Spitzgrundmühle !!; '/abeltitz bei Grossenhain (leg. Artzt); bei Radeburg !! und Dobra !!; auf den Moorwiesen ron Tauscha! (H. Dr.); an Dämmen der Volkersulorfer Teiche!!; hei Waltersdorf unweit liathen in der sächsischen Schweiz!! und am W'eg ron Rathen in's Polenzthal!!, sowie an dem nach dem Amselgrund!!; Königsbrück! (H. Dr, als procumbens bestimmt).

P. superreptans $>$ procumbens nenme ich eine der P. reptans durch ihre sehr grossen, fast immer fünfzähligen Blüthen, ihre ebenfalls grossen Blätter, ihre schwache Verzweigung und ihren ganzen Habitus sich stark nähernde Form rom Bachufer (Maner) im Dorfe Niecler-Rathen in der sächsischen Schweiz!!

P. superprocumbens $>$ reptans, welche sich durch stärkere Verzweigung, vortherschencle vierzählige und anch an den oberen Stengeltheilen und Zweigen vielfach gut ausgebilileten Stengelblätter, verschiedene andere Anzeichen und im Habitus der P. procumbens nähert. fand ich am Waldteich bei Lausa!! und in den Thalgründen bei Nieder-liathen!!

Ich zweifle nicht daran, dass die Standorte der P. procumbens $>$ reptans in Sachsen, besonder's im Gebiet der P. procumbens, sich mehren werden, sobald man genauer auf sie achtet. ['ause nennt als solche in seinem mehrfach erwïhnten hinterlassenen Manuscript: .. P'lanitz bei Zwickau, Lobsdorf bei Glauchan und einmal bei Lichtenwalde"; aber diese Standorte bedürfen der Bestätigung, denn seine Planitzer ,,mixta", von der sich ein Exemplar in meinem Besitz befindet, ist nur P'. procumbens.

Die ganze T'ormentilla-Gruppe verdient eine ausführlichere Behaindlung als die, welche ich ihr jetzt angedeihen lassen konnte; ihre Sichtung 
erscheint mir schwieriger, als z. B. die der Vernales-Gruppe. Vielleicht wird es mir gelingen, nach einigen Jahren weiterer Beobachtung und eifrigen Sammelns in verschiedenen Gegenden Sachsens meine vorläufigen Angaben zu erweitern und eventuell auch zu berichtigen, denn ich bilde mir nicht ein, stets den Nagel auf den Kopf getroffen zu haben. Ich bitte unsere sächsischen Floristen, mich in diesen Bemühungen durch Zusendung von Material (möglichst vollständige Exemplare!) und Mittheilung interessanter Beobachtungen zu unterstiitzen. Alles - auch was mir aus den anderen Gruppen der Gattung mitgetheilt wird - soll in späteren „Nachträgen" gewissenhaft verwerthet werden. 
Systematisches Verzeichniss der sächsischen Potentillen-Arten sowie deren Hamptvarietïten und Bastarde.

1. Potentilla alba $\mathbf{I}$.

\section{Trichocarpa.}

Gruppe Fragariastra.

Seite

$\dagger$ l. Fragariastrum Ehrl. . . . . . . . . . . . . . . 12

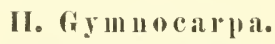

1. Terminales.

Von vorläufig zweifelhafter Stellung.

2. P. supina $\mathrm{I}_{\text {。 }}$.

3. P. norvegica $\mathbf{L}$

Gruppe Rupestres.

4. P. rupestris $\mathbf{I}$.

Gruppe Palustres.

5. P. palustris Scop.

Gruppe Canescentes.

6. P. argentea $\mathbf{L}_{\text {. }}$

a) Can. argenteae.

Var. typica.

$"$ decumbens (Jord.).

$"$ demissa (Jord.).

" tenniloba (Jord.).

$"$ incanescens (Opiz).

" dissecta (Walli.).

\%. P. collina auct.

b) Can. collinae.

*P. thyrsiflora Hiils. 30

Gruppe Rectae.

9. P. recta $\mathbf{I}_{\text {. }}$ (Var. pallida I,ehm.) . 
$\dagger$ P. thuringiaca Bernh.

\section{Gruppe Aureae.}

a) Aur. chrysanthae.

b) Aur. vernales.

10. P. opaca I. .

11. P. verna $\mathbf{L}$.

Var. typica.

$"$ hirsuta DC.

"Amansiana F. Schultz.

", incisa Tsch.

"Neumanniana (Rchb.).

", longifolia Borb.

$\times$ P. opaca $x$ verna

12. P. aurulenta Grmil. . . . . . . . . . . . . . . . . . . . 83

13. P. arenaria Borkh. . . . . . . . . . . . . . . . . . . . . 86

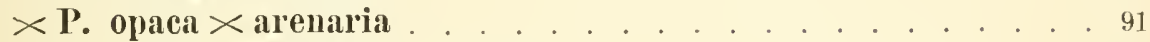

$\times$ P. verna $\times$ arenaria . . . . . . . . . . . . . . 92

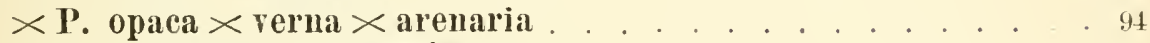

$\times$ P. anrulenta $\times$ arenaria . . . . . . . . . . . . . . . 97

B. Axillares.

Gruppe Anserinae.

14. P. anserina L.

Tar. discolor Wallr.

" concolor Wallr.

$"$ viridis Koch.

" minima Peterm.

Gruppe Tormentillae.

15. P. 'Tormentilla Silsth.

Var. typica.

", strictissima (Zimm.).

.. dacica Rorb.

"sciaphila (Zimm.).

$\times$ P. Tormentilla $\times$ procumbens . . . . . . . . . . . 115

16. P. procumbens Sibth.. . . . . . . . . . . . . 110

$\times$ P. Tormentilla $\times$ reptans . . . . . . . . . . . . . 112

$\times$ P. procumbens $\times$ reptans . . . . . . . . . . . . . . . 117

1\%. P. reptans L. . . . . . . . . . . . . . 106

Var. microphylla Tratt.

" pubescens Fiek. 


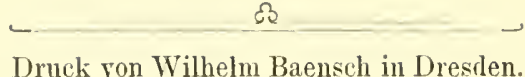




\section{Dr. THEODOR WOLF}

\section{PO'TENTILLEN-STUDIEN}

II.

\section{Die Potentillen Tirols}

nach den Ergebnissen einer Revision der Potentillensammhng im Herbar des ,Ferdinandeums", inchusive des Zimmeterschen Herbars in Innsbruck.

\section{Dresden}

Druck und Verlag von Wilhelm Baensch. 



\section{Die Potentillen Tirols}

\section{nach den Ergebnissen einer Revision der Potentillensammlung im Herbar des „Ferdinandenms“, inclusive des Zimmeterschen Herbars in Innsbruek*).}

Seit vielen Jahren mit dem Spezialstudium der Potentillen beschäftigt, war es längst mein Wunscl, das grofse Herbarium des um die Potentillenforschung hochverdienten und leider zu friuh verstorbenen Professors A. Zimmeter einzusehen, um mir über gewisse kritische Arten, die sich darin in Originalexemplaren der Auktoren befinden mufsten, Kilarheit zu verschaffen; denn beim Studium der Potentillen — wie bei dem anderer polymorpher, ähnlich schwieriger Gattungen — geht nichts ïber die Autopsie. Als ich nun im vorigen Sommer (Juli 1902) bei einem Besuch in Innsbruck mich mit meinem Anliegen an die Direktion des Landesmuseums wandte, fand ich daselbst, und ganz besonders beim Herrn Vorstand der naturhistorischen Sektion, Prof. K.W. v. Dalla Torre, ein so weitgehendes Entgegenkommen, dals mir die ganze in Betracht kommende Abteilung des Hlerbars auf sechs Nonate zum eingehenden Studium zur Verfügung gestellt und nach Dresden geschickt wurde, wo ich den ganzen Winter über mich damit befassen konnte. Für diese grolsmuitige Unterstützung, durch welche ich in meinen Potentillenstudien so sehr gefördert wurde, drängt es mich, der Direktion des Ifuseums und vor allem dem Sektionsvorstand Herrn Prof. v. Dalla Torre meinen tiefgefiihlten Dank auszusprechen.

Das Landesmuseum besitzt in seinem Potentillenherbar einen wertvollen Schatz, auf den ich die Fachgenossen aufmerksam machen möchte.

*) Der Artikel ist auf Veranlassung les Herru Prof. v. Dalla Torre fuir die Zeitschrift des Ferdinandeums verfafst worden. Aber nach Einsendung des Manuskripts (Mitte April) wurde es mir (Ende Mai) rom Museumsvorstand mit dem Vermerk zurïickgeschickt, dafs es sich fïr den Abdruck in dieser Zeitschrift, nach dem Beschlusse des .Ausschusses", nicht eigne, eimmal wegen seines grofsen Umfanges, und dann, weil dieselbe in erster Linie historische und kulturhistorische Aufsätze bringen miisse, naturhistorische aber nur ausnahmsweise bringen könne. Ich veröffentliche es taher als Fortsetzung meiner "Potentillen-Studien I" (1901), wenn es auch nicht im richtigen Verhältnis zu diesen steht. - Gegen die Ablehnungsgriunde des ,Ausschusses" läfst sich gewils nichts einwenden, hätte ich aber dieselben früher erfahren. so wïrde ich die Arbeit auch auf andere Alpenländer, besonders die Schweiz, ansgedehnt und ihr überhaupt ein etwas anderes Gewand gegeben haben. Derzeit mag ich nichts mehr daran ändern und sage: "quorl scripsi, scripsi!" 
Seine lohe liedeutung liegt darin, dafs ihn das ganze Zimmetersehe Herbar einverleilt ist, und dieses umfal'st alles, was Kimmeter im Laufe mehrerer Decomicn his zu seinem 'Tode (1896) durch eigenes eifriges Sammeln mud durch 'Lusendung aus allen Lïndern Europas an P'otentillen zusammenbringen konnte, also rol allem das lielegmaterial, welehes er zur Abfissung seiner zwei Hauptschriften uber die europäischen Potentillen beniitzte, und grofsenteils jenes, auf welehes seine Mitarbeiter auf demselben (reliet (Sicgfried, Borbás, Blocki, Waisbecker, Goiran etc.) früher oder später ihre nenen Species und V'arietäten gegründet haben. \ufserdem liegt aber auch cine grolse Menge unbearheiteter Bausteine, d. h. kritischer Formen ror, the noch der näheren Aufklärung und Bestimmung harren, und denen oft ron '/immeter oder den Einsendern handschriftliche Bemerkungen beigegeben sind.

Bei der grofien Auktorität, welche Zimmeter so lange /eit auf dem Spezialgebiet der I'otentillen besessen hat und zum Teil noeh besitzt ob verdient oder unverdient, mag dahingestellt bleiben - ist es natiirlich, dal's sein Herbar noch linge 'Leit eine sehr wichtige Hilfsquelle für den Fachmann bleiben wird, wenn es sich um die Abgrenzmug oder Bewertung der von ihm und andern aufgestellten formen handelt. Man mag sich als Gegner oder als Anhänger der Kimmeterschen Methode und Behandlungsweise bekennen, so wird ihm doch niemand sein hohes Verdienst schmälern können, das darin besteht, ein so grol'ses und wertvolles Studienmaterial in seinem Herhar vereinigt und hinterlassen zu haben.

Neben dem Zimmeterschen Grundstock enthält das Herbar des Landesmusenms atuch anderes, besonder's fuir dic Flora von 'Tirol wichtiges Material, so z. B. zahlreiche Belegstiiclee aus dem alten Hausmannsehen Herbar, endlich beinahe säntliche bis jetzt von H. Siegfried ausgegebenen Nummern seines grol'sen l'otentillen-Exsiceatenwerkes.

Letzteres, an und für sich gewil's ein sehr verdienstliches Unternehmen, welches dem Botaniker las Studium der Potentillen erleichtern sollte, liat seinen '/weck mur unvollkommen erreicht, nicht nur wegen der viel zu weitgehenden Zersplitterung der Potentillenarten in, neue Sipecies", welche schr vielen Botanikern das Studim dieser Gattung geradezu verleidet lat, sondern aueh wegen der gar zu häufigen fehlerhaften Bestimmung der Formen, sowohl der wildgewachsenen, als auch der in Siegfrieds Garten zu Winterthu kultivierten. Gerade bei den letzteren liegt in vielen Fällen eine sichere Terwechslung der Kulturpflanzen vor, sei es nun, dal's deren Samen schon ursprünglich falseh bezeichnet waren, oder dal's sie im Garten durcheinander gerieten (was in botanischen Gärten erfahrungsgemäls so lıäufig gesehieht). Das Sicgfriedsche Exsiceatenwerk kamn daher dem Anfïnger in der Potentillenkunde durchaus nieht als Auktorität und mal'sgehendes Vergleichsmaterial empfohlen werden; dagegen ist es für den iachmann von grolsem Wert, erstens, weil ihm manche schwer zugängliche, in fernen Lïndern gewaelısene Form zu Händen kommt, die er mun selbst studieren kann, falls ilım die jetzige Bestimmung nicht richtig erseheint, und zweitens, weil er an den vielen Kulturexemplaren - soweit keine offenbaren Verweelislungen vorliegen - die oft sehr weitgehende Veränderlichkeit der Arten durch den Standortsweehsel beobachten und daraus theoretische und selbst praktische Schlufsfolgerungen ziehen kann.

Bei der Revisionsarbeit habe ich mein seit Jahren mit Erfolg angewandtes Prinzip, jede Potentille ror allem auf ihre Behaarungsverluältnisse 
unter dem Mikroskop zu untersuchen, durchgeführt, und bin dadurch mitunter zu den iiberraschendsten Resultaten gelangt, welche der makroskopische Befund allein nie ergeben hätte. Besonders zur Erkennung vieler Hybriden ist die mikroskopische Untersuchung unerlälslich. Wenn ich so häufig in den Fall komme, Zimmeters und anderer Bestimmungen widersprechen zu müssen, so erklärt sich dies hauptsächlich darans, dafs er - wie die meisten seiner Mitarbeiter - das Mikroskop offenbar viel zu wenig konsultiert hat*).

Die zahlreichen Erfahrungen, welche ich durch ein mehrmonatiges Studium des Innsbrucker Herbars gewonnen und aufgezeichnet habe, gedenke ich seinerzeit in einer allgemeinen Monographie der Potentillen zu verwerten; doch dürfte es den Botanikern Tírols und benachbarter Alpenländer nicht unwillkommen sein, wenn ich schon jetat die tiroler Potentillen, die hier naturgemäls am reichsten vertreten sind, einer kurzen Besprechung unterzielıe. Sie sind auch in Herbar, dem besonderen $\mathrm{Zwecke}$ des Landesmuseums entsprechend, gesondert zusammengestellt und füllen sechs starke Fascikel. - Durch die besondere Zuvorkommenheit des Herrn Prof. J. Murr war es mir möglich, dessen an Potentillen reiches Herbar, das ich schon voriges Jahr revidierte, zu dieser kleinen Arbeit von neuem heranzuziehen.

Wenn es sich nur darum handelte, ein möglichst vollständiges Standortsverzeichnis der in Tirol vorkommenden Arten herzustellen, mülste noch manches andere Privatherbar durchgesehen werden, vor allem auch die prachtvolle Hutersche Sammlung, welche nun ihre bleibende Aufstellung in Brixen finden soll oder schon gefunden hat, und in die ich im letzten Sommer einen flüchtigen Einblick nehmen durfte. Allein mein jetziger Zweck besteht nicht so fast in der Auffiihrung aller bekannten Standorte - dies wird die Aufgabe der tiroler Floristen sein **) - sondern vielmehr in der kritischen Untersuchung der tiroler Arten, Varietäten und Formen und in der Richtigstellung ihrer Namen, falls sie bisher unrichtig aufgefalst sein sollten. Ich werde daher flïchtig über solche Arten hinweggehen, über welche unter den Botanikern keine Differenzen bestehen, und nur bei den ,kritischen Arten" eingehender verweilen, olne aber selbst bei diesen das Thema nach allen Richtungen hin erschöpfen zu wollen. So mufste z. B. hier von ausführlichen Beschreibungen der Formen abgesehen und notwendig eine gewisse Orientierung in der neuen Potentillenforschung vorausgesetzt werden; vor allem supponiere ich das Yertrautsein mit den zwei Zimmeterschen Abhandlungen: I. „Die europäischen Arten der Gattung Potentilla" (Steyr 1884) und II. „Keiträge zur Kenntnis der Gattung Potentilla" (Innshruck 1889), die ich kurz mit Z. I und Z. II citieren werde mit Beifügung der Seiten oder Nummern, unter denen die betreffenden Formen dort aufgeführt sind. Ferner würde es zu weit führen, wenn ich mein Festhalten an gewissen

*) Über die so leichte Untersuchung mit einem einfachen Mikroskop, die ich jerlem Potentillenfreund dringend empfehle, siehe: "Potentillen-Stndien I*6, $\mathrm{S}_{i .} 43$.

**) IVir besitzen bereits ein paar solcher" Standortsverzeichnisse: ,U be r die Potentillen des mittleren Tirols" von Dr. F. Sauter in Bozen (i). B. Z. 1889 Nr. 6). ,Die Potentillen Nordtirols, insbesondere der weiteren Inusbrucker Umgebung"t von Dr. J. M urr in Innsbruck (Dentsch-bot. Nonatsschr. Jahrg. IX [1891] Nr. 2). Beide Verfasser stehen ganz auf Zimmeters Standpunkt beziiglich der Nomenklatur und Auffassung der tiroler Potentillenformen. 
alten Namen gegeniiber den modernen Um- und Wiedertïufern rechtfertigen wollte, da dies wieder unfangreiche Literaturnachweise zur Folge hätte. Wemn ich in der Potentillenforschung bezüglich der Nomenklatur und Auffirssung der Formen nicht den Fulistapfen Zimmeters folge, sondern meine eigenen Wege gehe, so soll dies der Objektivitït meiner Arbeit nichts schaden. Besonders die Namengebung ist etwas mehr oder weniger Äul'serliches, gleichsam ein Ḱleid, das gewechselt werden kann, und der freund der "kleinen Species" wid sich leicht meine Sprache in die seinige ïbersetzen können; würde es sich doch in den meisten Föllen nur darum handeln, meine "Varietäten" zu "Species" zu erheben. Yudem wird auch der, welcher meinem Standpunkt ablehmend gegeniibersteht, wenigstens den toleranten Grundsatz gelten lassen: audiatur et altera pars*).

Noch weniger als die Nomenklatur wird für unseren gegenwärtigen \%weck die systematische Ricilrenfolge der Gruppen und Arten, in welcher ich sie auffülıre, ins Gewicht fallen. Für die Potentillen eines Lindes kommt immer nur ein kleiner Bruchteil des ganzen P'otentillensystems in lietracht, der ausser den Zusammenhang mit letzterem kaum genügend erläutert werden könnte. Deshalb folgen hier die Gruppen einfach und olne weitere Begriiudung in der Ordnung aufeinander, welche sie nach meiner lleinung annïhernd einnehmen würden, wenn man aus dem allgemeinen system die uns fehlenden Gruppen herausnähme.

Dresden-Planen, im April 1903.

Th. Wolf.

\section{FRAGARIASTRA.}

\section{Potentilla nitida $\mathbf{I}$.}

Diese schöne Art, eine der lieblichsten Alpenblumen überhaupt, ist in Tirol auf die siidlichen Kalk- und Dolomitalpen beschränkt, dort aber recht verbreitet. Wir finden sie im Innsbrucker Herbar sehr reichlich in 38 bogen aus 'Tirol von folgenden Standorten: Monte Baldo, Val di Ledro, Stenico, Alpen ïber Rovereto, Mt. Castellazzo in Folgaria, iiber Paneveggio, Ampezzaner Alpen, Drei Zinnen, Neunerkofl bei 'Toblach, Seekotl, Sextener Böden, Fischleinthal, Kirschbaumeralp u. a. in den Lienzer Alpen, Schlern (hesonders schön und häufig), Seifser Alp, I'eitlerkofl bei Brixen.

Die Bliiten der l'otentilla nitida sind bekanntlich pfirsichrot, doch findet man alle Schattierungen von dieser Farbe bis zur fast reinweilsen. Diese ,forma albiflora" erwähnt Sauter als selten für Sültirol, gibt aber keinen besonderen Standort dafür an. Die meist sehr verblal'sten llerbar-Exemplare eignen sich nicht zur Unterscheidung dieser Form.

*) Über meine Stellung zn \%immeters Methode habe ich mich ansführlicher geäufsert in meinen "I'otentillen-Studien I" (Dresclen 1901), anf welche ich liemit ver weise. 


\section{Potentilla Clusiana Jacu.}

Der einzige für Tirol sicher nachgewiesene und im Ilerbar durch ein Beleg-Exemplar vertretene Standort dieser Species ist das Wormserjoch, an welchem sie Zimmeter zuerst im Jahre 1871 auffand. Die Angabe: „Zillerthal nach Braune und Schrank.'“ bezweifelt auch Zimmeter. Vielleicht wurden kleine Exemplare der P. caulescens mit der P. Clusiana verwecliselt, was ohne genane Untersuchung der Staubfäden (ob behaart oder unbehaart) leicht geschehen kann.

Der ganz isolierte Standort am Wormserjoch ist höchst merkwürdig, da er aufserhalb des Verbreitungsgebietes der Species liegt. Sie fehlt in allen westlicher gelegenen Alpenländern und verbreitet sich erst von Salzburg und Kärnten an weit über die östlicher und sïdlichen hohen Gebirge bis nach Bosnien hinein. Erneute Nachforschungen am Wormserjoch wären sehr erwünscht, denn Zimmeter achtete zuerst nicht weiter auf sie und etiquettierte sie als „P. caulescens"; erst mehrere Jalıre später erkannte er ihre wahre Natur.

\section{Potentilla caulescens L.}

Die im Herbar vertretenen tiroler Standorte aufzuzählen, halte ich fuir überflüssig, da diese Art in Nord- und Südtirol, besonder's in allen Kalkgebirgen, von den Talsohlen bis zu etwa 1500 Meter hinauf sehr allgemein verbreitet ist. Sie liegt in 40 Bogen vor, darunter auch in der ,forma robusta Zimm." und in der ,forma pauciflora Zimm.", Standortsformen, wie sie sich schliefslich bei jeder Species wiederholen, und die man allenfalls auf den Herbar-Etiquetten notieren kann, nicht aber in die Literatur einführen sollte.

Var. petiolulata (Gaud. pro sp.) kann nur als Varietät der P. caulescens aufgefalst werden, bei der die mittleren Teilblättchen mehr oder weniger deutlich kurz gestielt sind (an manchen Blättern aber auclı nicht). - Schon die echte P. caulescens erscheint unter dem Mikroskop mitunter schwach- bis ziemlich starkdriisig an Stengeln und Blättern. Bei der Var, petiolulata steigert sich der Driisenreichtum an allen Pflanzenteilen oft bis zur Klebrigkeit, dann entsteht die

Forma viscosa (Huter als Var. der P. caulescens). - Aus Tirol liegen als ,P. petiolulata Gaud." Exemplare rom Schlols Hauenstein bei Seis (leg. Hausm.) und aus dem Val Vestino (leg. Porta) ror, und als „P. caulescens Var. viscosa Hut," solche von Storo in Judicarien (leg. Porta, Siegfr. Exs. No. 935) und von Felswänden bei Vela unweit Trient (leg. Gelmi, Siegfr. Exs. No. 935a). Nach meiner Ansicht gehören alle diese tiroler Pflanzen z.u Var. petiolulata f. viscosa (Hut.), - Eine ganz ähnliche Form ist die „P. caulescens Tar. cebennensis Siegfr." aus Sïdfrankreich und Ostspanien, welche bereits Rouy \& Camus in ihrer Flore de France (1900) zur Var. petiolulata gezogen haben; doch unterscheidet sie sich von Huters viscosa dadurch, dafs inre Staubfäden nur bis zur halben Höhe (nicht bis zur Spitze) behaart sind, wie bei den Varietäten petrophila (Boiss.), nebrodensis (Strobl) und Doerfleri (Wettst.).

\section{Potentilla alba $\mathrm{L}$.}

Auch über diese Art können wir, als in unserem Gebiete allgemein verbreitet, kurz hinweggehen, ohne Aufzählung der vielen Standorte aus 
ganz Tirol, die auf 32 Bogen vertreten sind. Nur auf eine auffallende Form aus Südtrol möchte ich aufmerksam machen; sie liegt in schönen Exemplaren. von Lofs gesammelt, ron Stenico in Judicarien und von Cles inn Val di Non vor. Ls ist bekannt, dass die länglichen Teilblättchen der P. alba in ihrer Breite sehr varieren - man könnte danach die extremsten Formen als f. stenophylla und fo platyphylla unterscheiden-. aber derart verbreiterte Teiblätter, wie sie die erwälnten Exemplare aufweisen, sind mir aus ganz. Europa noch nicht rorgekommen. Ihre Breite betrïgt $2-2{ }^{1}$ Centimeter bei einer L ainge von 3-4 Centimeter, und zwar liegt die grölste Breite nicht, wie gewöhnlich, in der Mitte, sondern im vorderen Drittel des Blättchens, wodurch dieses eine entschieden obovale Form bekommt, die sich durch die keilig zulaufende, zahnlose Basis noch mehr hervorhebt. Dabej besitzt jedes Tejlblatt an seinem breit-abgerundeten Vorderteil nur ein paar, in Verhältnis zu seiner Grölse sehr kleine und seichte Zahneinschnitte; das winzige Mittelzähnchen verschwindet fast ganz. Was aber tiese Pflanzen noch auffallender macht, ist ihre vom Typus abweichende Behaarung. An den Blättern und deren Rändern benerkt man sehr wenig ron den weifsen anliegenden, seidigglänzenden Striegelhaaren der gewöhnlichen I'. alba, und die Stengel und Blattstiele bei der typischen alba ebenfalls eng anliegend oder doch stark aufrecht abstehend behaart — sind hier dicht ron weichen, gelblichen, oft ganz horizontal abstehenden Haaren besetzt, ähnlich wie bei P. micrantha Ram. Wenn ich nur diese Behaarung in Betracht zöge, möclite ich an eine I'. alba $>$ micrantha denken (- die letztere kommt nämlich in Südtirol ror, nicht aber die ähnlich behaarte P. Fragariastrum -), aber die bezalnung der Blätter und andere Erwägungen lassen diesen Gedanken nicht recht aufkommen. Inrlem ich also diese l'flanze vorlïufig noch für eine auffallende Varietät der I'. alba arsehe, schlage ich für sie den Namen

frr. obrratu mh. vor, sie zugleich dringend der weiteren Beobachtung an Ort mil stelle empfehlend, welche schneller und besser zur vollen Aufliärung ihrer Natur führen wird, als das Studium alter Herbarpflanzen.

\section{Potentilla Fragariastrum Ehrh. (Fragaria sterilis L.).}

Sie konmt in Tirol nur in der Ungegend von Innsbruck und Hall vol" und liegt ron da in sieben Bogen anf; aufserdem findet sich in Herbar noch ein kleines lixemplar vom Schlolsberg bei liregenz in Vorarlberg (leg. Lhner). Zu besonderen liemerkungen bietet dieses Material kemen Anlals.

\section{$\times$ P. alba $\times$ Fragariastrum (P. hybrida Wallr.).}

Diese Bastardstufe, welche die Mitte zwischen den beiden Stammarten lält und die häufigste ist, liegt zwar im Innsbrucker Herbar aus 'Tirol nicht rol, (lagegen ein kleines von Gremblich im Gnadenwald bei Hall gesammeltes lixemplar, welches die P. superalba $\times$ Fragariastrum (P. Gremblichii (iandog.) darstellen soll. Schon Zimmeter (I. S. 29) vermochte es vou einer kiimmerlich entwickelten P. alba nicht $z$ u unterscheiden, und ich mul's grestehen, dass es mir ebenso ergeht. Andererseits steht aber fest und ist besonders durch ron P. Gremblich gezogene líulturexemplare 
bewiesen, dafs der Bastard in der Tat im Gnadenwald vorkommt (oder vorkam), und zwar nach den mir im Herbar MI urr vorliegenden Exemplaren in zwei Formen, von denen die eine der von Reinecke aus dem Steigerwald bei Erfurt ausgegebenen P. superalba $\times$ Fragariastrum (P. Gremblichii) ganz nahe kommt und nach meiner Ansicht wirklich diese Kombination darstellt, die andere aber, von Prof. Murr erst im August 1902 aus dem Franziskanergarten in Hall erhaltene, nach Blattform und Behaarung weit melır zu P. Fragariastrum neigt, so dafs sie mindestens als $P$. alla $\times$ Fragariastrum (P. hybrida), wenn nicht gar als P. super-Fragariastrum $\times$ alba (P. Reineckei Sagorski) angesprochen werden muls. Es fragt sich nun, ob diese zweite, von der ersten verschiedene Form auch ursprünglich aus dem Wald in den Garten verpflanzt worden, oder erst in diesem durch Kreuzung der ersten mit einer reinen P. Fragariastrum entstanden ist (vorausgesetzt, dass die letztere ebenfalls im Garten kultiviert wird)*). Daf's wir es bei der zweiten Form nur mit grol'sen Herbstblättern der ersten zu tun haben sollten, scheint mir nicht wahrscheinlich. Wer Zeit und Mühe nicht spart, wird vermutlich beim fleifsigen Nachsuchen um Innsbruck alle drei Hybridationsstufen auffinden, ähnlich wie sie Reinecke bei Erfurt nachwies.

\section{Potentilla micrantha Ram.}

Diese Art liegt aus Tirol in 10 Bogen vor, und zwar aus Nordtirol nur aus der Gegend von Innsbruck, gerade wie die vorhergehende P. Fragariastrum, z. B. über der Hungerburg und Hötting. Dann tritt sie wieder in den siidlichsten Landesteilen auf; nach dem Herbar rechts der Etsch in Judicarien: Val Vestino, Val Daone, Val Rendena; links der Etsch im Val Sugana: bei Vigolo, Vettaro und Centa.

Prof. Murr will beobachtet haben, dals um Innsbruck die P. micrantha erst an der oberen Verbreitungsgrenze der P. Fragariastrum beginnt und von dort bis gegen 1600 Meter hinaufsteigt. An der Berührungszone fincle sich dann der folgende Bastard. - Herr Murr erwähnt auch ,eine hübsche Form mit rosenroten Kronblättchen", welche Evers an der Arzler Alpe fand.

\section{$\times$ P. micrantha $\times$ Fragariastrum (P. spuria Kern.).}

Dieser zuerst bei Innsbruck von Kerner entdeckte und benannte Bastard kommt, wie schon bemerkt, in der Berührungszone beider Stamnarten über Hötting und Mühlau vor. Im Herbar befinden sich zwei Belegexemplare, das eine von Kerner selbst, das andere ron Hoffmann gesammelt. - Aufserdem liegen noch zahlreiche schöne Exemplare von Le Mont über Lausanne vor, welche Favrat eingesandt hat.

*) Bekanntlich bilden sich in botanischen Gärten ziemlich oft und leicht Potentillenbastarde. 


\section{PALUSTRES.}

\section{\%. Potentilla palustris Scop. (Comarum palustre L.).}

Sic liegr ron ziemlich zahlreichen Standorten Nord- und Süıltirols vor und scheint dmach iiber das ganze Land an geeigneten Stellen ('Torfsïmpfen) recht verbreitet zu sein. Ich salı kein Exemplar, das als Varietät von der typischen P. palustris zu tremnen wäre. Überhaupt sind die Varietäten, die man von dieser Art aufgestellt hat, sehr unbedeutend; sie bleibt sich in ihrem die ganze nördliche Halbkugel umfassenden Verbreitungsgrebiet fast gleich und stellt eine der konstantesten und iiltesten Typen der Gattung ror. Die Gruppe der Palustres ist monotyp.

Wemn man die P. palustris von den iibrigen Potentillen als besonderes Genns abtremen will, mul's man konsequent noch mehrere Grujpen als Genera abtremnen, welche in ihrem Ban (besonders in dem der Blitte und Frncht) vielleieht noch markantere Eigentiimlichleiten anfweisen als jene, so z. B. die Fruticosae nud die liupestres. In ter 'Tat hat A. Rydberg in seiner neneu grofsen Monographie der nordamerikanischen "Potentille a e" (1898) dieses Verfahren eingesehlagen und stellt z. B, für die Fruticosae das (iemus Iasiphora, für die Rupestres das Genus Irymocallis, für die Anserinae das Gemus drgentina ete. aut. Ich kamn mich diesem zersplitteruden Verfahren bis jetzt nicht auschliefsen, mufs aber dafïr folgerichtig das Comarum palustre L. zu den P'otentillen ziehen, wis ja neuerdings ron vielen Seiten geschicht*).

\section{RUPESTRES.}

\section{Potentilla rupestris $\mathbf{L}$.}

Diese schöne Art ist sowohl nach dem Herbarmaterial (etwa 15 Bogen ron ebenso vielen Standorten), als auch nach den Angaben Sauters und Murrs in Siid- und Nordtirol sehr verbreitet, aber niemand scheint bis jetzt auf ihre Formen näher geachtet zu hahen. Neben der in Centraleuropa verhreitetsten, ziemlich kleinblütigen, reichverzweigten, auf den Blättern schwachlehaarten, typischen Form findet sich sowohl in Nordals in Sültirol eine andere sehr grol'sblütige, wenig verästelte, auf den Blättern stark beharte und meist etwas niedrigere Form, welche mir identisch zu sein scheint mit der

Írr. gramulforu Heuffl. (var. villosa Lec. \& Lamt., P. Beniczkyi Friv., P.macrocalyx Huet). Es mag auffallend erscheinen, dal's ich zu dieser Varietät drei Synonyma citiere, die mehrfach als drei Species hingestellt wurden, doch bin ich durch Vergleichung zahlreicher Individuen der villosa aus Südfrankreich, der Benitzkyi aus den Balkanländern und der macrocalyx aus den Pyrenäen zur Überzeugung gelangt, daf's alle drei "Species" einer und derselben rupestris-Varietiit angehören, die sich durch die angegehenen Merkmale von der typischen P'. rupestris zwar unterscheidet, aber allenthalben Übergänge in diese zeigt. Aus den Alpen kenne ich diese Varietït

*) Siehe darüber "Potentillen-Studien I", S. 19. 
bereits aus der Südwest-Schweiz, aus Graubünlten und ans Tessin (Herb. Chenevard). - Dass die P. rupestris var. villosa Lec. \& Lamt. mit der var. grandiflora Heuffl. (P. Beniczkyi Friv.) übereinstimmt und dafs beide unwerklich in die typische 1'. rupestris übergehen (besonder's bezüglich der Behaarung und der Blütengrölse), bezweifle ich längst nicht mehr, dafs aber auch die P. macroculyx Huet, der man gewöhnlich kleinere Kronblätter (,petala calycem vix superantia") zuschrieb, zu derselben Varietät gezogen werden müsse, beweisen erstens mehrere Exemplare aus den Pyrenäen, die bei voller Wahrung ihrer übrigen macrocalyx-Charaktere, doch ebenso grofse Kronblätter besitzen als die grolsblütige Var. villosa, und zweitens der Umstand, dafs diese letztere in der neuesten Flore de France von Rouy \& Camus nur mehr als Synonym der macrocalyx figuriert, die nun ebenfalls als ,grofsblütig: bezeichnet wird. Schon Zimmeter stiegen zuletzt Bedenken ïber den spezifischen Wert der in Frage stehenden Form auf; er schreibt in seinen Beiträgen (S. 11): „P. macrocalyx Huet. dürfte nach Originalexemplaren aus dem Garten Boissiers in Valeyres wohl mit einer stärker behaarten Form der P. rupestris identisch sein". Nun, ganz dasselbe lälst sich von der P. Benitzkyi Friv. sagen, und da nacl meiner Meinung hier von keiner, ,Species" die Rede sein kam, fasse ich beide samt der villosa Lec. in der alten V'arietät grandiflora Heuffl. zusammen.

Exemplare dieser Varietät liegen im Innsbrucker Herbar vom Ritten bei Bozen und von Völs bei Innsbruck vor, von beiden Lokalitäten und von Lienz aber auch solche, die sich stark der var. typica zmneigen.

Die „P. rubric a ulis Jord.“ (Z. II, Nr. 3ăa) übergehe ich hier absichtlich; sie ist nach meiner Heinung einfach zu streichen und nicht eimmal als "forma" der P. rupestris mitzuschleppen, denu es können darunter nur die rotstengligen Individuen der letzteren vou sonnigen und dïrren Standorten verstanden werden, die gar nicht selten, jedenfalls auch in Tirol, mit der grünstengligen Form rorkommen (Z. II, S. 11) und ilren Charakter sofurt verlieren, wemn sie in den Schatten verpflauzt werden. Auch die Var. grandiflora besitzt häufig einen blutroten Stengel. Wenn wir mit solchen „Formen“ - und erst recht "Varietäten" oder gar "Species" - beginnen wollten, müfsten wir bei einer ganzen Reihe ron Potentillen, z. B. bei P. argentea, canescens, recta etc. eine „forma rubricaulis" einfülıren, was doch recht überflïssig" wäre. - Nebenbei sei bemerlit, dafs Zimneter nach seinem Prinzip (wie auch schou Jorlan) diese Form nicht mit dem binären Namen Pot. rubricanlis auftuihren durfte, da schon in ilen dreilsiger Jahren des vorigen Jahrhunderts eine gute bis hentzutag anerkannte nordamerikanische Art den Tamen P.rubricaulis Lehm. führt.

\section{RIVALES.}

Diese Gruppe wurde bis jetzt allgemein mit dem Namen ..Acephalac" oder ,Annucte belegt. Schon für den kleinen europäischen Bestandteil derselben (nur P. supina L. und P. norvegica L.) wird dieser Name bedenklich, wenn man das Verhalten der P. norvegica beachtet*); zieht man aber die zahlreichen aul'sereuropäischen Arten der Gruppe heran, so wird er ganz

*) Potentillen-Studien I, S. 14. 
unhaltbar, denn nach meiner Untersuchung gehören mehrere asiatische und amerikanische ausdauernde Arten nach ihrer Blüten- und Fruchtbildung, sowie nach anderen morphologischen Nerkmalen ohne allen Zweifel in dieselbe Gruppe ( - der einzige Untersehied der Vieljährigkeit ist kein Grund zu ihrer Ausscheidung -), so unter anderen die südamerikanische $P$. andicola Benth. und die centralamerikanische P. heterosepala Fritsch., die sich früher nirgends ungezwungen unterbringen hief'sen.Der Name Rivales scheint mir für die Gruppe nielıt nngeeignet zu sein, einmal weil wir in der nordamerikanischen $P$. rivalis Nutt. einen guten Repräsentanten von ihr haben, besonders aber weil er nicht nur für die einjährigen, gern an Gewässern lebenden, sondern auch für die mehrjährigen Arten bezeichnend ist, welche sich meistens an Bächen und quelligen Orten der Gebirgsgegenden finden*). (Aus ähnlichen Gründen benannte ich die Gruppen der ",Rupestres" und ,I'alustres".) In der Flora Tirols spielt die Gruppe der Rivales eine sehr untergeordnete Rolle.

\section{Potentilla norvegica $\mathbf{L}$.}

Sie gehört in Tirol zu den seltenen Pflanzen und wurde in neuerer Zeit wohl nur mehr im Lanser 'Torfstich bei Imnsbruck gesammelt, ist aber nach Murr auch hier im Aussterben begriffen. Von friber liegen aus dem Hausmannsehen Herbar zwei Bogen von Rattenberg vor mit der Bemerkung: ,stellenweise massenhaft". Aus demselben Hausmannschen Herbar stammen ein par von Facchini bei Primiero an der Südgrenze des Landes gesammelte Exemplare, leider ohne nähere Angabe des Standortes, weshall, nicht $\mathrm{zu}$ entscheiden ist, ob die Art dort, wie in Nordtirol, ursprünglich ist oder war, oder ob sie sich nur verschleppt auf liuderalstellen fand, was bei $P$. norvegica ebenso wie bei I'. supina öfters vorkommt.

\section{Potentilla supina $I_{\text {. }}$.}

Sefshaft und ursprünglich dïrfte diese weit ïber Europa hinans verbreitete Art in 'Tirol nur am Lanser See (neben der l'. norregica) auftreten. Alle übrigen 10 Exemplare stammen von ,Ruderalplätzen" in und um Innsbruck, Mühlau, Weer, Brixen und Salurn. Die P. supina führt abgesehen von ihren natuirlichen Standorten an Seen und Ufern grofser Flïsse - ein zigennerhaftes Vagabundenleben, hier und dort auftauchend und wieder versehwindend, und dïrfte sich in 'Tirol, wie anderwärts, durch den steigenden Verkehr, besonders den Eisenbahnen entlang, eher weiter ausdehnen, als vermindern. Aber sie trägt dann eben den Charakter einer unbeständigen Adventivpflanze, die sich allerdings stellenweise vollständig einbürgern kann.

Forma evecta Uechtr. (Spenn. als Var., P. limosa Zim., Boeningh. als Var.), eine kleine, aufrechte, unbedeutende Standortsform der P. supina,

*) Celakovský machte im Prodromus der Flora von Böhmen aus der P. supina nnd der P. norregica die Gruppe der ,Ripariae", olne jedoch Nachahmung zu finden. Der Name war, die zwei europäischen Species allein in Betracht ziehend, geschickt gewählt. 
liegt im Herbar nicht vor, sie wird sich aber an geeigneten Orten (vielleicht am Lanser See) zwischen der typischen Form und in Übergängen zu dieser sicher in Tirol ebenso gut finden lassen, wie anderwärts, wo man sie sucht und beachtet.

\section{CANESCENTES.}

\section{CANESCENTES BOREALES *).}

\section{Potentilla nivea $\mathrm{L}$.}

Diese in hochnordischen Gegenden sehr formenreiche Species tritt in Tirol - wie in der ganzen Alpenkette - nur in der kleinen

Var. alpina Lehm, auf. Belegexemplare liegen vor vom Hausstein bei Kitzbühel, Hühnerspiel am Brenner, Riedberg (IVeisspitz) bei Sterzing, Hörnle oberhalb Jagdhaus bei Defreggen, Dabertal (Umbraltal), Dorfer Alpe bei Prägraten, Schlern-Plateau, Sauriesel bei Laas, Schinig ober der Wand, Zefallberg am Wachthaus, Alpen im Tösnertal bei Tösnes.

\section{$\times$ P. nivea $\times$ alpestris r. firma (P. Breunia Hut.).}

Dieser unzweifelhafte, niedliche Bastard wurde bekanntlich ron Huter auf dem Riedberg (Weisspitz) am Brenner oberhalb Sterzing entdeckt und liegt im Herbar in zahlreichen Exemplaren auf. Meines Wissens ist er bis jetzt von keinem andern Fundort bekannt, was um so merkwürdiger ist, als die P. nirea meistens mit der $\mathrm{P}$. alpestris zusammen wächst.

Fïr eine $P$. superalpestris $\times$ nivea, also sozusagen für eine $z u$ P. alpestris zurückschlagende P. Breunia halte ich ein vereinzeltes Pflänzchen vom Hühnerspiel, welches im Herbar Murr zusammen mit ein paar Pflänzchen der P. alpestris $\times$ frigida liegt (leg. Murr 1897). Es unterscheidet sich von den letzteren durch den Blattschnitt der P. Breunia, durch das Fehlen der charakteristischen Sitzdrüsen der P. frigida und durch viele kurze starkgekrümmte Härchen auf der Blattunterseite, welche den nivea-Filz andeuten.

\section{CANESCENTES ARGENTEAE.}

\section{Potentilla argentea $I_{\text {. }}$.}

Die ungemein formenreiche Art der P. argentea macht vielen Botanikern grofse Schwierigkeiten, besonders wenn sie diejenigen Formen unterscheiden sollen, welche man in nenerer Zeit als besondere "Species" hingestellt hat. Etwas einfacher gestaltet sich die Sache für den, der diese

*) Siehe darüber „Potentillen-Studien I“", S. 54 Anm. 
Species für das nimmt, was sie in der 'Tat sind, für Varietäten, welche olne bestimmte Grenzen hundertfältig ineinander übergehen, und der durch lirfahrung weil's, dal's Mittel- und Zwischenformen ebenso häufig, ja oft noch häufiger auftreten, als die, welche wir ,typisch" nennen. Ieh kenne unter den vielen Varietaiten der P.argentea keine einzige, die einigermalsen abgesondert bliebe und keine Übergänge in eine oler einige andere zeigte. Die Formen incanescens-dissecta, typiea-incanescens, typica-tenuiloba, tenuilobadissectil sind meist viel häufiger, als die reine Tar. incanescens, dissecta, tenuiloba. Is geht eben bei der I'. argentea wie bei so vielen anderen polymorphen Arten: man hat aus dem grolsen Schwarm der Formen die extremsten Individuen herausgesucht und auf sie die Yarietäten gegründet und diagnosiert. Wir müssen ja leider so verfahren, wenn wir nicht in eine unendliche Zersplitterung lineingeraten und schlicl'slich auf eine unüutze Individuenbeschreibung zukommen wollen. Nur schade, daf's sich die Natur um unsere Abgrenzungen so wenig kümmert und uns so selten Fixemplare vorsetzt, die ganz unseren Anforderungen an den abstrahierten ,'Typus" unserer Varietäten (resp. kleinen Species) entsprächen; sie gibt uns dadurch einen Fingerzeig, dal's wir die Species oder Varietäten nicht zu engherzig auffassen sollen. Wo die Natur selbst keine Grenzen gezogen hat, können wir auch keine zielıen. Mit dieser Erkenntnis kommen wir weiter, als wenn wir fortfaliren, jede uns auffallende Form sofort mit einem neuen wohlklingenden Namen zu belegen und die Zwangsjacke immer fester zu schnïren.

Zimmeter hat, wie aus seinem Herbar und aus zahlreichen Revisionen nachzuweisen ist, mehrfach die Grenze oder den Unterschied zwischen den Collinae und den Argenteae nicht erkannt und dadurch eine gewisse Konfusion in die tiroler Formen dieser beiden Gruppen gebracht. So z. B. hat er einerseits verschiedene Collinae (aus Südtirol und Verona) für die P. confinis Jord. gehalten, welche er allerdings zuerst (I, S. 12) für eine P. collina (sensu lato) ansah, später aber (II, S. 20) ganz richtig in den Formenkreis ler P. ar'gentea versetzte; andererseits hat er aus Herbstformen der I'. argentea eine neue collina-Species, die P. Sauteri Zimm., gemacht (diese freilich später auch wieder mit richtigen Collinae vermiseht), und in anderen argentea-Formen Tirols die italienische P. Johanniniana Goir. oder auch P. Goirani Zimm, zu erkennen geglaubt. Kurzum, Zimmeter war sich iiber die Formenkreise der P. argentea und der P. collina durehaus nicht klar, was wir besonders auch bei der Besprechung des letzteren sehen werden, und so konnte es kommen, dass anch Murr, auf \%. bauend, die typische P. argentea in Nordtirol für selten hielt und dafür P. confinis, P. Johamniniana und P. Sauteri einsetzte.

Wir liönnen zunächst ein parr ,Species" als Steine des Anstofses ganz aus lem Weg räumen.

['. Sauteri Zimm. (II, No. $7 \%$ a) ist zu streichen; sie begreift, nach den Originalexemplaren ron Bozen, die durch Saisondinorphismus etwas veränderten Herbstpflanzen der P. argentea v. typica, aus deren Wurzelstock im Herbst - wie so liäufig bei P. argentea - sterile 'riebe (.,rosulae centrales") lierrorkommen, welche Zimmeter irregefiihrt zu haben scheinen. Wie er sie als ,oler P. thyrsiflora Hüls. nahestehend“ bezeichnen liounte, ist mir unbegreiflich. Eine ,P. Sauteri" von Halle a. d. Saale ist ein Herbstexemplar (nit Wurzelrosetten) der P. argentea Var. decumbens. Dic ron Siegfried kultivierte und unter No. 131 ausgegebene, ,I'. Sauteri: ist 
gemeine P. argentea. - Wenn dann Zimmeter auch echte Collinae (von Bozen, Verona, Moskau etc.) als P. Sauteri bestimmte, widersprach er damit seiner eigenen Diagnose, die er von der letzteren gegeben hatte, und bewies damit seine Unsicherheit auf dem Feld der Collinae.

P. argentata Jord. und P. confinis Jord. (Z., No. 82) gehören als Synonyma zur P. argentea Var. typica. Welche von den vielen Formen dieser Varietät Jordan mit jenen Namen bezeichnen wollte, ist kaum mehr herauszubringen, was anch nicht schadet, denn sie haben jedenfalls keinen höheren Wert als ihre anderen Mitformen. Von der Unbedeutendheit der $P$. argentata war Zimmeter selbst überzeugt, er schlägt sie einfach zu seiner P. argentea (s. stricto); die P. confinis dagegen machte ihm, wie oben gezeigt, Schwierigkeiten, trotzdem er sich an einem Jordanschen Originalexemplar in seinem eigenen Herbar hätte überzengen können, dass sie um nichts höher zu bewerten sei, als die P. argentata. Dieses Original, das übrigens nicht gut zu Jordans Diagnose stimmt, stellt eine kleine P. argentea der gewöhnlichsten Form dar, und so ist es nicht zu verwundern, dass eine ihr ganz ähnliche Pflanze im Herbar von Innsbruck (zwischen Lans und Rinn gesammelt) als „P. confinis" vorliegt. Zimmeter hatte das Jordansche Original an Blocki nach Lemberg geschickt, und dieser sandte es zurück mit der Bemerkung: ,Ich möchte die Pflanze von P. argentea nicht trennen". Es freut mich umsomehr, diesmal Herrn Blocki beipflichten zu können, je seltener mir dieses sonst möglich ist.

P. tephrodes (Richb.) Zimm. (I, No. 96) ist weiter nichts als eine kleine, starkbehaarte P. argentea Var. incanescens und höchstens als For'm von dieser weiterzuführen, wenn man sie nicht einfach als deren Synonym eintragen will. Sie wurde von Zimmeter am "Klobenstein bei Bozen" angegeben. In der Tat liegt sie von dort vor (leg. Hausm.), und wenn sie Sauter, wie er sagt, daselbst nicht sah, so kommt dies wahrscheinlich nur daher, weil er sich unter P. tephrodes etwas ganz anderes vorstellte als die Var. incanescens.

Auch die P. septemsecta (Mey.) Zimm. (I, No. 91) ist als Species oder als Varietät der P. argentea zu streichen und als forma septenata denjenigen Individuen anzuhängen, bei denen ausnahmsweise die Wurzel- und unteren Stengelblätter vorherrschend sieben- statt fünfzählig sind, gleichviel welcher Varietät sie angehören. Ich sehe mich zu dieser Restriktion der „P. septemsecta", die ich schon friiher machte*), immer mehr genötigt, je häufiger mir in den letzten Jahren unter dem Revisionsmaterial aus allen Ländern siebenzählige Formen aus allen argenteaVarietäten zu Gesicht kamen.

Nach dem Innsbrucker Herbar sind für Tirol die folgenden Varietäten der $P$. argentea $L$. zu verzeichnen:

Far. typica (P. argentea Zimm. sensu stricto; dazu P. argentata Jord., P. confinis Jord.) ist nur schwach vertreten in etwa zehn Bogen von Schwaz, Innsbruck, Zell, Welsberg, Brixen, Bozen, Meran; wohl nicht, weil sie überhaupt so selten wäre, sondern weil sie selten gesammelt wird, was bei den gewöhnlichsten Arten am häufigsten der Fall ist. Um ihre Formen einigermalsen $z u$ ordnen, kann man die mit breiten und kurzzähnigen Blättchen als forma latisecta (Rochel in sched.) und die mit schmalen

*) Potentillen-Studien I, S. 23. 
und meist langzähnigen Blättchen als forma angustisecta (Rochel) unterscheiden; doch fundet man zuweilen beide Formen an einer und derselben Pflanze, je nachdem die Blätter tiefer oder höher am Stengel stehen, oder je nach der Jahreszeit*). Alles weitere Pulverisieren der Varietät ist vom Übel und wiirde nur den umnützen literarischen Formenwust vermehren. Auch die Borbásschen ,Varietäten" altissima, macrotoma und perincisa liegen innerhalb der Grenzen individueller Abänderungen der Var. typica: die beiden ersteren stellen - nach Originalexemplaren Borbás' grof'se kräftige Individuen derselben dar, die letztere gehört zu deren forma angustisecta, welche hänfig zur Var. tenniloba (Jord.) neigt. Zimmeter stellte ein paar Hausmannsche Exemplare von Bozen und Klobenstein und ein von Gelmi bei Trient gesammeltes zu Var. perincisa liorb.; dieselben stimmen allerdings gut mit den Originalexemplaren von Borbís ïberein.

Var. decumbens (Jord.): ,Line grol'se flachblättrige Form der P. argentea" (Zimm. I, S. 13). Aus Tirol liegt nur das Hausmannsche Exemplar von Haslach bei Bozen vor, von welchem Zimmeter (I, No. 90) behauptet, daf's es genau mit einem Jordanschen Originalexemplar in 'T'ommasinis Ilerbar' zu 'Triest übereinstimme. - Eine bei Innsbruck zwischen Lans und Sistrans gesammelte Pflanze kömnte allenfalls zu dieser Varietät gezogen werden, sie ist aber nicht typisch und stellt möglicherweise eine decumbens-grandiceps dar. Eine andere, auf der Blattoberseite stark behaarte Form vou bozen kam man als Var. incanescens-decumbens bezeichnen.

Der vorhin citierten kurzen, von Zimmeter gegebenen Charakteristik kann man noch beifügen, dal's die Pflanze, trotz ihrer Gröfse, meist weiche, hingestreckte Stengel besitzt. Mehr läfst sich über diese Varietät kaum sagen, denn sie ist im Blattschnitt, in der Behanrung und in allen anderen Ierkmalen höchst veränderlich. Ihr systematischer Wert als "Varietät" ist mir recht zweifellıaft geworden, nachdem ich ihre Formen aus vielen Lïndern Europas mitemander verglichen habe, und ich möchte mit ihr am liebsten verfahren wie mit der schon aufgegebenen "Var. septemsecta", indem ich sie als forma decumbens versehiedenen Varietäten beigäbe. Die Pflanze von Haslach ist eigentlich eine stark verkahlte, niedergestreckte Var. dissecta Wallr.; eine andere von Bozen ist eine liegende Schattenform der Var. incanescens (Op.); Formen aus anderen Ländern haben den Blattschnitt der Var. typica f. latisecta oder f. angustisecta, oder gar den der Var. tenniloba (Jord.). Nimmt man dazu den Umstand, dafs die "P. decumbens" meistens an feuchten und schattigen Orten wächst, an denen sich erfalurungsgemäls die Biättchen der P. argentea schwach oder gar nicht am Rande umrollen, so liegt der Gedanke doch sehr nahe, dals dieselbe nur eine Standortsform verschiedener Varietäten sei. Ich bin überzengt, dal's jede argentea-Varietät, an den richtigen Standort versetzt, zu .,P. decumbens" werden kann. Selbst die schöne ,P. magyarica Borb." aus Ungarn scheint mir nur eine flachblätterige Standortsform der Var. incanescens zu sein.

Tar. demissil (Jord.) scheint in Tirol selten zu sein, sie wird hier durch die folgende, ihr sehr nahestehende Var. grandiceps ersetzt. Im Herbar liegt nur ein kleines Exemplar von Seis vor (leg. Hausmann), das Zimmeter für "P. demissa" erklärte, das aber sicher nicht typisch ist und

*) Potentilleu-Studien I, S. 22, über Saison-Dinorphismus. 
auch für: eine schwach entwickelte Form der Var. grandiceps genommen werden kann, die in der Tat dort gefunden wurde. Dagegen möchte ich eine als ,P. grandiceps": eingelegte Pflanze von Rinn bei Innsbruck für Var. demissa erklären. Übrigens sammelte ich selbst vor Jahren die letztere auf Teinbergsmauern bei Bozen. Auch Sauter gibt sie von Bozen an. In der Westschweiz kommt sie mehrfach zusammen mit Var. grandiceps vor.

Zimmeter hält die „P. demissa Jord," für identisch mit „P. minuta Ser.", doch unterscheiden die Franzosen (z. B. Rouy \& Camus in ihrer neuesten Flore de France VI. p. 188) die letztere als eine kleinere und zartere Form, „Subvarietas", der Var. demissa.

Vor. grandiceps (Zimm. pro spec.) halte ich nach eingehender Prüfung, entgegen einer früher ausgesprochenen Vermutung, für eine gute, selbständige Varietät, welche sich vor allen anderen durch die grofsen Blüte»- und Fruchtköpfe, und speziell der Var. demissa gegenüber, mit der sie im Habitus und Blattschnitt die meiste Ähnlichkeit zeigt, durch einen viel kräftigeren Wuchs und gröfsere Blätter auszeichnet. Nach Zimmeter ist sie die gewöhnlichste Form in den Talwegen der Centralalpen Tirols. Im Herbar finden sich Exemplare von Töls bei Innsbruck, aus dem Patznaun- und oberen Innthal, von Finstermünz, Spondinig, Bozen, Campiglio, Luttach. - Murr nennt für sie die Standorte: Matrei, Rinn und Tulfes, Stubaital, Oetztal, Fliess bei Landeck, Sexten im Pustertal. Sie ist wahrscheinlich durch die ganze Alpenkette verbreitet, wenigstens ist sie in der Westschweiz ebenso häufig wie in Tirol. Ob sie auch in nördlicheren Gegenden, wo sie sich hin und wieder gefunden hat, einheimisch oder nur eingeschleppt ist, müssen weitere Beobachtungen lehren. Poeverlein (Die bayrischen Arten der Gattung Potentilla, S. 60 nennt für sie vier Fundorte in Bayem (Oberpfalz und Oberfranken), ich selbst sah sie kürzlich in einem einzigen schönen Exemplar (leg. J. Schubert) von Aussig in Böhmen; unter dem sehr bedeutenden argentea-Naterial aus Mittel- und Norddeutschland, das ich bis jetzt zu revidieren Gelegenheit hatte, ist sie mir niemals zu Gesicht gekommen.

Die Var. tenniloba (Jord.), die sich hier anreihen wiirde, sah ich aus Tirol nicht, auch wirl sie weder von Zimmeter, noch von J Iurr und Salter für dieses Land angegeben. Da sie aber eine sehr weite Verbreitung in Centraleuropa hat, dürfte sie sich doch noch, besonders in Sïdtirol, finden lassen, wemn man einmal den argentea-Varietäten mehr Beachtung schenkt.

Vur. incanescens (Opiz) (dazu var. tephrodes Rchb.) unterscheidet sich von der P. argentea typica im wesentlichen nur dadurch, dais ihre Blätter auf der Oberseite sehr stark behaart (oft sogar filzig) sind und deshalb ein graues oder weilsgraues Aussehen bekommen. - Sie liegt in Herbar nur aus Südtirol, von Bozen, Klobenstein und Meran vor, ist aber dort nach meiner eigenen Erfahrung nicht selten. Sauter, der sie auch ron Klausen angibt, hat davon ganz praktisch eine forma (.var.") subincanescens unterschieden, mit welchem Namen man die auf der Blattoberseite weniger behaarten Individuen, also die Übergänge zu Var. typica bezeichnen kann. Davon, dals solche Übergänge in allen möglichen Abstufungen vorhanden sind, überzeugt man sich leicht in Ländern, in denen die Var. incanescens in Menge auftritt*). Dals sie auch in die Var. decumbens übergeht, ist schon bei dieser Varietät bemerkt worden. Ferner nenne ich noch eine Zwischenform Var. incanescens-dissecta von Bozen.

*) Siehe Potentillen-Studien J, S. $2 \%$ 
Tar. A issecta (Wallr.) unterscheidet sich von ter vorigen (Var. incanescens) nur durch die zerschlitzten, wiederholt gezähnten und gespaltenen Teilblättchen, aulserdem rerkahlt sie auf der Blattoberseite noch häufiger und stärlier als liese, so dafs man auch ron ihr eine forma subincanescens unterscheiden liönnte. Sie finclet sich im Herbar nur in einigen Exemplaren von Trient und aus dem Pustertal, und scheint in Tirol seltener zu sein als vorige.

Einige Bastarde der P. argentea werde ich besser im Anschluls an die Collinae besprechen, da sie diesen näher stehen.

\section{Potentilla canescens Bess.}

Eine unzweifelhafte P. canescens liegt mir aus Tirol nur auf zwei Bogen des Murrsclien II erbars vor. I'rof. Murr sammelte sie im Juni 1899 bei ,Noriglio unter den Felsen gegen Rovereto zu in den obersten Weingärten". Ls ist eine grolse Form, deren mittlere Teilblättchen oft zwei- bis dreispaltig sind und welche etwas an die Var. Sadleri erinnert.

Alles was im Innsbrucker Herbar in verschiedenen Convoluten als „P. canescens" aus Tirol bezeichnet wurde, ist zweifelhaft. So finden sich bei der ,P. commutata Blocki $(P$. argentea $\times$ recta)" vier Bogen sonderbarer P'Hanzen ron Bozen, welche Zimmeter zu P. canescens zu ziehen geneigt war. Die Pflanze des ersten Bogens (leg. Hausmann), die ihren Weg auch nach Lemberg gemacht hat, erklïrt Blocki als ,, von P. canescens bess. spezifisch verschieden"; er hält sie für identisch mit sciner P. commutata aus Galizien. Zimmeter sagt, sie stehe der "P. Kerneri Borb." sehr nahe und dürfte möglicherweise eine argentea $\times$ recta sein, behauptet aber zugleich: ,gehört zum Formenkreis der P. canescens". Blocki erwidert darauf, sie sei von Zimmeters P. Kerneri ,alssolut verschieden". Nach meiner Ansicht ist diese Pflanze eine stark behaarte Form der P. recta $\times$ argentea ron Haslach und dem Calvarienberg, ron der bei P. recta die Rede sein wird, und welche Zimmeter zum Teil auch bei der P. fissidens Borb. und bei P. canescens rar. polytricha Borb. untergebracht hat.

Verschieden von dieser Pflanze sind die drei anderen Bogen, von denen wieder einer von Hausmann, die beiden anderen von Sauter stammen. Auf den letzteren liegen zwei etwas unter sich abweichende Formen durchcinander, doch stimmen beide im grof'sen und ganzen mit der älteren Hausmannschen P'flanze, zu welcher Zimmeter schrieb: ,Yit dieser Pflanze stimmt genau I'. canescens var. leiotricha Borb. Flora croatica: Vrelo in $m^{\text {te }}$ Mosin, Aug. 1875. Ilerb. Borbás“6. Da hätten wir also wieder eine richtige P. canescens! Verdächtig ist sofort, dal's Zimmeter (in I, S. 9) von dieser leiotricha sagt, sie nähere sich den Collinis, besonders der P. Johanniniana Goir. Leider steht mir kein Borbássches Original der leiotricha zu Gebote.

Sauter nannte seine der Hausmannschen durchaus ähnlichen Pflanzen rom Guntschna- und Calvarienberg: $P$. superargentea $\times$ bolzanensis, und Zimmeter schreibt dazu: ,vielleicht P. Kerneri (P. argentea $\times$ recta)?،**) -

*) Der Name der „P. Kerneri Borb.“, einer angeblichen, mir aber selbst nach Borbásschen Originalexemplaren noch recht zweifelhaften $P$. argentea $X$ recta, ist nach reinen Vermutungen (auch ron Zimmeter) auf alle möglichen argentea-, collina- und canescensFormen, am seltensten aber auf eine wirkliche $P$. argentea $\times$ recta übertragen worden, was um so auffallender ist, als gerade die recta-Bastarde sich durch eine mikroskopische Untersuchung der Behaarung verhältnismälsig am leichtesten und sichersten nachweisen lassen. Vgl. Potentillen-Studien I, S. 44. 
also nicht mehr canescens v, leiotricha! Beide Deutungen scheinen mir unzulässig, da sich u.d. M. keine Spur von einem recta- oder bolzanensisEinflufs nachweisen läfst, abgesehen davon, dafs auch makroskopisch und im Habitus nichts an eine solche Kombination erinnert. Die wahrscheinlichste Deutung scheint mir zu sein: $P$. argentea $\times$ thryrsiflora. Jedenfalls kann ich in keiner dieser Pflanzen eine echte P. canescens Bess. erkennen, und darauf kommt es hier an.

\section{CANESCENTES COLLINAE.}

Die Gruppe der Collinae ist bekanntlich eine der schwierigsten der ganzen Gattung Potentilla; in keiner anderen sind die Formen so schwer zu begrenzen und von den Botanikern so verschieden aufgefafst worden, wie in dieser, was hauptsächlich in ihrer eigenen Natur liegen mag. Yon den besten Potentillenkennern werden sie für Mischformen der Argenteae und der Vernales gehalten, die sich, aus ursprünglichen Bastarden entstanden, durch genügende Fruchtbarkeit selbständig fortpflanzen und im Laufe der Zeit wie gefestigte Species benehmen, sich auch wieder in verschiedene Varietäten differenzieren konnten. Diese allgemeine theoretische Kenntnis nützt uns aber in der Praxis sehr wenig. Wenn wir alle Collinae als P. argentea-verna betrachten dürften, so könnte man sie einfach in eine Hauptspecies "Potentilla collina" zusammenfassen und dieser alle Formen als Varietäten unterordnen. Die Versuchung dazu liegt um so nläher, als in der Tat manche derselben anscheinend, d. h. nach oberHächlichen Merkmalen, einander nicht ferner stehen, als z. B. die argenteaVarietäten unter sich; und doch geht es hier nicht an, weil sie genetisch verschieden sind und sich nicht von einer Stammart ableiten lassen. Bei ihrer mutmafslichen Entstehung konnte von den Canescentes nicht nur die P. argentea, sondern auch die P. canescens, von den Vernales nicht nur die P. verna, sondern auch die P. arenaria oder P. Gaudini beteiligt sein. Beclenken wir nun noch den grofsen Varietätenreichtum der ebengenannten Species, so können wir uns vorstellen, welches chaotisches Formengewirr durch Kreuzung aller dieser Varietäten entstehen konnte und in der Tat entstanden ist.

Ich kann nun aber unmöglich P. argentea-arenaria, P. argentea-verna, P. canescens-verna, P. argentea-Gaudini etc. sozusagen in einen Topf werfen und als Varietäten einer Species behandeln. Wenn wir aucl in einzelnen Fällen mit ziemlicher Sicherheit auf Grund der mikroskopischen Behaarungsverhältnisse annehmen können, dafs z. B. eine P. argenteaarenaria oder eine P. argentea-verna vorliege, so bleibt dies, sowie auch, ob P. argentea oder P. canescens im Spiele war, in hundert Fällen unentschieden; und selbst wenn es gelänge - was, wie gesagt, nicht zutrifft - die beteiligten Hauptspecies zu eruieren, so müfsten wir doch auf die Ermittelung der direkt beteiligten Varietäten derselhen verzichten. Dazu kommt endlich noch der Umstand, dafs auch die Collinae selbst wieder allem Anschein nach garnicht selten mit P. argentea, P. arenaria, 
P. verna, P. Gaudini etc. primäre Bastarde bilden, welche aber nicht immer als solche sicher festzustellen sind und dann die Frage offen lassen, ob man sie als Bastarde oder als Species behandeln soll.

$\mathrm{Ob}$ es je gelingen wird, das Dunkel, welches über der Entstehung und genetischen Verwandtschaft der Collinae herrscht, aufzuhellen, muls die Zuknnft lehren; beim jetzigen Stand unserer Kenntnisse werden wir am besten tun, die meisten ihrer Formen vorläufig unter binärem Namen als eigene Species der Collina-Gruppe oder wenigstens als Subspecies der Collectivart „P. collina auct." hinzustellen. Dals diese "Species" man hat für Centraleuropa wenigstens 25 aufgestellt - nicht alle gleichwertig sein können, und dafs auch sogenamnte, ,kleine" darunter sein" müssen, wird nach dem Vorhergehenden einleuchten. Nur nach langem vergeblichem Bemülien um eine rationelle Klassifikation und Snbordination der Collinate habe ich mich in diesem Fall ungern zu dem Auskunftsmittel der ,kleinen Species" entschlossen, das ich im allgemeinen verwerfe. Ich kann mich mit locke trösten, der auch kein besonderer Freund der kleinen Species ist und dennoch sich in seiner Bearbeitung der Gattung Rubus in Aschersons Synopsis stellenweise mit ihnen behelfen mufste.

In Tirol kommen die Collinae nur in Etschtal von Neran abwärts bis zur italienischen Grenze und im Eisacktal von Bozen bis Brixen lıäufig vor, und setzten auch hier, wie allenthalben wo sic zahlreich auftreten, der richtigen Bestimmung grofse Schwierigkeiten entgegen. Ihr Ausstrahlungscentrum, wenn man so sagen darf, ist der potentillenreiche Guntschnaberg bei Bozen. In Innsbrucker Herbar sind sie sehr reich vertreten. Zimmeter und Sauter geben in ihren Druckschriften und auf den Herbaretiketten aus diesem Gebiete folgende zehn Arten an: P. ITimanniana Gïnth., P. thyrsiflora Hüls., P. brachyloba Borb., P. alpicola De la Soie, P. Johanniniana Goir., P. Sauteri Zinı. und P. confinis Jord., P. praecox F. Schltz., P. praccocioides Saut, P. porphyracea Saut. Das ist allerdings des Guten etwas zu viel! Schon der Umstand, dafs sich einerseits ganz dieselben Pflanzen und von denselben Standorten im Herbar unter zwei, drei oder vier Namen wiederholen, und daf's andererseits wieder ganz verschiedenartige Formen unter einem und demselben Namen zusammengefafst sind, beweist, daf's beide Botaniker mit den Collinae auf gespanntem Fufs standen, besonders wulste Zimmeter keine Grenze zwischen den Argenteae und Collinae zu ziehen, die - abgesehen von einigen Hybriden - doch bestelit.

Meine Bedenken gegen die Zimmeterschen und Sauterschen Bestimmungen kann ich hier leider nicht für jeden Fall ausfülnrlich begründen, weil dazu eine genaue Diagnostik und Beschreibung aller in Betracht kommender Species erforderlich wäre, die mich weit über den Rahmen dieser Arbeit hinausführen würde. Ich mufs mich damit begnügen, meine Ansichten über die mir aus dem Herbar vorliegenden oder sonst bekannt gewordenen Formen aus Tirol auszusprechen, wobei ich gern zugestehe, dal's die südtiroler und die norditalienischen (Veroneser) Collinae, über die bisher eine komplete Konfusion herrschte, nur durch ein mehrjähriges Studium an den Fundstätten selbst gesichtet worden könnten, dem da hilft kein Streiten über einzelne Herbarexemplare, von denen fast jedes vom anderen etwas abweicht. Zum richtigen Zusammenfassen des Zusammengelıörenden bedarf es eines geübten Blickes, der nur an sehr umfangreichem und vor allem auch an lebendem Vergleichsmaterial erworben wird. 
Potentilla collina auct. sensu latissimo (Sammelart).

Dals diese „Species" in einem anderen Sinne aufzufassen sei, als z. B. P. argentea, wurde bereits oben ausgeführt. Sie ist genetisch nicht so einheitlich wie die schon behandelten oder die noch folgenden, weshalb wir ihre Formen nicht als Varietäten, sondern als Subspecies betrachten und diesen binäre Namen beilegen*).

\section{Subspec. P. Wimanniana Günth. \& Schum**).}

Fïr die echte P. Wimanniana halte ich die Exemplare vom Kalterer See, davon eines von A. Kerner (im Herbar bei P. Johanniniana) und das andere von Sauter gesammelt und richtig bestimint, ferner ein Hausmannsches Exemplar von Klobenstein, ein paar von Bozen und Brixen vom selben Sammler (von Zimmeter zu P. Sauteri gestellt!), eines von Klausen (von Sauter als "P. alpicola" ausgegeben).

Nun kommen über 25 Bogen, die meisten von Bozen und ein paar von Brixen, welche der P. Wimanniana sehr nahestehende Formen enthalten, aber im Herbar unter die P. Johanniniana, P. Sauteri, P. confinis und P. alpicola verteilt liegen, teils mit diesen Namen versehen, teils ohne nähere Bestimmung. Auch die „P. brachyloba" Sauters von Bozen, die im Herbar als solche nicht vertreten ist, mag sich auf solche Formen beziehen. Aber alle die angeführten Arten sind von den hier vorliegenden Pflanzen verschieden; am meisten nähern sich die letzteren hin und wieder durch eine reichlichere und regelmälsigere Bezahnung als bei P. Wimanniana der P. thyrsiflora, die ja auch im Gebiet vorkommt. Nach meiner Ansicht haben wir es teils mit einer regionalen Form oder Tarietät der P. Wimanniana, teils mit Bastarden zwischen dieser Form und der P. argentea zu tun. Die letzteren mögen dazu Veranlassung gegeben haben, sie zum Teil als P. Johanniniana zu bestimmen, welche in der Blattform auch einigermafsen an P. argentea erinnert. Schon Uechtritz hat sich - wahrscheinlich auf Anregung Hausmanns - mit diesen sonderbaren Formen vom Guntschnaberg befalst und sie in schedis als P. Hausmanni bezeichnet. Sauter setzte nun auf seinen Etiketten zu den hier in Frage stehenden Pflanzen (soweit er sie nicht andern Species zuteilte) die Gleichung: „P. Johanniniana Goir. = P. Hausmanni Uechtr.", was gewifs nicht richtig ist, denn erstens ist die wahre P. Johanniniana Goir. von Verona sicher verschieden von den Pflanzen am Guntschnaberg, und zweitens ist nicht mit Sicherheit herauszubringen, welche Formen Uechtritz unter seiner P. Hausmanni verstand, ob die reine collina, oder die mit ihr zusammen rorkommende argentea $>$ collina. Ich besitze "Ex Herbario Uechtritz" eine kleine niedrige Pflanze mit der Etikette: „Potentilla collina, forma tyroliensis = P. Hausmanni Uechtr. ined. var. pumila??, prope Bozen, mit P. verna

*) Da ich „P. collina" nur als Namen einer sehr weitgefalsten Sammelart orler als Gruppennamen gebranche, so ist es kaum angängig, eine der seltensten Formen der Gruppe, welche Wibel bei seiner Beschreibung im Auge gehabt zu haben scheint, als "P. collina Wib." zu bezeichnen. Ich löse die ganze ".P. collina anct." in Subspecies auf und nenne, um aller Verwechsing ein Ende zu machen, die Wibelsche Form: Subsp. $P$. Wibeliana $m h$. (= P. collina Wib., non auct. al.).

**) Nach Petunnikov ist die übliche Schreibweise "Wiemamiana" unrichtig, da die Pflanze nach einem Dr. Wimann benannt ist. 
und P. argentea. Leg. Dr. R. Sallebeck". Diese scheint nach allem (z. B. Stieldriisen an (len Blättern) eine P. collina $>$ Gaudini v. virescens zu sein! Auch die von Sauter ausgegebenen Exemplare seiner ,P. Johanniniana $=$ P. Hausmanni" sind teils reine collina, teils ar'gentea $>$ collina.

Da nun Uechtritz seine ..P. Hausmamni" weder beschrieben noch veröffentlicht lıat, steht es uns frei, den Namen ganz zu verwerfen, ofer für eine der lormen beizubehalten. Ich wähle das letztere und verwende ihn, nach Absonderung der formen, die ich für P'. collina $\chi$ argentea ansehe, fiur dic

Irro. IInusmammi mh. (Uechtr. pl? pro spec.), welche ich also für eine reine collina und speziell für eine regionale Abünderung der 1. Wimanniana halte. Ihr Ilauptstandort ist, wie schon gesagt, der Guntschnaberg bei Bozen, von wo zalılreiche Exemplare vorliegen; an zweiter Stelle ist die Umgegend von Brixen zu nennen.

Sie unterscheidet sich von der typischen Wimamiana durch einen etwas schwächeren gekrüuselten Filz und durch eine oft dichtere lange Striegelbehaarung, auch sind ihre Blätter' zum 'Teil sechs-bis siebenzähligr. Einige kleine Exemplare mit wenig einschneidender und stmmpfer Bezahnung nähern sich der P. brachyloba Borb. (einer Form der P'. leuco. politana I'. Müill.), andere der l'. thyr'siflora Iliils., und diese letzteren stellen vielleicht die Mittelform P. Wimanniana v. Hausmanni $<$ tlyysiflora dar. Doch wer will hier, wo es sich um so nahestehende Arten handelt, entscheiden, was schon die ungesehlechtliche Veränderlichkeit hervorbringen kann und zu was eine Kreuzung notwendig ist?

\section{Subspec. P. thyrsiflora Hïls. (pro Var. collinae).}

Diese Art ist ron der P. Wimanniana besonders durch die reichere und regelmäfsigere Bezahnung, sowie die längliche Forn der'Teilblättchen zu unterscheiden; in der Bchaarung steht sie derselben, besonders der Tar. Hauswanni nahe. Sie hat eine weite Verbreitung durch Central- und Osteuropa.

\%u ilı rechne ich die Pflanze, welche Sauter zwischen Kilansen und Feldthurns sammelte und als ,P. collina Wib." ausgab, Zimmeter aber als I'. Wimanniana bezeichnete; ferner eine schöne Form, die Murr 1902 am Schlofs Krahkofel bei Brixen fand; endlich erwähne ich noch eine eigentïmliche PHanze, welche Hausmann, an kühlen Briumel:" bei Bozen als ,P. verna" sammelte und die Zimmeter in las lionvolut der P. argentea × verna auct. legte. Letrteres kann sie schon aus dem Grunde nicht sein, weil P. verna auct. in Siidtirol nicht vorkommt. Weun die Pflanze als Bastard gedeutet werden muifste, könnte man nur an eine P. super-thyrsiflora × Gaudini denken; (loch finde ich u. d. M. keine sicheren Spuren von Gaudini-Behaarung (Stern- und Zackenhare) und so stelle ich sie nach ihrer charaliteristischen Blattform hierher. - Limmeter nannte früher (I, S. 11) ebenfalls den Guntschnaberg und Brixen als Standorte für die P. thyrsiflora, zog aber später (II, S. 18) diese Angabe zurick und machte aus diesen Pflanzen seine ,P. Sauteri“. Daraus scheint herrorzugehen, daf's Zimmeter keine echte I'. thyrsiflora aus jener Gegend richtig unterschieden hat, demn seine ${ }^{P}$. Sauteri ist, wie wir gesehen, eine Herbstform der P'. argentea, die der P. thyrsiflora ganz ferne steht, und selbst die Collinae, die er später irrigerweise mit der P. Sauteri zusammenwarf, gehören nicht zur thyrsiflora. 


\section{(?) Subspec. P. Johanniniana Goir. (für Tirol fraglich).}

Diese einerseits an P. Wimanniana, in mancher Beziehung aber auch an P. argentea erinnernde Species hat zuerst Goiran für die Flora von Verona aufgestellt, Zimmeter glaubte sie dann in vielen tiroler Pflanzen, selbst in solchen aus Nordtirol wieder erkannt zu haben, ja er bestimmte sogar eine P. argentea Var. decumbens von Thorn in Westpreufsen und eine ebensolche von Rodna in Siebenbürgen als P. Johanniniana Goir.! Wenn man aber die Originale Goirans und die vielen von Rigo um Verona gesammelten Exemplare mit den tiroler Pflanzen genau vergleicht, die Zimmeter als P. Johanniniana bestimmte, findet man Unterschiede, die es zweifelhaft erscheinen lassen, dafs die letztere auf tiroler Gebiet bis jetzt gesammelt wurde.

Zuerst müssen hier wieder verschiedene Sachen ausgeschieden werden, welche Zimmeter und Sauter auch unter anderen (ebenso falschen) Namen ausgegeben haben, wie z. B. unter P. confinis und P. alpicola. Sie gehören grofsenteils zur P. Wimanniana Var. Hausmanni; die Pflanzen von Lans und Rinn und wahrscheinlich alle nordtiroler ,"Johanninianae" sind Formen der P. argentea Var. typica. - Diejenigen Pflanzen nun, welche sich am meisten der P. Johanniniana nähern und die wahrscheinlich den nächsten Anlafs zu einer Terwechselung mit ihr gegeben haben, sind die Hybriden zwischen P. argentea und P. Wim. Var. Hausmanni vom Guntschnaberg.

Zimmeter schickte ein solches Exemplar zugleich mit einem Originalexemplar der P. Johanniniana Goir. aus Verona an Blocki nach Lemberg, und dieser bemerkte (in scheda) zu der letzteren: „Diese Pflanze ist nach meiner tiefsten Überzeugung von P. Hausmanni Uechtr. total verschieden und ist von P. Wimanniana Günth. u. Schum. nicht zu unterscheiden". Ich weifs nicht, ob Blocki in der tiroler Pflanze die echte P. Hausmanni oder die P. argentea $\times$ Hausmanni vor sich hatte (- letzteres ist wahrscheinlicher, denn Zimmeter sagt, dafs Bl. die Pflanze von Bozen ,für eine Kreuzung" halte -) aber in beiden Fällen hat er recht, wenn er sie als von der P. Johanniniana aus Verona verschieden erklärt; dagegen kann ich ihm nicht beistimmen, wenn er die letztere mit P. Wimanniana identifiziert.

Die P. Johanniniana zeichnet sich der P. Wimanniana gegenüber durch die Form der Teilblättchen aus, die bei der letzteren breit und abgestumpft und ohne vorstehenden Mittelzahn sind, während sie bei der ersteren mehr denen der P. argentea gleichen und einen weit vorstehenden Mittelzahn aufweisen. Dieses letztere Merkmal, hob Zimmeter mit Recht hervor, prägte es sich aber so stark ein, dafs er nach ihm allein sich richtend, mehrfach auch echte argentea-Formen und argentea $>$ collina-Bastarde für P. Johanniniana erklärte.

Ich bin geneigt, in der P. Johamniniana eine ursprünglich aus $\mathrm{P}$, argentea $\times$ collina hervorgegangene Form zu erblicken, die allerdings leino primären Bastarde mehr darstellt, sondern, wie die anderen Collinae, als gefestigte Species oder Subspecies anzusehen ist und wenigstens morphologisch als P. argentea-collina bezeichnet werden könnte. Wenn diese Auffassung die richtige ist, läfst es sich begreifen, warum die primären Bastarde $(P$. argentea $\times$ collina) vom Guntschnaberg den sekundären (P. argentea-collina) von Verona oft so ähnlich sehen; auch bei ihnen 
ragt der Mittelzahn der Blättchen stark vor, doch sind die der letzteren oft noch mehr argentea-artig zerschlitzt, auch der feine argentea-Fil\% kommt stärker zm Geltung, wälıend die italienische Johanniniana melı die Striegelbelıarmng der collina zeigt. Zimmeter selbst gestelıt (in II, S. 20) „mamigfache Unterschicde“ zwisehen der Hozener und der Veroneser Pflanze zu und scheint, viellcicht auf Blockis Bemerkungen hin, über ihre Zusammengehörigkeit zweifelhaft gewouden zu sein; er zieht die erstere nur melr in den, Formenkreis" der letzteren mit der sie, jadoch nicht vollkommen identisch": sei.

Ich bemerke noch, dafs anch um Verona neben der P'. Johaminiana unzweifelhafte und zwar genetisch ungleichwertige Argenteae $>$ Collinae rorkommen, und dals dort ein älulliches Formengewirr wie um Bozen auch eine ïlnliche Unsicherheit und Verwirrung in ter Namengebung verursacht liat, deren lilärung mir aber an rieser Stelle nicht olliegt.

Ton allen tiroler l'flanzen, die ich gesehen, steht der echten P. Jolamniniana Goir. am nächsten eine, welche Gelmi in Gocciadoro bei Trient gesammelt hat. Hier wäre nachzusuchen, ob diese läufiger und konstant auftritt; denn es wäre doch möglich, dal's das vereinzelte Exemplar auch als eine ,.inter parentes" wachsende I'. argentea $>$ collina gedentet werden miifste. In der noch so unvollkommen bekamnten Collinac-Gruppe ist es immer gewagt, über eine einzige Herbarpflanze ein apodiktisches Urteil zul fällen.

\section{(?) Subspec. P. alpicola De la Soie (für Tirol zweifelhaft).}

Diese, besonders aus den Sül- und Westalpen der Schweiz bekannte Species zeichnet sich, nach der Beschreibung des Auktors, vor den meisten anderen Collinae (und der l'. argentea) dudurch aus, dal's ihr der argenteaartige Filz anf der Blattunterseite, an den Stengeln, Blïtenstielen und Kelchen fast ganz abgeht und kaum noch u. d. M. in Spuren zu entdecken ist, dagegen ilie Striegelhaare der Collinae an allen diesen Teilen sehr charakteristisch entwickelt sind. (Vgl. die Originaldiagnose in Zimm. II, S. 2\%.)

lch mufste dies besonders feststellen, um zu zeigen, dafs das meiste, was aus 'Tirol als I'. alpicola ausgegeben wurde, dieser Art durchaus fern stelit, demn diese P'flanzen besitzen einen starken gekräuselten Filz an den besagten 'Teilen, an welchen sie ihn nicht besitzen sollten. Wir begegnen unter den von '/immeter nud Sauter als, ,P. alpicola" bestimmten und ausgegebenen P'flanzen wieder denselben Formen, die auch als P. Johanniniana, $\mathrm{P}$. confinis und selbst als P. porplryracea Saut. bezeichnet wurden, ferner den bekamnten Formen rom Guntschmaberg, die sich unter I'. Wim. Var. llausmanni und P. argentea $>$ collina verteilen. Ich kann mur sagen, dafs keine einzige in Herbar als P. alpicola bezeichnete l'flanze aus Tirol zu dieser Art gehört. Iagegen mache ich auf zwei andere Exemplare aufmerksam, die einige Ähnlichkeit mit ilı haben und möglicherweise zu ilı gezogen werden köınten, wenn eimmal besseres und reichlicheres Herlyarmaterial ron den betreffenden Standorten vorliegen wird. I) as eine Exemplar stammt ron Gomagoi am Wormser Joch, wurde von /immeter anno 1888 gesammelt, mit,, $\mathrm{P}$. collina? praecox?" bezeichnet und in das Kionvolut ler I'. Wimamniana gelegt. Die zweite alpicola-ähnliche l'flanze wurde von Gelmi bei Trient gesammelt und ron Siegfried unter No. 143b 
als „P. confinis Jord." ausgegeben. Sie erimnert auch etwas an die P. Johanniniana Var. caespitosa Rigo, ist aber von der von Gelmi aus Trient ausgegebenen ,P. Johanniniana" verschieden, die ich weiter oben bei Besprechung der letzteren erwähnte. Gewils ist es nicht unmöglich, dafs sich P. alpicola im südlichen Tirol findet, aber sicher nachgewiesen ist sie bis jetzt nicht.

Um einen Vergleich im Herbar zu èrleichtern, bemerke ich, daf's die von M. Besse auf dem Nont Clou über Bovernier gesammelte und von Siegfried unter No. 145a ausgegebene Pflanze die echte P. alpicola De la Soie ist. Dieser durchaus ähnliche Exemplare sammelte P. Chenevard 1902 im Kanton Tessin. Ebenso halte ich die von Siegfried unter No. 143c als "P. confinis Jord." ausgegebenen Exemplare aus den Cottischen Alpen (leg. Ferrari 1894) für die richtige alpicola. Dagegen erscheinen mir die von Favrat aus dem Wallis ausgegebenen, im Herbar vertretenen, zweifel.haft und jedenfalls nicht die typische alpicola darstellend.

$\mathrm{Zu}$ den Collinae, die wir wenigstens vorläufig aus der Flora Tirols wieder streichen müssen, gehört auch die I. praecox F. Schltz. Zimmeter erwähnt (I, S. 11), ,eine ihr einigermafsen ähnliche Form, die P. Julius Gremblich bei Runkelstein nächst Bozen sammelte und als einen ,eklatanten Bastard" von argentea und verna auct. bezeichnete". Leider befindet sich dieser Bastard nicht im Herbar. Sauter erwähnt die P. praecox nur im allgemeinen ohne Fundortsangabe (und vielleicht nur auf Zimmeters Auktorität hin). - Die P. praecox ist bis jetzt nur aus der Gegend von Schaffhausen sicher bekannt; sie scheint eine sehr beschränkte lokale Verbreitung zu haben. Aus Tirol habe ich nichts gesehen, was mit dieser Pflanze übereinstimmte oder ihr auch nur ähnlich wäre.

Im Innsbrucker Herbar liegt, aulser zahlreichen Exemplaren von Schaffhausen, nur eine von Zimmeter als P. praecox bestimmte Pflanze aus Tirol vor, welche Murr 1893 bei Bozen sammelte. Die charakteristischen collina-Striegelhare fehlen ihr, u. d. M. findet man auf der Blattunterseite, an den Stengeln und Kelchen einen schwachen sehr kurzen gekräuselten Filz, der sich makroskopisch wenig bemerklich macht, so dafs die Blätter auch unterseits recht grün aussehen; die Blütenköpfe sind grölser als bei P. argentea. Die Pflanze mit niedrigen Stengeln macht ganz den Eindruck einer P. argentea $>$ verna, und es ist wohl möglich, daf's sie mit der von P. Gremblich am Runkelstein gesammelten übereinstimmt; nur mufs statt der P. verna auct. die P. Gaudini v. virescens untergeschoben werden, die in Südtirol jene vertritt. Da schon bei der reinen virescens die Stern- und Zackenhaare der P. Gandini oft schwer nachzuweisen sind, so ist es nicht zu verwundern, dafs sie an dem mutmafslichen Bastard selbst u. d. M. nicht deutlich hervortreten.

\section{$\times$ P. argentea $\times$ collina.}

Es ist bereits mehrfach darauf hingewiesen worden, dafs viele unter den Namen P. Johanniniana, P. confinis, P. Sauteri, P. alpicola ausgegebene Formen Siidtirols ziemlich unzweifelhafte Bastarde der obigen Kombination darstellen; doch sind offenbar nicht alle diese Bastarde morphologisch und 
genetisch gleichwertig, da sich dabei verschiedene argentea-Varietïten und verschiedene Subspecies der P. collina beteiligen konnten und sich allem Anscheine nach wirklich beteiligt haben.

Im allgemeinen lassen sich die argentea-Bastarde durch einen stärkeren und daher weifseren Filz atif Blattunterseite, Stengeln und Kelchen, durch Zuriicktreton der striegeligen collina-Behaarung, sowie durch die Blattform unterseheiden, welche durch muregelmäl'sige Bezahnung oder wiederholte Spaltung, besonders auch durch den vorstehenden Mittelzahn an P. argentea erimnert.

Die meisten am Guntschnaberg bei Bozen wachsenden, der P. Johamniniana älnlichen Pflanzen dürfen wir wohl für

$\times P$. argenter $\times$ Wimanmiana $v$. Hansmammi ansehen, da sie mit der letzteren morphologiseh und selbst standörtlich am engsten verbunden sind.

Es kommen aber bei Bozen auch Formen vor, die man wegen der Gestalt und reicheren Bezahnung der Teilblättehen als

$\times \boldsymbol{P}$. argenten $\times$ thyr.siflora bezeichnen kann. Fine solehe liegt z. 13. (in meinem Herbar) von Virgl bei Bozen vor, von Sauter als ,I. Johanniniana forma major" ausgegeben. Dieselbe Kombination diirfte eine hiibsche Pflanze von Gocciadoro bei Trient (leg. Sardagna 188t) darstellen, die Zimmeter als ,der P. tephrodes Richb. nahestehend" bestimmte. Auch eine "P. superargentea $>$ bolzanensis Saut." (leg. Santer an Guntsehnaberg), in der Zimmeter sogar die „P. Kermeri“ (eine argentea $>$ recta!) vermutete, ziehe ich hierher.

Bei anderen Formen ist eine genauere Deutung der komponierenden Faktoren kaum möglich, olme an Ort und Stelle die Pflanzenassociation studiert zu liaben; zu diesen gehört, wenigstens zum Teil, die P.praccocioides Saut., ,eine der P. praecox nahestehende, aber sich der argentea mehr nähernde Form" (Sauter). Sie ist nach meiner Ansicht eine argentea $\times$ collina. Es ist merkwürdig, dal's Sauter genau dieselbe Pflanze ron demselben Standort (Gries bei Bozen) auch als "P. confinis Jord." ausgab, zugleich mit einem kleinen Exemplar der P. argentea $>$ thyrsiflora (nach Belegen in meinem Ilerbar). Eine der ,praecocioides“ ähnliche Pflanze sammelte ich selbst 1896 bei Meran an Weg nach Schlofs Tirol. - Es scheint mir nun besser, den Hybriden, denen wir noch keine genau gefafste Bastardformeln, wie die obigen, beigeben kömen und unter denen wahrscheinlich auch die Kombinationen superargentea $x$ collina und supercollina $x$ argentea vertreten sind, vorerst den allgemeinen Namen P. argentea $\times$ collina zu belassen, mit dem wenigstens ihre systematische Stellung besser angedeutet wird, als mit etwaigen binären Speciesnamen, die nur das Gedächtnis beschweren, ohne uns irgend welche Aufkłärung zu verschaffen. Wenn wir einmal danit beginnen, jeder irgendwie unterscheidbaren Form einen besonderen Namen zu geben und sie zu beschreiben, so werden wir kein Ende finden, denn gerade die limnischen Bastarde varieren so selır, daf's selten zwei Individuen ganz genau miteinander iibereinstimmen. ,Es ist durch Erfahrung erwiesen, dal's in Artengruppen, innerhalb welcher einmal fruchtbare Hybriden entstanden sind, die Zahl der vorhandenen Formen ungemein rasch wächst, ohue dal's man genau anzugeben vermag, wie viel die Variabilitït der ersten Hybriden, 
wie viel spätere Kreuzungen dazu beitragen". So Focke in Syn. Rub. Germ. S. 5\%*).

\section{$\times$ P. collina $\times$ Gandini Var. virescens (P. porphyracea Saut.).}

Dr. Sauter stellte in Ö. B. Z. 1888 die P. porphyracea auf und sagt in seinem Aufsatz ïber die Potentillen des mittleren Tirols, dafs sie in den Kreis der Collinae gehöre. Als Standorte gibt er an das Kiesgerölle des Giefsbaches Rivelaun und den Calvarienberg bei Bozen, Manern in Gries, St. Valentin bei Meran. Zimmeter bemerkt zu ihr (II, S. 1\%): „macht fast den Eindruck einer P. argentea $>$ bolzanensis, scheint aber, wie Dr. Sauter bemerkt, kein Bastard zu sein". - Nach den zahlreichen Exemplaren, welche sich von den genannten Fundorten teils im Innsbrucker Herbar, teils in meinem eigenen befinden, und nach einer selır genauen mikroskopischen Untersuchung derselben, halte ich die Pfianze demnoch für einen Bastard und zwar von P. collina und P. Gaudini.

Auf P. collina deutet die lange starke Striegelbehaarung, während die Filzhärchen fast ganz zurïicktreten, auch erinnert der Blattschnitt durchaus nicht an eine argentea-Beeinflussung. Die Beteiligung der P. Gaudini (Var. virescens) gibt sich nicht nur durch den allgemeinen Habitus der Pflanze und die Blattform, sondern ganz besonders durch zall lreiche Stieldrüsen am Rande der Teilblättchen und an den Kelchen (spärlicher an den Blïtenstielen) zu erkennen. Auch unvollkommene Zackenhaare lassen sich am Blattrand, noch besser an den Blattstielen und den Kelchzipfeln nachweisen. - Je mehr die langen, seidigen Striegelhaare der collina zurücktreten, desto Gaudini-artiger wird die Pflanze; man kann daher Formen unterscheiden, die sich mehr der einen oder mehr der anderen Stammart nähern (super-collina $>$ Gaudini und super-Gaudini $\times$ collina). Welche collina-Art bei der Bastardbildung beteiligt ist, lälst sich hier nach dem Herbarmaterial nicht entscheiden. Ich will nur noch beiläufig bemerken, dafs diese $\mathrm{P}$. porphyracea manche Ähnlichkeit mit einer anderen $\mathrm{P}$. collina $\times$ Gaudini von Modena zeigt, welche Siegfried „P. mutinensis" nannte und für die er die Deutung wagte: P. (collina, subsp.) Schultzii $\times$ (Gaudini r.) benacensis, deren Verantwortung ich ihm überlassen mufs; auf die südtiroler Pflanze ist sie nicht anwendbar.

\section{RECTAE.}

\section{Potentilla recta $\mathbf{L}$.}

Var. pallida Lehm. (P. recta Zimm.). Nur diese Varietät soll nach Zimmeter die P. recta Limnés sein, was schwer zu beweisen wäre,

*) In seiner neuesten Bearbeitung der Gattung Rubus in Aschersons \& Graebners „Syn. d. mitteleurop Flora" Bd. VI, S. 448 sagt derselbe: "Wollte ich nach den Grundsätzen der meisten neneren Brombeerbeschreiber sämtliche umbestimmbaren Exemplare meiner Sammlung bearbeiten" (resp. mit Namen belegen), "so wiirde mir dies Material mindestens 300 , wahrscheinlich aber ïber 1000 , neue Arten" liefern". Iutatis mutandis kann ich dasselbe von meinem Potentillenmaterial behaupten. 
olne zugleich zu beweisen, dafs Linné keine andere gekannt habe. Aber, selbst wenn er nie eine andere geschen, so hätte er doch, soweit wir seine Species-Auffassung kennen, die Varietäten obscura, leucotricha, pilosa, laciniosa etc., falls sie ihm zu Gesicht gekommen wären, ebenso zu seiner P. recta gezogen, wie dies später Lehmann, Koch und die meisten anderen Floristen getan haben. Linné selbst hätte entschieden gegen die Zimmetersche Restriktion protestiert!

Es ist nun merkwïrdig, dafs Zimmeter aus Tirol nur seine P. recta (also die Tar. pallida) erwähnt, ebenso dal's Sauter in seiner Zusammenstellung der Potentillen des mittleren Tirols nur ron ,P'. recta L." spricht, worunter er jedenfalls die Zimmetersche recta versteht. Und doch ist es sicher, dafs in Nittel- und Südtirol - in Nordtirol scheint die RectaeGruppe ganz zu fehlen - die Var. obscura bei weitem vorherrscht, wenn überhaupt die Var. pallida wild vorkommt, was aus dem Innsbrucker Herbarmaterial nicht nachzuweisen ist. Da von den Unterschieden, die man zwischen Var. pallida und Var. obscura aufgestellt hat, nur der auf die Farbe und Grölse der Kronblätter sich beziehende (- bei der ersteren den Kelch weit überragend, hellschwefelgelb; bei der letzteren den Kielch nicht oder wenig ïberragend, goldgelb -) durchschlagend ist, so macht sich an Herbarexemplaren, an welchen geöffnete Bliiten fehlen, eine genaue Bestimmung oft unmöglich. Von allen mir aus 'Tirol vorliegenden Exemplaren kann ich nur eine von Hausmann in seinem Garten kultivierte Pflauze mit Sicherheit als Var. pallida ansprechen (woher sie H. bezogen hat, ist unbekannt); als zweifelhaft, weil blïtenlos, führe ich noch ein Exemplar aus dem Pustertal und eines vom Runkelstein bei Bozen an, die ïbrigen rechne ich zu der folgenden

Trer. obscura Lehm. (Wild. pro sp.)*). Im Jahre 1896 war es mir vergönnt. diese Varietät selbst in der Gegend von Neran und in den Gebüschen bei der Station Mori mehrfach zu beobachten und zu sammeln, und zwar in einer starkbehaarten Form, die sich sehr der Var. leucotricha Borb. nähert. '/nm Teil dieselbe, zum Teil etwas weniger starkbehaarte Formen liegen nun im IIerbar von: Bozen (mehrfach), St. Valentin, Obermais, Salurn und Brunneck.

*) Man hat in nenerer Zeit bezweifelt, dafs die Var. obscura Lehm. die Potentilla obscura Willd. sei, indem man sich auf ein angeblich aus Sibirien stammendes Exemplar in Willdenows Herbar beruft und dazu folgende Diaguose citiert (Z. I, S. 8): ,foliolis crebre et argute, quasi pectiuato-serratis excellit, dentibus utrimque usque 15 patentibus horizontalibusque; stipulae laciniatae, folia pedata". Nach diesem Citat Zimmeters sollte man meinen, dafs hier die Diagnose Willdenows rorliege. Dies ist aber nicht der Fall; sie scheint von Borbảs auf Grund des sibirischen Exemplars hergestellt zn sein. Die von Tilldenow selbst gemachte Diagnose seiner P. obscura lautet nach Borbás (En. pl. Comit. Castrif. S 312): ,foliis septenatis quinatisque, foliolis lanceolatis, grosse dentatis, petalis obcordatis longitudine calycis". Diese viel allgemeiner gehaltene Diagnose, an die wir uns doch halten miissen, pafst nicht nur auf das vereinzelte sibirische Exemplar, sondern ebensogut auf die europäische Var. obscura im Lehmannschen Sinne. Borbás selbst sagt (l. c.), dafs ein zweites als P. obscura etikettiertes Exemplar des Willdenowschen Herbars rielleicht die Var. lencotricha (eine der obscura ganz nahestehende Form) sei. Daraus und aus der augeführten Diagnose geht hervor, dafs Willdenow, wenn er anch in der Spaltung der Species weiter ging als Limé, doch die Haarspalterei nicht so weit trieb wie die morlernen "Spezialisten", und seinen Arten immerhin einen nicht zu engen Spielraum gönnte. Nach allem müsseu wir aunehmen, dafs er das beriihmte sibirische Exemplar für eine Form seiner P. obscura hielt 
Eine sehr schöne, grofsblütige, südeuropäische Varietät der P. recta fand Prof. Murr bei Pergine im Val Sugana. Sie wurde wohl sicher mit anderen Pflanzen beim Bahnbau aus Griechenland eingeschleppt. (Herb. Hux'!)

\section{$\times$ P. super-recta $\times$ argentea.}

Eine merkwürdige, der P. canescens Bess. makroskopisch nicht unähnliche Pflanze fand sich am Calvarienberg und bei Haslach unweit Bozen. Hausmann, der sie wohl zuerst sammelte und dann in seinem Garten kultivierte, nannte sie in schedis „Pot. Huteri“. Nach Sauter erkannte schon Huter ihre richtige Bastardnatur, von der auch er selbst überzeugt war, indem er die Pflanzen je nach ihrer schwächeren oder stärkeren Behaarung ,P. argentea $\times$ recta" und ,P. super-recta $>$ argentea" benannte. Blocki erklärt sie für identisch mit seiner ,P. commutata", die nach ihm eine P. recta v. obscura $\times$ argentea sein soll, nach meiner Ansicht aber eher eine canescens-Form ist. Zimmeter endlich stellte sie teils zu P. fissidens Borb. (einer Varietät der P. canescens), teils zu P. Kerneri Borb., die wieder eine $\mathrm{P}$. argentea $\times$ recta vorstellen soll, aber in der Ausdehnung, die Zimmeter nach seinem Herbar ihr gab, auch canescens-Formen umfalst. Nach dem ziemlich reichlich vorliegenden Herbarmaterial und dessen mikroskopischer Untersuchung haben wir es unzweifelhaft mit einem rectaBastard zu tun, so dafs also irgend eine reine canescens-Form, wie z. B. „P. fissidens" ausgeschlossen ist. Aber auch an eine P. recta $\times$ canescens dürfen wir, trotz einiger habituellen Anklänge an eine solche, kanm denken, da bis jetzt aus der Gegend ron Bozen keine P. canescens nachgewiesen ist. Es bleibt hier nur die Kombination P. recta $>$ argentea übrig, gegen die in der Tat weder das Zusammenvorkommen beider Eltern am Fundort des Bastards, noch das Mikroskop etwas eimzuwenden hat. - Die P. recta wiegt an diesem Bastard über die P. argentea vor, was besonders an den weniger behaarten Kulturexemplaren hervortritt, deshalb bezeichne ich ihn als P. super-recta $>$ argentea. Die stärker behaarten Exemplare (Sauters P. argentea $>$ recta) möchte ich nur als Standortsformen (ron sonnigen trockenen Stellen) auffassen, da an ihnen wohl die langen schlichten Haare auf Ober- und Unterseite der Blätter viel zahlreicher sind, sich aber der feingekräuselte argentea-Filz nicht derart vermehrt, dafs man für sie einen stärkeren argentea-Einflufs annehmen mülste.

Man mufs sich hïten, diesen Bastard, an dem unter dem Mikroskop die steifen Härchen und die Stieldrüsen der P. recta nachzuweisen sind, mit anderen ihm sehr ähnlichen, nur kleineren Pflanzen zu verwechseln, die aber andere mikroskopische Behaarungsverhältnisse zeigen und für die ich die Kombination P. collina $\times$ argentea in Anspruch nahm.

In Herbar Murr liegen zwei Bogen mit P. hivta L. Var.pedata Nestl., rom Besitzer am Bahndamm bei Pergine im Val Sugana in den Jahren 1900 und 1901 gefunden. Auch diese Pflanzen sehe ich, wie die obenerwähnte Varietät der P. recta, für eingeschleppt an. 


\section{AUREAE.}

\section{AUREAE CHRYSANTHAE.}

\section{Potentilla thuriugiaca Berulı.}

Ion dieser Species ist bis jetzt ein einziger Standort aus Tirol durch Huter bekinnt geworden: Livinalongo (Buchenstein) in Südosttirol, zwischen Andraz und Colle di Sta. Lucia, auf Feldmanern. Nach dem Belegexemplar im Innsbrucker Herbar (leg. Huter, 16. Jun. 1872) gehört die Pflanze 7u der typischen Varietät der' l'. thuringiaca.

Ls war interessant festzustellen, dass auch diese Pflanze an den unteren Stengelteilen und Blattstielen lange Stieldrüsen trägt, die Blütenstiele und lielche aber drüsenfrei sind. Das Vorhandensein solcher Drïsenhaare an den unteren l'flanzenteilen, während sie an den oberen fehlen, oder nur spärlich sich finden, ist eine merkwürdige Eigentümlichkeit der Gruppe der Chrysanthae gegenüber anderen drüsentragenden Potentillen, bei denen das umgekehrte Verhältnis stattfindet. (Siehe Potentillen-Studien I, S. 4\%.)

Im Herbar liegt auch eine "P. canonia Rota" aus dem Val di Ronchi bei Ala (leg. Sardagna 1885), welche nach Zimmeter bei den Chrysanthae unterzubringen wäre. Eine zweite, der tiroler durchaus ähnliche ,P. camonia" stammt von der südseite des Gotthard (leg. O. Hug, 1885). Zimmeter traute aber seinen bestimmungen selbst nicht und setzte beidesmal ein grofses Fragezeichen hinter den Namen. - Leider habe ich noch kein authentisches Exemplar dieser ,Species" gesehen und auch Zimmeter kannte sie wohl nur aus der Diagnose Rotas, die er in 1I, S. 28 abdrucken liefs. Dort vergleicht Rota allerdings seine PHanze mit anderen Formen der Chrysanthae-Gruppe; aber wenn man aus der ziemlich vagen Diagnose und Beschreibung den vorstehenden Mittelzahn der Blättchen herausnimmt, bleibt kaum etwas übrig, was nicht auch bei formen der P. alpestris Hall. fo vorkommen könnte, und schon diese lieschreibung lälst es recht fraglich erscheinen, ob das Original wirklich zu den Chrysanthae gehörte. Mlag nun dem sein wie ihm wolle, so steht für mich doch so viel fest, dafs die im Herbar vorliegenden Pflanzen nicht in diese Gruppe, sondern in den Formenkreis der P. alpestris zu ziehen sind und zwar die gewöhnliche Varietät derselben (Var. typica, P. villosa Zimm.), oder höchstens kleine Exemplare der Var. stricticaulis Grml. darstellen. Die Pflanzen haben nicht eimmal den rorstehenden Nittelzahn der Blättchen, welcher, wenn vorhanden, einiges bedenken erregen könnte; sie sind von kräftigem Wuchs, überschreiten aber nicht die Malse der P. alpestris, und dürften ron etwas tief gelegenen Standorten herriihren.

\section{AUREAE VERNALES.}

Nach dem Innsbrucker Herbar, dessen Potentillen ja grïistenteils aus Zimmeters Xachlafs stammen, könnte es scheinen, dal's T'irol cin an Vernales-Potentillen aufserordentlich reiches Land sei, fülırt doch Zimmeter 
teils in seinen Schriften, teils auf seinen Herbaretiketten nicht weniger als 18 ,Species"6 daraus auf, nämlich: $P$. verna $L$. (opaca Zimm.), $P$. monticola Z., P. glandulifera Krǎ̌., P. longifions Borb., P. benacensis Z., $P$. aestiva Hall. f., $P$. Amansiana $F$. Schultz, $P$. abbreviata $Z$., P. puberula Kraš., P. aurulenta Grml., P. explanata Z., P. Gaudini Grml., P. Gaudini × glandulifera Mur, $P$. Mumii Z., P. bolzanensis Z. mit verschiedenen Varietäten, P.Gelmiana Siegfr. (I’. bolzanensis $\times$ glandulifera), P. bolzanensiformis Saut., P. tiroliensis Zimm.

Das Durcharbeiten dieses Materials (in über 500 Bogen) war keine Kleinigkeit, denn in der Vernales-Gruppe mufs fast jede einzelne Pflanze unter dem Mikroskop untersucht werden, wenn man der richtigen Bestimmung sicher sein will, da sich gewisse Species - besonders manche der vorhin genannten - in ihrer äufseren makroskopischen Erscheinung so ähnlich sehen, dals Verwechslungen ganz nahe liegen. Wie oft findet man auf einem Blatt zweierlei Arten unter einem Namen vereinigt! Die Vermachlässigung des Mikroskops, des unentbehrlichen Hülfsmittels in dieser Gruppe, trägt die Schuld an der noch heute in ihr herrschenden Verwirrung, welche sich in jedem Herbar nachweisen lälst und die noch jährlich durch die Unzahl der von Tauschvereinen in Umlauf gesetzten, falsch bestimmten Exsiccaten vermehrt wird. Leider kann auch Zinmmeter der Vorwurf nicht erspart bleiben, dafs er offenbar das Mikroskop nur ausnahmsweise konsultierte, z. B. in hundert Fällen die Sternhaare und die Stieldrüsen übersah, so dals er einige ganz unnütze neue ,Species“ gemacht und diese, ,in den Formenkreis der P. verna auct." gestellt hat, während sie unbedeutende Formen der P. Gaudini sind, also zu den Vernales stellipilae gehören. Ferner scheint er keine Kenntnis des Saisondimorphismus der Potentillen gehabt zu haben, was dann wieder Veranlassung zu neuen Species oder zur Verwechselung der alten gab (siehe auch die P. Sauteri Zimm.). Auch hier ist wiederum, wie bei den Collinae, höchst auffallend, dal's genau dieselben Pflanzen und von denselben Standorten von ihm unter 2 bis 4 verschiedenen Namen bestimmt und in weit auseinander liegenden Konvoluten untergebracht wurden, und umgekehrt wieder sehr verschiedene Pflanzen denselben Namen tragen. Alle diese Umstände erschweren eine Revision sehr. Da die öfters angezogenen Arbeiten Sauters und Mur's uiber die Verbreitung der tiroler Potentillen im wesentlichen auf Zimmeters Bestimmungen und Anschauungen beruhen und jedenfalls auch kein mikroskopisches Studium zur Grundlage haben, ist es nicht zu verwundern, dals wir in ihnen den meisten der oben genamnten Species wieder begegnen. Ich selbst kam nun zu dem verblüffenden Resultat, dals von den 18 aufgeführten Species 10 für Tirol nicht in Betracht kommen (davon sind 6 überhaupt ganz zu streichen), dals 6 ,Species" blofs Formen oder Varietäten der P. Gaudini Grml. sind und 1 vielleicht einen Gaudini-Bastard vorstellt, so dals also nur eine einzige gute Species bleibt: die P. Gaudini Grml.!

Eine so kühne Behauptuug mülste natürlich ansführlich bewiesen werden. Der schlagendste Beweis liegt aber in der Autopsie und genauen Untersuchung der vorliegenden Herbarexemplare, die ich leider nicht jedem meiner Leser einzeln vorführen und demonstrieren kann. Hier muls jch mich darauf beschränken, zu jeder der auszuscheidenden ,Species“ einige Bemerkungen zu machen, die zur richtigen Beurteilung der in Herbarien oder in der freien Natur vorkommenden Formen dienen können, 
und mufs es damn jedem iiberlassen, meine Behauptungen selbst nachzuprïfen. Der blinde Auktoritätsglaube ist in der Botanik rom Übel, und wie ich denselben z. B. Zimmeter oder Siegfried gegenüber nicht habe, so bin ich auch weit daron entfernt, iln mir gegenüber ron anderen zu fordern. Niemand soll meinen Rezensionen und Bestimmungen aufs Wort glauben, sondern dieselben nur als Anregung zum Selbststudium benïtzen; mag dann das liesultat eine 'Lustinmung oder eine auf objektive Gründe gestuitzte Ablehnung sein: in beiden Fällen wird der Wissenschaft gedient, und dies allein ist es, worauf es mir ankommt.

Es gilt bei den neueren tiroler Floristen für ausgemacht, dals' in Tirol P. opaca I. (rubens Zimm.) und $P$. arenaria Borkh. fehlen. Bekanntlich ist es aber leichter zu sagen, was in einer Gegend rorkommt, als was nicht vorkommt, und in unserem fiall ist noch zu bedenken, clals, nach dem Herbar zu urteilen, in 'Tirol nur die gröfseren Ilaupttäler (Inntal, Eisacktal, Pustertal z. 'Tl. und Etschtal) grïndlicher auf die VernalesPotentillen abgesucht wurden. Gewils gehört das Allermeiste, was Hausmann eliemals als ,P. opaca" bezeichnete, ebenso das, was er ,P. verua r. pilosa" namnte, zu P. Gaudini Grml. (rar. virescens), aber man darf das Kind nicht mit dem Bade aussehütten. Beide genannten Arten liegen aus 'Tirol (nach Angabe der Etiketten), wenn auch nur äul'serst spärlich vor.

\section{Potentilla opaca $I_{\text {. }}$ et auct. plur.}

\section{(P. rubens Zimm. Fragaria rubens Crtz.)}

Ein leider schlecht erhaltenes Exemplar, von Hausmann gesammelt und richtig bestimmt, stammt von, Bozen an Fuls der Berge in Haslach". Ein zweites, kleines, aber besser erhaltenes Pflänzchen wurde ebenfalls von Hausmann gesammelt bei, ,Bozen 1859, am Judenfricdhof im Gebiisch". Auch dieses hat IIausmann ganz richtig bestimmt und Zimmeter hätte nicht ,P. bolzanensis Z." dazu schreiben sollen.

Beide Pflanzen bekunden sich durch die kurzen und breiten Nebenblättchen der Grundblätter, sowie durch ihre makro- und mikroskopischen Beharungsverliältnisse als echte P. opaca L. f. eglandulosa. lorausgesetzt, dal's in Hausmanns Herbar leine Verwechslungen mit ansländischen Ptlanzen vorkamen, fragt es sich nur, ob es sich um eine zufällige voriibergeliende Einschleppung dieser Art handelt, oder ob sie vielleicht in jener Gegend in früheren Keiten häufiger, zu Hausmanns Zeit aber schon selten war und dann ausstarb, oder endlich, ob sie noch (spärlich) rorhanden ist und in jüngster Zeit nur iberschen wurde. Die Beantwortung dieser Fragen muls ich den tiroler Floristen überlassen; jedenfalls lohnt es sich, an den bezeichneten Fundorten ron neuem nachzusuchen.

Über dic Grïnde meines Festhaltens an der P. opaca $L$ (statt P. rubens Zimm.) und an der $P$. verna $L$. (statt $P$. opaca Zimm.) im sinne Lehmamns, Kochs und der allermeisten älteren Botaniker bis zum Jahre 1881, in welchem Zimmeter seine Neneruıg einfiulnte, will ich mich hier nicht ausfïhrlich verbreiten. Einiges luabe ich in meinen Potentillen-Stulien I darüber gesagt. Es ist ja schon viel zu viel über dieses Thema geschrieben und gezankt worden und wir sind noch immer nicht zur Ruhe gekommen. Die neueste Anforderung stellt K. Fritsch in seiner "Exkursionsflora für Usterreich" (1897), nämlich, dafs wir weder P. verna L. \& auct., noch P. opaca Zimm., sondern "P. riridis (Neilr.) K. Fritsch" schreiben sollen. (Statt P. alpestris soll man .P. Crantzii" sagen!). Nun, wir wollen abwarten, ob Fritscl mit seiner Nenerung mehr Glück haben wird als Ascherson mit seiner "P. Taberuaemontani" und 
Zimmeter, dessen Schreibweise bezïglich der zwei Species opaca und rerna auf rielfachen Widerstand, besonders bei aufserdeutschen Botanikern stöfst. Man lese z. B., was Rouy \& Camus in ihrer nemesten Flore de France, Bd. VI. (1900) p. 200 dariiber sagen. In der Polemik zwischen Zimmeter und Čelakorský über P. opaca nnd rerna hat Čelakorský das letzte Wort behalten. Wer dessen lichtrollen Aufsatz über die Nomenklatur dieser zwei Species (in Result. d. bot. Durchforsch. Böhmens i. J. 1889. Prag 1890. S. 452-459) gelesen hat - Zimmeter hat nichts darauf entgegnet - und dann noch bei der P. rubens Z. u. P. opaca Z. beharrt, dem ist eben nicht zu helfen.

Nach meiner Ausicht hat Čelakorský unwiderleglich nachgewiesen, dafs die P. opaca Linnés identisch mit der Fragaria lubens Crtz. ist, also die Priorität roraus hat und keineswegs auf die P. verna anct. iibertragen werden darf. - Beziiglich der P. verna L. vergl. weiter unten eine darauf bezügliche Bemerkung gelegentlich der Besprechung der P. alpestris rar. firma Koch. - Über die Berechtigung des Namens P. opaca L. als gleichbedeutend mit P. opaca Koch et auct. vergl. auch Petunnikov ,Die Potentillen Centralrufslands" S. 30 (Acta Horti Petrop., rol. XIV, No. 1, 1895). Über das umstrittene Orginalexemplar in Linnés Herbar sagt er: „Das einzige in seinem Herbarium befindliche mit der Etikette P. opaca rersehene Exemplar ist nach Meinung Aschersous nicht das, was Koch nnter diesem Namen beschrieben hat, sondern P. verna Koch: aber nach der Ansicht Hartmanns und Smiths, die das Herbarium Linnés studiert haben, ist das gerade Gegenteil der Fall". Petunnikor bringt dann andere, positive Beweise. So z. B. ,ist in dem klassischen Werke ron Jacquin (Icones plant. rar.) auf 'Taf. 91 unter dem Namen P. opaca (im Conspectus tab. p. 9. ist die Diagnose gegeben and Linné citiert) die Abbildung einer Potentilla gegeben, auf welche schon im Jahre 1767 in der österreichischen Flora hingewiesen ist, umd welche sich als vollkommen identisch erweist mit der Art, welche Crantz später (1769) Fragaria rubens gellannt hat". "Zweitens befindet sich im Herbar Ehrharts, der Moskauer Universität gehörend, unter No. 3641 ein Exemplar ganz derselben Pflanze, wie sie bei Jacquin abgebildet ist, mit der eigenhäudigen Etikette Ehrharts : „P. opaca L." . . . „Es wird also die Priorität der Liméschen Art, die s päter von Crantz Frag. rubeus genannt wurde, durch Überlieferung bekräftigt" etc. und ich glaube, Jacquin, Ehrhart und andere Zeitgenossen Linnés werden besser gewurst haben, was Linné unter seiner P. opaca verstand, als Zimmeter.

\section{Potentilla rerna L. \& auct. plur.}

\section{(P. opaca Zimm., P. Tabernaemontani Aschers.).}

Sie scheint im eigentlichen Tirol zu fehlen, wenigstens ist mir kein Belegexemplar von ihr zu Gesicht gekommen; dagegen liegt sie aus dem westlichsten Teil Vorarlbergs in einem ron Schönach bei Feldkirch gesammelten Exemplar vor. Ein zweites Exemplar desselben Sammlers von ebendorther ist eine P. Gaudini f. glandulosa und ein drittes dürfte eine P. verna $x$ Gaudini f. parce glandulosa sein. - Ein reichlicheres Material von Feldkirch, das ich Herm Prof. Ch. Boetzkes verdanke, liegt in meinem eigenen Herbar; aber auch unter diesem finden sich nur ein paar Exemplare von P. verna v. typica, die meisten sind entweder echte P. Gaudini, oder nehmen eine Mittelstellung zwischen dieser und der P. verna ein und können füglich als verna $x$ Gaudini betrachtet werden.

Das westliche Vorarlberg ist insofern interessant, als sich hier das Voralpengebiet der.P. Gaudini mit dem grofsen deutschen Verbreitungsgebiet der P. verna, das sich auch weit in die nördliche Schweiz hineinzieht, berührt. Wie weit die P. verna (mit ihren Varietäten) rom Bodensee her ins Rheintal vordringt, ist noch festzustellen. Andererseits wissen wir auch noch nicht genau, wie weit die P. Gaudini gegen Westen und Norden reicht; nach einem Belegexemplar im Innsbrucker Herbar kommt sie noch am Pfänder bei Bregenz ror und es ist gar nicht unwahrscheinlich, dafs sie sich auch über das bayrische Algäu und über die oberbayrischen Alpen- 
täler rerbreitet, obgleich sie Poeverlein in seiner Arbeit über die bayrischen Potentillen nicht nennt*).

Abgesehen also ron dem Exemplar der P. rerna ron lieldlirch, gehören alle ïbrigen unter diesem Namen (resp. als opaca Z.) im betreffenden Konvolut liegenden P'tanzen aus 'Tirol zu P. Gaudini f.glandulosa, denn alle zeigen u. d. M. die chirakteristische Behaarung dieser Species, welche sie von P. verna unterscheidet. So zunächst die von Zimmeter als P. opaca bestimmten PHanzen von Kufstein, Kranebitten, Igels, Patsch und anderen Orten um Innsbruck, Brunneck, Bozen, Trient; sodam gegen 40 Bogen ans rerschiedenen Teilen Nord- und Südtirols - eine Aufzïhlung aller Fundorte wäre hier zwccklos - gesammelt und als ,l'. verna“ bestimmt von älteren Botanikern wie Loss, Tappeiner, Hausmann, Val de Lievre u. a. Sauter will die I'. verna nur von Lienz gesehen haben; aber auch diese wïrde wohl bei der Betrachtung unter dem Mikroskop zur P'. Gaudini geworden sein. Murr dagegen behauptet (viel richtiger): ,fehlt im Gebiet, wenigstens in typischen Exemplaren".

Das Verbreitmgsgebiet der P. verna und ihrer Varietäten, welches nach Angaben Lelmanns, Nymans (Consp. Fl. europ.) und anderer ,fast ganz Europa und das nörtlliche Asien" umfitsen soll, mufs nach neueren Untersuchungen ganz bedentend eingeschränkt werden, besonders nachdem die grofse, frïher nngeahnte Verbreitung der $P$. Gaudini nachgewiesen ist. welche die P. verna in vielen Ländern ansschliefst. Nur wenn man die P. verna in einem so weiten Simn nähme, wie ehemals z. B. Spenner, Wenderoth, Döll etc., welche sie mit P. opaca und P. arenaria vereinigten, könnte man allenfalls sagen, daf" sie ,per totau fere Europam" rerbreitet sei. Allein dies geht bekanntlich längst nicht mehr an, und wir müssen unter den mitteleuropaïischen Vernales mindestens vier gute Species unterscheilen, ron denen wielcr jede ron einem Kreis guter Varietäten umgeben ist:

Astelligerae.

Stelligerae.

P. opaca $L$.

P. verna L. T. Gaudini Grml.

P. arenaria Borkh.

Stipulis infer. brevibus oratis.

Stipulis inf. protractis linearibus.

Ich huldige gewif einem weiten Species-Begriff, aber diese vier Species wagte ich nicht eimmal, wie Ascherson in ,Flora d. nordostl. Flachlandes", in eine "Gesamtart P. verna" zn vereinigen. Die Schwierigkeit, welche ihre richtige Unterscheilung vielen Floristen macht, beweist noch nicht, daf: sie so eng zusammengehören. Nach meiner Ansicht ist diese "Gesamtart" eine Gruppe ron Hauptspecies; die P. opaca steht vielleicht der $P$. verua ferner als z. B. P. alpestris oder $P$. aurea, und man miilste auch die beiden letzteren und noch manche andere in die .Gesamtart" einbeziehen. Gewifs stehen alle Species der Vernales-Grupe in einem genetischen Nexus, aber ein solcher hält schliefslich alle I'otentillen unter sich zusammen; es fragt sich nur, wie nahe er zwischen den Formen sein mufs, nm sie in eine Species oder Wenigstens in eine „Gesamtart" vereinigen zu diuffen. Leider gehen darüber die Meimugen noch weit anseinander, weil wir eben die wahre Entwickelungsgeschichte der einzelnen Formen nicht mit authentischen Dokumenten beweisen kömnen.

In Zimmeters Katalogen der europäischen Potentillen folgen zwischen der Potentilla verna (seiner opaca) und den Vernales stellipilae, die bei

*) Pflanzen ans der Gegenıl des Eibsees im Loisachtal stellt er „rorläufigi:, wic er sagt, zu den Formen der $P$. verna $\times$ arenaria (subarenaria Borb.) und behizlt sich ein Urteil über dieselben noch vor, wïhrend sie (uach Poeverlein) Woerlein als ,Zwergform der P. Gaudini Grml." bezeichuete. Woerlein wird wohl recht geseben und bestimmt laben. Man denlie bei diesem Standort an lie Nïhe des Gaudini-reichen Inntales! Der Fermpals kann fiir die Terbreitumg lieser Art gegen Norlen ebensowenig ein Hinteruis sein, als der Bremnerpafs gegen Siiden. - Um linfstein wächst die P. Gaudini massenhaft, wie ich noch voriges Jahr selbst zu beobachten Gelegenheit hatte. Die blanweifsen Grenzpfähle in unmittelbarer Nähe himlern sie sicher nicht, sich im Inntal weiter nordwärts mnd vielleicht weit uiber die oberbayrische Ebene hin za ergehen. Wer sie sucht (und NB. kennt), der wird sie finden! 
ihm mit P. Gaudini beginnen, 23 ,Species“, von denen die ersten 17 ,d er typischen P. opaca (d. h. verna) zunächst stehen" und ,keine Spur von Sternhaaren" besitzen sollen, die übrigen aber ,der P. rubens (d. h. opaca) sich nähernde Formen", respektive opaca $>$ vernaBastarde sein sollen und daher auch keine Spur von Sternhaaren aufweisen dürfen.

Über diesen Speciesschwarm liefse sich gar vieles — nicht das beste sagen, er mufs einmal gründlich gesichtet und gelichtet werden; aber dies wïrde jetzt zu weit führen und ich beschränke mich auf die Kritik der zehn Species, welche Zimmeter daraus für Tirol reklamiert.

Da haben wir zuerst eine P. monticola Zimm. (II, S. 31): ,eine der P. serotina nahestehende subalpine Form". Die P. serotina Vill. ist die P. verna Var. incisa Tsch. und von der verna typica gar nicht (spezifisch) zu trennen, in deren Gebiet allein sie vorkommt und mit der sie überall durch Zwischenformen verbunden ist. Da P. verna in Tirol fehlt, wird natürlich auch ilıre Var. incisa fehlen. Aber das schönste ist, dafs die „P. monticola" nach Zimmeter's Originalexemplaren unter dem Mikroskop die deutlichsten Stern- und Drüsenhaare trägt und weiter nichts als eine niedrige rasige (subalpine) Standortsform von dieser darstellt! Zimmeter hat diese Gaudini-Behairung gar nicht bemerkt und daher in seiner ganz belanglosen Diagnose nichts davon gesagt. - Im Herbar liegen Exemplare von: Gschnitztal und Larchtal, Arzleralp bei Innsbruck, Mühlau und Hungerburg bei Innsbruck. - Anch die Exemplare aus den Cottischen Alpen (leg. Rostan) und eines aus dem Loibltal in liärnten (leg. Jabornegg, Siegfr. Exs. No. 197a) sind P. Gaudini f. glandulosa; dagegen gehört das vom Mt. Suchet in Canton Wiadt (leg. Moelurlen, Siegfr. Exs. No. 197b) wahrscheinlich zu P. verna, wie auch die Pflanze vom Salève bei Genf. Übrigens stellen die Exemplare von den zuerst aufgeführten Fundorten nicht einmal eine einheitliche Gaudini-Forn dar. Die P. monticola Z. ist also einfach zu streichen!

P. glandulifera Kraš. Kieine Vernales-,,Species" hat so viel Verwirrung angerichtet wie diese; es ist hohe Zeit, dafs sie endgiltig aus der Welt geschafft wird. Sic wurde zu einer Zeit aufgestellt (1867), als man den Stieldrüsen der Potentillen noch wenig Beachtung schenkte und sie daher gewöhnlich ïbersah. Als Kirašan eine sehr drüsenreiche Form fand, machte er sofort eine Species daraus und zwar mit zwei Varietäten: r) procera und $\beta$ ) cuneifolia. Sie sollte der P. verna am nächsten stehen und sich von dieser besonder's durch ,drüsentragende Flaumhaare" unterscheiden. Auch Zimmeter stellte sie in den Formenkreis der P. verna (seiner opaca). Bei Abfassung der Diagnose wurde offenbar nur der makroskopische Befund berücksichtigt, und keiner der beiden Herren hat das Mikroskop konsultiert, sonst mül'sten sie die halbbïschelförmigen Haare (Zackenhaare) auf der Rï̈ckseite und am Rande der Blätter gesehen und die falsche Stellung der Pflanze bei P. verna erkannt haben. Da nun dieses Hauptmerkmal in der Diagnose fehlte und diese im übrigen auf verschiedene Vernales-Formen zu passen schien, wurde die..P. glandulifera" bald allenthalben ,entdeckt", wo man nach ihr suchte oder zufällig Drüsen an solchen Formen schon mit blofsem Auge sah. Der Name wurde auf alles mögliche, auf $\mathrm{Y}$. opaca f. glandulosa, auf opaca $×$ verna f. glandulosa, auf drüsige verna $x$ arenaria-Formen, auf P. Gaudini f. glan- 
dulosa etc., selbst auf die echten verna-larietäten, wenn sie ansnahmsweise einmal in der forma glandulosa auftraten, angewandt.

Diese .,Species" hat anch mir scinerzeit grolise Schwierigkeiten bereitet und ich sprach schon vor einigen Jahren meine Bedenken gegen sie aus (Potentillen-Studien I, S, 65 bis 6\%). In Ermangelung ron Kirašanschen Uriginalexemplaren vermutete ich clamals, dals sie zu den so hüutig drüisenreichen opaca > verna-liastarden gehöre, welche mit der l)iagnose gut zu stimmen schienen. Letztes Jahr hatte nun Her'r Prof. Krasan auf einen kleinen ron mir (in Allgem. Bot. Zeitschr. 1902, S. 45) publizierten Artikel ïber die l'. Gaudini hin die Freundlichkeit, mir ein paar kritische VermalesFormen aus der Gegend ron Graz zu senden, darunter seine ,P. glandulifera". Mit llilfe des Mikroskops klärte sich die Sache sofort auf: es lag die P. Gaudini forma glandulosa ror, teils mit spärlichen und unvollliommenen, teils nit sehr dentlichen Zackenhaaren. "/u derselben Art und Iorm gehören aber auch zwei zu gleicher Zeit von dort erlialtene l'flanzen, die erste von Kirasan als P. riridis Fritsch (d. h, verna L. \& auct.), die zweite als, Mittelform zwischen l'. viridis (Neilr.), P. glandulifera hraš und P. rubens Kimm." bezeichnet. Beide sind sehr drüsemreich und hesitzen charakteristische Gaudini-Beharung. - Um die Verwirmug roll zu machen, sagt Zimmeter in der Scheda zu No. 836 der Flora Exs. Austro-Hungarica, unter welcher die P. glandulifera líaš. aus líoatien ausgegeben wurde ( - sie ist auch hier eine echte P. Gaudini f. glandulosa - ), dal's sie ein Bindeglied zwisclıen P. verna L. (opaca \%.) und patula W. K. einerseits und opaca L. (rubens Z.) andererseits bilde. Wieder ist von den Sternharen keine Rede, dafür wird die unschuldige P. patula herangezogen, der sie absolut fern steht, wahrscheinlich weil in F. Schultz Herb. norm. nov. Ser. No. 51 unter $\mathrm{l}$. glandulifera Kiraš. Exemplare von Gyöngyös in Ungarn ausgegeben wurden, die Krasan selbst für seine Pflanze erklärt haben soll, dic ,jedoch der P. patula IV. K. etwas näher stehen", (Z. I, S. 18). Nun, ich habe diese ungarische ,P. glandulifera" aus dem Schultzschen Herbar sehr genau studiert und daran keine Spur ron Drüsen, freilich auch keine Steru- und Zackenhaare gefunden; sie ist höchst wahrscheinlich eine $P$. opaca $>$ patula, wemn nicht blol's eine etwas abnorme Form der P. patula, für dic sie Janka erklärte. Schon makroskopisch ist sie, nach lirašans und Zimmeter's Diagnosen der ,P. glandulifera“, durchaus nicht mit dieser zu vereinigen.

Wenn ich mun noch bedenke, dafs die 30 Bogen, welche im Zimmeterschen Herbar für P. glandulifera kraš. crklärt werden, nämlich die tiroler Pflanzen yon Mühlau bei Innsbruck, rom Ifänder bei Bregenz, von Bozen und von Trient, sowie eine grol'se Anzahl aus der Süd- und Westschweiz, W'estungarn, Mähren, Oberösterreich und Kïrnten, mit einziger Ausnahme (ler P. patula ( $>$ opaca:) aus Ungarn, sämtlich unzweifelhafte formen der P. Gaudini f. glandulosa sind, und dal's andere von mir revidierte Herbarien teils ebenfalls Gaudini-Formen, teils aber auch andere driisentragende Vernales als .,P. glandnlifera Kras." fülıren, so erledigt sich für mich die Angelegenheit dahin, dal's die letztere ursprïnglich einige drüsige GaudiniFormen umfafste, deren richtige Natur und Stellung aber verkannt wurde, und dals dann wegen mangelhafter Diagnose ilır Name ron den Floristen auch auf anderc Vermales-Arten olne Sternhare übertragen wurde.

Ua num Krašan seine P. glandulifera im Jahre 1869 (als P'. glandulosa schon 1867), Gremli dagegen seine P. Gaudini erst $18 \% 4$ aufgestellt hat, 
und beide grofsenteils sich auf die gleichen Pflanzen beziehen, so fragt es sich, ob man der ersteren die Priorität zuerkennen und die letztere streichen müsse. Meines Erachtens keineswegs; denn erstens wurde die „P. glandulifera“" von Krašan und Zimmeter ganz verkannt und als eine besondere „Species aus dem Formenkreis der P. verna" hingestellt, weil sie Drüsen trug (das soll ja das Spezifische an ihr sein!). Wir wissen aber jetzt, dafs jerle Species der Vernales (opaca, verna, arenaria etc.) und jede ihrer Varietäten in der forma glandulosa und in der forma eglandulosa auftreten kann, ohne dafs sich sonst das geringste an ihr zu ändern braucht, mit anderen Worten, dafs in dieser Gruppe die Drüsen stets eine ganz untergeordnete Rolle spielen und nie Veranlassung zur Aufstellung einer Species geben können. Gremli dagegen hat die wahre Natur seiner P. Gaudini erkannt und sie mit Recht als eine besondere Species der Vernales stellipilae hingestellt. Zweitens wiirde sich die P. glandulifera Kraš, selbst wenn man ihr in der Diagnose die übersehenen Sternhaare nachträglich beifuigen wollte, doch mit der P. Gaudini nicht decken, sondern nur einige drüsige Formen derselben umfassen, während doch Gremli seiner Species mit rollem Recht eine weitere Ausdehnung gab und auch deren drüsenlose Formen und andere Varietäten mit inbegriff. Die P. Gaudini können wir als Species nicht entbehren; die „P. glandulifera“ dagegen ist selbst als besondere Tarietät der P. Gaudini oder irgend einer anderen V'ernalis überflüssig, da alle Varietäten in der forma glandulosa erscheinen können.

P. Iongifrons Borb. Leider macht sich hier schon wieder eine längere Auseinandersetzung notwendig. Als ich im Jahre 1901 in meinen Potentillen-Studien 1, S. 67 diese ,Species" besprach und nachwies, dafs alles, was Zimmeter für solche ausgab, zu P. Gaudini gèhöre, ging ich von der Ansicht aus, dafs Borbís wirklich eine Varietät der P. verna mit länglichen Teilblättchen darunter verstehe, da er sie doch früher, bevor er der Manie der ,kleinen Species" verfallen war, ,P. rerna $v$, longifolia" genannt hatte (Borbássche Originale konnte ich leider nicht untersuchen); ferner war ich der Meinung, dals dann Zimmeter diesen Namen irrtümlich auf Gaudini-Formen übertragen habe, an denen er die Sternhare übersah. Ich sprach daher von einer P. longifrons Borb. und von einer P. longifrons Zimm. und behielt die erstere als P. verna Tar. longifolia Borb. bei. Nun ersehe ich aber aus der Scheda, welche Zimmeter in der Flora Exs. Austro-Hung. No. 835 der „P. longifolia Borb." von Garsten bei Steyr beigab, dafs Borbás seine Originale, die mit den Pflanzen aus Garsten vollständig übereinstimmen sollen, bei Kufstein in Tirol sammelte und sie unter dem Namen P. verna v. longifolia in sein Herbar legte. Da einerseits kein Grund vorliegt, diese Behauptung Zimmeters anzuzweifeln, andererseits aber um Kunfstein die P. verna nicht, wohl aber die P. Gaudini in Menge vorkommt, so folgt daraus, dafs die Zimmetersche longifrons identisch ist mit der Borbásschen, dafs beide aus dem Formenkreis der P. verna gestrichen und in den der P. Gaudini verschoben werden mïssen. Borbás hat demnach die Sternhaare ebenso übersehen wie Zimmeter und letzterer nur die Drüsenhaare daran erkannt. Ich mufs also in Zukunft schreiben: P. Gaudini Tar. longifolia (Borb.) $m h$. (P. longifrons Borb.), und bei der P. verna Var. longifolia "mihi" statt „Borb." setzen; denn überflüssig nird die letztere durchans nicht, da sie in der Tat eine weitrerbreitete, ausgezeichnete verna-Varietät ist, die allerdings in ihrem Blattschnitt eine 
grofse Ähnlichkeit mit der P. Gaudini Var. longifolia besitzt, sonst aber morphologisch wie biologisch den Varietäten Billoti $\mathbf{N}$. Bonl. und pseudoincisa mihi nahesteht und durchaus frei ron Stern- und Drüsenhaaren ist, obgleich letztere bei ihn - wie bei anderen verna-Varietäten - nicht absolut ausgeschlossen wären.

Nach diesen Ansführmngen müssen also im Herbar die als .,P. longifrons Borb," aufliegenden P'flanzen ans Tirol (Imnsbuek und Steinach), sowie der gauze Stol's aus Oberösterreich (Steyr, Garsten, Reichraming etc.) als $I$. Gundini Var. longifolia (Borb.) bezeichnet werlen. Dagegen gehören zwei I'flanzen zur I. verna Var. longifolia mh. eine ans der Gegend von Nïrnberg (leg. I'rechtelshaner) und eine von Neftenbach bei Winterthm' (leg. Siegfried); heide stammen also ans dem Verbreitungsgebiet der P'. rerma und ans Gegenden, in denen bis jetzt die P. Ciaudini nicht gefunden wurde. Es zeigt sich hier wieder, dafs Zimmeter Varietiten vou zwei verschiedenen Species nicht zu unterscheiden vermochte.

P. benacensis Zimm. (in sched, of MS.) fehlt in den beiden Ablandlungen Zimmeters, denn sie wurde erst im Jahre 1892 auf Grund einiger von Rigo um Verona (.,ad lacum Benacum") gesammelter und an Siegfried eingesandter Pflanzen anfgestellt und handschinftlich diagnosiert. Zimmeter sagt mit Recht, dal's sie der l', longifrons Borb. am nächsten verwandt (,maxime affinis") sei, iibersah aber auch hier wieder die IIauptsache, die Sternhare, und setzte sie wie jene irrtümlich in den Formenkreis der I'. verna, den sie ferne steht. Sie zcigt u. d. M. die schönste Gaudini-Behaarung, ist äufserst drüsenreich, und unterscheidet sich von der P. Gandini Var. longifolia (Borb.) eigentlich nur durch eine stärkere, fast horizontal abstehende Behaarung. Wenn man diese schöne Pflanze nicht als Form zu der genannten longifolia ziehen, sondern ihr den Varietätsrang eimänmen will, so mufs sie P. Gaudini Var.benacensis ('Kimm.) heifsen. - Aus Tirol liegt sie nicht vor; denn ron Gelmi bei Trient gesammelte und ron Siegfried (Exs. No. 952b) als ,P. benacensis" ausgegebene Exemplare stimmen reder makroskopiseh noch mikroskopisch mit denen ron Terona, sie stellen die gewöhnliche P. Gaudini (virescens) f. parce glandulosa vor. Ebensowenig kam man eine von siegfiried (Exs. No. 952 a) aus Modena (leg. Mori) ausgegebene „P. benacensis" weder nach Blattschnitt noch nach Behaarung zu der Pflanze von Verona ziehen; sie ist eine ganz drüsenlose P. Gaudini. Viel mehr nähert sich der echten Var. benacensis eine Form, welche Ferrari in der Gegend ron 'Turin gesammelt und Siegfried unter No. 952 c ausgegeben hat, wem auch ihre Teilblättchen weniger reich bezahnt sind.

$P$. aestiva Hall. f, wurle ron jeher und allgemein als eine Varietät (oder "kleine Species") der P, verna angesehen; sie fehlt in Tirol ebenso wie die verna typica. Trotzdem funden sich im Ilerbar acht von Zimmeter als „P. aestiva“ bestimmte Bogen mit Pflanzen ron Gschnitz, Pfunds, 'Zirl, l'atznauntal. Alle gehören aber zu der lmsbruckes $P$. Gundini f. glandulosa, welcher wir schon unter verschiedenen Namen begegnet sind und noch öfters begegnen werden.

Damit wäre die P. aestiva für uns an dieser Stelle abgetan. Ich möchte aber noch liurz bemerken, dafs nach meiner festen Überzeugung eine P. aestiva (wie auch eine P. autumnalis Op.) als einheitliche Species oder Varietät nie existiert lat und wieder ganz verschwinden muls. Es hat sich mehr und mehr herausgestellt und kann durch reiches Herbar- 
material nachgewiesen werden, dafs man von jeher an erster Stelle Sommer- und Herbstformen verschiedener Varietäten der P. verna mit ihren grofsen, oft sechs- bis siebenzähligen Blättern und einer stärkeren Behaarung zu dieser ,,Species" vereinigt hat. Besonders begegnet man darunter den so gern in den Sommer und bis in den Herbst hinein blühenden Varietäten longifolia, Billoti und pseudo-incisa, welche einen sehr interessanten biologischen Varietätenkreis bilden. Aber auch andere Tarietäten, wie die typica. Amansiana, incisa etc. treten im Spätsommer oft in zweite Blïte mit einem gänzlich veränderten Habitus bezïglich der Blattform und Behaarung und werden damn zu ..P. aestiva" oder "P. autnmnalis". Man findet unter diesem Namen jedoch nicht selten auch opaca $>$ verna-Bastarde oder gewöhnliche Frühlingsformen der $P$. verna, die dem abstrakten Ideal der $P$. aestiva, jenachdem sich einer dasselbe vorstellt, zu entsprechen scheinen. - Wie wir gesehen, hat nun Zimmeter auch die tiroler P. Gaudini in den offenen Salon der P. aestiva eingefülnt, wodurch die bunte Gesellschaft noch ,gemischter"s wurde. Von 22 anderen Bogen der ..P. aestiva" im Herbar stammen 21 aus der Schweiz und sind grölstenteils Formen der P.verna Tar. pseudo-incisa mh.*) oder Mischformen zwischen dieser und der Tar. longifolia mh. aus der Gegend ron Zürich und Winterthur; nur ein paar ron Farrat eingesandte aus dem Kanton Waadt scheinen verna $\times$ Gaudini-Bastarde zu sein. Der letzte Bogen endlich enthält eine eklatante $P$. verna $>$ arenaria von der Rolstrappe im Harz (leg. Haufsknecht pro „P. opaca?'6).

Die interessante "Tar. pseudo-incisa" lernte ich zuerst aus dem Elsafs genauer kennen. In den Jahren 1901 und 1902 erhielt ich rou Herrn Issler in Colmar nnter vielen anderen Potentillen seines Sammelgebietes eine schöne Varietät der P. rerna, welche sich nach der Form der Teilblättchen am meisten der Var. incisa Tsch. (P. serotina Vill.) näherte, aber sich (iurch eine viel stärkere und längere, oft beinahe hor izontal abstehende Behaarung an Stengeln und Blattstielen unterschied. In meiner Scheu, nene Varietäten aufunstellen, nannte ich sie (in schedis) zuerst blofs Var. incisa f. hirsuta, fühlte aber bald, dafs dies doch nicht ihre richtige Stellung sei. Besonders als ich im Jai 1902 ron Herrn Issler ein sehr reiches lebendes Material der P. rerna Var. Billoti (N. Boul.) rom locus classieus, den Sandsteinfelsen ron MLutzig i. E. erhielt (zugleich nit anderen rerna-Varietäten jener Gegend), erkannte ich die nahe Verwandtschaft jener scheinbaren $V$ ar. incisa, die ich nun $V a r$ psendo-incisa nannte, mit der Var. Billoti. Letztere tritt bei II utzig in mehreren Formen anf, von denen die stark und fast horizontal abstehend-behaarte nach der Diagnose Bonlays als die typische angesehen werden mufs. Sie unterscheidet sich ron der Var.pseudo-incisa nur durch einen etwas rerschiedenen Blattschnitt, geht aber unmerklich in sie über, und beide Varietäten haben einige Hauptmerkmale gemeinsam. Zu diesen gehört ror allem ihr biologisches Verhalten: sie treiben rom Früh $h_{1}$ ahr an sehr verlängerte Triebe und Stengel, von denen, fast zweizeilig geordnet, immer wieder neue Blïtenäste ausgehen, so dafs sie lange. hängende Rasen bilden, wo immer der Standort es zuläfst, und sie gedleihen daher am besten an Felsabstiuzen, anf Weiubergs- und Feldmanern, an sehr steilen Feld- und Wiesemrainen und ähnlichen ihrer freien Entfaltung güinstigen Orten. Die Stipulae der Grundblätter sind sehr lang und lineal ausgezogen. Schon dieser Umstand, rerbunden mit den sehr langen und leicht wurzelnden Trieben, unterscheidet diese Pflanzen, trotz ihrer stark abstehenden Behaarung, scharf von den Formen der P. opaca und P. opaca $>$ verna. welche breitere und kürzere untere Nebenblätter besitzen, nie so lange Triebe machen und aufserdem anch eine zartere und wei chere Behaarung haben. Die P. verna Var. longifolia zeigt dieselben biologischen Eigenschaften, wie die Tar. psendo-incisa und Var. Billoti und gehört in denselben Varietätenkreis. Alle drei bilden Zwischenformen unter

*) Ganz dieselben Formen kehren im Herbar uuter dem Namen „P. a urulenta Grml." wieder (siehe diese). 
sich und finden sich fast immer in denselben Gebieten beisammen. Die Teilblättchen der longifolia sind lïnglich und reichbezahnt, die der Billoti breit verkehrt-eiförmig, ärmer und unregelmäfsiger bezahnt, oft gelappt, die der pseudo-incisa sind, weun typisch ausgebildet, lang kcilförmig in eine schmale Basis auslaufeud, hinten ganzrandig und vorn jederseits mit ein paar milsig tief einschneidenden, gewöhnlich etwas bogig der Spitze zn gerichteten spitzlichen Zähnen. Die Var. incisa Tsch. unterscheidet sich ron der derberen psendo-incisa durch stumpfe, ctwas tiefer cinschneidende Zähne der sonst ähnlichen Teilblättchen, besonders aher durch eine schwache, angedriickte Behaarnng, zartere und dïmnere Blätter, sowie einen schwächlicheren Wuchs, sie steht der T'. verna typica viel näher, als die Tar. pseudo-incisa.

Die Verbreitung der bisher ganz verkannten Var. psendo-incisa ist eine sehr grofse, aber nur im Gebiet der P. verna. In der nördlichen Schweiz (Zürich, Winterthur, Schaffhausen, westlich bis zum Genfer See) ist sie ebenso luäufig als im Elsals, und ron Siegfried unter den Namen P. turicensis, vitodurensis, Siegfrieviii und anderen massenhaft rerbreitet worden. Sehr schön erhielt ich sie als verschierlenen 'Teilen Böhmens, besonders trpisch aus dem Mittelgelirge (von J. Schubert) und aus der Gegend ron Prag (ron K. Domin), aus dem Harz (ron L. Osswald); in Sachsen liommt sie, wie es scheint, spärlicher vor, aber in allen genannten Länleru zusammen mit Tar. Billoti und Var. longifolia. - Ich habe gewichtige Griunde (- besonders anch nach der Dia@nose mnd mach mehreren Standortsangaben, wie "Nahetal" etc. -) zu rermnten, dal's die "P. praenutorum F. Schultz" nur eine Form der P. verna Var. psendo-incisa ist, obgleich er selbst in seinem Herbarium normale unter jenem Namen die $P$. saxatilis Boul. (eine alpestris-Varietït!) ausgegeben hat, zu welcher seine Diagnose der P. praeruptorum gar nicht palst.

P. Amansiana Z. (E. Schltz. pro var. vernae) ist zwar eine schöne Tarietät der P. verna, muls aber aus der Flora Tirols ebenfalls gestrichen werden. Sie stellt eine sehr grofsblütige, platypetale Form dar, welche der P. verna typica ganz nahe steht, nur im Gebiet von dieser auftritt und vielfach in diese übergeht (von einer eigenen "Species" kann keine Rede sein). Nun giebt es aber ganz ähnliche sehr grolsblütige Gaudini-Formen und solche hat Zimmeter einfach, olne Beachtung der total verschiedenen Behaarungsverhältnisse, für P. Amansiana erklärt. Sie liegen in 13 Bogen im Herbar von: Igels, Absam, Kranebitten, Zirl, Fragstein, Innsbruck, Feldkirch, Bozen. Alle gehören zu P. Gaudini f. glandulosa; dabei sind nicht einmal alle grofsbliitig, was doch eine echte Amansiana stets sein mufs. - Auch das übrige, nicht-tiroler Herbarmaterial enthält nur drei Bogen der echten Amansiana (oder Chaubardiana, wie sie die Franzosen nemnen) aus Frankreich, die ibrigen stellten sich als P. verna Var. typica und Var. pseudo-incisa (Schweiz), als P. verna Var. Billoti (Westungarn) und als $\mathrm{P}$. verna $>$ arenaria (Harz) heraus.

P. ab breviata Zimm. ist nach Zimmeters Herbarexemplaren identisch mit dem, was er später auch P. monticola nannte und mul's demselben Schicksal wie diese verfallen, d. h. einfach gestrichen werden. Sie ist ebenfalls eine kurze, rasige, subalpine Standortsform der P. Gaudini f. glandulosa, an welcher 'Zimmeter die (sehr deutlichen) Sternhaare und Driisen iibersehen hat, weshalb er sie wiederum in den weiteren Formenkreis der P'. verna riickte. - Sie liegt vol aus dem Fischleintal (leg. Sauter in $1600 \mathrm{~m} \mathrm{H}$.), von den Grammartböden ober Hötting (leg. Billek), aus Luttach (leg. Treffer, dies ist aber die gemeine höhere Form) und aufserdem von 'Tarasp in Graubünlten (leg. Killias). - Wem es Vergnügen macht, derartige Standortsformen besonders zu benennen, der nenne diese P. Gaudini forma abbreviata, mache aber keine verna-Species daraus.

P. puberula Kraš. Ich fürchte sehr, dals auch diese "Species" weiter nichts ist, als eine auf den Blättern ziemlich stark kurz-behaarte 
Gaudini-Form. Zwar babe ich Krašansche Originale nicht gesehen, aber wir wissen schon von der "P. glandulifera" her, dafs Krašan die Sternhaare so wenig beachtete als Zimmeter; sodann kommt am locus classicus „Wippachtal bei Görz" - wo auch die Original-,,glandulifera" herstammt! gar keine P. verna, sondern nur P. Gaudini vor. Es ist wohl möglich, dafs andere Floristen, und vielleicht Kra亡an selbst, später auch makroskopisch ähnliche richtige verna-Formen für P. puberula erklärten, was man ihnen kaum verdenken könnte, da in deren Diagnose der Hauptcharakter der Sternlıare fehlt. Es geht hier genau wie mit der P. glandulifera Kraš.

Über die zwei Exemplare der „P. puberula" aus 'Tirol, die sich im Herbar befinden, kann gar kein Zweifel walten: das eine, von ..Felsen am Maso Caturani bei Trient (leg. Sardagna)", erweist sich als ganz gemeine $P$. Gaudini (virescens) $f$. glandulosa, die nicht einmal stärker behaart (puberula) ist; das zweite, von Stenico (leg. Lofs), ist eine kleine filzkranke (d. h. von Zoocecidien infizierte), daher an den Kiöpfchen wollige P. Gaudini gland., die sich an den gesunden Teilen stark sternhaarig zeigt!

Hiermit wären wir über die "Species" hinweg, die nach Zimmeter ,zur Gruppe der P. verna auct, gehören und der typischen P. verna zunächst stehen" sollen, und kommen nun zu den „der P. rubens (d. h. opaca) sich nähernden Formen", die er im allgemeinen für opaca $\times$ vernaBastarde hält. Glücklicherweise hat er von diesen sechs nur zwei für Tirol reklamiert, nämlich die P. aurulenta Grml. und P. explanata Zimm., aber auch mit diesen zweien wieder entschieden Unglück gehabt.

P. anrulenta Grml. Es findet sich im Herbar eine Pflanze mit der Originaletikette: „P. salisburgensis Hk. (seidenhaarig). Col Santo, Huter". Zimmeter" schrieb daruber: „P. aurulenta Grml.!"6, also mit Ausrufungszeichen, als seiner Sache ganz gewils. Zunächst hätte er sich doch fragen sollen: wie käme eine $\mathrm{P}$. opaca $\times$ verna auf den ïber $2000 \mathrm{~m}$ hohen Col Santo im Südosten von Rovereto hinauf? Aber bei genauerer Untersuchung mulste er finden, dafs diese Pflanze in den Formenkreis der $P$. alpestris Hall. $f$. (seiner P. villosa) gehört und deren Varietät baldensis (Kern.) ganz nahe steht. Diese sehr ähnliche Pflanzen kenne ich aus der Schweiz, besonders aus der Gegend über Zermatt im Wallis, und habe sie (in schedis) Var. subsericea genannt.

Die übrigen 18 Bogen des Konvolutes der ,P. aurulenta" stammen alle aus der Schweiz, meist von Siegfried, und stellen sämtlich die P. verna Var. pseudo-incisa mh. dar, zum Teil der ihr innig verwandten Var. Billoti nahe kommend. Es ist keine einzige richtige P. aurulenta Grml. dabei, vorausgesetzt, dafs man unter dieser eine $\mathrm{P}$. opaca $>$ verna versteht. Übrigens begegnet man im Herbar ganz denselben oder sehr ähnlichen Formen und von denselben Standorten wieder unter den Namen P. explanata, turicensis, vitodurensis, Siegfridii, aestiva, Amansiana etc. etc., so dals sie zusammengestellt einen dicken Band füllen würden. - Am meisten interessierte mich im gegenwärtigen lionvolut eine "P. aurulenta", welche Siegfried anno 1883 bei Winterthur sammelte und an Zimmeter einschickte, weil letzterer auf deren Etikette mit eigener Hand schrieb: ,Gremli ipse determinavit". Also endlich einmal ein von mir längst ersehntes AuktorExemplar! Aber, ist es auch in der Tat ein solches, oder hat Gremli nur die Bestimmung Siegfrieds - vielleicht nach oberflächlicher Betrachtung der Pflanzen - sanktioniert? Dieser Zweifel ist gerechtfertigt, denn es wäre nicht das erste Mal, dals ein Auktor gelegentlich seine eigene Species mit 
einer andern verwechselte (wie oft ist dies Zimmeter passiert!). Es kommen ja in der nördlichen Sehweiz die I'. rerna und P. opaca zusammen ror und deshahl, sind bastarde von ihnen hier nicht ausgeschlossen, im Gegenteil sogar wahrscheinlich. Wenu aber die P'tlanzen, auf welche Gremli seine. Species zuerst griindete, wirklich so aussahen wie die rorliegenden Siegfrieds, damn hatte er sicher unecht, sie für ,.Mittelform oder Bastard“ (zwischen opaca und verna) \%u erklären, und ich mïlste meine bisherige Ansicht über die P. aurulenta Crml. aufgeben (efr. Potentillen-Studien 1, S. 83). Ich latte den Namen für eine schöne und in Sachsen nicht seltene P. opaca-verna adoptiert; vorsichtigerweise müste ich nun eigentlich schreiben: "l'. aurulenta nihi (Gremli?)". Darauf, dal's die Var. psendoincisa kein opaca-Bistard sein kann, wurde schon bei der Besprechung derselloen hingeviesen.

I'. explanata Zimm. soll nach dem Auktor diasselbe sein, was Gremli schon 1Sזt P. prostrata genannt hat, und ehenfalls eine form der I'. opaca × rerna darstellen, daher der I'. aurulenta nahe stehen. Wenn wir nun diese angebliche Art nach dem lielegmaterial in '/immeters Herbar untersuchen, so sehen wir sofort, dals wieder ganz Y erschiedenartiges beisammen liegt. \%uerst müssen wir diese, species" wiedel aus der Flora von 'Tirol aussehalten, denn die drei Bogen von Bozen (leg. Hausmamm) enthalten nur die umremeidliche P. Gaudini (ivescens). Sodann muls sie aber ïberhaupt als ïberfliissig gestrichen werden: Originalexemplare Gremlis ron dessen ,I'. prostrata (verna $>$ opaca) ${ }^{6}$, ron Osterfingerbad bei Schaffhausen stammend, stellen kłeine Pflänzchen der dort häufiger P. verna $v$. psendo-incisa dar; zwei Bogen ron Farrat ebendaselbst gesammelt, bringen dieselbe Varietät in kläftigeren Exemplaren (sonst von 'Zimmeter P'. aurulenta genannt); drei Bogen kleiner P'tlauzen von Winterthur (leg. Siegfr.) gleichen durchaus den Gremlischen Originalen; eine fragmentarische I'flanze von Misox in Graubündten (leg. Killias) ist zur Abwechstung wieder eine P'. Gaudini f, rlandulosa; endlich liegen noch nach Zimmeters Bestimmungen als P. explanata kleine PHänzchen der P. verna v. typica rou Weifswasser in Böhmen, von Ilalle a. S., ron Walkenried am Harz unl ron Bienne im Jura vor. - Eine wirkliche P. opaca $>$ rerna findet sich im ganzen lionvolut nicht.

Yimmeter sagt (I. S. 20), die ,H' explanata scheint überhaupt in Südcuropa weiter verbreitet", und in dieser Voraussetzung nahm er keinen Anstand, für Herrn R. Iluter eine von Rigo auf dem Monte Pollino in Calabrien gefundene Form, die von allen anderen, die er für P. explanata crklärt hat, himmelweit verschieden ist, ebenfalls als solche zu bestimmen. Man belenke: in Unteritalien, in eimer alpinen llöhe von ca. $2000 \mathrm{~m}$, cin Bastarel der I'. opaca und der L'. verna, die beide dort gar nicht vorkommen! Ich sah voriges Jahr diese schöne P'flanze in llerbar und im Gáten Huters, kultiviere sie jetzt auch selbst und gedenke sie als eine nene, der I'. opaca zwar nahestehende, aber doch specifisch ron ihr verschiedene Art zu beschreiben. Sie besitzt die sehr kurzen und breiten (unteren) Vehenblättchen der P. opaca und rückt schon durch dieses Merkmal - abgesehen von manchen anderen - weit von der sogenannten P. explanata $\%$. ab, welche sehr lang ausgezogene lineale untere Nebenblättchen aufweist.

Die Besprechung der vorhergchenden zehn ..Species" auf Grund des rorliegenden Herbarmaterials war gewifs keine angenehme Peschäftigung und gern hätte ich mich 
dabei kiirzer gefafst, z. B. durch einfache Richtigstellung der Namen auf den einzelnen Etiketten. Allein auf diese Art stünde nur Name gegen Name, Behauptung gegen Behauptung ohne jede Begrindung, und dies schaffte keine Klärung. Es war unerlälslich, wenigstens darauf hinzuweisen, wie in der Termales-(Fruppe eine so babylonische Verwirrung' entstehen konnte, wie die Belegexemplare der Auktoren ihren eigenen Diagnosen so oft geradezu widersprechen, wie die Formen ganz verschiedener Artenkreise durcheinander geschoben wurden und oft in falsche Stellungen kamen, oder, wie dieselben Formen immer und immer wieder ander's bestimmt werden komnten, wie schliefslich eine rollständige Begriffsrerwirrung eintrat.

Neben der schon öfter gerïgten Ternachlässigung des Jikroskops und dem dadurch bedingten İbersehen ron wichtigen Merkmalen, woraus sich wieder die Mangelhaftigkeit der Diagnosen herleitet, neben dem Haften an sehr rariabeln und unwesentlichen Äufserlichkeiten und Kleinigkeiten bei gleichzeitiger Verkennung der biologischen Eigentiumlichkeiten vieler Potentillen (Saison-Dimorphismus und dergleichen), glanbe ich einen Hauptgrund der umrationellen Zersplitterung der Gattung in der nach meiner Ansicht unglücklichen Nethode der",kleinen Species" zu erblicken. welcher die Koryphäen auf dem Gebiet der Potentillenforschung huldigten. 1ch will nicht sagen, dafs sich nach dieser Yethode absolut keine Ordnung in eine polymorphe Gattung bringen liefse, wenigstens auf dem Papier, wo man durch rerschiedenen Druck etc. die Ungleichwertigkeit der vielen kleinen (binär benannten) Species und Bastarde ausdrüicken könnte; aber die Erfahrung bestätigt hundertfach, dafs die Gefahr der Oberflächlichkeit sehr nahe liegt. Ist es doch riel leichter und bequemer, eine etwas abweichende Form, die einem irgendwie auffällt, als eine „Species nova“" mit einem wohlklingenden Namen hinzustellen, ohne sich weiter um sie zu kümmern, als mühsam zu erforschen, in welcher morphologischen und genetischen Beziehung sie zu den bereits gut studierten Species stehe, ob sie nicht etwa nur eine leichte Standortsform oder eine konstantere morphologische Varietät oder eine geographische Rasse sei, kurzum, welche genaue Stellmng nud Bewertung ihr im Srstem zukomme, um sie dann nach längerem Studium als blolise Form oder als Tarietät richtig zu subordinieren, oder aber eventuell als den guten Arten gleichwertig zu koordinieren und diese ihre Stellung auch durch die Tomenklatur auszudrücken.

WVir haben eine lange Reihe solcher "Species", um die sich ihre Väter, nacbdem sie sie in leichtfertiger Weise in die Welt gesetzt hatten, nie mehr gekïmmert haben, und von denen wir heute noch nicht wissen, was sie eigentlich rorstellen, weil uns die Anktoren über deren Stellung und systematischen Wert - den sie rielleicht meist selbst nicht gekannt haben werden - ganz im unklaren liefsen. Auch der eifrigste Potentillenforscher kann oft unmöglich herausbringen, was mit derartigen nominibus nudis, wie sie unter anderen besonders Siegfried aufzustellen beliebte, g'emeint sei, wenn er sich keine Auktorenexemplare verschaffen kann; und wenn ihm endlich dies gelingt, wie erstaunt und enttäuscht steht er dann gewöbnlich daror! Wer kann z. B. ahnen, dafs die ,P. milabilis Siegfr. \& Höhrl. 1894" weiter nichts ist als eine P. alpestris Hall. f. forma trisecta (mit meist dreizähligen Blättern, wie wir sie anch bei P. aurea, P. arenaria, P. Gandini etc. mitunter antreffen)? Da kömnte ich dieser sofort eine andere ".Species" entgegenstellen: „P. aeque-mirabilis mihi!:", ich werde mich aber damit bescheiden, sie P. alpestris forma septenata zu nennen, damit weifs jeder, was sie rorstellt und wo er sie zu suchen hat.

Aber selbst wenn bei der Methode der kleinen Species durchans ernst und wissenschaftlich vorgegangen wïrde, gäbe ich doch der möglichst weitgehenden Subordination der Varietäten und Formen unter weiter gefafste Species den Vorzug. schon aus praktischen Gründen, weil sie eine viel klarere, leichter fafsliche Übersicht der Gattung gibt und durch die Nomenklatur selbst die phylogenetischen Beziehungen der Formen ausdrückt orler andentet. Wenn man nur tür den engsten Kreis der Fachgenossen schriebe - die Potentillenspezialisten lassen sich fast an den zehn Fingern abzählen könnte man allenfalls sagen, diese sollen mit den 500 oder 600 Yotentillen-,Speciest der Erde, oder sagen wir nur den etwa 250 europäischen, so vertraut sein, dafs sie beim Hören der binären Namen sofort wissen, welches die .grofsen" und welches die ..kleinen" Species sind und wie sich diese zu jenen stellen, ebenso, welche binären Namen Bastarde bedeuten. Aber wie ganz anders stellt sich die Sache, wenn wir uns dem weiteren Leserkreis der Botaniker verstänłlich machen wollen; wie unendlich erschweren wir den meisten Floristen das Stndium der Potentillen mit den kleinen Species und wie sehr erleichtern wir es ihnen durch direkte Unterorduung so rieler Formen unter etwa 80 g’ute europäische Arten, die sie vielleicht schon gröfstenteils kemnen oder deren Kenntnis sich schliefslich jeder aneignen kamn! 
Man rühmt zu Gunsten der kleinen Species die Kürze der Ausdrucksweise, welche die rasche Terstïndigung fördern soll. Was nïtzt die Kürze, wenn sie an das Gedächtnis und den Orientierungssinn weit höhere Anforderungen stellt, als die etwas längere Ausdrucksweise nach Species, Varietäten und Formen? MInls ich nicht viel weiter ansholen, wemn ich einem Potentillenfreund die Natur und Stellung z. B. der P. agrivaga, P. fallacina, P. Benitzkyi, P. alpina, P. serotina, P. Amthoris, P. Gremlii, die für ihn sozusagen isoliert in der Luft hängen, erklären will, als wenn ich dieselben "Species" folgendemafsen benenne: P. verna r. hirsuta, P. recta r. obscura, P. rupestris v. grandiflora, P. anrea v. minor, P. verna $\mathrm{r}$. incisa, $\mathrm{P}$. alpestris $\times$ minima, $\mathrm{P}$. 'Tormentilla $\times$ reptans"? Da bedarf es weiter keiner Erklärmo, dieselbe liegt schon in den Namen. Zulem kann man ja den systematischen Wert der Varietäten genan so hoch einschätzen als den der kleinen Species, es ändert sich nur die Ausulucksweise und die Frage wird eine rein praktische. Die Erfahrung hat mich gelehrt, dals die Methode der kleinen Species und besonders deren sinnlose Ubertreibung gar manchem soust tüchtigen Botaniker das Studium der Potentillen vollstïndig verleidet, und dafs andererseits ilie Riickkehr zur alten Nomenklaturmethou manchen diesen Studium wieder zugefiihrt hat. Wäre man bei dieser alten Methode geblieben und hätte man sich durch ein gründliches Studium der For'uen, statt durch Aufstellung recht vieler Species beriihnt zu machen gesucht, so hätte z. B. unter den Vernales-P'otentillen jedenfalls keine derartige Konfusion einreilsen kömnen, wie wir sie oben gelegentlich der Besprechmng eines ganz kleinen Teiles derselben kennen gelernt haben; man hätte damn auch einem zukiinttigen Monographen der Gattung seine Arbeit nicht so unendlich erschwert. Was soll er mit den vielen, so oft ganz ungenïgenden und irrefiihrenden Diagnosen der „Species" anfangen? Was käme dabei herans, wenn er nach ihnen und anf Grund der ganzen modernen Potentillen-Literatur eine ILonographie kompilieren wollte? Weiter nichts als die Schematisiermng unzähliger Irrtümer. Hier hilft keine Stubengelehrsamkeit und kein Auktoritätsglaube; mur wer nach vieljährigen, selbständigen Untersuchungen an lebendem und Herbarmaterial die Potentillen grïndlich kemnen gelernt hat, wird sie richtig beurteilen und auch in ihrer Literatur die Spreu ron den keinfähigen Körnern sondern lömmen, folglich sich zu einer monographischen Bearbeịtung derselben befähigt fühlen Eines der ersten Resultate seiner Forschnng wird lie Überzeugung sein, dafs wir viel zu riele unnïtze Species haben, während der stubengelehrte Kompilator sich verpflichtet fühlt, jede einmal aufgestellte "Species" beizubehalten und vielleicht anf Grund seiner "Quellenstudien" in alten Schmöliern sograr noch ein paar dazı zu stiften.

Kehren wir nach dieser Episode wieder zu den tiroler Potentillen zurïck. Leider sind wir noch immer nicht über die Vermales hinweg, ja die Hauptsache steht sogar noch aus. - Während die vorhergehenden zehn „Species" nach Zimmeter keine Sternhaare besitzen durften — wie es aber damit stand, haben wir gesehen - sind die folgenden sieben nach Zimmeter , der P. arenaria Borkh. sich nähernd", gehören also zu den Vernales stellipilae und müssen Sternhare besitzen. In der Tat tragen sie alle diesen Charakter und bilden eine natürliche Verwandtschaft, ja sie sind nach meiner Auffussung sämtlich Formen einer und derselben Species, der P. Goudini Grml. Aulser der letzteren, die Zimmeter zuerst aufführt, gehören hierher (aus 'Tirol): P. Gaudini $<$ ylandulifera MLurr, P. Murrii Z., P. bolzanensis Z., P. Gelmiana (bolzanensis $\times$ glandulifera) Siegfr., L.bolzanensiformis Saut. und P. tiroliensis $Z$.

\section{Potentilla Gaudini Grml.}

Diese Art beherrscht Tirol durchaus und vertritt hier, wie in melıreren anderen Alpenländern, die I'. verna in jeder Beziehung, ja sie ist, wenn wir von der zweifelhaften oder doch hö́chst seltenen P. opaca bei Bozen und der ebenfalls noch etwas zweifelhaften (später zu erwähnen(len) P. arenaria aus Suidtirol absehen, die einzige Vernalis-Potentilla Tirols, 
deshalb mufs etwas über ihr Wesen und Treiben gesagt werden*). Wenn man sie nur hin und wieder in dem Gebiet anträfe, in welchem P. verna, P. opaca und P. arenaria zusammen vorkommen, so könnte man sie vielleicht als ein Mischprodulit dieser drei Species ansehen, da sie von jeder derselben etwas entlehnt $\mathrm{zu}$ haben scheint; allein schon ihre geographische Verbreitung spricht gegen diese Annahme, und selbst morphologisch geben doch die unzweifelhaften opaca $x$ verna $x$ arenaria-Bastarde, wie sie $z$. B. in Sachsen und Böhmen vorkommen, meist ein von der echten P. Gaudini ziemlich verschiedenes Bild. Auch wenn sie eliemals ans Kireuzungen hervorgegangen sein sollte, was nicht unmöglich ist, mïlsten wir sie doch als eine längst von ihren Urahnen unabhängige, gefestigte Species anerkennen, die sich wieder in mehrere Varietäten und regionale Formen differenziert hat. Von der ihr äulserlich am ähnlichsten P. verna unterscheidet sie sich vor allem durch die Anwesenheit von Stern- und Zackenhaaren, von der P. opaca durch dasselbe Merkmal und anfserdem durch viel dickere und steifere Striegelhare und die sehr lang ausgezogenen, linealen Nebenblättchen der Grundblätter, von der P. arenaria und deren Varietäten durch die viel spärlicheren und unvollkommeneren Sternhaare der Blattunterseite, die niemals einen geschlossenen Sternfilz darstellen und stets den grölseren Teil der Blattfläche frei lassen. Von der typischen Gaudini-Behaarung bekommt man freilich nur mit Hilfe des Mikroskops ein richtiges Bild, wer sich dieses aber einmal eingeprägt, wird irgend eine Varietät der P. Gaudini schon durch ein einzelnes Blatt oder ein Blattfragment (u. d. M.) von jeder der vorhin genannten drei Arten unterscheiden.

Bei P. arenaria herrscht das vielstrahlige Sternhaar vor, welches wie ein halbierter Seeigel aussieht, teils ohne, teils mit einem Striegelhaar in der Mitte der strahlentragenden Warze, bei P. Gaudini dagegen kombiniert sich stets ein langes, starkes Striegelhaar mit sehr kurzen, an seinem Fuls entspringenden und diesen wie eine Krone umgebenden Borstenhärchen zum "Zackenhaar". Zuweilen findet man ziemlich regelmälsig jedes Striegelhaar der Blattunterseite und des Blattrandes mit einer Krone von sechs bis zehn Zacken umgeben; ein anderes Mal zeigen sich sehr viele einfache Striegelhaare neben spärlichen Zackenhaaren, oder letztere treten gar nur sporadisch auf neben vielen einzeln oder zu zwei und drei gruppierten kurzen Borstenhärchen. Auch reduzieren sich mitunter die Zacken am Fufs des Striegelhares auf ein oder zwei, oder sie erscheinen auch u. d. H. nur mehr als kurze Höcker, so dal's man sie selbst mit der schärfsten Lupe nicht mehr sehen kann. In solchen Fällen bleiben aber immer noch die vielen einzeln oder gepaart und gedreit stehenden, nicht selten horizontal oder rückwärts gerichteten Borstenhärchen an Blättern und Blattstielen, welche ein vorzügliches Erkennungsmittel u. d. M. abgeben, weil sie bei P. verna und P. opaca ganz fehlen oder doch anders gestaltet und nie halbbüschelförmig gruppiert sind. Man findet und erkennt sie besonders leicht am untersten Rand der T'eilblättchen und an den kurzen Stielchen, mit denen sich diese dem gemeinsamen Blattstiel angliedern, sowie am obersten Teil des letzteren zwischen den langen starken Striegelhaaren. An denselben Stellen (und am übrigen Blattrand) wird man gewöhnlich auch mehr oder weniger zahlreiche Stieldrüsen

*) Vgl auch über P. Gaudini den Aufsatz in Allgem. Bot. Zeitschr. 1902, S. 45. 
finden, sclbst bei formen, an denen man sie mit der Iupe liaum melır wahrnehmen kann, denn ganz drüsenlose Gaudini-Formen sind selı selten (一 aus 'Tirol habe ich unter den viclen hundert untersuchten Pflanzen lieine einzige ganz drïsenreine gefunclen-).

Qualitativ bleibt dic soeben kur\% beschriebene Behaarung, wie sie sich unter dem Mikroskop zeigt, konstant und unterscheidet die P. Gaudini stets ron den anderen Vernales, aber quantitativ ist sowoln dic mikroskopische, als auch die makroskopische (längrere) Wehaarung sehr grol'sen Schwankungen unterworfen, so dals die darauf heruhenden extremen fiormen verschiedenen Arten anzugehören schienen, wenn wir nicht alle möglichen 'wischenstufen zwischen ihnen verfolgen könnten. Kottige lormen wechseln mit fast verkilnlten, stark ahstehend behaarte mit anliegend behaarten, stark drüsige mit beinahe drüsenlosen, solche mit deutlichen, schon dem unbewaffneten Auge sichtbaren Lackenhaaren mit anderen, an denen diese sellust unter den Mikroskop nur schwer nachzuweisen sind, und zwar geschicht dieser Wechsel teils sprungweise, teils durch unmerkliche Übergänge, oft auf einem kleinen Gebiet. Zu der grofsen Variabilität der Brhaarung lommt num dic ebenso grofse oder noch grölsere in der Blattbiklung und Blüte. Die Gaudini-lormen bilden in dieser Hinsicht eine vollkommene Parallelreihe zu der der verna-Formen und dadurch erklärt sich die leichte und so oft vorkommende T'erwechslung der entsprechenden Varietïten beider lieihen, sobald man ihren sperifischen, in den liehaarungsverlältnissen liegenden Unterschied aulser Augen lälst. In beiden lieilien begegnen wir formen mit fïnf- und mit sechs- his siebenzähligen Blättern, nit längliclıen, mit keiligen, mit obovalen, mit wenig- und vielzähmigen, mit stumpf- und mit spitzrezähnten Teilblättchen, mit kleinen, mittelgrolsen und sehr grolsen Blïten, mit schmalen und mit breiten Kronblättern ete, und das schlimmste ist, dal's sich nicht etwa einige dem Blatt, der Blïte und der Behaarung entnommene Charaktere standig zusammenfinden und dadurch gute Varietäten bilden, sondern dal's jeder für sich wieder an jeder beliehigen Kombination auftreten kann, z. B. jede Blattform mit jeder Behaarung, jede Blütenform und -grölse mit jeder Blattform etc., so dals sich die Formen schier ins Ungemessene multiplizieren. Die P. Gaudini gehört ehen zu jenen Arten, welehe, gleich der P. verna, in der gegenwärtigen Keit in ilner vollen Entwickelung begriffen zu sein scheinen, wähend welcher der ganze formenschwarm noch unbestimmt durcheinander wirbelt und gute Virietäten sich schwer abgrenzen lassen. Es wirl woln anch für sie einmal die Zeit kommen. in der viele schwankende Zwischenformen verschwunden sein und die lebensfähigeren eine grölsere Konstanz erlangt laben werden. Wahrscheinlich werden sich allmählich auch schärfere regionale Varietïten und liassen herausbilden.

Die P. Gaudini hat eine weit grölsere Verbreitung und spielt eine weit gröl'sere Rolle, als man bisher angenommen hat, und in dieser Hinsicht steht sie fast ehenbürtig neben der l'. verna. Aul'ser 'Tirol beherrscht sie gegen Osten und Südosten Salıhurgr, Ober- und Unterösterreich, Steiermark, Kïrnten, Krain, Görz und goht wahrscheinlich durch Dalmatien, die Ierzegowina, Bosnien und Serbien weit in die lialkanländer hinein, üherall die fehlende l'. verma ersetzend; im westlichen Ungarn, südlichen Mähren und östlichen Böhmen kommt sie mit $P$. verna und $P$. opaca zusammen vor und bildet auch bastarde 
mit diesen. Westlich von Tirol findet sie sich in Graubündten; dann überspringt sie das von ihr gemiedene verna-Gebiet der Nordschweiz vom Bodensee fast bis zum Genfer See, tritt dann aber in den westlichen Kiantonen von Waadt, Genf und besonders im Wallis, öfter's mit Varietäten der P. verna zusammen, auf, Auch aus den französischen Alpen ist sie bekannt und von Savoyen geht sie durch Piemont, die südlichen Alpen der Schweiz, Tirols und Italiens zum Adriatischen Meer hinüber. Wie weit sie von diesem südlichen Alpengiirtel aus gegen Süden in Italien vordringt, ist noch zu ermitteln, sie überschreitet jedenfalls den Po, von Modena wenigstens ist sie mir sicher bekannt. Ich vermute, dal's sie von den Seealpen und dem Rhonetal aus sich in westlicher Richtung auch weit durch die südfranzösischen Gebirge verbreitet. Im ganzen nördlichen Europa scheint sie zu fehlen. Ihr nördlichster, aber ganz isolierter Standort, den ich kenne, liegt in Mitteldeutschland, nahe bei Leipzig.

Zimmeter sagt (II, S. 33), dafs die P. Gaudini im Sinne Gremlis auch die P. Murrii Z., P. bolzanensis Z. uni P. tiroliensis Z. mit umfasse. Er konnte gleich die P. vindobonensis Z., P. benacensis Z. und die P. longifrons Borb., sowie einige andere "Species ans der verna-Gruppe", die wir bereits hennen gelernt haben, beifigen, wenn er deren Gaudininatur erkannt hätte. Aber, nachdem er gesagt, daf's Gremli die Art in einem weiteren Simn als er selbst aufgefafst habe, mufste er, streng genommen, statt P. Gaudini "Gremli“", Zimmeter schreiben; dem er hat eigenmächtig die Gremlische Art restringiert und aus ihren Formen neue Species gemacht. Da ich um dem weiter gefalsten Speciesbegriff huldige, muls ich konsequenterweise die genannten ",Species" ebenfalls als Varietäten und Formen der G. Gaudini Grml. ansehen und dieser subordinieren. Dies ist aber nicht ganz einfach und leicht, wie schon ans der obigen Beschreibung dieser polymorphen Art hervorgeht, und je mehr man die Formen verschiedener Gegenten mit einander vergleicht, desto schwieriger wird die Sache. Vor allem stellt sich heraus, dafs es noch keine gut ausgebildeten regionale Varietäten gibt, wie dies die Auktoren durch die Namen bolzanensis, tiroliensis, vindobonensis, benacensis, ossulana, bormiensis etc. anzunehmen schienen. Die von einzehnen Exemplaren abstrahierten Diagnosen - wenn solche iiberhaupt gegeben wurden - passen immer nur auf eine Form einer bestimmten Gegend, die sich aber meist in anderen Gegenden wieder findet und neben der auch andere Formen wachsen, die nach anderen Gegenden benannt sind. Sobald man die Namen in einem etwas weiteren Sinn, als die enge Diagnose es gestattet, nehmen, also z. B. unter Var. bolzanensis die siidtiroler und unter Var. oenipontana (Murr in sched.) die nordtiroler P. Gaudini verstehen wollte, so miilste man sofort einen Formenkreis un jede bilden, der sich dann in jeder Gegend wiederholte; dies geht aber nicht an, demn sonst würlen bessere morphologische oder anch biologische Varietäten, z. B. die Var. longifolia, zı blofsen Formen regionaler, zu weit gefalster Varietäten degradiert. - Es ist mir wohl bekannt, dafs gewisse Species und Varietäten in verschiedenen Gegenden einen etwas abweichenden Eiudruck machen, den man mehr fühlen, als genau beschreiben kann. Dies fiel mir z. B. beim Stndium gröfserer Suiten vou verua-Varietäten aus Sachsen, Central-Böhmen, Ost-Böhmen, dem Harz, dem Nahetal, dem Elsals etc. auf. Trotz dieser regionalen Färbungen und Schattierungen bewahren aler die Varietäten typica, incisa, pseudo-incisa, longifolia, Billoti, Amansiana etc. ihren Varietätencharakter und es wäre ganz verkehrt, z. B. eine $P$. verma Var. alsatica f.' incisa, eine P. verna Var. bohemica f. lougifolia etc. aufzustellen*). - Unter solchen Umständen schiene es mir viel richtiger und anch zweckmäfsiger, dals man die Hauptvarietäten der P. (iandini, sowie deren Formen, ähnlich wie bei P. verna, nur auf die morphologischen Eigentümlichkeiten wie Blattform, Behaarungsverhältnisse, Blïtenform und -grölse, Drïsigkeit etc. gründete und auch bei der Namengebung das zufällige lokale Vorkommen unberiicksichtigt liefse, es sei denn,

*) So verfahren z. B. die Auktoren der nenen Flore de France (Bıl. VI p. 198) mit der P. alpestris der Vogesen. Es kommen dort zwei Formen vor, voll denen die eine zur Var. firma Koch und die andere, stark behaarte, nach meiner Ansicht zu Var. baldensis (Kern.) gehört. Statt dies zum Ausdruck zu bringen wird aus beiden eine "Var. alsatica nobis" gemacht! 
dafs ausnahmsweise die Beschränkung einer Varietät auf eine Gegend sicher nachgewiesen wäre. Ich hoffe, dafs mir bei Beriicksichtigung und Vergleichung aller bekannten Gandiniformen eine solehe Neben- und Unterordnung der Varietäten in der allgemeinen Monographie gelingen werde und beschränke mich für jetzt wierler anf die Rezension der tiroler Formen, ohne diese bis ins kleinste hinein durch nene Diagnosen zu sondern.

Bei der Besprechung der Herbarexemplare ist zu bedenken, dal's wir bereits eine selır grofse Anzahl falsch bestimmter Pflanzen in den Formenkreis der P. Gaudini ziehen mufsten, so dafs deren Konvolut, aus den Konvoluten (ler ,P. verna, monticola, glandulifera, longifrons, aestiva, Amansiana, abbreviata, puberula, explanata" etc. ergäinzt, wolıl um das Doppelte anschwellen dürfte. Ich verweise daher beziiglich der Standorte auch auf die bei den betrefienden ,Species" gemachten lemerkungen. In vielen Fïllen habe ich mich bei diesen Kiorrekturen der llerbaretiketten damit begnügt, die P'flanzen mit „P. Gaudini Grml." zu bezeichnen, um ihnen ihre richtige Stellung anzuweisen, ohne einen weiteren Varictätenoder formennamen heizufïgen, weil es nicht immer möglich ist, anf Grund einzelner, oft schlecht erhaltener Individuen mit Sicherheit einen solehen zu geben.

Irer. typicu (P. Gaudini Zimm.) kamn man jene Varietät nennen. welche wahrscheinlich Gremli bei der Aufstellung seiner Species zunächst (wenn auch nicht ausschliefslich) im Auge hatte, da sie im Wallis die häufigste zu scin scheint. Sie besitzt derbe, fünf- bis siebenteilige Blätter, mit ziemlich breiten obovalen, etwas keiligen Teilblättchen, die jederseits an der vorderen Hälfte zwei bis vier stumpfliche Säge- oder Kerbzähne haben und unterseits graulich sind, welche Farbe aber nicht von einer sehr starken Behaarung herzurihren braucht, sondern, als der BlattEpidermis eigentümlich, auch bei schwachbehaarten Formen auftritt; man könnte deshalb diese Varietït der virescens gegenüber auch ,Var. cinerascens" nemnen. Die charakteristischen Zackenhaare sind oft sehr reichlich vorhanden, stets aber mit einer guten Lupe zu erkenuen; die makroskopische Behaarung ist ebenfalls meist reichlich, an den Stengeln und besonders an den Blattstielen lang, stark aufrecht abstehend, selten fast horizontal oder auch anliegend. Es gibt (im Wallis und anderswo) eine drüsenlose Form, aber aus 'Tirol habe ich sie bis jetzt nur in der drüsigen gesehen; die Zahl der Stieldrüsen schwankt jedoch aufserordentlich, bald ist die ganze Pflanze mit ihnen bedeckt (f. glandulosissima, „P. glandulifera Kraš." p. p.), hald finden sie sich nur an den Bliitenstielen und Kielchen (f. glandulosa und f. parce glandulosa) und werden dann leicht übersehen. Die Kronblätter sind gewöhnlich (nicht olme Ausnahme) mittelgrol's und breit, den Kelch bedeutend ïberragend.

In dieser typischen Varietät tritt die P'. Gaudini besonders in Nordtirol, in der Gegend von Innsbruck auf und liegt von da in mehr als 30 Bogen (abgesehen von den vielen falsch bestimmten) vor. Eine Aufzählung der einzelnen Standorte macht sich hier überfliissig; nur will ich noch bemerken, dafs die Sommer- und Herbstblätter nicht selten in länglicher Form mit etwas reicherer Bezahnung auftreten und dann die Pflanzen leicht mit der folgenden Var. longifolia verwechselt werden können. Eine scharfe Grenze zeigt übrigens die Var. typica weder gegren diese noch gegen andere Varietäten hin. - Auch in Südtirol gibt es Formen der Var. typica, so manche ron Bozen, welche ron Sauter zu ,P. glandulifera, 
P. abbreviata und P. puberula" gezogen wurden, und andere von ,graugrünem Aussehen" und "mit dichten Sternhaaren an den Blattflächen" von Kaltern und Meran, die er trotz dieser Eigenschaften noch für „P. bolzanensis" hält, weil eben Zimmeter die P. Gandini für Südtirol nicht angegeben hat.

An die Var. typica schliefsen sich als forma ablreviata die „P. abbreviata Z." und "I. monticola Z." wenigstens p.p. an, wenn man eine niedrige Standortsform von rasigem Wuchs besonders benennen will. (Siehe weiter oben die Besprechung dieser zwei ,Species".) Andere Formen dieser Pseudo-Species müfste man als forma abbreviata zu der Var. virescens ziehen.

Var. Zongifolia (P. longifrons Borb. dahin auch P. tiroliensis Zimm.), deren unzweifelhafte Zugehörigkeit zu P. Gaudini ebenfalls schon früher dargelegt wurde, unterscheidet sich von der vorhergehenden hauptsächlich durch einen andern Blattschnitt. Die derben Teilblättchen sind im allgemeinen gröfser, ziemlich schmal, länglich-lanzettförmig, unten keilig in ein kurzes Stielchen auslanfend (wenigstens die mittleren), fast bis zum Grunde mit zahlreichen spitzen (selten stumpflichen) Zähnen versehen, insbesondere an den sehr grofsen Sommer- und Herbstblättern (fünf bis neun Zähne jederseits), nur die ersten Frühlingsblättchen sind vorn abgestumpft, lang verkehrt-keilförmig und tragen an der vorderen Hälfte weniger Zähne. Die makroskopische Behaarung ist meist schwächer als bei der Var. typica, die Farbe der Blattunterseite weniger grau, oft grün oder gelblichgrïn. Die Zackenhaare sind spärlicher und oft nur mit dem Mikroskop deutlich zu erkennen; die Drüsenbehaarung zeigt sich ebenso variabel wie bei Var. typica, in welche die Var. longifolia vielfach und unmerklich ïbergeht.

Aus 'Tirol liegt sie im Herbar, zum Teil als „P. tiroliensis" bestimmt, von Innsbruck, Natters, Sellrain, Höttinger Au, Nassereck, Untersberg, Ahrenwald, Steinach. Nicht zu vergessen ist Kufstein, als Originalstandort der P. longifrons Borb., obgleich sie von dort im Herbar nicht vertreten ist. - Diese Varietät scheint ebenso verbreitet $\mathrm{zu}$ sein wie die Var. typica, z. B. im Wallis (Zermatt, von den Scluweizern als P. tiroliensis bestimmt), in Ober-Österreich (Steyr, Garsten, Reichraming) in Ostböhmen (Leitomischl) etc.

Die „P. tiroliensis Z." kann ich auf Grund zahlreicher Originalexemplare und selbst nach Zimmeters Diagnose kaum als leichte Spielform der Var. longifolia ansehen, denn sie unterscheidet sich in nichts wesentlichem yon dieser und stellt keine besondere Varietät, geschweige denn Species dar, atm besten liefse man sie als überflüssig ganz fallen. Von den 33 Bogen der P. tiroliensis aus Tirol (Gschnitztal, Steinach, Aldrans, Sterzing etc.) sind 16 mit Hochsomner- und Herbstformen belegt, welche die reichıezahnten länglich-lanzettlichen Blättchen aufweisen, auf die Zimmeter die Species hauptsächlich gründete, die aber genau so an der Var. longifolia sich finden; die anderen 17 euthalten teils Frühlingspflanzen mit etwas anders geformten Blättern, teils die gewöhnliche Var. typica oder die Var. virescens. (- Die Exemplare aus Samaden, Oberkärnten und Bormio gehören nicht zu Var. longifolia, resp. P. tiroliensis. - ) Die $P$. tiroliensis $f$. aprica Hut. ist eine stärker behaarte Standortsform der Var. longifolia. - Ich bin überzeugt, dafs 
Zimmeter" seine P. tiroliensis „P. longifrons" genannt hätte, wenn er an der letzteren die Zackenhare nicht aul'ser acht gelassen hätte.

Eng an die Tar. longifolia schliel'st sich die für Tirol noch nicht nachgewiesene Tar. benacensis (Z.) an, welche dem Blattschnitt nach eine ausgezeichnete longifolia darstellt, sich aber durch eine sehr starke, horizontal abstehende Beharung unterscheidet.

Irer. virescens $m h$. (Dahin P. bolzanensis Z., P. oenipontana Murr in litt. 1901, P. vindobonensis Z., P. glandulifera Kraš. p. p. etc.). Ich sehe im Geiste einige Leser bedeutend die Achseln zucken und bitte daher um geduldiges Anhören der Gründe für die vorgeschlagene Änderung, bevor sie dieselbe verwerfen.

Dic P. Gandini Var. typica und Var. longifolia mit ihren Formen sind schon makroskopisch ziemlich leicht von der P. verna typica zu unterscheiden; es gibt aber eine lieihe anderer Formen, welche der letzteren so nahe treten, dafs es sehr oft erst mit dem Mikroskop gelingt, ihro Gaudininatur festzustellen. Der gemeinsame Charakter dieser Formen besteht darin, daf's sie weniger derbe, oft sogar recht weiche, fünf- bis siebenteilige Blätter besitzen, deren breit obovale oder kurzkeilige Teilblättchen jederseits nur zwei bis vier spitzliche oder stumpfliche Zähne tragen und beiderseits gr in sind. Ihre makroskopische Behaarung an Stengeln, Blattsticlen und Blättern ist gewöhnlich kürzer, spärlicher und anliegender als bei den vorigen Varietäten; die Zackenhaare stehen zerstreuter auf der Blattunterseite und am Blattrand und sind meist nur mit einer scharfen Lupe oder gar nur mit dem Mikroskop wahrzunehmen; die Drüsenbehaarung dagegen ist wieder so veränderlich wie bei den anderen Varietäten (von f. glandulosissima bis f. eglandulosa). Wenn die Zackenhaare ganz fehlten, so gäbe es gar keinen Unterschied mehr zwischen diesen Formen unil der $P$. verna typica*). In Gegenden, in welchen $P$. verna und P. Gaudini zusammen vorkommen, ist es oft unmöglich, zu entscheiden, ob man es mit dieser P. Gaudini-Yarietät oder mit einer $P$. verna $\times$ Gaudini zu tun hat. Ich sellost lielt längere Zeit verschiedene tiroler Pflanzen für besagten Bastard, ehe ich daron überzeugt war, dal's die 1'. verna in 'Tirol fellit, also auch nicht bastardieren kann. Ebenso schwer ist es, die hier besprochene Gaudini-Varietät ron gewissen Formen der P. superverna $\chi$ arenaria zu unterscheiden; doch kann auch von solchen in Tirol keine Rede sein.

Die Var. virescens tritt überall zusammen mit den Varietäten typica (cinerascens) und longifolia auf, und zwar in allen möglichen Übergängen und Mischformen (Blendlingen?), sich in Blattschnitt und Behaarung bald dieser, bald jener nühernd. Überhaupt ist sie die formenreichste Varietät, und die Formen wiederholen sich fast in allen Gegenden nach derselben Schablone und zum Verwechseln ähnlich, man kann nur die hauptsächlichsten und auffallendsten besonders hervorheben (z. B. f. grandiflora, parviflora, stenopetala, glandulosissima oder eglandulosa etc.). Auch ihre Trennung in regionale Varietäten hat keinen Zweck und erleichtert ihr Studium gewil's nicht. Wozu die in Sïdtirol wachsenden P. bolzanensis", die in Nordtirol gefundenen „P. oenipontana“, die ans Unter- und

*) Es ist wohl sicher, dals gar manches oder das meiste, was man ans den Alpenländeru, in welchen die $P$. (Gaudini herrscht, bisher für P. verna („P. viridis Eritsch,“!) hielt, zu dieser Tar. virescens gehört. 
Ober-Österreich stammenden „P. vindobonensis" etc. nennen, wenn doch alle ein und derselben Varietät angehören? Sauter hat z. B. fïr die „P. bolzanensis" die Varietäten (respective Formen) macrantha, micrantha, astelligera (Zackenhaare makroskopisch gar nicht zu entdecken), glandulifera, umbrosa, prorepens und latifolia aufgestellt, man könnte noch mehrere beifügen, aber derselbe Formenkreis liefse sich bei Var. virescens um Wien, um Innsbruck, in Ostböhmen, in der Schweiz etc. nachweisen. Statt ihn bei vier oder fünf regionalen Varietäten (,Species") zu wiederholen, genügt es vollständig, ihn für die morphologische Var. virescens anzugeben, welche jene vier oder fünf umfafst und sozusagen synonym mit ihnen ist. Ein schwacher regionaler Anbauch genügt noch nicht, die im übrigen gleichen korrespondierenden Formen verschiedener Gegenden bei verschiedenen Varietäten unterzubringen. Jede Reduktion unnötiger Species und Varietäten erleichtert das Studium und phylogenetische Verständnis der Gattung!

Die Standorte für diese in Tirol sehr verbreitete Varietät wären im Herbar aus den Konvoluten der „P. bolzanensis, vindobonensis, glandulifera, Gaudini (respective oenipontana)" und noch einiger anderer zusammenzusuchen; aber eine Einzelaufzählung derselben ist bei ihrer Häufigkeit kaum notwendig. Ich habe es auch bei den meisten Bogen zunächst bei der allgemeinen Speciesbezeichnung „P. Gaudini" belassen, weil ich nicht der Zustimmung zu meiner „Var. virescens“ vorgreifen möchte. — Nur einige Bemerkungen über ein paar auffallende Formen sollen hier noch folgen.

In forma Mrurriana möchte ich die „P. Murrii Zimm." umändern, welche nach meiner Ansicht keine besondere Species, nicht einmal eine gute Varietät (in meinem Sinn), sondern nur eine abnorme, allerdings sehr auffallende Form der Var. virescens (oder vielleicht der Var, typica?) darstellt und nur einmal (1883) von Herrn Professor Murr auf sandigen Dämmen der Inzinger $\mathrm{Au}$ in ihrer extremen Ausbildung gefunden wurde. Die Pflanze, deren Diaguose Zimmeter in I, S. 21 gab, unterscheidet sich von der normalen Var. virescens durch die Kleinheit aller ihrer Teile, besonders der Blüten, durch die weit auseinander stehenden, schmalen, länglichen, nicht ausgerandeten, schwefelgelben Kronblättchen, die kürzer als die Kelchzipfel sind. Neben den kleinen fünfteiligen Blättern finden sich auch vier- und dreiteilige. „Das kleine zarte Pflänzchen macht mit seinen hellgelben, schmalen, weit getrennten Kronblättchen von ferne den Eindruck einer Saxifraga oder eines Sedum" (Murr). Mir scheint hier etwas Ähnliches vorzuliegen, wie bei P. arenaria f. trisecta Scholz, welche sicher oft nur eine kleine Kummerform der P. arenaria mit sehr kleinen, stenopetalen und ebenfalls oft heller gelb gefärbten Blüten ist. Ganz ähnlichen kleinen und kleinblütigen Formen begegnet man bei der P. verna typica, ja selbst mitunter bei P. alpestris. - In späteren Jahren wurden ebenfalls von Herrn Prof. Murr der forma Murriana nahestehende, aber schon kräftigere und etwas grolsblütigere Formen bei lils nächst Hall und in Gries am Brenner gefunden, welche den Übergang zur gewöhnlichen Var. virescens $f$. parviflora bilden und welche ich von einer "P. bolzanensis v. micrantha" von Padergnone bei Toblino (leg. Murr) kaum unterscheiden kann. - Die f. granditlora (Zimmeters „P. Amansiana" etc.!) der Gegend von Innsbruck tritt auch in Südtirol als ,P. bolzanensis v. macrantha Saut.) und „P. Mezzocoronae Evers“" (!) wieder auf, z. B. zusammen mit der f. parviflora bei Padergnone bei Toblino (leg. Murre. 
Man hat schon mehrere Bastarde der P. Gaudini Grml, einige daron auch für Tirol, aufgestellt. Hier sind nur die letzteren zu prüfen. Zunächst erledigen sich deren zwei, nämlich die ,P. glandulifera Kraš. $\times$ P. Gaudini Grml. Murr" (1885) und die ,P. Gelmiana (P. bolzanensis \%. $\times$ P. glandulifera Kraš.) Siegfr:" (1894) von selbst, wenn man der Deutung der P'. glandulifera Kraš. als I'. Gaudini f. glandulosa zustimmt; denn, schieben wir die letztere statt der ersteren in die Formeln ein, so erhalten wir beidemal eine P. Gandini $\times$ I'. Gaudini! In der 'Tat sind alle Exemplare beider angeblicher Bastarde, die ich zu prüfen Gelegenheit hatte (- von Innsbruck für den ersten und von S. Nicolo bei Trient für den zweiten -) weiter nichts als Formen der $P$. Gaudini Var. virescens, an denen die Drïsen durch ihre Häufigkeit leicht auffallen. Sauter hat solche Formen viel richtiger als ,P. bolzanensis forma glandulifera" bezeichnet. Beide Bastarde sind nach meiner festen Überzeugung zu streichen.

Ir ritischer ist die "P. bolzanensiformis Saut." (1888), welche der Auktor als ,eine hybride Kombination zwischen P. bolzanensis und argentea" zu deuten sucht. Im Herbar liegen drei Bogen mit Originalexemplaren Sauters rom Calvarienberg bei Bozen, darunter die in der Flora Exs. Austr.-Hung. unter No. 1611 ausgegebenen. Diese letzteren sind sehr stark, fast seidig behaart; aber Anzeichen von einer Beeinflussung der P'. argentea (gekräuselte dümne Filzhärchen auf der Blattunterseite) konnte ich auch unter dem llikroskop bei keiner dieser Iflanzen, besonders auch nicht an den stark verkahlten ron Siegfried ausgegebenen Kulturexemplaren (No. 229) entdecken. Einige derselben mit schwacher Behaarung, unvollkommenen 'Lacken- und spärlichen Drüsenhaaren gelı̈ren offenbar zu P. Gaudini Var. virescens; die stärker behaarten sehe ich für eine Mittelform zwischen dieser und der Var. typica an. Wenn darunter Bastarde sein sollten, könnten sie wohl nur Formen der P. super-Gaudini (Var. virescens) $\times$ collina darstellen und kämen zu Sauters „P. porphyracea“" Im allgemeinen IIabitus weichen die Pflanzen nicht von P. Gandini Var. virescens $a b$ und vor allem erimert in der Form und Bezahnung der Blätter nichts an $\mathrm{P}$. argentea. Noch will ich bemerken, dafs mir (ex Herb. Murr) eine der P. bolzanensiformis aufserordentlich älnliche Pflanze vom I'lumesköpfle bei Natters unweit Innsbruck (leg. Murr 1884) vorliegt, nach 'limmeter: „P. aestiva IIall. (nicht typisch), vielleicht aestiva $\times$ Gaudini oder aestiva $>$ tiroliensis". Ls ist eine etwas stark behaarte, sonst aber ganz gute 1. Gaudini Var. virescens f. glandulosa.

Ich möchte hiermit über die „P. bolzanensiformis Saut.", was die Pflanzen um Bozen anbelangt, nicht das letzte Wort gesprochen haben, sondern sie der weiteren Beobachtung und genaueren Untersuchung empfehlen; denn das mir zugängliche Material war nur gering. Aus demselhen Grund enthalte ich mich eines endgültigen Urteils über eine merkwürdige Ptlanze, welche Prof. Murr anno 1898 bei S. Nicolo unweit Trient sammelte und seinem Herbar einverleibte. Nach der makroskopischen und mikroskopischen Behaarung gleicht sie einer P. opaca $<$ arenaria so sehr, dals ich sie mbedingt dafür ansehen würde, wenn nicht gewichtige ptlanzengeographische Berlenken gegen diese Kombination sprächen. Da nun aber die P'opaca für Südtirol doch nicht ganz ausgeschlossen erscheint, so wäre es wohl erlaubt, wenigstens an eine P. opaca $>$ Gaudini zu denken, bei der die P. Gaudini die P. arenaria ersetzen würde. Pflanzen 
dieser Kombination aus Ostböhmen (Leitomischl) stehen der von Trient morphologisch sehr nahe. Die dichte, lange, ganz horizontal abstehende und sehr weiche Behaarung der Stengel und Blattstiele, im Verein mit der Zartheit der Blätter, erinnert ganz unwillkürlich an P. opaca. Unter dieser Behaarung stehen die gutgebildeten Zackenhaare ebenfalls ziemlich dicht und Stieldrüsen sind läutig. Jedenfalls lohnte es der Mühe, dieser interessanten Form bei Trient weiter nachzuspüren; sollte sich dabei herausstellen, dafs die P. opaca daran durchaus unbeteiligt ist, würde ich sie zunächst als seltene abnorme Form zu P. Gaudini Var, virescens stellen, ohne ihr gleich auf Grund eines einzigen Herbarexemplars einen neuen Namen beizulegen.

Ein unzweifelhafter Gaudini-Bastard, die P. collina $\times$ Gautini Var. virescens (P. porphyracea Saut.) von Bozen und Meran wurde schon am Ende der Collinae-Gruppe besprochen. Habituell steht er der P. Gaudini näher als der P. collina und fände vielleicht hier seinen naturgemäfseren Platz.

Die Wichtigkeit, welche die P. Gaudini fïr Tirol (und andere Alpenländer) besitzt, und die riel zu geringe Beachtung, die ihr im allgemeinen bis jetzt geschenkt wurde, möge das lange Verweilen bei ihr entschuldigen. Erschöpft ist der G'egenstand selbst für Tirol noch nicht, denn ich hätte noch mindestens ein Dutzend ",neuer Species“ besprechen müssen, welche G. Evers in seinen „Beiträgen zur Flora des Trentino" (Verhandl. d. K. K. zool.-bot. Ges. in Wien 1896) aufgestellt hat und die wenigstens zum gröfsten Teil - bei allen ist es aus der Diagnose nicht herauszubringen - zu der P. Gandini zu schlagen wären (die P. Gaudini selbst erwähnt er gar nicht!). Solche "Species norae" sind: P. bruginoënsis, Vasonis, Pari, Mezzocoronae, Rivae, viscida, Toarnae, Bondonis, Ronchi, Ponale, dubiosa, loppiensis.

Ich glaubte ïber die Arbeit Evers mit Stillschweigen hinweggehen zu dürfen, nicht nur, weil kein einziges Everssches Original dieser famosen "Species“ im Innsbrucker Herbar vorliegt (obwohl die meisten unter anderen Namen vorhanden sein werden), sondern besonders auch deshalb, weil mir die auf die Entlarrung dieses Wustes aufzuwendende Zeit zu kostbar schien. Es gibt gewisse literarische Erzeugnisse, die man ignorieren darf, ohne sich einer wissenschaftlichen Gewissenlosigkeit zeihen zu müssen, und zu diesen gehört nach meiner Ansicht - und anch nach der anderer Lente*) - die Arbeit des Herrn G. Evers, der am besten seine Feder nicht wieder in den Dienst der Potentillen stellte, bevor er sie etwas besser studiert haben wird. Jit der Vermehrung des schon übergrofsen "Komposthaufens" der Potentillen-Literatur kann uns nicht gedient sein, und meine Leser werden es mir sicher danken, wenn ich diesen nicht nuter ihren Augen weiter umrühre, als unumgänglich notwendig ist.

\section{Potentilla arenaria Borkh.} Subsp. (oder Var.) Tommasiniana F. Schultiv.

Diese Species wird ron keinem neueren Botaniker aus Tirol erwähnt. Aber im Konvolut der P. Gaudini des Innsbrucker Herbars finden sich auf einem Bogen drei ganz kleine, nicht blïhende Pflänzchen mit der Etikette: „P. cinerea Chaix, $\beta$ ) trifoliata, Tirol, Tierser Tal, Felsen bei Aicher. Val de Lievre 25. 8. 186t", die ich nur für die in der Überschrift genannte Species halten kann. Blätter drei- und fünfzählig, mit ihren

*) Ein hartes, aber nicht ungerechtes Urteil fällte der rerstorbene E. Gelmi (in Atti dell' I. R. Accademia d. Sc. Lett. ed Arti degli Agiati Ser. III. Vol. II. fasc. III. 1896) über diesen "prolifico botanico", der die Wissenscbaft schon dadurch lächerlich mache, dals er jedem Dorf und jedem Berg, an dem er rorüberging, ein Hieracium, einen Rubus, eine Potentilla widme. „Un laroro simile non merita certamente d'esser preso in alcuna considerazione, di fronte a tali puerilitá ogni commento sarebbe inutile e superfluo, ogni critica sarebbe rana". 
Kerbzähnen und in der Form durchaus denen der Tommasiniana ähnlich, ebenso ist die Behaarung der Blattunterseite (dichter Sternfilz) die der arenaria und nicht die der Gaudini. - Ferner findet sich im Konvolut der P. alpestris Hall. f, auf einem Bogen zusammen mit einer P. Gaudini Var. virescens und einer P. aurea eine ziemlich kräftige, blïhende Pflanze, die ich nach dem dichten Sternfilz der Blattunterseite ebenfalls zu P. arenaria zichen muls. Sie ist nach den Blättern und der Beharung den Pfä̈nzehen aus dem Tierser 'Tal aufserordentlich älunlich und zuden drüisenlos, wie die P. Tommasiniana fast immer. Auf dem Bogen steht nur: „P. rema, Brixen in Tirol. Ex Herb. Kogeler". - Wenn also die Pflänchen wirklich ron den besagten Lokalitiiten herrihren und wenn keine Verwechslungen von Herbarexemplaren vorliegen, kommt die P. Tommasiniana in Südtirol vor oder kan wenigstens fruher daselbst ror, und es wäre zu wünschen, dals man sich im Tierser Tal und $\mathrm{mm}$ Brixen nach ilı umsähe. Jedenfalls schien es mir angezeigt, auf diesen Fund im Herbar anfmerksam zu machen. Fin nener Fund irgend einer arenaria-Form in Südtirol würde mich nicht sehr überrasehen, wenn ich bedenke, dafs IIuter am Monte Serva bei Belluno (Venetianisehe Alpen), nur acht bis neun geographische Meilen südöstlich von den genannten Standorten, die "P. cinerea Chaix." - die ich allerdings eher für eine grolse Form der P. Tommasiniana mit fünfteiligen blättern ansehen möchte - anfgefunden hat, welche daselbst sogar einen interessanten Bastard mit P. alpestris Var. baldensis erzeugt hat.

\section{AUREAE ALPESTRES.}

\section{Potentilla aurea $\mathbf{I}$.}

Eine der verbreitetsten Potentillen der Alpenkette, findet sich auch in Tirol allenthalben in Höhen, welche $1500 \mathrm{~m}$ übersteigen. Sie liegt im Herbar, von älteren und neueren Botaniker'n gesammelt, in etwa 50 Bogen vor, welche aber keine besonders erwähnenswerte Formen aufweisen, mit Ausnahme der

Var. mimor Lehm. (var. alpina Willk. Zimm. pro spec.), welche Huter am Griesherg (Bremner) und Kugler auf der 'Tierser Alp gesammelt haben. Sie wird sich wohl anch anderwärts finden lassen, da sie eigentlich nur likeine, ein-bis zweibliitige Exemplare der P. aurea umfal'st, lie sich in iibrigen in nichts rom 'Jypus unterseheiden und nach meiner Ansicht eher eine Standortsform ans höheren Lagen, als eine gute Varietä, nie und nimmer aber eine besondere Species (anch keine, kleine"!) darstellen. In den Walliser Alpen ist diese Form recht häufig; es giebt aber keine Grenze zwischen ihr und der typischen.

\section{Potentilla alpestris Hall. $f$.}

(P. maculata Poul'r. P. salisburgensis Hänke).

Über diese fornemreiche P'otentille, welche unter den alpinen die gröfste Verbreitung - weit über Europa hinaus - besitzt, liefse sich wieder sehr 
vieles sagen, doch werde ich mich so kurz wie möglich fassen und nur wieder die tiroler Formen berücksichtigen.

Da ich die moderne Zersplitterung dieser Art in viele kleine Species verwerfe, mufs ich einen Namen für sie wählen, der alle Zimmeterschen Species umfalst, und da kann es sich nur um die drei älteren handeln: P. maculata Pourr. (178s), P. salishurgensis Hïnke (1788) und P. alpestris Hall. f. (1817? oder 1823). Die Fragaria villosa Crtz., die Zimmeter nur auf einen Teil der P. alpestris ibertragen hat, kann für mich aus mehr als einem Grunde nicht in Frage kommen. Zudem ist eine ganz verschiedene Potentilla villosa Pallas ganz allgemein anerkannt*). - An der P. maculata halten bis heute noch besonders die nordischen Botaniker (Schweden, Norweger, Dänen, Engländer und Nordamerikaner) fest, und auch Lehmann lat sie in seiner Revisio Potentillarum acceptiert; die P. salisburgensis fand früher mehr Anklang in Deutschland, zum Teil auch in Frankreich, wo sie nun anch durch die neueste Flore de France von Rouy et Camus (Bd. VI.) wieder auf lange Zeit hinaus an Halt gewonnen hat; doch fand die P. alpestris, besonder's seit Kochs Synopsis allgemein als eine der ersten Auktoritäten galt, mehr und mehr Anklang in Dentschland, Frankreich und der Schweiz. Eine Einigung könnte wohl nur durch den Machtspruch eines internationalen Nomenklatur-Kongresses erzielt werden. Unter solchen Umständen darf ich bis auf weiteres mich an den gutgewählten Namen $P$. alpestris Hall.f. laalten, der sich auch heute noch grolser Verbreitung und Beliebtheit erfreut, wie zu Kochs Zeiten**), ohne auf meine speziellen Gründe fuir dieses Festhalten weiter einzugehen.

Var. typica (P. villosa Zimm. Dahin die Var. gracilior bei Koch und Lehmann). Eine solche Varietät, die man auch Var. communis nennen könnte, müssen wir nach meiner Überzengung aufstellen, wenn wir die Art ganz aufteilen wollen, was bei so polymorphen Arten wünschenswert erscheint. Bei Koch kann es den Anschein haben, dafs er eine solche Aufteilung durch seine Varietäten $\alpha$ ) firma, $\beta$ ) gracilior, $\gamma$ ) debilis versucht habe; bei Lehmann dagegen ist nur ein Teil mit besonderen Varietätennamen ausgeschieden, er beginnt mit $\beta$ ) pyrenaica (die für uns hier wegfällt), dann folgen $\gamma$ ) firma, $\delta$ ) gracilior und $\varepsilon$ ) debilis, also ganz wie bei Koch; aber der grölsere Teil steckt in dem weggelassenen $c$ ), dessen Diagnose in der allgemeinen der Species enthalten ist. Dafs dem so ist, geht daraus hervor, dal's er bei den Standortsangaben wirklich ein $c$ ) anfïhrt und diesem, also der alpestris schlechtweg oder der typischen alpestris die grölste Yerbreitung giebt: ,in tota fere arctica zona atque in pluribus Europae alpibus"; dann folgen die Standorte für $\beta$ ) bis $\varepsilon$ ). Darans scheint zu folgen, dal's die Var. gracilior bei Lehmann einen viel beschränkteren Simn habe, als bei Koch, bei dem sie eigentlich alles umfassen müfste, was nicht firma oder debilis ist. In dieser Auffassung haben auch Rouy \& Camus in der Flore de France die liäufigste und verbreitetste Varietït der P. alpestris , $\alpha$ ) gracilior Koch" genannt. Sieht man sich aber die Sache genauer an, besonders die kurze Diagnose der gracilior und die paar Synonyma zu ihr, so scheint es doch, dafs auch Koch die

*) Zimmeter will für die P. rillosa Pall. $=$ P. lencochroa Lindl. einführ'en. Aber er wufste nicht, dafs letztere zu einer ganz anderen Gruppe als die villosa Pall. gehört und eine Form der P. argyrophylla Wall. ist (nach Hooker fil.).

**) ,Nomen Potentillae alpestris, licet prioritate nou gaudeat, tamen nunc anteposui, quum botanicis gratius esse videatur" Koch, Syn. fl. germ. ed. III. p. 189. 
Art mit seinen Varietäten $\alpha) \beta$ ) $\gamma$ ) nicht ganz aufteilen wollte und die

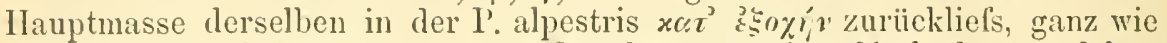
Lehmann, und dafs er hier nur aus Verselien von seiner Methode, in solchen Fällen mit $\beta$ ) zu begimnen, abgewichen ist. Ich glaube, das riclitigste ist, die var. gracilior, wie der Name sagt, als eine zarte, dümnstänglige Form der gewöhnlichen alpestris, also der Var. typica aufzufassen, denn aufser den ,caulibus gracilioribus" gibt es ja kaum einen Anhalt zu ilnrer Unterscheidung. Auch Zimmeter zog ohne Bedenken die gracilior als Synonym zu seiner $P$. villosa.

Diese Varietït ist die verbreitetste von allen; zu ilır gehören besonder's auch die Formen der arktischen und subarktischen Gegenden der alten und neuen Welt, ebenso sind einige der asiatischen Gebirge kaum von ihr zu trennen. Zimmeter hat ihre Verbreitung selbst für die Alpen viel zu sehr unterschätzt, wenn er sie auf die Kalkgebirge beschränkte und für die nördlichen Länder gar nicht erwähnt. Es ist zu bemerken, dals sie mit allen anderen Varietäten durch Übergänge verbunden und oft schwer von diesen abzugrenzen ist, ja sie erscheint wie der genetische Ausgangspunkt für alle anderen alpestris-Varietïten, die mehr oder weniger einen regionalen Charakter tragen. Es lassen sich nach Gröfse und Färbung der Kronblätter, nach dem Blattschnitt ete. wieder zahlreiche Formen unterscheiden, die aber einen geringen systematischen Wert besitzen und sicher oft nur individueller Natur oder auf Standortsverhältnisse begründet, sind, so dafs es genügt, sie in schedis zu notieren, olne sie mit besonderen Namen in die Literatur einzuführen.

Aus Tirol liegt im Herbar auffallend wenig Material der P. alpestris typica vor, vielleicht nur, weil man sie heim Sammeln über anderen ,interessanteren" Varietäten vernachlässigt hat. Ihr Konvolut (,I. villosa Zimm.") umfalst zwar 30 Bogen aus Tirol, aber von diesen gehören viele zu Var. stricticaulis Grml. und einige sogar zu P. Gaudini. Nach Absonderung ron diesen bleiben nur die Exemplare vom Schlern (in einer prïchtigen forma grandiflora), Trient, Folgaria, Rittenalp, Col santo bei liovereto, Luttach, Längental, Lansertal, Kiaiseralpen und Gamperdontal in Vorarlberg, zu welchen dann noch ein paar (vom Schlern und Stenico) aus dem lionvolut der Var. firma heribergezogen werden müssen. - Zahlreicher ist die Varietït aus der Schweiz vertreten.

V'ar. firma Koch. (P. verna Zimm. non L.!) Ieh sage mit Absicht: ,non L.", aus dem einfachen Grund, weil Linné diese Varietät höchst wahrscheinlich gar nicht gekannt hat. Zimmeter war in einem grofsen Irrtum begriffen, als er glaubte, dafs diese Ptlanze in den nördlichen Ländern („Lappland, Oeland, Schweden, Nord- und NordwestRufsland") die herrschende sei. Unter den vielen Exemplaren, die ich aus besagten Ländern, sowie aus Fimnland, Schottland und England zu untersuchen Gelegenheit hatte, befand sich kein einziges. das zur Var. firma pafste. Die nordischen Botaniker - wenigstens die, welche sie aus den Alpen kennen - erwälnen sie nicht, Lehmann kennt sie nur aus den Alpen Österreichs, Italiens und der Schweiz, und selbst der Monograph der nordamerikanischen Potentillen, Rydberg, sagt, dal's sie anscheinend auf die Alpen beschränkt sei. Ich bin fest überzeugt, dafs die echte Var. firma Koch eine ausschlief'slich alpine Varietït ist und dafs die nordischen Formen, soweit sie nicht ein paar seltenen bei uns fehlenden Varietäten angehören, zu der Var, alpestris typica (P. villosa Z.) gezogen 
werden müssen. Wenn also Linné die $\mathrm{P}$. alpestris mit der $\mathrm{P}$. verna auct. plur. vereinigt hat, so mufste er die in Schweden wachsende Var. typica (P. villosa Z.) im Auge gehabt haben und Zimmeter mufste die letztere (nicht aber die Var, firma Koch) zu "P. verna L." machen, wenn er bei seiner übrigens falschen Ansicht beharren wollte, dals Linné die P. verna auct. plur. „P. opaca" genannt habe. Pöverlein hat in der Tat die $P$. villosa Z, in „P. verna $L_{0}$ " verwandelt, freilich aus einem anderen Grund, der auch seine Richtigkeit hat, nämlich, weil Zimmeters rerna sich von dessen villosa spezifisch gar nicht abtrennen lasse*). Dieser Meinung bin ich auch, aber ich sage: wenn Linné unter P. verna die P. alpestris Hall. f. und die $P$. verna auct. verstand - was jetzt allgemein angenommen wird - und wenn man diesen Namen einer von beiden belassen will, so sollte man jene darunter verstehen, welche $\mathrm{Hudson}$ schon im Jahre 1778 von der Linnéschen Gesamtart als "P. verna L." abtrennte, und nicht jene, welche erst später, von 1788 an, die Namen P. maculata, P. salisburgensis, P. alpestris erhielt. Weshalb denn eine seit über hundert Jahre bestehende Ordnung umkehren auf Grund Zimmeters unzutreffenden Mutmafsungen? Jedenfalls kann die Var. firma Koch unter keinen Umständen weder als Varietät noch als Species den Namen "verna L." behalten.

Belegexemplare der echten Var. firma im Tiroler Herbar stammen besonders aus der Umgegend des Brenners (Hühnerspiel, Riedberg), sodann aus dem Suldental und Navistal, im ganzen nur etwa zwölf Bogen. Einige als "P. verna L." etikettierte Exemplare gehören zu Var. typica, und viele andere aus Nordtirol halte ich für die folgende Var. stricticaulis, welche sich allerdings nicht scharf von der Var. firma trennen lälst. - Von den übrigen Pflanzen des Konvoluts gehören die aus Graubündten und dem Wallis zur richtigen Var. firma, dagegen alle aus nordischen Ländern stammenden zur Var. typica.

Far. stricticaulis (Grml. 1864 P. engadinensis Brügg. pp.? 1867). Zimmeter zog zuerst (I, S. 15) die P. engadinensis (nach Brügger eine $\mathrm{P}$, thuringiaca $x$ alpestris) als Synonym zu $P$. gentilis Jord., was ihm aber später (II, S. 28) nicht mehr statthaft schien - mit Recht, denn nach der neuen Flore de France gehört die P. gentilis als Varietät zu P. thuringiaca. In seiner zweiten Broschüre sagt er auch, dals die P. engadinensis Brügg. der P. villosa (respective alpestris) nahe stehe und dafs mit ihr ein Herbarexemplar der P. stricticaulis Greml. (in litt. 1864) übereinstimme. Auf einem Zettel zu einem Herbarbogen, auf dem zwei unbestimmte Pflanzen von Rattenberg in Tirol und eine als ,P. intermedia" bezeichnete aus dem Kianton Waadt aufgeklebt sind, schrieb er ferner: „Diese Pflanzen und namentlich die Pot. intermedia vom Kanton Waadt stimmen sehr gut mit P. stricticaulis Greml. im Herbar Strobl, von Masson im Ober-Engadin gesammelt; nur ist letztere etwas mehr behaart und ihr Stengel etwas düıner und mehr hin und her gebogen. Diese stricticaulis stimmt genau mit P. inclinata Vill., mit der Abbildung in seiner Hist. d. pl. d. Dauph. t. XIV." - Da nun der Name Gremlis dem Brüggers gegenüber die Priorität für sich hat und zudem nicht feststeht, ob letzterer ursprünglich unter seiner engadinensis doch einen Bastard

*) Vgl, über diesen Punkt die zutreffenden Ausführungen Pöverleins in seiner citierten Abhandlung S. 106. 
verstand*), mit dem aber dam auch Pflanzen der stricticaulis verwechselt wurden (- alle, welche ich aus dem Engadin gesehen habe, scheinen mir keine Bastarde zu sein -), so behalten wir die stricticaulis bei, und zwar als larietät der P. alpestris, zu der sie sicher gehört, wie auch Burnat \& Briquet in der l'lore d. Alp. marit. und Rouy \& Camus in der Flore d. France getan haben. Ein Bastard ist diese Varietät sclon deshalb nicht, weil sie an Orten wächst, wo keine thuringiaca-Form vorkommt, z. B. in Nordtirol. Doch hat sie einige luabituelle Älnlichlieit mit der sogenannten ,I'. parviflora Gaud." (,P. intermedia auct. helv.") und mag mehrfach irrtimlich zu dieser gezogen worden sein. Sie ist die gröliste mir bekannte alpestris-Varietät: sie besitzt einen bohen Wuchs, langgestielte, grol'se, oft sechs bis siebenzählige Grundblätter, mit grobgezähnten, oft kurzgestielten, länglich obovalen, nach unten keiligen Teilblättchen, die beiderseits grim, zart und weich behaart sind. Stengel und Blattstiele sind meistens ziemlich dicht und stark abstehend langharig, doch giebt es auch kahlere Formen. Bliiten meist grofs, sclten mur mittelgrofs. Sie verhält sich zur P. alpestris typica ungefähn wie die Var. Billoti zur P. verna typica. Ihre nächste Verwandte scheint mir die Var. firma zu sein, mit der sie in Tirol durch Zwischenformen verbunden ist, doch besitzt die letztere viel derbere, breitere und kahlere Teilblättchen und einen niedereren Wuchs etc. - Von allen thuringiaca-Formen unterscheidet sie sich unter anderem durch die kleinen, meist einfachen (stark reduzierten) Blättchen oberhalb der ersten Stengelgabelung (bei jenen gehen gröl'sere, dreiteilige Stengelblätter bis an die obersten Gabelungen hinauf).

In Herbar finden sich ziemlich viele Exemplare der Var. stricticaulis aus Tirol, aber nur zwei davon im Konvolut von dieser, respective der „l'. engadinensis“, nämlich das schon erwähnte von Rattenberg und ein anderes aus den Jantal (Patznaun), die anderen sind als ,P. villosa Z,"“ (Var. typica) und als ,P. verna Z." (Var.firma) bestimmt und liegen zwischen diesen zerstreut; sie stammen aus dem Fimbertal (Patznaun)**), von den Alpen bei Rattenberg, Sonmwendjoch, Achental, Hausstein bei Kitzbühel, Wipptal, Navistal (uicht recht typisch, aber sehr ähnlich der vom Jamtal), Pragser See, Bad Mühlbach in Tauferertal, seil'seralp, Stenico. Im Herb. Murr: vom Almajurjoch in Lechtal. Fast alle diese Exemplare stimmen selı gut mit den zahlreichen aus Graubindten und anderen Kantonen der Schweiz vorliegenden.

Iar. ballensis (Keru. pro. sp.) ist, wenn typisch ausgebildet, eine gute und schöne Varietät, deren Unterschiede von Var. firma und Var. typica Zimmeter auf der Sclıeda zu den in der Flora Exs. Austro-IIung. No. 833 ausgegebenen Exemplaren auseinandergesetzt hat. Von der Var. stricticaulis, mit der sie noch nicht verglichen wurde, unterscheidet sie sich besonders durch viel zartere, niedergestreckte Stengel und die fast seidige Belıarung der Blätter; in letzterer Hinsicht kommt sie der noch

*) In diesem Falle miliste sie P. Mathoneti Jord. heifsen, denn diese soll nach Rony \& Camus die richtige $P$. thuringiaca (respective parviflora) $\times$ alpestris sein: "plante peu comme et considérée mal ì propos come critique". - So mufs also die P. engadinensis anf jerlen Fall gestrichen werden, mag sie ein Bastard sein oder nicht.

**) Zwei Bogen ans lem Fimbertal hat Zimmeter für P. rhaetica Brügg. (P. alpestris - grandiflora) crehalten, aber ich kam darin nur die Tar. stricticaulis erkennen, clie hier zufällig einige dreizïhlige Gruntblätter besitzt; von P. grandiflora entrecke ich absolut nichts daran. Die sehr interessante $P$. alpestris $\times$ grandiflora, die ich in ein paar Formen ans den Walliser Alpen besitze, sieht ganz anders aus; im tiroler Herbar befindet sie sicl micht. 
viel stärker seidigbehaarten Var. subsericea $m h$. aus der Westschweiz nahe, die ich aus Tirol noch nicht gesehen habe.

Aus Tirol liegt sie vor vom Monte Baldo, Tal di Ledro, Judicarien und Predazzo (Herb. Murr)*). Aulserdem in mehreren Exemplaren aus den Venetianischen Alpen und in einem von Siegfried (No. 269b) ausgegebenen rom Tolujak im Karstgebirge an der Grenze von Montenegro (leg. Brandis). In Südbosnien sammelte sie Beck und die P. alpestris rom Vlasic bei Travnik, welche von Siegfried "f. carstiensis Siegfr." genannt wurde, steht ihr ganz nahe, wenigstens nach vielen Exemplaren, die ich kürzlich von Professor Brandis selbst erhalten habe. - Von ihr kaum zu trennende alpestris-Formen bekam ich melirfach durch Professor Ch. Boetzkes aus der Umgegend des Matterhorns, und auch die stark behaarte alpestris rom Gebweiler Belchen im Elsals (leg. Issler) möchte ich als Form zu ihr stellen, während die vom Hohneck nach meiner Meinung eine Form der Var. firma darstellt. Die Var. baldensis scheint also ebensowenig auf Kalkgebirge beschränkt zu sein als die Var. typica. Zwischen beiden finden auch offenbare Übergänge statt, ob durch Kreuzung, ob durch ungeschlechtliche Abänderung, mag dahingestellt bleiben. Eine solche Tar. typica-baldensis sammelte z. B. Prof. Murr auf der Pallonspitze am Bondone bei Trient, ganz ähnliche besitze ich aus Zermatt. Dagegen halte ich eine ron Murr in schedis "P. Hellwegeri" genannte Pflanze, welche Ilellweger anno 1896 bei Predazzo gesammelt hat (Herb. Murr!), nur für eine leichte Spielform der Var. baldensis; ich kann keinen wesentlichen Unterschied von dieser finden.

Var. tridentina (Gelmi pro sp.) unterscheidet sich von den vorhergehenden alpestris-Varietäten hauptsächlich durch die im Verhältnis zur Länge sehr breiten Kelchzipfel, von denen die äufseren viel kürzer als die inneren, rundlich oval und stumpf sind, während die inneren eine beinahe dreieckige Gestalt besitzen. - Sie liegt im Herbar nur spärlich auf zwei Bogen vor. Die Exemplare beider sind von Gelmi selbst auf dem Monte Vasone bei Trient gesammelt, und zwar die des ersten (ausgegeben von Siegfried unter No. 98\%) im April 1894 in $1200 \mathrm{~m}$ Höhe, und die des zweiten im Juni 1896 in $1800 \mathrm{~m}$ Höhe. Die Pflanzen rles ersten Bogens sind klein, besitzen sehr kleine Wurzelblätter, kleine Blïten und die starke Behaarung der Var. baldensis. Ich wiirde sie vielleicht als kleine Standortsform zu dieser ziehen, wenn mich nicht die abweichende Form der kleinen äufseren Kelchblättchen davon abhielte. Die Pflanzen des zweiten Bogens, ron einem höheren Standort stammend, sind ebenfalls klein, aber die Blätter grölser und die Blüten verhältnismälsig sehr grofs; die Behaarung ist schwächer* und kaum stärker als bei mancher P. alpestris typica; anch die äufseren Kelchblättchen sind nicht mehr so auffallend elliptisch, sondern mehr länglich-oval. Jedenfalls nähert sich diese zweite Form sehr der Var. typica, und ich wage es kaum, sie von dieser zu trennen, besonders da Gelmi selbst sagt, dals die tridentina in ca. $1500 \mathrm{~m}$ Höhe wachse lind höher am Monte Vasone, in 1800 bis $2000 \mathrm{~m}$, die Var. typica vorkomme.

*) Kürzlich (Mitte Juni) erhielt ich von Herrn Prof. M u rr in Trient eine hübsche kleine Form der Var. ballensis, welche er in Poro unweit Trient in der geringen Höhe von höchstens $550 \mathrm{~m}$ ï. l. MI, unterhalb der obersten Weinberge fand, während er dieselbe, wie er sagt, weiter obell im Gebirge, z. B. in der ron ihm öfter begangenen Zone zwischen 900 bis $1100 \mathrm{~m}$ noch nie angetroffen hat. Ein höchst merkwïrdiger Standort! 
Herr Evers erwähnt in seinen früher citierten „Beiträgen zur Flora des Trentino" die "P. tridentina" auch von der Bordala und vom Monte Brugino bei Mori, sowie vom Monte Canfedin bei Trient und zerlegt sie dann nach seiner Art in: 1. forma dumetorum, 2. Var. bordalensis Ev. und 3. Var. canfedinensis Lr., über die sich aber der Auktor der tridentina, Gelmi selbst, lustig maehte*). Was mit diesen Namen gemeint ist, entrieht sich auch meiner Beurteilung, da ich Belegexemplare dieser "Varietäten" nicht gesehen habe. Gelmi behauptet, die Pflanzen der Eversschen Standorte gehören nicht zur tridentina. Eine weitere Untersuchung der Var. tridentina an ihren natürlichen Standorten und das Einsammeln eines reichlicheren Herbarmaterials wäre erwünseht und wïrde zu besseren Resultaten führen, als eine Diskussion der Eversschen Diagnosen.

\section{$\times$ P. super-alpestris $\times$ Gaudini (P. aurigena Kern.).}

Nach Sauter (1. e. S. 4) soll Zimmeter diese Pflanze fïr eine P. aurea $x$ alpestris gehalten haben. Aber in Zimmeters Schriften finde ich keine Andeutung dafür, im Gegenteil nennt er sie (I, S. 22), ,P. Billoti et villosite affinis", dachte also eher an eine P. alpestris $x$ verna auct. und stellte sie auch unmittelbar neben andere „Species", die er ebenfalls fiir Zwischenformen zwisehen der alpestris und der verna hielt.

Meine Deutung der "P. aurigena Kern" beschränkt sich auf die Pflanzen aus dem Fischleintal (Pustertal) bei Sexten, welche im Herbar, von Aufserdorfer und Sauter in einer Höhe von $1300 \mathrm{~m}$ gesammelt, vorliegen, erstreckt sich aber nicht auf das, was Siegfried aus der Schweiz, unter diesem Namen ausgegeben hat. - Auf den ersteı Blick möchte man die Pflanze von Sexten für eine schöne Form der P. alpestris halten, die der Tar. firma nicht zu fern steht. Makroskopisch erinnern nur die ziemlich lang ausgezogenen Stipulae der Grundblätter, sowie die Striegelbehaarung der Blattstiele und der Blattunterseite etwas an die P. Gaudini, aber mit dem Mikroskop lassen sich die Zackenhaare von dieser, wenn auch in geringer Zahl und sehlecht ausgebildet, mit Sicherheit nachweisen, ebenso finden sich sporadische mittellang gestielte Drüsen, welche unseren alpestris-Varietäten fehlen. - Eine etwas abweichende Form der P. superalpestris $\times$ Gaudini sammelte Prof. Murr im Juli 1896 über Bad Ratzes (Herb. Murr!). Wahrseheinlich liegt hier eine andere alpestris-liorm zu Grunde als bei der Pflanze ron Sexten. Auch II uter fand eine ganz ähnliche Pflanze bei Landro im Pustertal; sie liegt in seinem Ilerbar als „P. jurana Reut.?" - Die von Moehrlen im Kanton Waadt bei Rocheray und bei Bavois gesammelten und von Siegfried unter No. $23 \%$ a und $23 \% \mathrm{~b}$ als „P. aurigena Kern." ausgegebenen Pflanzen stehen zwar der l'. alpestris (var. typica) anch sehr nahe, es fehlt ihnen jedoch jede Spur von Zackenund Drüsenhaaren, und sie stellen wahrscheinlich die Kombination I'. superalpestris $>$ verna dar (wenn es nicht blofs Formen der alpestris von tiefgelegenen Standorten sind).

Diesem tiroler Bastard sehr angenäherte Formen besitze ich von Zermatt im Wallis; doch herrscht dort mehr die Mlittelform 7 . alpestris $\times$ Gaudini (P. Schroeteri Siegfr.) vor, welehe sich schon makroskopiseh

*) "Dio degli Dei! ma questo è mettere in ridicolo la botanica, questo si chiama trasformare la "Scientia amabilis' in "Scientia bordalensis et cognolensis'." 
sofort als einen Bastard bekundet und die zahlreicheren Zackenhaare schon unter der Lupe erkennen lälst. Dort tritt der Bastard, wie die P. Gaudini selbst, bald als f. glandulosa, bald als f, eglandulosa auf. Es ist mir sehr wahrscheinlich, dafs sich auch in Tirol, wo die P. Gaudini eine so grofse Verbreitung hat, diese P. alpestris $>$ Gaudini, vielleicht auch die P. superGaudini $>$ alpestris finden wird. $\mathrm{Zu}$ diesen Bastarden würde dann auch eine von Gelmi erwähnte „P. triclentina $>$ glandulifera (P. Vasonis Evers!)“ gehören. Es wird sich meistens nur an Ort und Stelle durch Beobachtung der Pflanzenassoziation, selten aber an einzelnen Herbarexemplaren feststellen lassen, welche Varietäten der Gaudini und der alpestris bei der Hybridation beteiligt waren.

\section{$\times$ P. aurea $\times$ alpestris (P. Huteri Siegfr. 1890).}

Dieser in der Schweiz nicht seltene Bastard liegt aus Tirol im Herbar nur in einem Exemplar vom Platzerberg über Gossensals vor, von Huter entdeckt und gesammelt und von Siegfried unter No. 324 ausgegeben. Wahrscheinlich wird er sich auch anderwärts finden lassen, wo beide Stammarten zusammen wachsen.

Siegfried hat zugleich noch eine $P$. super-alpestris $\times$ aurea (P. Trefferi Siegfr. 1890) aufgestellt, welche Treffer im Weil'sbachtal (Pustertal) gesammelt hat; auch sie liegt von dort im Herbar in einem von Siegfried unter No. 266 ausgegebenen Exemplar vor. Doch muls ich gestehen, dafs ich diese Pflanze, die ich in ziemlich vielen Exemplaren von Treffer selbst erhielt, kaum von der gewöhnlichen P. alpestris typica zu unterscheiden vermag. Unter den vielen Bastarden der Zermatter Gegend finde ich alle möglichen Zwischenstufen von der P. aurea $>$ alpestris bis zur reinen alpestris.

\section{P. minima Hall. f. (P. dubia Zimm. Fragaria dubia Crtz.).}

Diese kleinste unserer Alpenpotentillen, die einst Crantz etwas dubiös vorgekommen zu sein scheint, und der man den bezeichnenden, seit so langer Zeit und allgemein eingebürgerten Namen lieber hätte belassen sollen*), ist auf den höheren Alpen Nord- und Südtirols sehr verbreitet und liegt im Herbar in 18 Bogen vor. Eine Aufzählung der Standorte scheint mir hier überflüssig.

Ich will nur bemerken, dafs ich auch eine von Zimmeter als „P. frigida $\times$ aurea? Kultiv. im Garten des Herrn Malfatti in Innsbruck. 1892." bezeichnete Pflanze für ein grolses, kräftiges Kulturexemplar der P. minima ansehen mul's. Blätter alle dreizählig, Behaarung und Kelchbildung ganz die der minima, nichts deutet auf P. aurea, auch fehlen die den frigidaBastarden eigenen Sitzdrüsen.

Die Kombination aurea $x$ frigida hat sich bis jetzt in der Alpenkette

*) Beck von Mannagetta verwendet den Namen "P. dubia Sut." in der Flora von Nieder-Österreich bekanntlich für die P. opaca L. \& anct., so dal's also der Name "dubia" wieder dubiös geworden ist, wenn es anch die Pflanzen selbst keineswegs sind. Was gewinnt denn die Wissenschaft mit solchen Altertumsstudien und ewigen Namensänderungen? Wäre es nicht besser, die Zeit auf das Studium der Pflanzen selbst, als auf die Aufsuchung längst vergessener Namen zu verwenden? 
noch nicht gefunden; doch wird sie in der Flore de France (Bd.VI.p. 192) unter dem Namen ,l’. Eynensis Rouy \& Cam, 1900“ aus den Pyrenäen erwähnt.

$\times$ P. anrea $\times$ minima (P. subnivalis Briigg. P. semiternata Hut. \& Porta).

Sie wurde für 'Tirol ron Iluter anf dem Griesberg und Platzerberg an Brenner mer den Stammeltern entdeckt und von ihm für eine grolse Seltenheit erklärt. In Herbar hefindet sich nur ein Bogen mit von Huter selbst gesammelten und von Siegfried unter No. 254b ausgegebenen P'flanzen, aufserdem noch ein Kiulturexemplar aus Siegfrieds Garten (auch vom Griesberg stammend), das aber sehr degeneriert ist und fast wie eine gewöhnliche P. aurea aussieht. - Die von Jabornegg im Gailtal ïber der Alpe Feistritz (Kärnten) gesammelten und von Siegfried unter No. 254a ansgegebenen PHanzen des Herbar's scheinen mir nicht hierher zu gelören; ihre Blätter sind durchgehends fünfzählig und nicht seidig bewimpert. Ich kann in ihnen nur eine kleine P. alpestris, höehstens eine kleine superalpestris $>$ aurea erkemmen. Sie weichen sehr ab von den nicklichen Pflänzchen vom Riffelhorn über Zermatt, denen man ihre aurea $\times$ minimaNatur auf den ersten Blick ansieht. In besagter Gegend um das Riffelhorn mul's der Bastard sehr häufig sein, dem ich bekam ihn in mindestens 100 kleinen Exemplaren von dorther.

\section{$\times$ P. alpestris $\times$ minima (P. Amthoris Hut., P. subternata Brügg.).}

Wiederum ist es der um die Flora Tirols hochverdiente Iluter, welcher diesen Bastard zuerst in Tirol auffand, und zwar an der Amthorspitze am Hühnerspiel (Brenner). Die von ihm gesammelten und von Siegfried unter No. 326 ausgegebenen drei Pflänzchen sind die einzigen im llerbar. - Aufser ihnen findet sich nur noch ein Exemplar aus den Graubündtner Alpen. In der Schweiz scheint die P. alpestris $>$ minima recht verbreitet zu sein, besonders in der an l'otentillen überreichen Gegend über Zermatt, von woher ich sie in allen Abstufungen von superalpestris $\chi$ minima bis superminima $>$ alpestris besitze. Wälnend der Bastard am Hïhnerspiel wohl eine P. alpestris Var. firma $\times$ minima darstellen wird, mul's er im Wallis, wenigstens grofsenteils, als P. alpestris Var. typica $\times$ minima gedeutet werden. Eine Grenze zwischen beiden Formen ist in dieser Gegend ummöglich zu ziehen, wie eben eine solche auch zwischen den zwei bezüglichen alpestris-Varietäten hier durchaus nicht besteht. Es ist aussichtslos, für jede Bastardform die Kombination bis zur letzten Varietäts- oder Formenstufe der Eltern verfolgen zu wollen, und zwecklos, auf Grund unbeweisbarer Vermutungen den herausgetüftelten Kombinationen noch binäre Namen anzuhüngen. Die allgemeinere Bastardformel genïgt, die man ja noch durch Einschaltung von ,super-" modifizieren kann.

\section{Potentilla grandiflora $I_{\text {. }}$.}

Wie in den übrigen Alpenländern, so auch in Tirol allgemein verbreitet. Belegexemplare liegen in 25 liogen vor vom Brenner, Riedberg, Jaufen, Riedertal, Stubaital, Iffinger, Stilfserjoch, Wormserjoch, Laas, Trafoi, Pitzlat bei Nauder's, Telferweisen, Brixen, Vallorz, Monte Tonale. 
Alle Exemplare gehören der typischen Varietät an und keines bietet Veranlassung zu besonderen Bemerkungen.

\section{$\times$ P. grandiflora $\times$ aurea (P. Peyritschii Zimm.).}

Von diesem Bastard, den ich ebenfalls aus der Zermatter Giegend in zwei oder drei Formen kenne, befinden sich im tiroler Herbar nur die Exemplare, welche von Zimmeter im Juli 1888 an der Wormserjoch-Strafse zwischen Franzenshöhe. und Ferdinandshöhe gesammelt wurden (Cfr. II, S. 35). - Aufserdem noch ein von Siegfried unter No. 278 ausgegebenes, wenig charakteristisches Kulturexemplar, von Riddes im Unter-Wallis stammend.

Der angeblichen $P$. alpestris $\times$ grandiflora (P. rhaetica Brigg.) aus dem Fimbertal wurde bereits früher ihre richtige Stellung bei $P$. alpestris Var. stricticaulis angewiesen.

\section{Potentilla frigida Vill.}

Auch über diese Species ist, soweit sie aus Tirol vorliegt, nichts besonderes zu bemerken. Wir finden sie im Herbar auf 23 Bogen vom: Rolskogl bei Innsbruck, Hühnerspiel, Weisspitz, Riedberg, Griesberg, Sellrain, Stubaital, Pfossental, Schnalsertal, Natscher Joch bei Glurns, Laaser Alpen, Alpen im Pustertal, Umbralthörl, Kalsertal.

\section{$\times$ P. alpestris $\times$ frigida (P. Hegetschweileri Brïgg.).}

Das einzige aus Tirol stammende und mit diesem Namen bezeichnete Exemplar des Innsbrucker Herbars von der ,Spitze des Hocheder bei Telfs in Tirol, leg. Gremblich" mufs ich leider nur für eine etwas hochstengelige Form der $P$. frigida erklären, wie sie z. B. sehr liäufig auf der Riffelalp über Zermatt vorkommt, und ich mülste danach die Existenz des Bastards als zweifelhaft für Tirol hinstellen, wenn er mir nicht aus dem Herbar Murr vorläge. Herr Prof. Murr sammelte ihn im Juli I897 und zuletzt im Juni 1902 auf dem Hühnerspiel am Brenner in einer starkbehaarten und einer weniger behaarten Form. Wo der Bastard liäufig ist, wie in den Walliser Alpen bei Zermatt, kann man alle Zwischenformen von der reinen alpestris bis zur reinen frigida beobachten.

\section{ANSERINAE.}

\section{2\%. Potentilla Anserina L.}

Eine kosmopolitische Art, die auch in Tirol allgemein verbreitet ist.

Var. discolor Wallr. (Blätter oberseits grün, nur unterseits weifsseidig) ist, wie allenthalben, so auch hier die häufigste, gelit jedoch an vielen Orten allmählich in die folgende über, so dal's man dann beide Varietäten in typischer Ausbildung samt den Übergängen nahe beisammen 
sammeln kann. Auch in den Herbarien liegen nur zu häufig beide Varietäten in demselben Bogen veroinigt.

Forma geminiflora (Nestl. pro var.) ist keine besondere Varictät (viel weniger Species), sondern eine seltene Mil'sbildung, die auch bei anderen Varietäten vorkommen kann und nur darin besteht, dals ausnahmsweise ein oder der andere Blütenstiel zweiblütig ist. Sie liegt im Herbar in einem kleinen Exemplar von "Campo Tactino" in Südtirol (leg. Val de Lievre 1867) vor, das im übrigen zu var. discolor gehört.

Iar. concolor Wallr. (var sericea Koch, Zimm. pro spec.). (Blätter beiderseits glänzend weifsseidig.) In Südtirol häufiger als in Nordtirol, oft zusammen mit Übergangsformen zu Var. discolor.

Zimmeter (II, S. 10) hält die ,P. sericea in ihrer typischen Form, wie sie in Ungarn vorkommt, für spezifisch verschieden von der mehr in Westeuropa heimischen P. Anserina" (d. h. var. discolor), während er ,dagegen die P. viridis Kioch für blofse Varietät der P. Anserina" erklärt. Dieser Ansicht kann ich mich nicht anschliefsen. Zunächst ist die Var. discolor in Osteuropa (Centralrufsland, Balkanländer etc.) ebenso hïufig als in Central- und Westeuropa; sodann sind viele Exemplare der Var. concolor aus nördlichen Gegenden (Brandenburg, Posen, Sachsen), der Schweiz und Westeuropa (z. B. England) von der nach Zimmeter ,typischen Form aus Ungarn" in nichts zu unterscheiden, und überall, wo ich sie im Freien beobachten komnte, fand ich neben typischen Exemplaren zweifelhafte Übergänge zur Var. discolor in der Nähe (gewöhnlich mul's man sich "typische Lxemplare" fürs Herbar besonders aussuchen). Endlich weicht die höchst seltene Var. viridis Koch (Blätter beiderseits grün und fast kahl), welche Zimmeter wahrscheinlich nie gesehen hat - in seinem Herbar kommt sie nicht vor - in manchen Punkten mehr von der Var. discolor ab als die Var. concolor, wie ich noch kürzlich an einem von Salzwiesen in Böhmen stammenden Exemplar beobachten konnte. Die Var. viridis scheint bis jetzt in Tirol noch nicht beobachtet zu sein.

\section{TORMENTILLAE*).}

28. Potentilla Tormentilla Sibth., Neck. (1\%ro) et anct. plur. (P. silvestris Neck. (1768), P. erecta Dalla Torre, Tormentilla erecta L.).

Var. typica (P. erecta Zimm.) ist die gomeinste Form dieser über fast ganz Europa und einen grofsen Teil Asiens verbreiteten Species, und liegt natülich auch im Innsbrucker Herbar zahlreich auf. Sie spaltet sich wiederum in viele Formen, denen aber nur der Wert von individuellen Abändcrungen und Staudortsformen zukommen dürfte, und deren

*) Ïber diese schwierige Gruppe, die in Tirol weniger formenreich auftritt als in vielen anderen, besonders nördlicheren Ländern, werde ich mich hier kurz fassen; ich erlaube mir auf meine "Potentillen-Studien I" hinzuweisen, wo ich deren Arten und Bastarde ziemlich eingehend besprochen habe. 
weitere Vermehrung in der Literatur nicht vorteilhaft wäre. Zu solchen Standortsformen rechne ich auch zwei für Tirol aufgestellte: die "Var. minor Sauter" der Alpenmoore und die ,f. depressa alpina Huter", wenn die letztere nicht etwa zu Var. sciaphila gehört, was ich nicht entscheiden kann, da sie im Herbar nicht vorkommt. Die aus der Schweiz von Siegfried unter No. 951 a mit dem Huterschen Namen ansgegebenen Exemplare (gesammelt von Moehrlen auf dem Suchet, Kant. Waadt) sind nichts weiter als kleine Pflänzchen der var. typica, wie man sie vielfacl findet.

Tar. strictissima (Zimm, pro sp.) liegt vor ron Imst, vom Kellerjoch bei Schwaz, von Kaltern, aus dem Val Vestino; weniger typisch von Bozen und Trient; in einer Zwischenform (strictissima-dacica) vom Lanser Torfmoor.

Tar. dacica Borb. (Z. pro spec.). Diese in ganz Centraleuropa lïufige Varietät lag merkwürdigerweise im Herbar aus Tirol nicht als solche bezeichnet vor; doch konnte ich aus dem Faszikel der ,P. erecta" wenigstens acht Bogen ausscheiden, welche als Var. dacica etikettiert werlen müssen: von der Kranebitter Klanm, vom Haller Salzberg, vom Ritten bei Bozen, aus Val Vestino und Val Fersina. Sicher ist sie in Tirol sehr verbreitet, aber wenig beachtet, wie die Var. strictissima. Ähnlich mag es sich mit der folgenden Var. sciaphila verhalten.

In dem mit ,P. Favrati Zimm." bezeichneten Faszikel liegt eine von Zimmeter selbst gesammelte „Potentilla . . . . ? vom Hühnerspiel am Brenner bei den Alpenhiitten". Er schreibt auf der Etikette dazu: ,der P. dacica Borb. ziemlich ähnlich"s. Dies ist ganz richtig, sie ist aber auch von sciner P. Favrati, welche vom locus classicus, der Hayenwand am Rhonegletscher, zahlreich in Favrats Originalexemplaren aufliegt, nicht zu unterscheiden! Ich kam in dieser ,neuen Species" nichts sehen, als eine Mittelform dacica-strictissima, wie sie garnicht selten, z. B. im sächsischen Erzgebirge und selbst in der Dresdner Heide, auftritt. Nach meiner Ansicht lat der Name „P. Favrati Z." keine Existenzherechtigung, demn man kanu doch unmöglich alle Zwischen- und Lokalformen mit binären Species- oder auch nur besonderen Varietätsnamen belegen; man käme damit im Formenkreis der P. Tormentilla an gar kein Ende.

Tar. sciaphila (Zimm. pro sp.) liegt typisch in sechs Bogen vor: von Völs bei Innsbruck, Lanser Kopf, Sterzing, Seis und zwei unleserlichen Fundorten. Die Mittelform typica - sciaphila wurde bei Klobenstein und die dacica-sciaphila bei Seis gesammelt.

\section{$\times$ P. Tormentilla $\times$ reptans $($ P. adscendens Grml. P. Gremlii Zimm.).}

Ihre Anwesenheit in Vorarlberg bei Bregenz am Bodensee wird durch ein Herbarexemplar bestätigt, das v. Ebner im Jahre 1854 dort gesammelt hat und welches auch Zimmeter (I, S. 6) erwähnt. Letzterer sagt, dafs sic auch bei Bozen von Hausmann gefunden wurde (II, S. 10) und stützt sich dabei auf ein Exemplar im Herb. Aichinger.

Ich möchte raten, sie in Nordtirol in der Gegend von Rattenberg zu suchen. Von dort liegt nämlich in Herbar eine ihr ähnliche Pflanze ror (leg. Waldmüller $1845 \mathrm{im}$ Wald am Fufs des Sonnenwendjochs), die nach 
ihrer Zartheit auch der P. procumbens Sibth. angehören könnte -- bei der grofsen Ähnlichkeit der I'. Tormentilla $\times$ reptans mit der P. procumbens (= P. Tormentilla-reptans) lïlst sich ohne vollständigeres Material keine sichere Entscheidung trefłen -; doch erscheint ihre Zugehörigkeit zur crsteren walı'scheinlicher, da bis jetzt die P. procumbens weder ans 'Tirol noch aus der Schweiz*) mit Sicherheit nachgewiesen ist, und sie schon in Mitteldeutschland die Mainlinie gegen Süden wahrscheinlich nicht überschreitet.

\section{Potentilla reptans $I_{\text {L. }}$}

Die gewöhnliche, allgenein verbreitete form bedarf keiner besonderen Standortsangaben. I ch möchte nur auf ein aufserordentlich likinblïtiges Exemplar (f. parviflora) anfmerlisam machen, das Ilausmam bei Bozen sammelte.

Trar. microphylla Trottu. liegt im Herbar vor: typisch vom ,Zimmerslehner W'eilher bei Völs" (leg. Hausm.) und von Lienz; weniger typisch von Hall, vom Ritten bei Bozen und aus dem Val die Non.

Var. minor Sauter. (Ö. B. Z. 1889), ,I'flanze und Blïte viel kleiner, Blattstiele kürzer oder wenig länger als die IBlätter, diese beiderseits behatart." In scinel Abhandlung ,,über die Potentillen des mittleren Tirols" gibt Sauter keine Standorte an. Ich sah die Pflanze nicht und weifs daher nicht, inwieweit sie sich der Var. mierophylla näher't, vermute aber, dal's es sich hier nur um eine der gewöhnlichen P. reptans noch mehr genäherte Standortsform handelt als bei der microplyylla, oder un eine Zwischenform zwischen dieser und der typisehen reptans. Bei der systematischen Geringwertigkeit solcher ,Varietiiten" bin ich der Ansicht, dafs die beiden genannten besser als ,forma microplnylla (Trattn. im erweiterten Sinn). aufgefal'st und der P. reptans typica angehängt würden, wobei es — wie bei der łetzteren - gleichgültig wäre, ob die Błätter ganz kahl oder etwas behaart sind. Auch die folgende Var. pubescens kam in der ,forma mierophylla" auftreten.

Tar. mbescens Fiel: (var. mollis Borb.?) liegt sehr schön vor aus dem Stubaital ,zwischen Madraz und Neder" (leg. v. Sarnthein); weniger typisch von ,Bozen gegen Sigmundskron" (leg. Hausm.).

Wem die von Zimmeter als var. mollis bestimmten Exemplare aus der Schweiz und anderen Ländern wirklich die Borbíssche Tarietït sein sollten, was ich aus Mangel eines Borbásschen Originalexemplars leider nicht entscheiden kann, dann ist es sicher, dafs diese mit var. pubescens Fiek illentisch ist und vielleicht gegen diese die Priorität für sich hat. Dann ist es aber anch ebenso sicher, dafs Zimmeter sehr im Irrtum war, als er diese Var. mollis mit ler I. lunata Lange aus Spanien identifizierte. lis scheint, dal's Zimmeter diese spanische sehr abweichende Form, die

*) Die von Zimmeter (I, S. 6) zu P. procumbens gezogene Pflanze rom Eschen. berg bei Winterthur, von der ich sehr viele Exemplare untersncht habe, halte ich fïr eine P. superreptans . Tormentilla (respective P. arlscendens reptans), welche der genetisch rerwandten P. procumbens reptans (P. mixta Nolte) besonders anch biologisch ganz nahe steht. Die echte 1'. procumbens ist sie nicht. 
wenigstens eine ausgeprägte gute Rasse oder Subspecies der P. reptans darstellt, nicht gesehen hat - im Herbar befindet sie sich nicht. Leider hat Zimmeter durch seine reine Vermutung Anlafs dazu gegeben, dals man nun in den Herbarien häufig der Var. pubescens (respective Var. mollis) unter dem Namen „P. lanata Lange" begegnet.

Nachtrag zu Pot. recta L. Var, pallida Lehm. (S. 29).

Wälırend des Druckes dieser Arbeit gingen mir lebende Exemplare dieser Varietät durch Herrn Prof. Murr aus 'Trient und Herrn Dr. Pfaff aus Bozen zu, sodals also dieselbe für Südtirol, neben der Var, obscura, als wildwachsend konstatiert ist. Die Kronblätter dieser Pflanzen sind zwar für Var. pallida etwas klein, aber ihre Farbe und die Häufigkeit der Stieldrüsen an Kelchen, Blütenstielen und Blättern sprechen für diese Varietät, jedenfalls liegt eine andere vor, als in den Pflanzen, die ich selbst bei Mori und Meran gesammelt und als Var. obscura bestimmt habe. 
Systematisches Ver'zeichnis der tiroler Potentillen.

\section{FRAGIRIASTRA.}

1. Potentilla ıitida L.

2. P. Clusiana Jcq.

3. P. caulescens $L$.

t. P. alba L. Dar, obovata Th. Wolf.

Var. petiolulata Gaud. - F. viscosa (Hut.).

5. P. Fragariastrum Ehrh. .

$\times$ P. alba $\times$ Fragariastrum.

P. hybrida $1 \mathrm{~T}$ alli.).

$\times$ P. super-alba $\times$ l'ragariastrum (P. Gremblichii Gidg.).

$\because \times$ P. super-Fragariastrum $>$ alba (P. Reineckei Sag.).

6. P. micrantha Ram.

$\times$ P. micrantha $\times$ Fragariastrum $($ P. spuria Kern. $)$. . . . . . . 9

\section{PALSTRES.}

\%. P. palustris Scop. (Comarum palustre I.) .

\section{RUPESTREN.}

8. P. rupestris L.

Var. grandiflora Heuffl.

\section{RIVALES.}

9. P. norvegica $L$.

10. P. supina L.

\section{CANESTENTES.}

Canescentes boreales.

11. P. nivea L. Var. alpina Lehm. . . . . . . . . . . . . . . . 13

$\times$ P. nivea $\times$ alpestris v. firma $(\mathrm{I}$. Beunia llut. . . . . . . . . 13

$\times$ P. super-alpestris $>$ nivea. 
12. P. argentea L.

Canescentes argenteac.

Var. typica.

" decumbens (Jord.).

", demissa (Jord.).

" grandiceps (Zimm.).

(?) ,, tenuiloba (Jord.).

", incanescens (Op.).

,, dissecta Wallr.

13. P. canescens Bess.

Canescentes collinae.

P. collina auct. (Sammelart).

14. *P. Wimanniana Günth. et Schum.

Var. Hausmanni Th. Wolf.

15. *P. thyrsiflora Hüls.

(?) *P. Johanniniana Goir.

(?) *P. alpicola De la Soie

$x$ P. argentea $\times$ collina

$x$ P. argentea $\times$ Wimanniana $v$. Hausmanni.

$\times$ P. argentea $\times$ thyrsiflora.

$\times$ P. collina $\times$ Gaudini v. virescens (P. porpliyracea Saut.)

\section{RECTAE.}

16. P. recta L.

Var. pallida Lehm.

obscura Lehm.

(,, ? eingeschleppt.)

$\times$ P. super-recta $x$ argentea

(P. hirta L. Var. pedata (Nestl.) eingeschleppt.)

\section{AUREAE.}

Aureae chrysanthae.

1\%. P. thuringiaca Bernh.

Aureae rernales.

18. P. opaca L. (P. rubens Zimm.) . . . . . . . . . . . . . . . 32

19. P. verna L. (P. opaca Zimm.). - (In Vorarlberg.) . . . . . . . . 33

20. P. Gaudini Grml.

Var. typica Th. Wolf.

" longifolia (Borb.) Th. Wolf. virescens Th. Wolf.

21. P. arenaria Borkh. *P. Tommasiniana F. Schultz.

Var. minor Lehm. 
23. P. alpestris Hall. $f$.

Var. typica.

.. firma Kóoch.

,. stricticanlis (Grml.).

". baldensis (Kern).

", tridentina (Gelmi).

$\times$ P. super-alpestris $\times$ Gaudini $\left(I^{\prime}\right.$. aurigena Kern) . . . . . . . 60

$\times$ P. aurea $\times$ alpestris (P. Huteri Siegfr.) . . . . . . . . . . . 61

$\times$ I. super-alpestris $x$ aurea (P. Trefferi Siegfr.).

24. P. minima Hall. f.

$\times$ P. aurea $\times$ minima (P. subnivalis Briuggg. P. semiternata Hut. et P'orta) $\quad 12$

$\times$ P. alpestris $\times$ minima (I'. Amthoris Hut. I'. subternata Brügg.) . . 62

25. P. grandiflora L. . . . . . . . . . . . . . . . . 69

$\times$ P. grandiflora $\times$ aurea (P. I'eyritschii 'Zimm.) . . . . . . . . 63

26. P. frigida Vill. . . . . . . . . . . . . . . . . 63

$\times$ P. alpestris $x$ frigida (P. Hegetschweileri Briigg.) . . . . . . . . (i3

\section{ANSERINIE.}

27. P. Anserina L.

Var. discolor Wallr.
,e concolor Wallr.

TORM EN'TILLAE.

2S. P. Tormentilla Sibth.

Var. typica.

„, strictissima ('Zimm.).

" dacica Borb.

,. sciaphila (Zimm.).

$\times$ P. Tormentilla $\times$ reptans $(\mathrm{P}$. adscendens (irml.) . . . . . . . . . 65

29. P. reptans L.

Var. microphylla 'Trattn.

$\therefore$ pubescens Fiek. 


\section{Einige Berichtigungen und Nachträge zu „Potentillen-Studien I“6.}

Potentilla Fragariastrum Ehrh. (S. 12), die ich für verschwunden hielt, hat sich an ein paar Stellen des Rabenaner Grundes wiedergefunden. Sie wurde (nach gef. Nitteilung des Herrn Prof. K. Wobst) anno 1857 von Weiker auch bei Grünhainichen im Flöhatal gesammelt, und wird dort wahrscheinlich jetzt noch vorkommen. Nachforschung erwünscht.

$P$. supina $L$. und P. norvegica $L$. (S. 12-15), deren systematische Stellung ich 1901 noch als unsicher hinstellte, gehören beide in die ziemlich polymorphe Gruppe der. Rivales (mh.), welche allerdings in Europa nur durch diese zwei, in Amerika und Asien dagegen durch eine gröfsere Anzahl, darunter auch auslauernder Arten, vertreten sind.

Nach der P. norvegica $L$. ist einzufügen:

Potentilla intermedia I. (P. norvegica-argentea), vou mir im Sommer 1901 auf Schutt- und Bauplätzen bei Dresden-Plauen aufgefunden. Für Sachsen neu, aber eingeschleppt, wie in Norddeutschland und anderwärts. Stammt aus Central-Rulfsland. - Sie wird nach meiner Ansicht besser den Rivales (speziell der P. norvegica) angereiht als den Canescentes, wie gewöhnlich geschieht.

„P. grandiceps Zimm." (S. 25) mufs ich jetzt, nachdem ich sie genauer kennen gelernt, für eine gute Varietät der P. argentea $L$. halten. Cfr. Potentillen-Studien II, S. $1 \%$.

P. argentea L. Var. dissecta (S. 28) bekommt als Auktor Wallr. (statt "Wallr. p. p.?"); denn die mir durch Herrn L. Ofswald in Nordhausen zugegangene Original-Diagnose Wallroths lautet: $\gamma$ ) dissecta W. foliolis in lacinias lineares plus minusve profunde dissectis, supra incanis, subtus cauleque niveo-tomentosis", wonach also Wallroth diese Varietät genau so aufgefalst hat, wie wir heutzutage, d. h. als auf der Blattoberseite stark behaart.

S. 39, Zeile 23 v. oben lies: P.argentea $\times$ recta, statt P. argentea $\times$ canescens. " 42, " 21, , ": P. reeta var. pallida, statt P. recta und pallida. " $44, \quad, 9,, ", \quad$ : gekräuselten, statt geschlängelten.

", 60, unterste Zeile lies: drüsenreichen, statt drüsenlosen.

" 61, Zeile 15 von unten lies: Leckwitz, statt Lockwitz.

Zu „P. glandulifera Kraš. (S. 65 und 66) ist zu bemerken, dafs dieselbe, wach den mir von Professor Krašan zugesandten Originalexemplaren, in den Formenkreis der P. Gandini Grml. (zu Var. virescens mh.), durchaus nicht in den der $\mathrm{P}$. verna oder den der $\mathrm{P}$. opaca $X$ verna - wie ich ehedem vermutet hatte - gehört. (Siehe „Potentillen-Studien II" S. 35.)

"P. longifrons Borb." (S. 67 und 76) gehört nach den Ergebnissen der Revision des Zimmeterschen Herbars ebenfalls in den Formenkreis der P. Gaudini Grml. Hinter P. verna L. Var. longifolia (S. r6) mufs ich daher $m h$. statt "Borb." setzen und die "P. longifrons" wird num zu P. Gaudini Grml Var. longifolia (Borb.) $m h$. 
Zu S. 70, Zeile 19 von unten. Ich bin bereits durch eigene Beobachtung eines besseren belehrt, dafs nämlich die $\mathrm{P}$. verna in seltenen Fïllen und dann meist spärlich Stieldrïsen trägt.

P. verna v. Jirsutu DC. (S. 72). Nach genancrer Kenntnisnahme der südwestemropäischen Formen dieser Varietiit scheint es mir doch besser, dieselbe nicht auf die starkbehaarten mitteleuropäischen Formen der P. verna auszudehnen, wie ich rersucht hatte. Die Var. hirsuta DC. (= I. agrivaga Timb.-Lagr.) weicht $\mathrm{zu}$ sehr von (len letzteren ab und bildet eine Varietiit für sich mit geographischer Beschränkung (Spanien, Süidfrankreich — im Rhonetal bis Genf -, Seealpen, Ligurien). Unsere stark beharten Formen lassen sich als f. pilosa oder f. hirsutior den Varietäten anschliefsen, denen sie im übrigen, nach 13lattschnitt etc. angehören. - Die ,P. albescens Zimm." mul's ganz gestrichen werden, denn nach den Opizsehen Originalexemplaren iu Kimmeters Herbar stellt sie nur , filzkranke", d, h. von \%oocecidien infizierte Individuen der P. verna v. incisa T'Tsh. vor. - ,P. adpressa Op.", ein nomen nudum, unter welchem Opiz, wie Herr K. Domin an zahlreichen Originalexemplaren in den Herbarien l'rags nachweisen konnte, allerlei Veruales und selbst Collinae ausgegeben hat, mul's ebenfalls eingezogen werden. — ,P. muerala Kraš. ist nach .. I'otentillen-Studien II" S. 40 sehr wahrscheinlich eine Form der P'. Gandini Grml.

Nach der P. verna v. longifolia (S. 7\%) sind, als für Sachsen neu, noch einzuschalten:

Var. Billoti (N. Boul.). Im Eilbtal bei Nieder-Lommatzsch und im Grund ron lilattersleben (! leg. Hofm.). Wahrscheinlich in Sachsen weiter verbreitet; aus Böhmen mehrfach erhalten.

Var. pseudo-incisa mh., cine in Centraleuropa weitverbreitete, bisher verkannte und unter verschiedenen falschen Namen laufende Varietät, ïber welche man in ,I'otentillen-Studien II" S. 39 nachlesen mag. - Aus Sachsen liegrt sie nir bis jetzt nm spärlich und nicht gamz eharakteristisch von Kötitz bei Coswig vor. Sehr schön besitze ich sie von vielen Standorten Böhmens, sodann aus dem Harz, dem Rheinland (Náhetal), Elsals, Württemberg (Tübingen), Nord- und Westschweiz.

Beile Varietäten, Billoti und psendo-incisa, sind mit der Var. longifolia sehr nahe verwandt und durch Übergänge verbunden; sie bilden mit dieser einen engeren bilologischen "Tarietätenkreis" (ler P'. verna.

Nach 1'. aurulenta $>$ arenaria (S. 97) ist einzuschalten:

Potentilla Gaudini Grml. Var. virescens mh. Yon mir a. 1901 bei Panitzsch unweit Borsdorf aufgefunden. Siehe dariiber den Aufsatz in Allg. bot. Zeitschr. 1902, No. 34 , sowie Potentillen-Studien II, S. 50.

P. anserina L. Var. concolor Wallr. (S. 98) kommt auch in Sachsen in Sümpfen und an Teichrändern vor, z. B. am Baselitzer Weiher bei Kamenz (!!), hei Skassa unweit Grofsenhain (! If fm.).

P. I'ormentilla Sibth. Var. strictissima (Zimm.) (S. 105) ist im höchsten Erzgebirge häufig, z. B. am lïchtelber's, am Keilberg und in Zechgrund (!!), aber anch in niederen Gegenden, wic in der Dresdner Heide. Überall findet man jedoch die '/wischenform strictissima-dacica noch häufiger.

Dresden-Plauen, im Jnni 1903. 




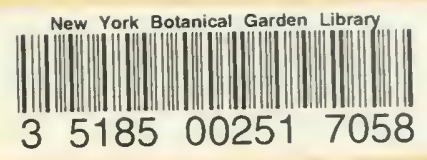

MACKENZIE

9683

\section{LLITARY OF THE}

HERTICULTUHAL SOLIE Y OF N. Y.

598 MrWLISON AVENUE

NEW YCRK 
